\title{
ANÁLISE EXPERIMENTAL DE PILARES DE CONCRETO ARMADO SOB AÇÃO CENTRADA COM RESISTÊNCIA DO CONCRETO DE 25MPa
}

Ricardo Ferreira Ramos

Dissertação apresentada à Escola de Engenharia de São Carlos, da Universidade de São Paulo, como parte dos requisitos para a obtenção do título de Mestre em Engenharia de Estruturas.

Orientador: José Samuel Giongo

São Carlos

2001 
“Amarás o Senhor teu DEUS de todo o teu coração, de toda a tua alma e de todo o teu entendimento." Mateus 22:37 


\section{AGRADECIMENTOS}

Primeiramente a DEUS, pois sem a benção do Senhor nada seria.

Aos meus pais João e Nilza, e aos meus irmãos Sandra, Silmara e João Luís, pelo amor, ensinamentos, apoio e honra de tê-los como minha família.

Ao Professor Dr. José Samuel Giongo, pela orientação cuidadosa, ensinamentos e amizade demonstrada no decorrer destes dois últimos anos.

Ao Professor Dr. Roberto Chust Carvalho, pela amizade, ensinamentos, apoio e sugestões dadas para a melhoria deste trabalho.

Aos meus sobrinhos Carolina, Caio Augusto, João Luís Júnior, Réa Sílvia, Camila e Luís Phelipe, pelo carinho disposto ao tio que tanto os ama.

À minha namorada Regina Mambeli Barros, pelo amor e compreensão.

À minha ex-namorada Rosana Gomes, pela compreensão e apoio dados desde a época da graduação na Universidade Federal de São Carlos.

Aos meus amigos de longa data Alexandre Rigazzo e Robson Nelson, pela amizade inestimável e apoio.

Aos grandes amigos de mestrado Andrea, Fábio, Luciano, Luis Claudio, Valentim e Valério, pela amizade e momentos de descontração compartilhados.

Aos colegas de pós-graduação Humberto, Romel e Adilson Takeuti pelas contribuições e sugestões relativas ao trabalho.

Aos funcionários do Laboratório de Estruturas, não só por tornarem possível este trabalho, como também pela amizade construída.

À Bibliotecária Maria Nadir, pela amizade, paciência e disposição no esclarecimento de dúvidas.

Aos funcionários da Marcenaria e Transportes, e demais funcionários do Departamento de Engenharia de Estruturas, da EESC-USP, pelos serviços prestados que foram de elevada importância para a concretização do trabalho.

Aos funcionários, alunos e professores dos Laboratórios de Construção Civil e de Madeiras e Estruturas de Madeiras, pelo apoio na caracterização dos materiais.

Ao Departamento de Engenharia de Estruturas, da EESC-USP, pela oportunidade de ter cursado o mestrado em Engenharia de Estruturas.

À Camargo Corrêa Cimentos S.A., pela doação de material essencial ao desenvolvimento da pesquisa.

Ao CNPq (Conselho Nacional de Desenvolvimento Científico e Tecnológico), pela bolsa de estudo concedida. 


\section{SUMÁRIO}

LISTA DE FIGURAS..........................................................................................ii

LISTA DE TABELAS.......................................................................................xx

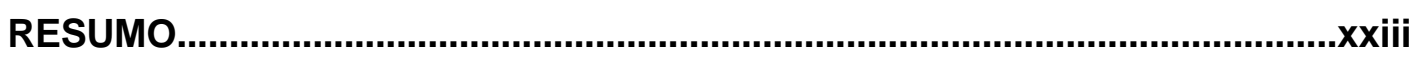

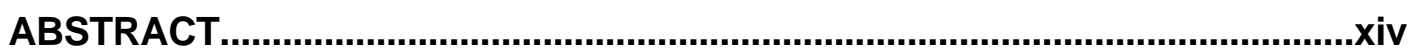

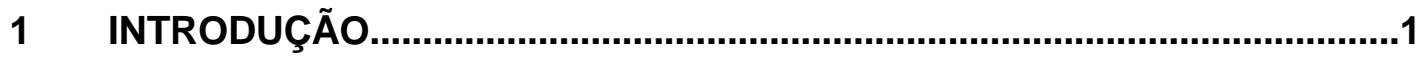

1.1 Considerações Iniciais...................................................................

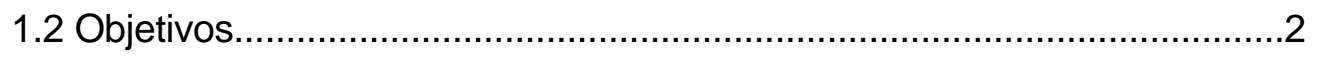

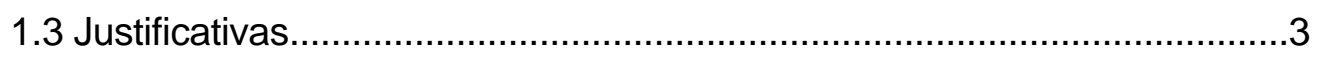

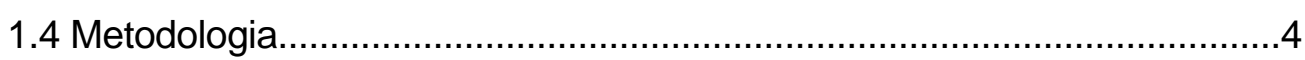

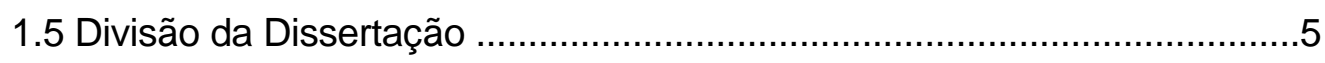

2 CONCRETO DE RESISTÊNCIA USUAL....................................................

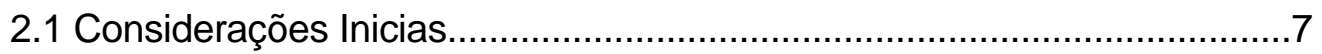

2.2 Definição do Concreto de Resistência Usual...........................................7

2.3 Classificação dos Concretos.................................................................

2.4 Vantagens e Desvantagens do Concreto de Resistência Usual..................8

2.5 Aplicabilidade do Concreto de Resistência Usual...................................10

2.6 Materiais Constituintes do Concreto de Resistência Usual.......................13

2.6.1 Cimento................................................................................. 13

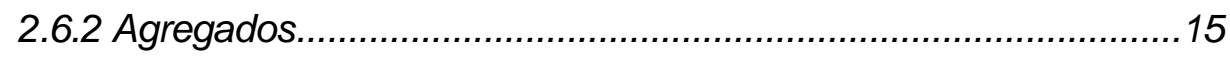

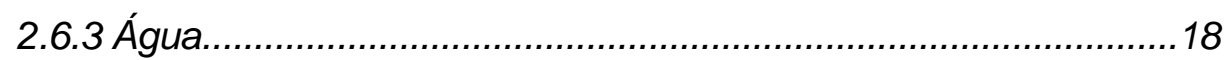

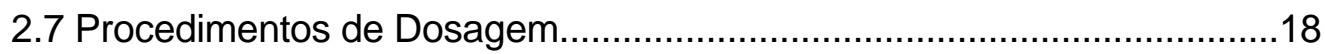

2.8 Procedimentos de Cura.......................................................................19

2.9 Propriedades Mecânicas do Concreto de Resistência Usual.....................20

2.9.1 Resistência àCompressão...................................................20

2.9.2 Resistência àTração............................................................24

2.9.3 Deformação Última..................................................................25

2.9.4 Módulo de Deformação Longitudinal........................................26

2.9.5 Relação Tensão-Deformação...................................................30

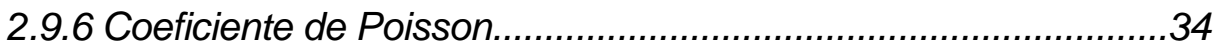




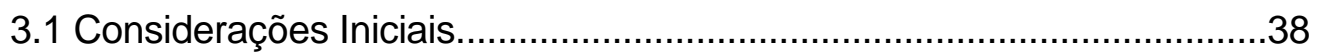

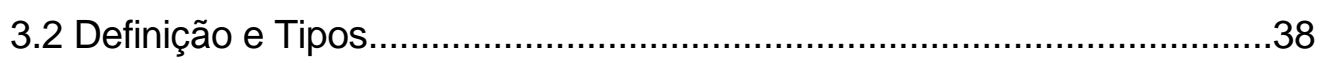

3.3 Histórico das Pesquisas.....................................................................45

3.4 Cálculo da Capacidade Resistente.......................................................63

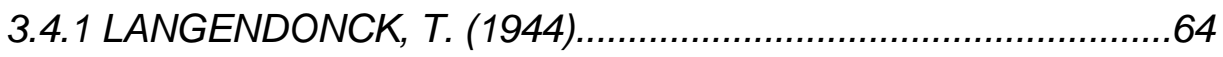

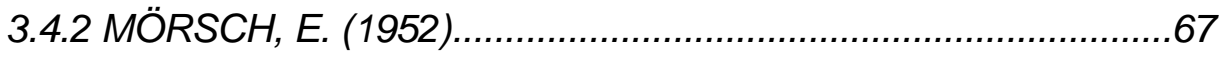

3.4.3 ROCHA, A. M. (1970)..........................................................

3.4.4 PFEIL, W. (1983) e FUSCO, P. B. (1986)...............................74

3.5 Modelos Teóricos de Confinamento do Concreto....................................77

3.5.1 SHEIKH \& UZUMERI (1982).............................................. 78

3.5.2 MANDER et al. (1988b)......................................................... 88

3.5.3 SAATCIOGLU \& RAZVI (1992) ...........................................95

3.5.4 CUSSON \& PAULTRE (1993)........................................... 102

3.6 Avaliação da Ductilidade.......................................................................104

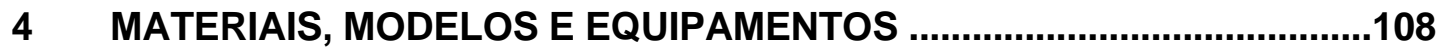

4.1 Considerações Iniciais................................................................. 108

4.2 Estudo de Dosagem.................................................................... 108

4.3 Caracterização dos Materiais..........................................................111

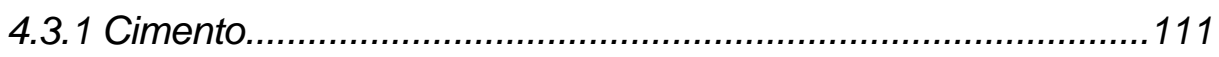

4.3.2 Agregado Miúdo.................................................................111

4.3.3 Agregado Graúdo.............................................................112

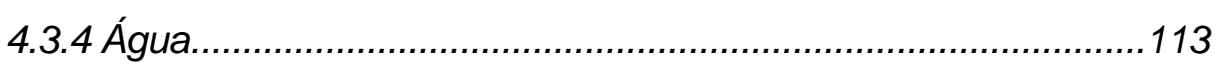

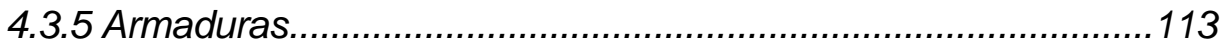

4.4 Definição dos Modelos de Pilares......................................................115

4.4.1 Resistência àCompressão do Concreto...................................115

4.4.2 Dimensões dos Pilares..........................................................116

4.4.3 Categoria e Diâmetro Nominal das Armaduras.........................117

4.4.4 Taxa Geométrica da Armadura Longitudinal.............................118

4.4.5 Espaçamento da Armadura Transversal.................................119 
4.4.6 Armadura de Fretagem..........................................................121

4.4.7 Detalhamento das Armaduras.................................................121

4.4.8 Previsão para Força Última...................................................130

4.4.9 Medida das Deformações.....................................................131

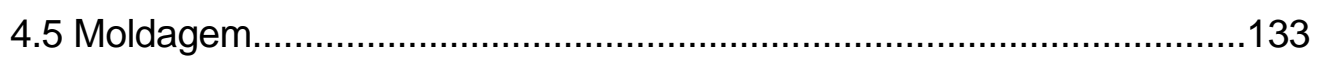

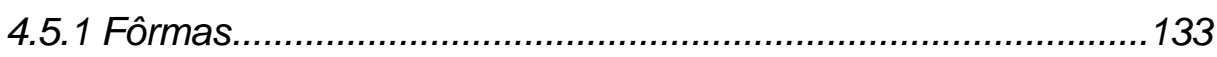

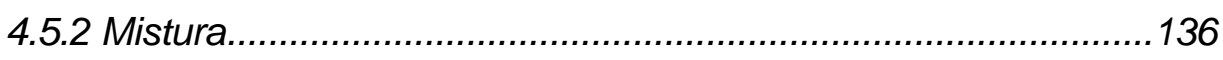

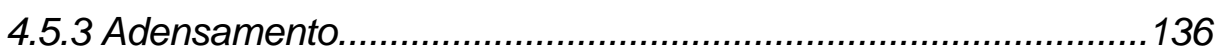

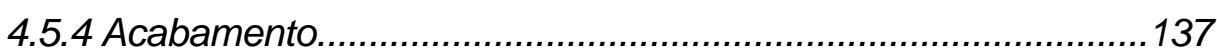

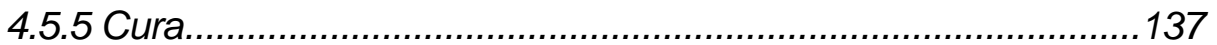

4.6 Equipamentos para os Ensaios dos Pilares..........................................138

5 ENSAIOS E RESULTADOS...............................................................140

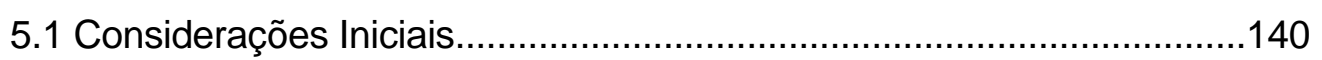

5.2 Descrição dos Ensaios dos Pilares.....................................................140

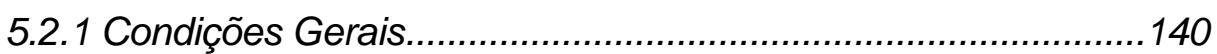

5.2.2 Descrição Individual.............................................................141

5.3 Resultados dos Ensaios dos Pilares...................................................158

5.3.1 Diagramas Força-Deformação.................................................158

5.3.2 Deformações Registradas na Ruína...........................................189

5.4 Ensaios Complementares.................................................................193

5.4.1 Ensaios de Compressão e Tração do Concreto...........................193

5.4.2 Ensaio de Módulo de Deformação Longitudinal do Concreto.....195

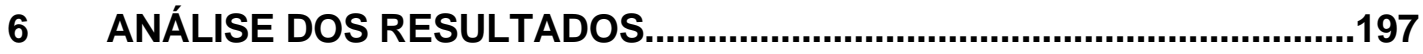

6.1 Considerações Iniciais.......................................................................197

6.2 Análise dos Diagramas Força-Deformação...........................................197

6.2.1 Análise Individual.............................................................198

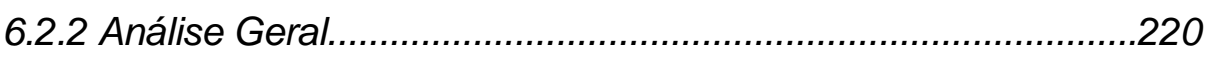

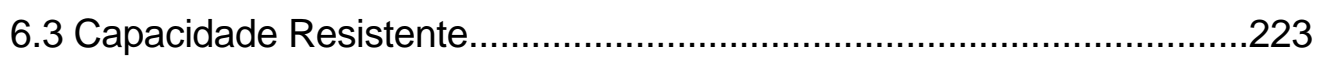

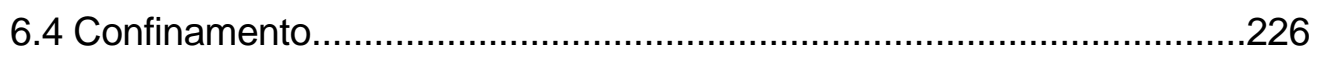

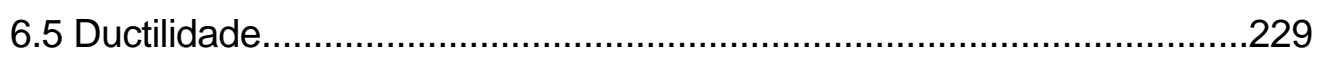


7 CONCLUSÃO.

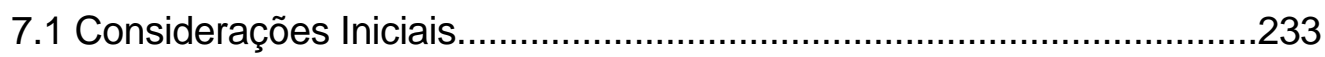

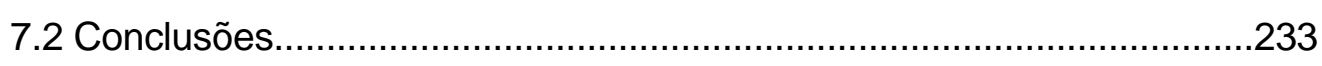

7.3 Sugestões para Continuidade da Pesquisa........................................237

REFERÊNCIAS BIBLIOGRÁFICAS.............................................................238

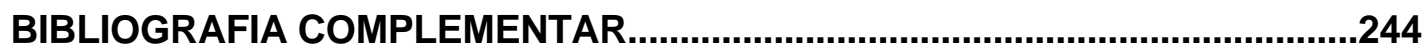




\section{LISTA DE FIGURAS}

\section{Capítulo 1}

Figura 1.1. Núcleo resistente de concreto. .2

\section{Capítulo 2}

Figura 2.1. Taxa de armadura nos pilares dos últimos 17 pavimentos dos edifícios Villa Lobos e Solar da Serra, CAMPOS (2000) 12

Figura 2.2. Da esquerda para a direita, edifícios Texas Commerce Tower e Water Tower Place, MEHTA \& MONTEIRO (1994). .13

Figura 2.3. Influência da cura úmida sobre a resistência do concreto com uma relação água/cimento igual a 0,50, NEVILLE (1982)... 20

Figura 2.4. Efeito conjunto das cargas de longa duração e da maturação do concreto, FUSCO (1989). .23

Figura 2.5. Representação dos estágios na relação tensão-deformação do concreto sob carregamento uniaxial, MEHTA \& MONTEIRO (1994). .31

Figura 2.6. Influência da resistência do concreto àcompressão uniaxial na forma da curva tensão-deformação, COLLINS et al. (1993). 32

Figura 2.7. Diagrama tensão-deformação do concreto àcompressão para análises no estado limite último, NBR 6118 (2000). .34

\section{Capítulo 3}

Figura 3.1. Pilar de seção retangular constituído por armadura transversal em forma de anéis formados por barras chatas, FANTI (1917)

Figura 3.2. Seções transversais de pilares de concreto armado, SEGURADO (1921)

Figura 3.3. Seções transversais e vistas laterais de pilares de concreto armado, MÖRSCH (1952). .40

Figura 3.4. Seções transversais e armaduras mais empregadas atualmente em pilares de concreto armado.

Figura 3.5. Vista lateral e seção transversal do pilar Matrai, SEGURADO (1921) 
Figura 3.6. Ligação das armaduras de pilares submetidos àcompressão simples de um piso a outro, SEGURADO (1921). .43

Figura 3.7. Ligação das armaduras de pilares de um piso a outro, MÖRSCH (1952).

Figura 3.8. Seção transversal e vista lateral dos modelos de pilares, MÖRSCH (1952)

Figura 3.9. Modelos rompidos em comemoração ao $25^{\circ}$ Aniversário da Indústria Alemã, MÖRSCH (1952).

Figura 3.10. Distribuição de tensões nas extremidades de pilares com barras longitudinais de pequeno e grande diâmetro, MÖRSCH (1952) 48

Figura 3.11. Seções transversais e configurações das armaduras empregadas na série II, MÖRSCH (1952)

Figura 3.12. Da esquerda para a direita, cabeça de pilar desenvolvida pela Comissão Austríaca de Concreto Armado e cabeça de pilar proposta por Mörsch, MÖRSCH (1952) . .50

Figura 3.13. Seção transversal e vista lateral de um dos modelos de pilares ensaiados pelo Laboratório de Stuttgart, MÖRSCH (1952). .53

Figura 3.14. Análise estática das forças que envolvem a armadura transversal dos pilares, MÖRSCH (1952).

Figura 3.15. Detalhamento dos modelos de pilares, SHEIKH \& UZUMERI (1980). .57

Figura 3.16. Seções transversais e vistas laterais dos pilares de seção circular (a), quadrada (b) e retangular (c), MANDER et al. (1988a). 58 a 59

Figura 3.17. Comparação entre as relações de tensão-deformação teórica e experimental de pilares variando-se os seguintes aspectos: a) configuração da armadura transversal (a simbologia R6-25 significa: armadura transversal com $6 \mathrm{~mm}$ de diâmetro e espaçada de $25 \mathrm{~mm}$ ); b) espaçamento da armadura transversal; c) taxa de deformação aplicada no ensaio; e d) distribuição da armadura longitudinal (a simbologia 10-D12 significa: armadura longitudinal composta por 10 barras de diâmetro 12mm). Figura extraída de MANDER et al. (1988a). 61

Figura 3.18. Relação força-deslocamento em pilares com resistência àcompressão do concreto alta (CAR) e usual (CRU), CLAESON et al. (1996). 62 Figura 3.19. Pressões oriundas do cintamento da armadura transversal, ROCHA (1970). .73 
Figura 3.20. Proposta de relação tensão-deformação do concreto confinado, SHEIKH \& UZUMERI (1982). .79

Figura 3.21. Área de concreto não confinado ao nível dos estribos, SHEIKH \& UZUMERI (1982)

Figura 3.22. Estimativa da área de concreto não confinado ao nível dos estribos, SHEIKH \& UZUMERI (1982). .81

Figura 3.23. Estimativa da área de concreto não confinado entre os estribos, SHEIKH \& UZUMERI (1982). 82

Figura 3.24. Determinação da seção crítica - uma visão tridimensional do concreto confinado e não confinado, SHEIKH \& UZUMERI (1982). 83

Figura 3.25. Coeficiente $\lambda^{*}$ em função da relação entre o espaçamento entre estribos $(s)$ e a dimensão do núcleo de concreto $(B)$, SHEIKH \& UZUMERI (1982) .86

Figura 3.26. Modelo de relação tensão-deformação para concreto confinado e não confinado proposto por MANDER et al. (1984), MANDER et al. (1988b) 88

Figura 3.27. Núcleo de concreto efetivamente confinado para armadura transversal composta por estribos circulares, MANDER et al. (1988b). .90

Figura 3.28. Núcleo de concreto efetivamente confinado para armadura transversal composta por estribos retangulares e barras retas com ganchos nas extremidades, MANDER et al. (1988b). .90

Figura 3.29. Determinação da resistência à compressão do concreto confinado em função das pressões de confinamento efetivas em seções retangulares, MANDER et al. (1988b). .93

Figura 3.30. Efeito da taxa de deformação na relação tensão-deformação do concreto, MANDER et al. (1988b). .95

Figura 3.31. Modelo de relação tensão-deformação para concreto confinado e não confinado proposto por SAATCIOGLU \& RAZVI (1992), SAATCIOGLU \& RAZVI (1992)

Figura 3.32. Variação do coeficiente $k_{1}$ com a pressão lateral de confinamento, SAATCIOGLU \& RAZVI (1992) 97

Figura 3.33. Ensaios comprovaram a concordância entre os resultados experimentais e o modelo analítico, SAATCIOGLU \& RAZVI (1992). .97

Figura 3.34. Pressão lateral de confinamento em pilares de seção circular, SAATCIOGLU \& RAZVI (1992) .98 
Figura 3.35. Pressão lateral em pilares quadrados, SAATCIOGLU \& RAZVI (1992) .99

Figura 3.36. Distribuição das pressões laterais nos pilares: a) Distribuição da pressão lateral ao longo do pilar; e b) Pressões laterais real, média e equivalente no pilar, SAATCIOGLU \& RAZVI (1992). .101

Figura 3.37. Distribuição das pressões laterais em pilares de seção retangular, SAATCIOGLU \& RAZVI (1992) 102

Figura 3.38. Manipulação gráfica utilizada para se calcular as deformações elástica e plástica de pré-pico. 104

Figura 3.39. Consideração gráfica utilizada para o cálculo da deformação plástica de pós-pico. .106

\section{Capítulo 4}

Figura 4.1. Evolução da resistência à compressão com o tempo para as dosagens de $25 \mathrm{MPa}$ e $40 \mathrm{MPa}$ 110

Figura 4.2. Limites granulométricos para a areia fina de acordo com a NBR 7211 (1983) 112

Figura 4.3. Da esquerda para a direita, diagramas tensão-deformação das barras de diâmetro nominal de 5,0mm e 6,3mm, respectivamente. 114

Figura 4.4. Da esquerda para a direita, diagramas tensão-deformação das barras de diâmetro nominal de 10,0mm e 12,5mm, respectivamente..............................114 Figura 4.5. Dimensões dos modelos de pilares...................................................116

Figura 4.6. Configurações das armaduras (medidas em $\mathrm{mm}$ )..............................119

Figura 4.7. Espaços entre as barras longitudinais (medidas em $\mathrm{mm}$ )....................120

Figura 4.8. Configurações da armadura transversal...........................................120

Figura 4.9. Armadura de fretagem nas extremidades dos pilares.........................121

Figura 4.10. Detalhamento da armadura do pilar P1-10,0-120............................122

Figura 4.11. Detalhamento da armadura do pilar P1-12,5-200............................122

Figura 4.12. Detalhamento da armadura do pilar P1-12,5-150...........................123

Figura 4.13. Detalhamento da armadura do pilar P1-12,5-100 ...........................123

Figura 4.14. Detalhamento da armadura do pilar P2-10,0-120 ............................124

Figura 4.15. Detalhamento da armadura do pilar P2-12,5-150 ............................124

Figura 4.16. Detalhamento da armadura do pilar P2-12,5-100............................125

Figura 4.17. Detalhamento da armadura do pilar P2-12,5-75.............................125 
Figura 4.18. Detalhamento da armadura do pilar P3-10,0-120..........................126

Figura 4.19. Detalhamento da armadura do pilar P3-12,5-150............................126

Figura 4.20. Detalhamento da armadura do pilar P3-12,5-100............................127

Figura 4.21. Detalhamento da armadura do pilar P3-12,5-75 ............................127

Figura 4.22. Detalhamento da armadura do pilar P4-10,0-120 ............................128

Figura 4.23. Detalhamento da armadura do pilar P4-12,5-150 ...........................128

Figura 4.24. Detalhamento da armadura do pilar P4-12,5-100 ............................129

Figura 4.25. Detalhamento da armadura do pilar P4-12,5-75.............................129

Figura 4.26. Instrumentação empregada nas armaduras dos modelos de seção

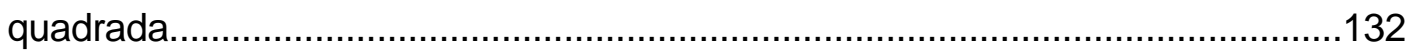

Figura 4.27. Instrumentação empregada nas armaduras dos modelos de seção retangular .132

Figura 4.28. Instrumentação das faces dos pilares por meio de extensômetros elétricos colados ao concreto e defletômetros....................................................133

Figura 4.29. Projeto da fôrma dos pilares de $200 \mathrm{~mm} \times 200 \mathrm{~mm} \times 1200 \mathrm{~mm}$............134

Figura 4.30. Projeto da fôrma dos pilares de $150 \mathrm{~mm} \times 300 \mathrm{~mm} \times 900 \mathrm{~mm}$.............135

Figura 4.31. Betoneira utilizada no amassamento do concreto..............................136

Figura 4.32. Pilares sendo concretados sobre mesa vibratória.............................136

Figura 4.33. Pilares já concretados e àesp era do serviço de acabamento...........137

Figura 4.34. Pilares e corpos-de-prova sendo curados em câmara úmida............138

Figura 4.35. Pilares P2-10,0-120 e P3-12,5-75 sendo ensaiados na Instron..........139

Figura 4.36. Sistema utilizado para a leitura e aquisição de dados.......................139

\section{Capítulo 5}

Figura 5.1. Pilar $\mathrm{P} 1-10,0-120$ posicionado e pronto para o ensaio. 142

Figura 5.2. Pilar P1-10,0-120. a) Primeira fissura; b) Flambagem de uma das barras longitudinais; c) Fissura inclinada à 30우 ; e d) Detalhe da face mais deteriorada que demonstrou a ação de flexão composta sobre o pilar. 143

Figura 5.3. Pilar P1-12,5-200. a) Primeira fissura; e b) Fissuras decorrentes da flambagem de uma das barras longitudinais. 144

Figura 5.4. Pilar P1-12,5-150. a) Primeira fissura; e b) Configuração de fissuras denuncia a flambagem das barras longitudinais das quinas. .145

Figura 5.5. Pilar P1-12,5-100. a) Primeira fissura; e b) Fissura inclinada à $30^{\circ}$. 146 
Figura 5.6. Pilar P2-10,0-120. a) Flambagem das barras longitudinais de uma face; e b) Descolamento do cobrimento da parte superior na fase de pós-pico associado ao carregamento centrado que sobre o pilar. 147

Figura 5.7. Pilar P2-12,5-150. a) Flambagem das barras longitudinais de uma face; e b) Esquema de fissuras característico de elementos submetidos àcompressão simples. 148

Figura 5.8. Pilar P2-12,5-100. a) Estágio em que o cobrimento está destacando-se e a fissura inclinada mais evidente; e b) Estado de fissuração do pilar ao final do ensaio 149

Figura 5.9. As fotos a e b foram tiradas do pilar P2-12,5-75 em diferentes etapas de carregamento, porém, de um mesmo ângulo de visão. Isto permitiu observar a maior fissuração em um dos lados do modelo, fato este que revela o estado de flexão composta ao qual o pilar foi submetido. 150

Figura 5.10. Pilar P3-10,0-120. a) Lado esquerdo do pilar mais deteriorado revela a flexão composta que atuou sobre o modelo; e b) Estado de fissuração do pilar ao final do ensaio. 151

Figura 5.11. Pilar P3-12,5-150. a) Lado esquerdo do pilar mais deteriorado revela a flexão composta que atuou sobre o modelo; e b) Descolamento do cobrimento e flambagem das barras longitudinais do modelo já na fase de pós-pico. 152 Figura 5.12. Pilar P3-12,5-100. a) Lado esquerdo do pilar mais deteriorado revela a flexão composta que atuou sobre o modelo; e b) Estado de fissuração do pilar ao final do ensaio. 153

Figura 5.13. Pilar P3-12,5-75. a) Detalhe da barra longitudinal flambada entre os estribos por conta da eficiente contenção lateral imposta por esta armadura transversal; e b) Estado de fissuração do pilar ao final do ensaio. 154 Figura 5.14. Pilar P4-10,0-120. a) Força de primeira fissura; e b) Estado de fissuração do pilar ao final do ensaio 155 Figura 5.15. Pilar P4-12,5-150. a) Flambagem das barras longitudinais na fase de pós-pico; e b) Descolamento do cobrimento e desenvolvimento da fissura inclinada à $30^{\circ}$ 156

Figura 5.16. Pilar P4-12,5-100. a) Fissura decorrente da flambagem de uma das barras longitudinais das quinas; e b) Lado esquerdo do pilar mais deteriorado revela o estado de flexão composta que atuou sobre o modelo. 157

Figura 5.17. Pilar P4-12,5-75. a) Fissuras horizontais na face menos carregada do pilar; e b) Estado de fissuração da face mais carregada do pilar. 158 
Figura 5.18. Numeração dos transdutores e extensômetros do pilar P1-10,0-120. 159

Figura 5.19. Diagrama relativo aos transdutores do pilar P1-10,0-120.... 159

Figura 5.20. Diagrama relativo aos extensômetros da armadura longitudinal do pilar P1-10,0-120. 159

Figura 5.21. Diagrama relativo aos extensômetros dispostos longitudinalmente sobre as faces do pilar P1-10,0-120. 160

Figura 5.22. Diagrama relativo aos extensômetros da armadura transversal do pilar P1-10,0-120. 160

Figura 5.23. Diagrama relativo aos extensômetros dispostos transversalmente sobre as faces do pilar P1-10,0-120. .160

Figura 5.24. Numeração dos transdutores e extensômetros do pilar P1-12,5-200... 161

Figura 5.25. Diagrama relativo aos transdutores do pilar $\mathrm{P} 1-12,5-200$. 161 Figura 5.26. Diagrama relativo aos extensômetros da armadura longitudinal do pilar P1-12,5-200. 161

Figura 5.27. Diagrama relativo aos extensômetros dispostos longitudinalmente sobre as faces do pilar P1-12,5-200. 162

Figura 5.28. Diagrama relativo aos extensômetros da armadura transversal do pilar P1-12,5-200. 162

Figura 5.29. Diagrama relativo aos extensômetros dispostos transversalmente sobre as faces do pilar P1-12,5-200. 162

Figura 5.30. Numeração dos transdutores e extensômetros do pilar $\mathrm{P} 1-12,5-150$. .163

Figura 5.31. Diagrama relativo aos transdutores do pilar $\mathrm{P} 1-12,5-150$ 163

Figura 5.32. Diagrama relativo aos extensômetros da armadura longitudinal do pilar P1-12,5-150. 163

Figura 5.33. Diagrama relativo aos extensômetros dispostos longitudinalmente sobre as faces do pilar P1-12,5-150. .164

Figura 5.34. Diagrama relativo aos extensômetros da armadura transversal do pilar P1-12,5-150. 164

Figura 5.35. Diagrama relativo aos extensômetros dispostos transversalmente sobre as faces do pilar P1-12,5-150. 164

Figura 5.36. Numeração dos transdutores e extensômetros do pilar P1-12,5-100. .165 
Figura 5.37. Diagrama relativo aos transdutores do pilar P1-12,5-100. 165

Figura 5.38. Diagrama relativo aos extensômetros da armadura longitudinal do pilar P1-12,5-100. 165

Figura 5.39. Diagrama relativo aos extensômetros dispostos longitudinalmente sobre as faces do pilar P1-12,5-100. 166

Figura 5.40. Diagrama relativo aos extensômetros da armadura transversal do pilar $\mathrm{P} 1-12,5-100$. 166

Figura 5.41. Diagrama relativo aos extensômetros dispostos transversalmente sobre as faces do pilar P1-12,5-100. 166

Figura 5.42. Numeração dos transdutores e extensômetros do pilar P2-12,5-150. 167

Figura 5.43. Diagrama relativo aos transdutores do pilar P2-12,5-150. 167

Figura 5.44. Diagrama relativo aos extensômetros da armadura longitudinal do pilar P2-12,5-150. 167

Figura 5.45. Diagrama relativo aos extensômetros dispostos longitudinalmente sobre as faces do pilar P2-12,5-150 168

Figura 5.46. Diagrama relativo aos extensômetros da armadura transversal do pilar P2-12,5-150. 168

Figura 5.47. Diagrama relativo aos extensômetros dispostos transversalmente sobre as faces do pilar P2-12,5-150. 168

Figura 5.48. Numeração dos transdutores e extensômetros do pilar P2-12,5-100...... 169

Figura 5.49. Diagrama relativo aos transdutores do pilar P2-12,5-100. 169 Figura 5.50. Diagrama relativo aos extensômetros da armadura longitudinal do pilar P2-12,5-100. 169

Figura 5.51. Diagrama relativo aos extensômetros dispostos longitudinalmente sobre as faces do pilar P2-12,5-100. 170

Figura 5.52. Diagrama relativo aos extensômetros da armadura transversal do pilar P2-12,5-100. 170

Figura 5.53. Diagrama relativo aos extensômetros dispostos transversalmente sobre as faces do pilar P2-12,5-100. 170

Figura 5.54. Numeração dos transdutores e extensômetros do pilar P2-12,5-75 171

Figura 5.55. Diagrama relativo aos transdutores do pilar P2-12,5-75 171 
Figura 5.56. Diagrama relativo aos extensômetros da armadura longitudinal do pilar P2-12,5-75. 171

Figura 5.57. Diagrama relativo aos extensômetros dispostos longitudinalmente sobre as faces do pilar P2-12,5-75. 172

Figura 5.58. Diagrama relativo aos extensômetros da armadura transversal do pilar P2-12,5-75. 172

Figura 5.59. Diagrama relativo aos extensômetros dispostos transversalmente sobre as faces do pilar P2-12,5-75. .172

Figura 5.60. Numeração dos transdutores e extensômetros do pilar P3-10,0-120. 173

Figura 5.61. Diagrama relativo aos transdutores do pilar P3-10,0-120.... 173

Figura 5.62. Diagrama relativo aos extensômetros da armadura longitudinal do pilar P3-10,0-120. 173

Figura 5.63. Diagrama relativo aos extensômetros dispostos longitudinalmente sobre as faces do pilar P3-10,0-120. 174

Figura 5.64. Diagrama relativo aos extensômetros da armadura transversal do pilar P3-10,0-120. 174

Figura 5.65. Diagrama relativo aos extensômetros dispostos transversalmente sobre as faces do pilar P3-10,0-120. .174

Figura 5.66. Numeração dos transdutores e extensômetros do pilar P3-12,5-150. 175

Figura 5.67. Diagrama relativo aos transdutores do pilar P3-12,5-150.... 175 Figura 5.68. Diagrama relativo aos extensômetros da armadura longitudinal do pilar P3-12,5-150. 175

Figura 5.69. Diagrama relativo aos extensômetros dispostos longitudinalmente sobre as faces do pilar P3-12,5-150. 176

Figura 5.70. Diagrama relativo aos extensômetros da armadura transversal do pilar P3-12,5-150. 176

Figura 5.71. Diagrama relativo aos extensômetros dispostos transversalmente sobre as faces do pilar P3-12,5-150. 176

Figura 5.72. Numeração dos transdutores e extensômetros do pilar P3-12,5-100...... 177

Figura 5.73. Diagrama relativo aos transdutores do pilar P3-12,5-100. 177

Figura 5.74. Diagrama relativo aos extensômetros da armadura longitudinal do pilar P3-12,5-100. 
Figura 5.75. Diagrama relativo aos extensômetros dispostos longitudinalmente sobre as faces do pilar P3-12,5-100 178

Figura 5.76. Diagrama relativo aos extensômetros da armadura transversal do pilar P3-12,5-100. 178

Figura 5.77. Diagrama relativo aos extensômetros dispostos transversalmente sobre as faces do pilar P3-12,5-100. 178

Figura 5.78. Numeração dos transdutores e extensômetros do pilar P3-12,5-75. 179

Figura 5.79. Diagrama relativo aos transdutores do pilar P3-12,5-75 179

Figura 5.80. Diagrama relativo aos extensômetros da armadura longitudinal do pilar P3-12,5-75. 179

Figura 5.81. Diagrama relativo aos extensômetros dispostos longitudinalmente sobre as faces do pilar P3-12,5-75. 180

Figura 5.82. Diagrama relativo aos extensômetros da armadura transversal do pilar P3-12,5-75. 180

Figura 5.83. Diagrama relativo aos extensômetros dispostos transversalmente sobre as faces do pilar P3-12,5-75. 180

Figura 5.84. Numeração dos transdutores e extensômetros do pilar P4-10,0-120. 181

Figura 5.85. Diagrama relativo aos transdutores do pilar P4-10,0-120. 181 Figura 5.86. Diagrama relativo aos extensômetros da armadura longitudinal do pilar P4-10,0-120. 181

Figura 5.87. Diagrama relativo aos extensômetros dispostos longitudinalmente sobre as faces do pilar P4-10,0-120. 182

Figura 5.88. Diagrama relativo aos extensômetros da armadura transversal do pilar P4-10,0-120. 182

Figura 5.89. Diagrama relativo aos extensômetros dispostos transversalmente sobre as faces do pilar P4-10,0-120. 182

Figura 5.90. Numeração dos transdutores e extensômetros do pilar P4-12,5-150.. 183

Figura 5.91. Diagrama relativo aos transdutores do pilar P4-12,5-150. 183 Figura 5.92. Diagrama relativo aos extensômetros da armadura longitudinal do pilar P4-12,5-150. 183

Figura 5.93. Diagrama relativo aos extensômetros dispostos longitudinalmente sobre as faces do pilar P4-12,5-150. 
Figura 5.94. Diagrama relativo aos extensômetros da armadura transversal do pilar P4-12,5-150. 184

Figura 5.95. Diagrama relativo aos extensômetros dispostos transversalmente sobre as faces do pilar P4-12,5-150. 184

Figura 5.96. Numeração dos transdutores e extensômetros do pilar P4-12,5-100...... 185

Figura 5.97. Diagrama relativo aos transdutores do pilar P4-12,5-100. 185

Figura 5.98. Diagrama relativo aos extensômetros da armadura longitudinal do pilar P4-12,5-100. .185

Figura 5.99. Diagrama relativo aos extensômetros da armadura transversal do pilar P4-12,5-100. 186

Figura 5.100. Numeração dos transdutores e extensômetros do pilar P4-12,5-75. 187

Figura 5.101. Diagrama relativo aos transdutores do pilar P4-12,5-75. 187

Figura 5.102. Diagrama relativo aos extensômetros da armadura longitudinal do pilar P4-12,5-75.. 187

Figura 5.103. Diagrama relativo aos extensômetros dispostos longitudinalmente sobre as faces do pilar P4-12,5-75. 188

Figura 5.104. Diagrama relativo aos extensômetros da armadura transversal do pilar P4-12,5-75. 188

Figura 5.105. Diagrama relativo aos extensômetros dispostos transversalmente sobre as faces do pilar P4-12,5-75. 188

Figura 5.106. Esquema de ensaio àcompressão dos corpos -de-prova: a) Placas de neoprene; b) Painel de Controle da ELE Autotest; e c) Corpo-de-prova na máquina ELE Autotest. .193

Figura 5.107. Esquema de ensaio à tração dos corpos -de-prova: a) Instrumento empregado no ensaio de tração; e b) Corpo-de-prova na máquina ELE Autotest. .194

Figura 5.108. Corpo-de-prova instrumentado com dois transdutores de deslocamento.. 196

Figura 5.109. Diagramas tensão-deformação dos corpos-de-prova ensaiados. 196 


\section{Capítulo 6}

Figura 6.1. No detalhe do diagrama dos extensômetros da armadura longitudinal do pilar P2-12,5-100, observa-se a pequena queda na força aplicada decorrente da redução na velocidade de deslocamento dos ensaios. .221

Figura 6.2. Da esquerda para a direita, diagramas dos transdutores dos pilares P3-12,5-150 e P3-12,5-75. 222

Figura 6.3. Da esquerda para a direita, diagramas da armadura longitudinal dos pilares P3-12,5-150 e P3-12,5-75. 222

Figura 6.4. Da esquerda para a direita, diagramas da armadura transversal dos pilares P3-12,5-150 e P3-12,5-75. 222

Figura 6.5. Diagrama $F / F_{u} x$ deformação dos transdutores do pilar P4-12,5-100 e a curva resultante da regressão polinomial feita com o auxílio do programa de cálculos matemáticos MATHCAD 7.0..........................................................230

Figura 6.6. Relação $I D_{\text {p-pós }} \times r_{w}$ para os modelos de seção retangular.................232 


\section{LISTA DE TABELAS}

\section{Capítulo 2}

Tabela 2.1. Classificação dos concretos, AMARAL FILHO (1997)............................8

Tabela 2.2. Classificação dos concretos, MEHTA \& MONTEIRO (1994)...................8

Tabela 2.3. Características dos edifícios, CAMPOS (2000)...................................11

Tabela 2.4. Análise dos custos pela área de construção, CAMPOS (2000)............11

Tabela 2.5. Índices da estrutura em relação àárea da obra, CAMPOS (2000).......12

Tabela 2.6. Composição dos minerais principais do clínquer e suas porcentagens no cimento Portland comum, MEHTA \& MONTEIRO (1994). .14

Tabela 2.7. Volume de agregado graúdo compactado em estado seco, em $\mathrm{m}^{3}$, por unidade de volume de concreto, MEHTA \& MONTEIRO (1994)..... .17

Tabela 2.8. Valores típicos de deformação última, NEVILLE (1982) .25

Tabela 2.9. Efeito do tipo de agregado sobre o módulo de deformação, CEB-FIP Model Code (1990) .29

\section{Capítulo 3}

Tabela 3.1. Dados das armaduras dos pilares ensaiados, MÖRSCH (1952). 46

Tabela 3.2. Principais pesquisas sobre confinamento do concreto em pilares submetidos àcompressão centrada, SHEIKH \& UZUMERI (1982). .56

Tabela 3.3. Classes de eficiência do confinamento de acordo com os valores do I.E.C., CUSSON \& PAULTRE (1993). 103

\section{Capítulo 4}

Tabela 4.1. Consumo unitário de materiais para a dosagem de 25MPa 109

Tabela 4.2. Consumo unitário de materiais para a dosagem de $40 \mathrm{MPa}$ 109

Tabela 4.3. Resistência à compressão do concreto dos corpos-de-prova aos 14 dias. 110

Tabela 4.4. Limites granulométricos da pedra britada segundo a NBR 7211 (1983)

Tabela 4.5. Propriedades das armaduras. .115

Tabela 4.6. Variação da armadura longitudinal nos pilares 
Tabela 4.7. Características geométricas dos modelos de pilares. 130

Tabela 4.8. Previsão da força de ruína dos pilares 131

\section{Capítulo 5}

Tabela 5.1. Deformações de pico nos pilares da série $P 1$, em $\mathrm{mm} / \mathrm{m}$. 189

Tabela 5.2. Deformações de pico nos pilares da série $P 2$, em $\mathrm{mm} / \mathrm{m}$ .190

Tabela 5.3. Deformações de pico nos pilares da série $P 3$, em $\mathrm{mm} / \mathrm{m}$. 191

Tabela 5.4. Deformações de pico nos pilares da série $P 4$, em $\mathrm{mm} / \mathrm{m}$ 192

Tabela 5.5. Resultados dos ensaios dos corpos-de-prova aos 13 e 14 dias .195

\section{Capítulo 6}

Tabela 6.1. Deformações longitudinais médias no pilar P1-10,0-120...................199

Tabela 6.2. Deformações transversais médias no pilar P1-10,0-120.....................199

Tabela 6.3. Deformações longitudinais médias no pilar P1-12,5-200....................201

Tabela 6.4. Deformações transversais médias no pilar P1-12,5-200.....................201

Tabela 6.5. Deformações longitudinais médias no pilar P1-12,5-150..................203

Tabela 6.6. Deformações transversais médias no pilar P1-12,5-150....................203

Tabela 6.7. Deformações longitudinais médias no pilar P1-12,5-100_...................204

Tabela 6.8. Deformações transversais médias no pilar P1-12,5-100.....................204

Tabela 6.9. Deformações longitudinais médias no pilar P2-12,5-150...................206

Tabela 6.10. Deformações transversais médias no pilar P2-12,5-150...................206

Tabela 6.11. Deformações longitudinais médias no pilar P2-12,5-100..................208

Tabela 6.12. Deformações transversais médias no pilar P2-12,5-100...................208

Tabela 6.13. Deformações longitudinais médias no pilar P2-12,5-75...................209

Tabela 6.14. Deformações transversais médias no pilar P2-12,5-75.....................209

Tabela 6.15. Deformações longitudinais médias no pilar P3-10,0-120..................211

Tabela 6.16. Deformações transversais médias no pilar P3-10,0-120..................211

Tabela 6.17. Deformações longitudinais médias no pilar P3-12,5-150.................212

Tabela 6.18. Deformações transversais médias no pilar P3-12,5-150 ..................212

Tabela 6.19. Deformações longitudinais médias no pilar P3-12,5-100.................213

Tabela 6.20. Deformações transversais médias no pilar P3-12,5-100..................213

Tabela 6.21. Deformações longitudinais médias no pilar P3-12,5-75....................215

Tabela 6.22. Deformações transversais médias no pilar P3-12,5-75....................215 
Tabela 6.23. Deformações longitudinais médias no pilar P4-10,0-120................216

Tabela 6.24. Deformações transversais médias no pilar P4-10,0-120...................216

Tabela 6.25. Deformações longitudinais médias no pilar P4-12,5-150.................217

Tabela 6.26. Deformações transversais médias no pilar P4-12,5-150...................217

Tabela 6.27. Deformações longitudinais médias no pilar P4-12,5-100..................218

Tabela 6.28. Deformações transversais médias no pilar P4-12,5-100 ..................218

Tabela 6.29. Deformações longitudinais médias no pilar P4-12,5-75...................219

Tabela 6.30. Deformações transversais médias no pilar P4-12,5-75....................220

Tabela 6.31. Forças de primeira fissura e de ruína dos pilares.............................221

Tabela 6.32. Capacidades resistentes dos modelos de pilares ensaiados............224

Tabela 6.33. Resistências dos concretos dos pilares de acordo com o modelo teórico de confinamento de SAATCIOGLU \& RAZVI (1992)

Tabela 6.34. I.E.C. e capacidades resistentes dos pilares considerando-se 0 confinamento dado pela armadura transversal de acordo com SAATCIOGLU \&

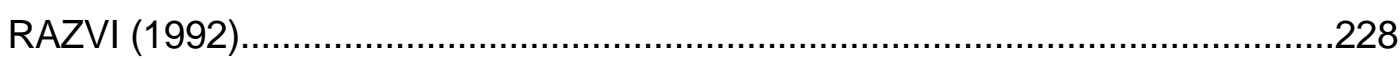

Tabela 6.35. Efeito de cintamento causado pelo confinamento dado pelas armaduras. .229

Tabela 6.36. Avaliação numérica da ductilidade com o emprego do critério desenvolvido por LIMA JUNIOR \& GIONGO (2001). 230

\section{Capítulo 7}

Tabela 7.1. Índices de ductilidade obtidos a partir dos ensaios de corpos-de-prova cilíndricos de dimensões de $15 \mathrm{~cm} \times 30 \mathrm{~cm}$, adaptado de LIMA JUNIOR \& GIONGO (2001). .235 


\section{RESUMO}

RAMOS, R. F. (2001). Análise experimental de pilares de concreto armado sob ação centrada com resistência do concreto de 25MPa. São Carlos, 2001. 247p. Dissertação (Mestrado) - Escola de Engenharia de São Carlos, Universidade de São Paulo.

Este trabalho analisou o comportamento teórico e experimental de pilares de concreto armado submetidos à força de compre ssão centrada e executados com concreto de resistência à compressão em torno de $25 \mathrm{MPa}$. Durante a fase experimental, foram ensaiados 16 modelos com dimensões das seções transversais de $200 \mathrm{~mm} \times 200 \mathrm{~mm}$ e $150 \mathrm{~mm} \times 300 \mathrm{~mm}$, sendo as alturas iguais a seis vezes a menor dimensão da seção, ou sejam, $1200 \mathrm{~mm}$ e $900 \mathrm{~mm}$, respectivamente. Além das dimensões dos pilares, outros parâmetros foram considerados, tais como a taxa de armadura longitudinal e o espaçamento e a configuração da armadura transversal. Os ensaios foram realizados em uma máquina hidráulica servocontrolada que permitiu aplicar a força de compressão com controle de deslocamento. Assim, foi possível obter o trecho pós-pico da curva forçadeformação dos pilares. Os resultados experimentais mostraram que não há formação de núcleo resistente. Foi notado que as fissuras surgiram em etapa de carga muito próxima do colapso dos modelos. Para as taxas de armadura transversal adotadas, foi verificado um ligeiro cintamento e um expressivo aumento na ductilidade dos pilares. Por fim, verificou-se que o estribo suplementar, em forma de barra reta com ganchos nas extremidades, contribuiu para cintar e ductilizar os modelos de pilares.

Palavras-chave: Pilares; Concreto Armado; Experimentação. 


\section{ABSTRACT}

RAMOS, R. F. (2001). Experimental analysis of reinforced concrete columns under axial force with concrete strength of 25MPa. São Carlos, 2001. 247p. Dissertação (Mestrado) - Escola de Engenharia de São Carlos, Universidade de São Paulo.

This work analysed the theoretical and experimental behaviour of reinforced concrete columns under axial compression force with concrete compressive strenght around of $25 \mathrm{MPa}$. In the experimental stage it was tested 16 specimens with cross sections of $200 \mathrm{~mm} \times 200 \mathrm{~mm}$ and $150 \mathrm{~mm} \times 300 \mathrm{~mm}$. The height of the columns were six times the smallest dimension of the cross section, i.e., $1200 \mathrm{~mm}$ and $900 \mathrm{~mm}$, respectively. Besides the dimensions of the columns, other parameters, like longitudinal reinforcement ratio and the spacing and arrangement of the transverse reinforcement were varied. The columns were loaded concentrically in an servohidraulically controlled testing machine that permitted applying the compression force with displacement control. Therefore, it was possible to obtain the force-strain curve post-peak. The results showed that were not formed resistent cores. Cracks appeared in a load stage near the failure of the specimens. For the transversal reinforcement ratio adopted, it was verified a small gain in strength and an significant increase in ductility. At last, the supplementary cross ties provided gain of strength and ductility in the columns.

Keywords: Columns; Reinforced concrete; Tests. 


\section{INTRODUCÃO}

\subsection{Considerações Iniciais}

O estudo de pilares de concreto armado tem sido tema de várias dissertações e teses que foram produzidas ou que estão em andamento no Departamento de Engenharia de Estruturas da Escola de Engenharia de São Carlos, Universidade de São Paulo. Neste trabalho, pilares de concreto armado com resistência média à compressão do concreto de $25 \mathrm{MPa}$, aos quatorze dias de idade, foram analisados teórica e experimentalmente sob força de compressão centrada.

Um dos pontos centrais da pesquisa foi averiguar a formação ou não de núcleo resistente em pilares de Concreto de Resistência Usual (CRU), baseado nas verificações feitas por MÖRSCH (1952), SHEIKH \& UZUMERI (1980), AGOSTINI (1992), PAIVA (1994), LIMA et al. (1997) e QUEIROGA et al. (1999). Isto pois, para pilares não cintados executados com $\mathrm{CRU}$, os ensaios revelaram que suas capacidades resistentes são o somatório das resistências do aço e do concreto da seção íntegra. Além disso, foi constatada a semelhança nas deformações médias durante sua fase elástica, quando armados ou não, o que permitiu concluir que a seção resistente, no pré-pico, é a seção transversal total, inclusive com o cobrimento. Enquanto isso, para pilares não cintados executados com Concretos de Alta Resistência (CAR), observou-se que as deformações médias na fase elástica dos pilares armados eram superiores æ̀̀ deformações médias dos pilares não armados. Os ensaios ainda demonstraram que a capacidade experimental dos pilares $\left(F_{\text {exp }}\right)$ estava entre as capacidades teóricas considerando-se a seção íntegra $\left(F_{\text {teór }}\right)$ e a delimitada pelos eixos dos estribos mais externos $\left(F_{\text {teór,n }}\right)$, ou seja, $\mathrm{F}_{\text {teór, } \mathrm{n}}<\mathrm{F}_{\text {exp }}<\mathrm{F}_{\text {teór. }}$ Isto levou às seguintes conclusões:

- nos pilares de CAR não armados, toda a seção transversal participa como seção resistente; 
- nos pilares armados de CAR, as armaduras longitudinal e transversal definem um núcleo resistente de concreto, como mostra a figura 1, o que implica na não contribuição da camada de cobrimento na resistência. Além disso, este núcleo sofre efeito de cintamento pelas armaduras, visto que $F_{\text {exp }}>F_{\text {teór,n. }}$.

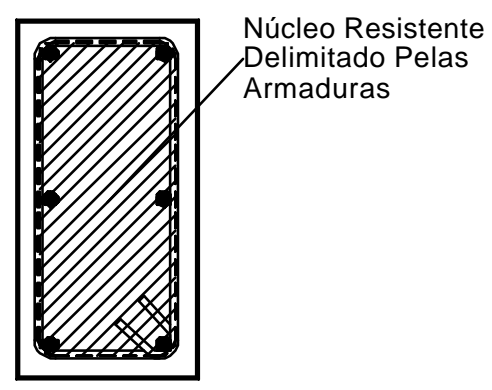

Figura 1.1. Núcleo resistente de concreto.

Os ensaios dos modelos da presente pesquisa foram realizados com velocidades relativamente rápidas e, portanto, não foram contemplados os efeitos da maturação, fluência e retração do concreto decorrentes das cargas de longa duração.

Para finalizar, os resultados, análises e conclusões obtidas neste trabalho somam-se aos de LIMA (1997) e QUEIROGA (1999), visto que estes pesquisadores trabalharam com pilares de concreto armado com resistências do concreto de $80 \mathrm{MPa}$ e $60 \mathrm{MPa}$, respectivamente, e submetidos às mesmas condições de ação e vinculação aqui empregadas. Deste modo, disponibiliza-se à comunidade científica um abrangente estudo sobre o comportamento de pilares de concreto armado submetidos à ação centrada, com ampla variação da resistência do concreto (25MPa, 60MPa e $80 \mathrm{MPa})$ e o emprego de diversas taxas e configurações das armaduras transversal e longitudinal nos pilares.

\subsection{Objetivos}

Estes foram os principais objetivos da pesquisa:

- obter informações sobre o comportamento teórico e experimental de pilares de concreto armado submetidos à compressão centrada e executados com concreto de resistência àcompressão de 25MPa; 
- determinar, por meio da análise experimental, a existência ou não de núcleo resistente em pilares executados com concretos de resistência usual;

- verificar os efeitos oriundos do confinamento do concreto dado pelas armaduras no que diz respeito aos fenômenos de ductilidade e cintamento. É importante salientar que não é objetivo desta pesquisa provocar o cintamento do concreto dos pilares, porém, ainda assim, os resultados experimentais foram analisados levando-se em conta a possibilidade disso ocorrer;

- verificar as recomendações da NBR 6118 (1978), quanto æ̀s taxas e configurações das armaduras transversal e longitudinal nos pilares não cintados e que tenham todas as suas barras longitudinais comprimidas; e

- fornecer subsídios para a formulação de modelos teóricos que retratem o comportamento de pilares de concreto armado sob ação centrada, tendo-se fixado a resistência do concreto em $25 \mathrm{MPa}$ e variada as taxas e configurações das armaduras transversal e longitudinal dos pilares.

\subsection{Justificativas}

As seguintes justificativas embasam a importância desta pesquisa:

- o Projeto de Revisão da NBR 6118 (2000) prescreve a utilização de resistência mínima àcompressão de 20MPa para concretos com apenas armadura passiva. Além disso, concretos nesta faixa de resistência são classificados como Concretos de Resistência Usual (CRU). Desta forma, justifica-se o estudo de pilares sob ação centrada com resistência de $25 \mathrm{MPa}$, pois, praticamente se abrange o limite inferior de atuação do Projeto de Revisão da NBR 6118 (2000), ao mesmo tempo em que se trabalha com uma resistência bastante empregada em estruturas de concreto armado, como a própria classificação "usual" sugere;

- comprovação ou não das afirmações feitas por MÖRSCH (1952) e PAIVA (1994) sobre o comportamento de pilares executados com CRU. Para isso, deverá 
ser verificado experimentalmente se a seção resistente, na fase pré-pico, é a seção transversal total, inclusive com o cobrimento, nos pilares armados;

- obtenção de dados sobre ganhos de ductilidade em pilares sob ação centrada, executados com $\mathrm{CRU}$, como função das armaduras transversal e longitudinal adotadas nos modelos;

- possibilidade de avaliação da eficiência das prescrições da NBR 6118 (1978), referentes æ̀̀ armaduras transversal e longitudinal, em pilares não cintados de concreto armado; e

- criação de subsídios para a formulação de modelos teóricos que avaliem e representem o comportamento de pilares de concreto armado sob ação centrada.

\subsection{Metodologia}

Para que os objetivos levantados no item 1.2 fossem alcançados com êxito, a seguinte metodologia de trabalho foi aplicada:

- levantamento bibliográfico sobre aspectos relativos à pesquisa em questão, ou seja, estudo dos materiais que constituem o CRU e estudo do comportamento, dimensionamento e detalhamento de pilares de concreto armado;

- caracterização dos materiais em laboratório;

- determinação da dosagem que forneceu a resistência média àcompressão do concreto de $25 \mathrm{MPa}$, aos quatorze dias de idade;

- determinação das dimensões transversais e alturas, taxas, espaçamentos e configurações das armaduras dos pilares. Com isso, foi possível estipular o número de modelos, bem como, suas respectivas instrumentações;

- ensaio das quatro séries de pilares pertencentes ao programa experimental. Cada série era composta por quatro modelos, sendo que, na primeira série, estes 
modelos possuíam seção transversal de $200 \mathrm{~mm} \times 200 \mathrm{~mm}$ e altura de $1200 \mathrm{~mm}$. Nas demais séries as dimensões dos pilares eram de 150mm x 300mm x 900mm. Dentro de cada série, a diferenciação entre os elementos estava no espaçamento da armadura transversal e na taxa de armadura longitudinal empregada;

- análise teórica e experimental dos resultados obtidos nos ensaios. Deste modo, foi possível avaliar o comportamento apresentado pelos modelos e, assim, concretizar os objetivos definidos pelo pesquisador; e

- redação das conclusões.

\subsection{Divisão da Dissertação}

A seguir, apresentam-se a ordem e os conteúdos dos capítulos que compõem esta dissertação:

CAPÍTULO 1: Introdução - apresentação do tema, objetivos, justificativas e metodologia empregada neste trabalho;

CAPÍTULO 2: Concreto de Resistência Usual - abordagem de aspectos relativos a definição, composição e propriedades mecânicas do CRU;

CAPÍTULO 3: Pilares de Concreto de Resistência Usual - apresentação de um apanhado geral sobre os tipos de pilares, pesquisas realizadas e processos de cálculo de pilares de CRU com e sem armadura de confinamento, ao longo do século XX;

CAPÍTULO 4: Experimentação e Resultados - descrição do programa experimental e dos resultados dos ensaios realizados nesta pesquisa;

CAPÍTULO 5: Análise dos Resultados - análises dos resultados experimentais feitas de pilar em pilar e, posteriormente, de forma geral. Além disso, são confrontados os valores calculados teoricamente com aqueles obtidos nos ensaios; 
CAPÍTULO 6: Conclusões - apresentação das conclusões finais de acordo com os objetivos apontados no capítulo introdutório e algumas constatações feitas ao longo do trabalho;

Referências Bibliográficas - textos citados na dissertação; e

Bibliografia Complementar - textos que, apesar de não terem sido citados ao longo da dissertação, contribuíram para a elaboração deste trabalho. 


\section{CONCRETO DE RESISTÊNCIA USUAL}

\subsection{Considerações Iniciais}

O concreto utilizado para a execução dos modelos foi o concreto de resistência usual. Assim, pareceu interessante a elaboração deste capítulo com os intuitos de justificar a sua utilização, orientar sua produção e conhecer seu comportamento mediante a presença de esforços semelhantes aos que ocorreram nos corpos-de-prova e pilares ensaiados nesta pesquisa.

\subsection{Definição do Concreto de Resistência Usual}

Ao longo dos anos em que o concreto tem sido utilizado como material estrutural, em poucas oportunidades, visto a quantidade de estruturas executadas com concreto no mundo, sua resistência à compressão superou os $30 \mathrm{MPa}$. Conseqüentemente, concretos com resistências até o limite de $30 \mathrm{MPa}$ são denominados de Concretos de Resistência Usual (CRU). Isto concorda com DAL MOLIN et al. (1997), a partir dos quais os concretos de resistência usual são aqueles com resistências amplamente utilizadas em determinado local e época. Desta forma, como grande parte dos arranha-céus construídos nas regiões metropolitanas dos Estados Unidos, destacando-se as cidades de Chicago, New Yorque e Houston, possuem concretos de alta resistência (MEHTA \& MONTEIRO (1994)), isto permite classificar os concretos de alta resistência, nestes locais, como de resistência usual. 


\subsection{Classificação dos Concretos}

Segundo AMARAL FILHO (1997), os concretos podem ser classificados, quanto a sua resistência à compressão uniaxial, conforme mostrado na tabela 2.1. MEHTA \& MONTEIRO (1994) sugerem a classificação apresentada na tabela 2.2.

Tabela 2.1. Classificação dos concretos, AMARAL FILHO (1997).

\begin{tabular}{cc}
\hline Resistência à Compressão (MPa) & Classificação \\
\hline$<25$ & Baixa \\
$25-50$ & Média \\
$50-90$ & Alta \\
$>90$ & Ultra Alta \\
\hline
\end{tabular}

Tabela 2.2. Classificação dos concretos, MEHTA \& MONTEIRO (1994).

\begin{tabular}{cc}
\hline Resistência à Compressão (MPa) & Classificação \\
\hline$<20$ & Baixa \\
$20-40$ & Moderada \\
$>40$ & Alta \\
\hline
\end{tabular}

Diante das classificações contidas nas tabelas 2.1 e 2.2, pode-se dizer que o concreto de resistência usual, empregado no Brasil, é de resistência baixa a moderada.

\subsection{Vantagens e Desvantagens do Concreto de Resistência Usual}

Nas duas últimas décadas, os avanços tecnológicos sobre o concreto resultaram no melhoramento de suas propriedades mecânicas e de durabilidade, fazendo surgir o Concreto de Alta Resistência (CAR). Por conta das vantagens adquiridas com o emprego do CAR, nas estruturas, a utilização destes concretos aumentou sensivelmente. Porém, como o próprio nome sugere, o CRU ainda é o mais utilizado no mundo e, assim, coube aqui listar algumas das vantagens e desvantagens do emprego do $\mathrm{CRU}$ em relação ao CAR que, talvez, possam explicar a conformação deste quadro de consumo. 
As vantagens do CRU em relação ao CAR são as seguintes:

- a maior ductilidade do CRU permite que o cálculo, dimensionamento e detalhamento dos elementos estruturais sejam realizados com menores cuidados em relação a esta propriedade;

- o cálculo e a execução de estruturas com CRU são amplamente amparados por normas e literatura técnica nacional e internacional;

- a produção e o controle do CRU são simples, o que permite a instalação de centrais de produção no canteiro de obras; e

- a tecnologia para produção e aplicação do CRU é de amplo conhecimento dos técnicos e da mão-de-obra do canteiro.

Quanto æ̀̀ desvantagens, têm-se:

- elementos estruturais com maiores dimensões da seção transversal, o que implica em menor área útil dos pavimentos e maior volume de concreto;

- maior peso-próprio da estrutura influindo no aumento das cargas na fundação;

- aumento da área de fôrmas e, portanto, dos custos com fôrmas;

- maior segregação;

- maiores reparos e tratamentos superficiais;

- maior porosidade;

- maior exsudação;

- maior fluência; 
- menor durabilidade; e

- maior manutenção.

\subsection{Aplicabilidade do Concreto de Resistência Usual}

Ainda que haja uma grande tendência de utilização do CAR, o CRU possui aplicação garantida em edificações de pequena altura e construções fora dos grandes centros urbanos. Além disso, outra forma de aplicação do $\mathrm{CRU}$, visando aproveitar ao máximo as potencialidades da estrutura, está na possibilidade do edifício ser executado com concreto de resistência variável ao longo das partes que o compõe.

Após análises teóricas sobre o comportamento estrutural e a viabilidade financeira de edifícios executados com concretos de resistências variando de $20 \mathrm{MPa}$ a $80 \mathrm{MPa}$, CAMPOS (2000) apresenta o resumo de um estudo comparativo entre três edifícios construídos por uma mesma construtora no decorrer dos anos de 1995 a 2000. As características destes edifícios estão descritas na tabela 2.3. Após uma avaliação dos custos reais, apurados durante a construção das obras, foram montadas as tabelas 2.4 e 2.5. Por fim, na figura 2.1, é avaliada a taxa de armadura nos pilares dos últimos 17 pavimentos dos edifícios Villa Lobos e Solar da Serra.

Como parte de suas conclusões, CAMPOS (2000) observa a redução no custo das estruturas da ordem de $5 \%$ a $20 \%$, advinda do aumento da resistência do concreto e da melhor distribuição desta resistência ao longo das partes que compõem os edifícios. Além disso, por meio da figura 2.1, verifica a existência de um ponto ótimo de distribuição das resistências, o qual pode ser determinado com uma análise criteriosa no momento do lançamento da estrutura. Por fim, identifica vantagens como a menor manutenção e a maior durabilidade das estruturas mediante o emprego do CAR no lugar do CRU. 
Tabela 2.3. Características dos edifícios, CAMPOS (2000).

\begin{tabular}{|c|c|c|c|}
\hline Edifício & Villa Lobos & Dom Henrique & Solar da Serra \\
\hline N. ${ }^{\circ}$ de Quartos & 2 & 3 & $2 / 3$ \\
\hline $\begin{array}{l}\text { Aptos por } \\
\text { Pavimento }\end{array}$ & 4 & 4 & 4 \\
\hline N. de Apartamentos & 68 & 44 & 80 \\
\hline $\begin{array}{c}\text { Área Privativa } \\
\text { Int. }\left(\mathrm{m}^{2}\right)\end{array}$ & 68,00 & 86,85 & $69,00 / 82,00$ \\
\hline $\begin{array}{l}\text { Área Total } \\
\text { Const. }\left(\mathrm{m}^{2}\right)\end{array}$ & $8.309,00$ & $6.382,60$ & $9.957,80$ \\
\hline Tipo de Fundação & $\begin{array}{c}\text { Tubulão a Céu } \\
\text { Aberto }\end{array}$ & $\begin{array}{c}\text { Tubulão a Céu } \\
\text { Aberto }\end{array}$ & $\begin{array}{c}\text { Tubulão a Céu } \\
\text { Aberto }\end{array}$ \\
\hline Caract. da Fundação & $9 \mathrm{~m}$ e $0,35 \mathrm{MPa}$ & $9 \mathrm{~m}$ e $0,35 \mathrm{MPa}$ & $8 \mathrm{~m} \mathrm{e} 0,45 \mathrm{MPa}$ \\
\hline $\mathbf{f}_{c k}$ da Fundação & $13,5 \mathrm{MPa}$ & $13,5 \mathrm{MPa}$ & $13,5 \mathrm{MPa}$ \\
\hline Tipo de Estrutura & $\begin{array}{c}\text { Lajes Maciças e } \\
\text { Vigas }\end{array}$ & $\begin{array}{c}\text { Lajes Maciças e } \\
\text { Vigas }\end{array}$ & $\begin{array}{c}\text { Lajes Maciças e } \\
\text { Vigas }\end{array}$ \\
\hline$f_{c k}$ da Estrutura & $20 \mathrm{MPa}$ & $30 \mathrm{MPa}$ & $25 / 30 / 40 / 50 \mathrm{MPa}^{*}$ \\
\hline Administração & \multicolumn{3}{|c|}{ A mesma nas três obras } \\
\hline $\begin{array}{l}\text { Epoca da } \\
\text { Construção }\end{array}$ & 01/04/95 a 01/04/97 & 01/01/97 a 01/05/98 & $01 / 12 / 98$ a $01 / 05 / 00$ \\
\hline
\end{tabular}

\footnotetext{
* Neste edifício o $\mathrm{f}_{\mathrm{ck}}$ variou conforme a posição, no intuito de aproveitar ao máximo as potencialidades da estrutura.
}

Tabela 2.4. Análise dos custos pela área de construção, CAMPOS (2000).

\begin{tabular}{ccccc}
\hline \multirow{2}{*}{ Edifício } & \multicolumn{4}{c}{ Custos $\left(\mathbf{R} \mathbf{\$} / \mathbf{m}^{\mathbf{2}}\right)$} \\
\cline { 2 - 5 } & Concreto & Aço & Fôrmas & Total \\
\hline Villa Lobos & 25,20 & 16,01 & 14,40 & 55,61 \\
Dom Henrique & 25,35 & 13,30 & 14,00 & 52,65 \\
\% de dif. p/ Villa & $-0,59$ & 20,30 & 2,87 & 5,61 \\
\hline Edifício & & Custos $\left(\mathbf{R} \$ \mathbf{m}^{\mathbf{2}}\right)$ & Total \\
\cline { 2 - 5 } & Concreto & Aço & Fôrmas & 55,61 \\
Villa Lobos & 25,20 & 16,01 & 14,40 & 45,23 \\
Solar da Serra & 20,45 & 12,61 & 12,17 & 22,95 \\
\% de dif. p/ Villa & 23,21 & 26,94 & 18,37 & \\
\hline
\end{tabular}

Correção pela fundação diferente do Solar da Serra $\left(R \$ / \mathrm{m}^{2}\right)=1,10$

Correção pela fundação diferente do Solar da Serra $(\%)=2,93$

Redução de Custo Real Ajustada (\%) $=20,02$ 
Tabela 2.5. Índices da estrutura em relação àárea da obra, CAMPOS (2000).

\begin{tabular}{ccccc}
\hline Edifício & $\begin{array}{c}\text { Espessura Média de } \\
\text { Concreto }(\mathbf{c m})\end{array}$ & $\begin{array}{c}\text { Aço } \\
\left(\mathbf{k g} / \mathbf{m}^{2}\right)\end{array}$ & $\begin{array}{c}\text { Aço } \\
\mathbf{( k g / \mathbf { m } ^ { 3 } )}\end{array}$ & $\begin{array}{c}\text { Fôrmas } \\
\left(\mathbf{m}^{\mathbf{2}} / \mathbf{m}^{2}\right)\end{array}$ \\
\hline Villa Lobos & 15,94 & 13,72 & 86,07 & 1,87 \\
Dom Henrique & 15,33 & 11,68 & 76,18 & 1,72 \\
Solar da Serra & 13,14 & 11,73 & 89,27 & 1,78 \\
\hline
\end{tabular}

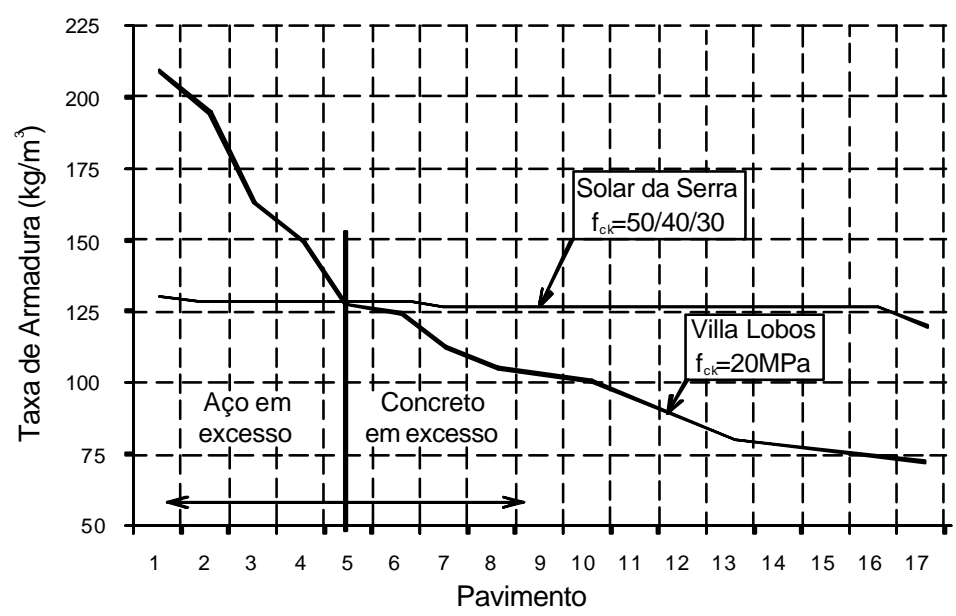

Figura 2.1. Taxa de armadura nos pilares dos últimos 17 pavimentos dos edifícios Villa Lobos e Solar da Serra, CAMPOS (2000).

MEHTA \& MONTEIRO (1994) citam os edifícios Texas Commerce Tower e Water Tower Place (ver a figura 2.2) como exemplos de construções com estrutura composta por várias resistências de concreto. Assim sendo, o Texas Commerce Tower, localizado na cidade de Houston e com 75 andares, teve sua estrutura formada por pilares e paredes com resistência do concreto de $53 \mathrm{MPa}$ até $08 .^{\circ}$ pavimento, 42MPa do $8 .^{\circ}$ ao $30 .^{\circ}$ pavimento, $35 \mathrm{MPa}$ do $30 .^{\circ}$ ao $60 .^{\circ}$ pavimento e 28MPa do $60 .^{\circ}$ pavimento até a cobertura. Enquanto isso, o Water Tower Place, localizado na cidade de Chicago, teve os pilares do $5 .^{\circ}$ ao $25 .^{\circ}$ pavimento executados com resistência do concreto de 63MPa, e acima do $25 .^{\circ}$ pavimento, a resistência do concreto dos pilares foi sendo progressivamente reduzida de $53 \mathrm{MPa}$ a $28 \mathrm{MPa}$. 

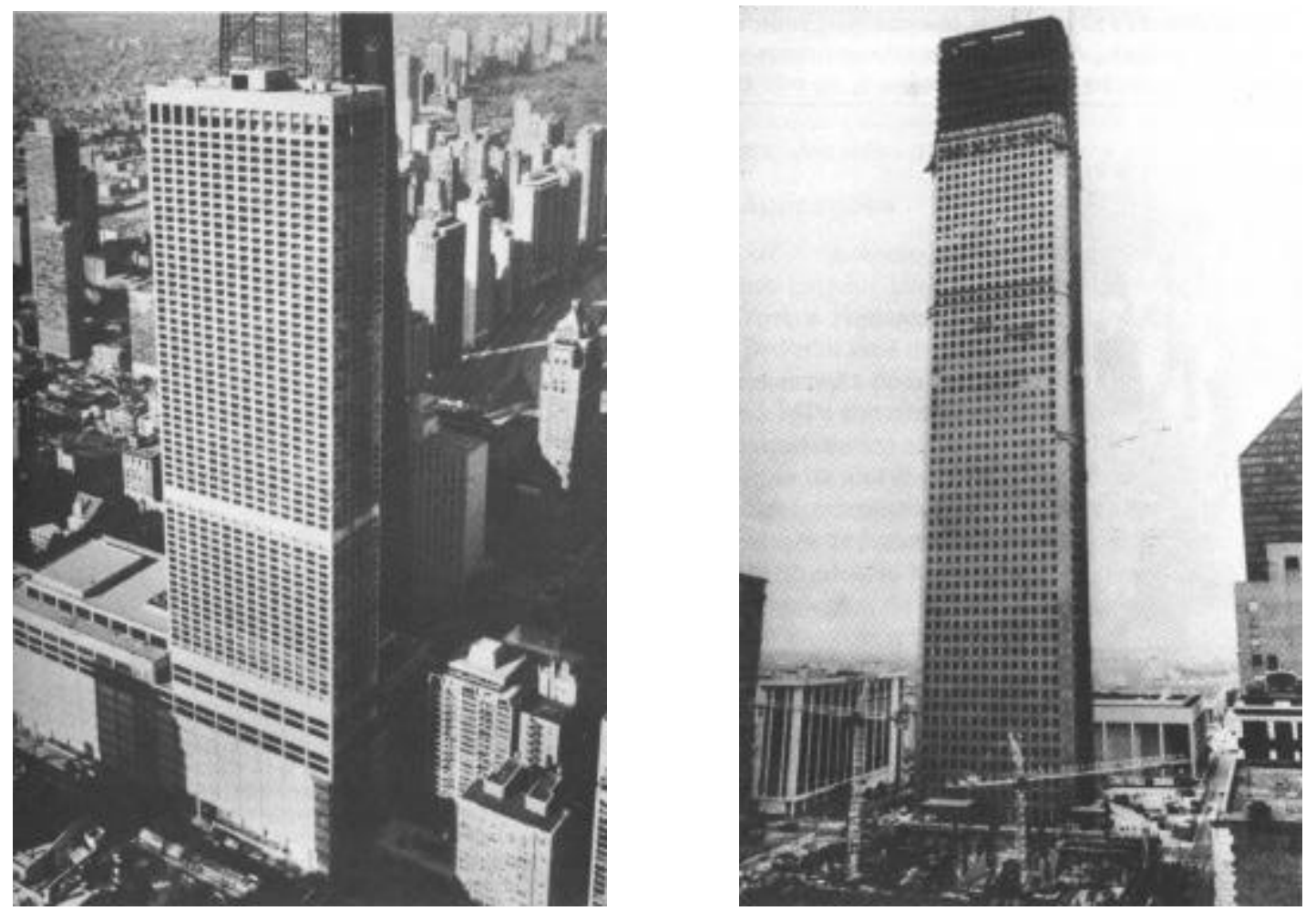

Figura 2.2. Da esquerda para a direita, edifícios Texas Commerce Tower e Water Tower Place, MEHTA \& MONTEIRO (1994).

\subsection{Materiais Constituintes do Concreto de Resistência Usual}

\subsubsection{Cimento}

Segundo NEVILLE (1982), pode ser considerado como cimento todo material com propriedades adesivas e coesivas, capaz de ligar fragmentos de minerais entre si de modo a formar um todo compacto. Sendo assim, o emprego de cimentos é bastante antigo, tendo sido utilizado pelos egípcios gesso impuro calcinado e pelos gregos e romanos calcário calcinado em suas estruturas.

Comparado aos aglomerantes gesso e cal, o cimento Portland, patenteado por Joseph Aspdin em 1824, e suas variações são os principais cimentos utilizados hoje em dia para a produção de concreto estrutural. Isto porque o cimento Portland é um aglomerante hidráulico que não só endurece por meio de reações com a água, como também forma um produto resistente à água. Contudo, cuidados devem ser tomados para que na mistura com agregados dotados de materiais 
deleteriamente reativos com os álcalis do cimento não ocorra a expansão e conseqüente degradação do material endurecido.

MEHTA \& MONTEIRO (1994) definem o cimento Portland anidro como um pó cinza que consiste de partículas angulares de tamanho comumente entre $1 \mu$ e $50 \mu$. Este é produzido pela moagem do clínquer com uma pequena quantidade de sulfato de cálcio, sendo o clínquer uma mistura heterogênea de vários minerais produzidos em reações a alta temperatura, entre óxido de cálcio e sílica, alumina e óxido de ferro. A composição química dos minerais principais do clínquer e suas porcentagens no cimento Portland comum estão apresentadas na tabela 2.6.

Tabela 2.6. Composição dos minerais principais do clínquer e suas porcentagens no cimento Portland comum, MEHTA \& MONTEIRO (1994).

\begin{tabular}{cccc}
\hline Composto & Constituição & Símbolo & Porcentagem \\
\hline Silicato tricálcico & $3 \mathrm{CaO} . \mathrm{SiO}_{2}$ & $\mathrm{C}_{3} \mathrm{~S}$ & $45-60$ \\
Silicato dicálcico & $2 \mathrm{CaO} . \mathrm{SiO}_{2}$ & $\mathrm{C}_{2} \mathrm{~S}$ & $15-30$ \\
Aluminato tricálcico & $3 \mathrm{CaO} \cdot \mathrm{Al}_{2} \mathrm{O}_{3}$ & $\mathrm{C}_{3} \mathrm{~A}$ & $6-12$ \\
Ferroaluminato tetracálcio & $4 \mathrm{CaO} \cdot \mathrm{Al}_{2} \mathrm{O}_{3} \cdot \mathrm{Fe}_{2} \mathrm{O}_{3}$ & $\mathrm{C}_{4} \mathrm{AF}$ & $6-8$ \\
\hline
\end{tabular}

A proporção destes compostos no cimento é capaz de influir no desenvolvimento da resistência e no calor de hidratação. Assim, se o cimento tiver grande quantidade de $\mathrm{C}_{3} \mathrm{~S}$ e $\mathrm{C}_{3} \mathrm{~A}$, suas resistências iniciais aos 3,7 e 28 dias serão altas. Todavia, o contrário ocorrerá se houver elevada proporção de $C_{2} S$. Além disso, a resistência final de cimentos com elevada proporção de $\mathrm{C}_{2} \mathrm{~S}$ será maior do que àquela com baixa proporção. Quanto ao calor de hidratação, espera-se que os cimentos com elevado teor de $\mathrm{C}_{2} \mathrm{~S}$ liberem menos calor.

O desenvolvimento da resistência e o calor de hidratação podem também ser controlados pela finura do cimento. Deste modo, um aumento da área específica Blaine resultará em aumento da resistência à compressão da argamassa de cimento e aumento da liberação de calor.

Segundo NEVILLE (1982), o cimento Portland possui compostos denominados secundários, os quais são assim chamados, pois representam uma parte reduzida da massa do cimento. São eles: $\mathrm{MgO}, \mathrm{TiO}_{2}, \mathrm{MnO}_{3}, \mathrm{~K}_{2} \mathrm{O}$ e $\mathrm{Na}_{2} \mathrm{O}$. Cuidado especial deve ser dado aos óxidos de sódio e potássio $\left(\mathrm{Na}_{2} \mathrm{O}\right.$ e $\left.\mathrm{K}_{2} \mathrm{O}\right)$ conhecidos como álcalis. Estes álcalis reagem com alguns agregados e os produtos das reações causam desintegração do concreto. 
Como foi demonstrado, as alterações da finura e das proporções dos componentes principais do cimento definem cimentos com características diferentes. Além desta possibilidade, adições como a escória de alto forno, cinza volante e cinza vulcânica resultam em cimentos com características bastante particulares. Por exemplo, as cinzas vulcânicas têm propriedades pozolânicas e, portanto, quando em contato com o hidróxido de cálcio e na presença de umidade formam produtos com capacidade cimentante. Desta adição, surge o Cimento Portland Pozolânico.

Para os concretos de resistência usual não há necessidade do emprego de um determinado cimento, no entanto, o uso de um ou outro dependerá das características que envolvem o projeto e a obra. As normas de projeto procuram estabelecer valores mínimos relativos ao teor de cimento e máximos quanto à relação água/cimento para a produção de concretos estruturais. É desta forma que a NBR 6118 (1978) prescreve um consumo mínimo de cimento de $300 \mathrm{~kg} / \mathrm{m}^{3}$ de concreto fresco. Além disso, o Projeto de Revisão da NBR 6118 (2000) fixa a relação água/cimento, em função de critérios de durabilidade, como sendo no máximo 0,65. Assim, obedecendo-se a estes valores, pode-se produzir CRU com teores de cimento entre $300 \mathrm{~kg} / \mathrm{m}^{3}$ e $400 \mathrm{~kg} / \mathrm{m}^{3}$ e relação água/cimento entre $0,50 \mathrm{e}$ 0,65 .

\subsubsection{Agregados}

De acordo com MEHTA \& MONTEIRO (1994), o agregado é um material granular, tal como a areia, o pedregulho, a pedra britada ou a escória de alto forno, usado com um meio cimentante, para formar um concreto ou argamassa de cimento hidráulico.

A NBR 7211 (1983) define o agregado miúdo como sendo areia de origem natural ou resultante do britamento de rochas estáveis, ou a mistura de ambas, cujos grãos passam pela peneira ABNT 4,8mm e ficam retidos na peneira ABNT 0,075 mm. Enquanto isso, o agregado graúdo é definido como sendo pedregulho ou brita proveniente de rochas estáveis, ou a mistura de ambos, cujos grãos passam por uma peneira de malha quadrada com abertura nominal de $152 \mathrm{~mm}$ e ficam retidos na peneira ABNT 4,8mm. 
A granulometria dos agregados, determinada pela NBR 7217 (1987), deve estar dentro das faixas especificadas pela NBR 7211 (1983). Agregados que não se enquadrem nestas faixas poderão ser utilizados desde que sejam realizados estudos prévios de dosagem ou então a faixa granulométrica seja de uso consagrado em determinada região.

As propriedades dos agregados influem nas proporções de dosagem e no comportamento do concreto fresco e endurecido. Algumas das propriedades dos agregados são: massa específica, absorção de água, resistência, dureza, módulo de elasticidade, sanidade, tamanho, forma, textura superficial das partículas e presença de substâncias deletérias.

Em geral, a resistência dos agregados não é um fator determinante na resistência dos concretos de resistência usual, pois, à exceção dos agregados leves, as partículas dos agregados são várias vezes mais resistentes que a matriz e a zona de transição do concreto.

No que diz respeito ao tamanho dos grãos dos agregados, NEVILLE (1982) afirma que para um mesmo teor de cimento e mesma consistência do concreto, agregados com partículas grandes requerem menos água de amassamento, o que resulta em menor relação água/cimento e conseqüente aumento da resistência. Assim, a escolha da dimensão máxima característica dos agregados graúdos deve ser a maior possível, desde que coerente com as dimensões da estrutura.

Tanto NEVILLE (1982) como MEHTA \& MONTEIRO (1994) concordam que concretos com agregados de textura rugosa e angulosa apresentam maior resistência (em especial à tração) e maior tensão de fissuração nas primeiras idades que concretos contendo agregados lisos. No entanto, a utilização destes agregados exige mais água de amassamento, para uma mesma trabalhabilidade e teor de cimento, que quando são utilizados agregados lisos como o seixo rolado. Com isso, o ganho de resistência em função da maior rugosidade e angulosidade de alguns agregados pode ser diminuído por conta do aumento da relação água/cimento no concreto.

Segundo NEVILLE (1982), observações experimentais levaram a concluir que a influência do agregado graúdo diminui com o aumento da relação água/cimento, presumindo-se que a resistência da pasta passe a prevalecer. De fato, para a relação água/cimento de 0,65 não se observou diferença entre resistências de concretos preparados com brita ou com seixo rolado. Esta conclusão é bastante importante, pois indica que os concretos de resistência usual, com relações 
água/cimento altas, podem ser dosados sem maiores preocupações com a forma e textura dos agregados.

De acordo com a NBR 7211 (1983), os agregados para uso em concreto não devem conter qualquer material deleteriamente reativo com os álcalis do cimento em uma intensidade suficiente para causar a expansão do concreto, a menos que o cimento empregado tenha menos de $0,6 \%$ de equivalente alcalino expresso em $\mathrm{Na}_{2} \mathrm{O}$ e for adicionado de substâncias que comprovadamente previnam a expansão prejudicial causada pela reação álcali-agregado.

Por fim, MEHTA \& MONTEIRO (1994) demonstram, a partir de um grande número de ensaios, que para materiais com distribuição granulométrica adequada, quanto maior a finura da areia e maior a dimensão máxima característica do agregado graúdo, maior a proporção de agregados graúdos adicionados ao concreto para uma certa trabalhabilidade e, portanto, maior a economia obtida na produção do concreto (ver a tabela 2.7). Quanto à utilização de areias mais grossas, NEVILLE (1982) diz que isto irá resultar em mistura áspera, sendo necessário um teor elevado de areia para se conseguir maior trabalhabilidade. Já para se obter misturas consideradas "normais", devem ser utilizadas areias médias numa relação entre o agregado miúdo e graúdo igual a 1:2, de tamanho máximo igual a $20 \mathrm{~mm}$.

Tabela 2.7. Volume de agregado graúdo compactado em estado seco, em $\mathrm{m}^{3}$, por unidade de volume de concreto, MEHTA \& MONTEIRO (1994).

\begin{tabular}{ccccc}
\hline $\begin{array}{c}\text { Dimensão máxima } \\
\text { característica do } \\
\text { agregado, em mm }\end{array}$ & \multicolumn{4}{c}{$\begin{array}{c}\text { Volume de agregados secos por unidade de volume de } \\
\text { concreto para os seguintes módulos de finura da areia }\end{array}$} \\
\cline { 2 - 5 } & 2,40 & 2,60 & 2,80 & 3,00 \\
\hline 9,5 & 0,50 & 0,48 & 0,46 & 0,44 \\
12,5 & 0,59 & 0,57 & 0,55 & 0,53 \\
19 & 0,66 & 0,64 & 0,62 & 0,60 \\
25 & 0,71 & 0,69 & 0,67 & 0,65 \\
38 & 0,75 & 0,73 & 0,71 & 0,69 \\
50 & 0,78 & 0,76 & 0,74 & 0,72 \\
75 & 0,82 & 0,80 & 0,78 & 0,76 \\
150 & 0,87 & 0,85 & 0,83 & 0,81 \\
\hline
\end{tabular}




\subsection{3 Água}

As impurezas na água de amassamento, quando em excesso, podem afetar a resistência e o tempo de pega, provocar a ocorrência de eflorescência (depósitos de sais sobre a superfície do concreto) e a corrosão da armadura passiva e ativa.

Tanto a NBR 6118 (1978) como NEVILLE (1982) presumem que as águas classificadas como potáveis ou que tenham pH entre 6,0 e 8,0 e estejam ausentes de sabor salino sejam aptas ao amassamento do concreto. No entanto, NEVILLE (1982) alerta para um caso em que a água potável não é adequada para o amassamento: é quando existe o perigo de reação álcali-agregado e a água contém teor elevado de sódio ou potássio.

NEVILLE (1982) e MEHTA \& MONTEIRO (1994) apresentam um teste simples para se verificar se uma água serve ou não para o concreto. Este teste é baseado na comparação entre o tempo de pega e a resistência de argamassas preparadas com a água suspeita e a água tida como potável ou destilada. Admitese uma variabilidade na resistência da ordem de $10 \%$. Este teste deve ser aplicado no caso de águas desconhecidas ou que tenham sólidos dissolvidos em concentrações superiores a 2000ppm, ou, no caso de carbonatos ou bicarbonatos alcalinos, superiores a 1000ppm.

Por fim, concretos de resistência usual são obtidos quando empregadas relações entre a massa de água e a de cimento compreendidas entre 0,50 e 0,65.

\subsection{Procedimentos de Dosagem}

A literatura técnica dispõe de vários procedimentos de dosagem, porém, sabe-se que todos eles foram desenvolvidos a partir das prescrições normativas e materiais disponíveis na região em que atuou o respectivo pesquisador. Com isso, diferentes roteiros experimentais poderão resultar em dosagens diferentes para um concreto com determinadas especificações. Assim, sugere-se que os roteiros experimentais sirvam apenas de base para se obter, por meio de tentativas, um concreto com as características mínimas de consistência, resistência e durabilidade exigidas pelo projeto. 


\subsection{Procedimentos de Cura}

NEVILLE (1982) define a cura como sendo o nome dado aos procedimentos adotados para promover a hidratação do cimento e consiste num controle da temperatura e da movimentação de umidade do interior para o exterior do concreto e vice-versa. De forma mais específica, o objetivo da cura está em manter o concreto saturado até que os espaços inicialmente ocupados pela água na pasta sejam tomados pelos produtos da hidratação.

Fatores como a temperatura e a umidade do ar que circunda o concreto, além da velocidade do vento sobre sua superfície, têm grande influência sobre a evaporação da água do concreto e, portanto, sobre a cura do concreto. Assim, de forma combinada ou independente, a maior temperatura do ar, maior velocidade do vento ou menor umidade do ar, provocam o aumento da perda de água. Além disso, quanto maior a diferença entre a temperatura do concreto e do ar, maior a perda de água.

Segundo NEVILLE (1982), a cura de elementos esbeltos pode ser facilitada untando com óleo e molhando as fôrmas antes do lançamento do concreto. Posteriormente, as fôrmas podem ser molhadas até a desforma, instante a partir do qual o concreto deve ser aspergido com água e protegido com folhas de polietileno ou outro material adequado.

O uso de membrana ou papel impermeável pode constituir-se num método eficiente de cura, desde que ela não esteja furada ou danificada. Um dos problemas no uso da membrana está no fato da mesma não permitir a entrada de água para repor a que foi perdida por autodessecação. Além disso, as folhas impermeáveis podem causar descoloração ou manchas em virtude da condensação não uniforme da água sob essas folhas.

Em função da cura úmida ser quase sempre aplicada de modo intermitente, a cura por selagem costuma ser mais eficiente (em termos de resistência). Independente disso, a NBR 6118 (1978) prescreve a proteção contra secagem prematura do concreto de pelo menos sete dias após o lançamento do concreto, aumentando este mínimo quando a natureza do cimento exigir. Porém, esta norma permite a antecipação do endurecimento do concreto por meio de tratamento térmico adequado e controlado, não se dispensando a proteção contra secagem.

A figura 2.3 exemplifica a influência da cura úmida sobre a resistência, obtida com concreto de relação água/cimento igual a 0,50. É importante dizer que em 
elementos delgados esta perda de resistência é mais pronunciada, mas é menor em concretos com agregados leves.

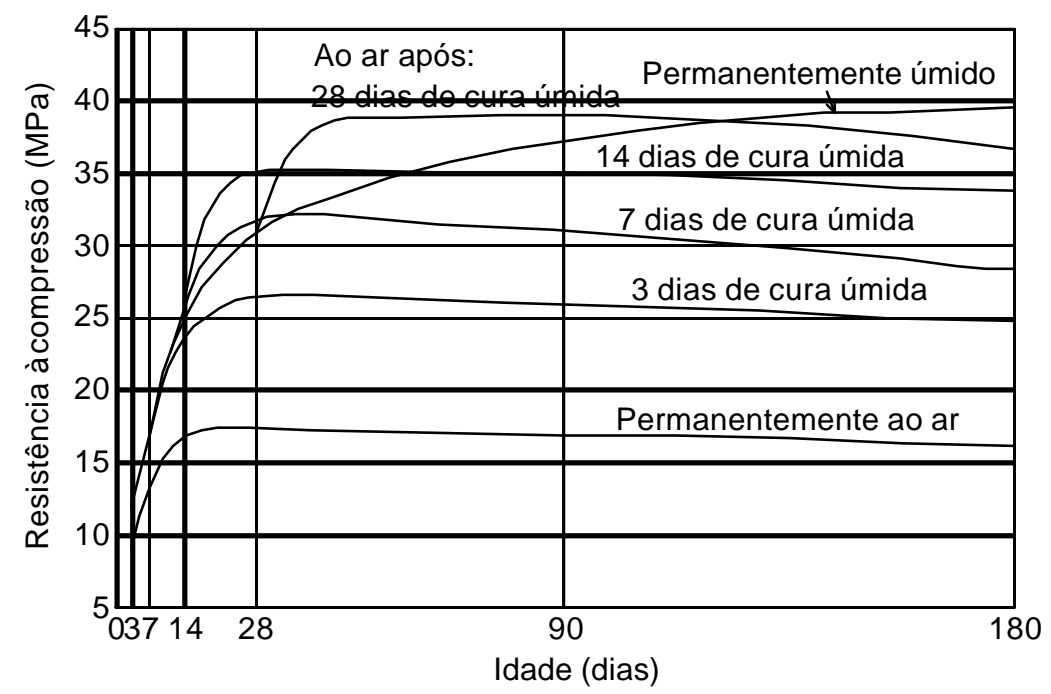

Figura 2.3. Influência da cura úmida sobre a resistência do concreto com uma relação água/cimento igual a 0,50, NEVILLE (1982).

\subsection{Propriedades Mecânicas do Concreto de Resistência Usual}

Apesar das inúmeras características apresentadas pelo concreto, tais como as características mecânicas, de durabilidade, condutividade etc., acredita-se que as propriedades mecânicas sejam as mais importantes para o andamento desta pesquisa. Sendo assim, são apresentadas, a seguir, algumas propriedades mecânicas do Concreto de Resistência Usual.

\subsubsection{Resistência à Compressão}

Nas estruturas de concreto armado, considera-se o concreto como o material mais apropriado para resistir aos esforços de compressão e, portanto, a especificação de sua resistência à compressão é imprescindível. Além disso, apesar de na maioria dos casos o concreto estar submetido a uma combinação de esforços de compressão, tração, cisalhamento e torção, o parâmetro resistência à compressão é utilizado como base para definir todos os demais, pois é simples de se obter e aceito e empregado no mundo inteiro. 
A grande porosidade na matriz, que é a pasta de cimento endurecida, bem como na zona de transição entre a matriz e o agregado graúdo, é um fator limitante na resistência dos concretos de resistência usual. Assim, esta propriedade mecânica é inversamente proporcional à porosidade, o que faz com que os fatores que definem a porosidade, tais como a relação água/cimento, o adensamento, as condições de cura, as dimensões dos agregados etc., sejam tratados com cuidado.

De maneira mais detalhada, MEHTA \& MONTEIRO (1994) afirmam que, nas idades menores, o "elo mais fraco da corrente" é a zona de transição do concreto. Isto porque não são necessários níveis elevados de energia para estender as fissuras já existentes na zona de transição (chamadas "fissuras de cisalhamento"), até com tensões da ordem de $40 \%$ a $70 \%$ da resistência última, para se obter maiores incrementos de deformação por unidade de força aplicada. Somente a níveis de tensão superiores a $70 \%$ da resistência última, as concentrações de tensão nos poros da matriz ocasionam novas fissuras. Assim, com o acréscimo de tensões, as fissuras da matriz e da zona de transição se unem e, geralmente, uma superfície de ruptura desenvolve-se a aproximadamente $20^{\circ}$ a $30^{\circ}$ a partir da direção da carga. Este comportamento do concreto perante tensões de compressão o qualifica como um material elasto-plástico.

Para a medida da resistência à compressão uniaxial do concreto, está padronizado na NBR 5739 (1980) o ensaio de compressão de corpos-de-prova cilíndricos de concreto. A NBR 5738 (1994) prescreve a confecção e cura dos corpos-de-prova cilíndricos e, no caso de se utilizarem concretos de resistência usual, costuma-se definir os corpos-de-prova com 150mm de diâmetro e $300 \mathrm{~mm}$ de altura. Contudo, é importante conhecer a relação entre a resistência àcompressão do concreto nas condições reais de carregamento da estrutura e nas condições do ensaio em laboratório.

Segundo FUSCO (1989), para representar a diferença entre a resistência do concreto da estrutura e a dos corpos-de-prova de controle, proveniente da influência das placas da prensa sobre os corpos-de-prova, utiliza-se um coeficiente de redução no valor de 0,95. Admitindo-se que as cargas das estruturas permanecem por longos períodos de tempo, a resistência de longa duração do seu concreto pode ficar reduzida para 0,75 da resistência potencial que poderia ser atingida com longos períodos de maturação. Este fenômeno é conhecido como "efeito Rüsch" por ter sido estudado pelo alemão Hubert Rüsch. Por fim, quando se utilizam cimentos de endurecimento normal, tem-se um acréscimo de resistência, 
obtido depois dos 28 dias até se atingir alguns anos de idade, da ordem de $20 \%$. Em resumo, pode-se agrupar estas três influências para definir um único coeficiente de modificação $k_{\bmod }$, o qual irá representar a relação entre a resistência à compressão do concreto nas condições reais de carregamento da estrutura e nas condições do ensaio em laboratório. Assim, tem-se:

$$
f_{c, \text { estrutura }}=k_{\bmod } \cdot \bar{f}_{c, 28}
$$

onde:

$f_{c, \text { estrutura }}$ é a resistência àcompressão do concreto da estrutura;

$\bar{f}_{c, 28}$ é a resistência média àcompressão do concreto dos corpos-deprova de controle aos 28 dias de idade; e

$k_{\text {mod }}=0,95 \cdot 0,75 \cdot 1,20=0,85$ é o coeficiente de modificação que relaciona a resistência à compressão do concreto nas condições reais de carregamento da estrutura e nas condições do ensaio em laboratório.

Para a pesquisa em questão, algumas particularidades tiveram de ser consideradas na determinação do $k_{\text {mod }}$. Ou seja, como os pilares e os corpos-deprova foram ensaiados no mesmo dia e sob ação de curta duração, os respectivos coeficientes receberam o valor igual a 1,00. Além disso, a data dos ensaios foi aos 14 dias e, portanto, teve-se $\bar{f}_{c, 14}$ ao invés de $\bar{f}_{c, 28}$. Deste modo, a relação passou a ser:

$$
f_{c, p i l a r}=k_{\bmod } \cdot \bar{f}_{c, 14}
$$

onde:

$f_{c, p i l a r}$ é a resistência àcompressão do concreto do pilar;

$\bar{f}_{c, 14}$ é a resistência média à compressão do concreto dos corpos-deprova de controle aos 14 dias de idade; e 


$$
k_{\text {mod }}=0,95 \cdot 1,00 \cdot 1,00=0,95 \text { é o coeficiente de modificação que }
$$

relaciona a resistência à compressão do concreto nos modelos de pilares e nos corpos-de-prova de controle.

Uma última observação feita por MEHTA \& MONTEIRO (1994) diz respeito a maior resistência, em torno de $20 \%$ a $25 \%$, dos corpos-de-prova secos ao ar em relação àqueles ensaiados em condição saturada. Esta menor resistência do concreto saturado é atribuída à existência de uma pressão de desligamento na pasta. Independente da causa, esta constatação é muito importante, uma vez que a NBR 5738 (1994) prescreve a cura dos corpos-de-prova em água saturada de cal ou em câmara úmida ( $95 \%$ de umidade). Deste modo, caberá ao pesquisador garantir a igualdade de condições de cura para os modelos de pilares e os corposde-prova de controle.

Para finalizar este item, a figura 2.4 descreve, em termos de diagrama, o efeito conjunto das cargas de longa duração e da maturação do concreto para ensaios realizados em corpos-de-prova aos 56 dias de idade. Esta idade padrão foi adotada com a finalidade de se diminuir a variabilidade da resistência em função do efeito da maior maturação dos corpos-de-prova. As resistências em ensaios rápidos realizados aos 28 e 56 dias foram representadas por $f_{c, 28}$ e $f_{c, 56}$, respectivamente.

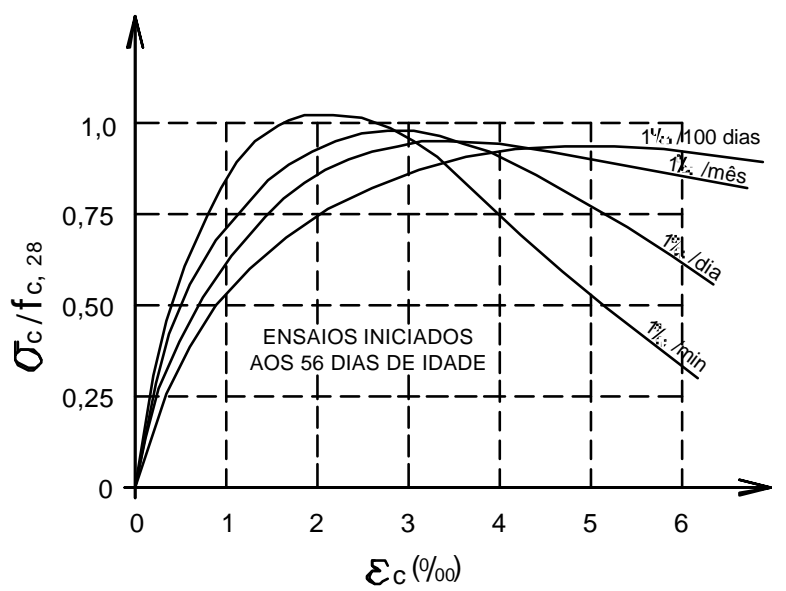

Figura 2.4. Efeito conjunto das cargas de longa duração e da maturação do concreto, FUSCO (1989).

Além da queda de resistência pela carga de longa duração, nota-se, pela figura 2.4, que a resistência obtida no ensaio rápido, definido pela velocidade de 
deformação de $0,001 /$ min, é maior que a resistência padrão usual $f_{c, 28}$, mostrandose assim a influência da maturação do concreto.

\subsubsection{Resistência à Tração}

No caso de solicitações que provoquem tração, a propagação das fissuras pela matriz e zona de transição dá-se a um nível de tensão bem menor que sob tensão de compressão e, por isso, o concreto acaba apresentando ruptura frágil à tração. Além disso, o aumento da resistência àcompressão do concreto aumenta a resistência àtração, porém, numa razão decrescente.

A NBR 7222 (1983) prescreve a determinação da resistência à tração do concreto por compressão diametral de corpos-de-prova cilíndricos. Esta propriedade mecânica ainda pode ser obtida com ensaios de tração direta ou tração por flexão com carregamento nos terços do vão de uma viga com dimensões padronizadas (NBR 12142 (1991)).

Os diferentes métodos de ensaio costumam fornecer diferentes valores de resistências. Segundo MEHTA \& MONTEIRO (1994), o ensaio de compressão diametral superestima a resistência àtração do concreto de $10 \%$ a $15 \%$, enquanto que, o ensaio de flexão pode superestimar a resistência de $50 \%$ a $100 \%$. O Projeto de Revisão da NBR 6118 (2000) especifica a resistência àtração direta sendo 90\% e $70 \%$ daquelas obtidas por ensaios de compressão diametral e flexão, respectivamente.

$\mathrm{Na}$ falta de determinação experimental, as normas de projeto permitem a utilização de relações entre as resistências àtração e àcompressão do concreto. A NBR 6118 (1978) prescreve o seguinte:

$$
\begin{gathered}
f_{t k}=\frac{f_{c k}}{10} \text { para } f_{c k} \leq 18 M P a \\
f_{t k}=0,06 \cdot f_{c k}+0,7 M P a \text { para } f_{c k}>18 M P a
\end{gathered}
$$

onde:

$f_{t k}$ e $f_{c k}$ são as resistências características do concreto àtração e a compressão, respectivamente, em MPa. 
Enquanto isso, o Projeto de Revisão da NBR 6118 (2000) estabelece as relações descritas abaixo:

$$
\begin{gathered}
f_{c t m}=0,3 \cdot f_{c k}^{2 / 3} \\
f_{c t k, \text { inf }}=0,7 \cdot f_{c t m} \\
f_{c t k, \text { sup }}=1,3 \cdot f_{c t m}
\end{gathered}
$$

onde:

$f_{c t m}$ é a resistência do concreto àtração direta média; e

$f_{c t k, \text { inf }}$ e $f_{c t k, s u p}$ são as resistências características do concreto à tração, inferior e superior, respectivamente, em MPa.

Dada a baixa relação entre as resistências à tração e compressão do concreto de 0,07 a 0,11 , o cálculo da maioria dos elementos de concreto armado despreza a resistência àtração do concreto.

\subsubsection{Deformação Última}

Segundo NEVILLE (1982), sob compressão uniaxial, quanto maior a resistência do concreto à compressão, menor a deformação longitudinal última. $\mathrm{Na}$ tabela 2.8, são apresentados alguns valores típicos de deformação última.

Tabela 2.8. Valores típicos de deformação última, NEVILLE (1982).

\begin{tabular}{cc}
\hline Resistência à Compressão (MPa) & Deformação Máxima $(\mathbf{m m} / \mathbf{m})$ \\
\hline 7 & 4,5 \\
14 & 4 \\
35 & 3 \\
70 & 2 \\
\hline
\end{tabular}

A NBR 6118 (1978) e o Projeto de Revisão da NBR 6118 (2000), aplicadas aos concretos com limite de resistência à compressão igual a 50MPa, sugerem o 
valor de $2 \mathrm{~mm} / \mathrm{m}$ como deformação última de ruptura do concreto sob compressão simples.

\subsubsection{Módulo de Deformação Longitudinal}

O módulo de deformação estático também é um parâmetro utilizado no cálculo de estruturas de concreto armado. Sua obtenção faz-se com a medida da declividade do trecho linear do diagrama tensão-deformação do concreto sob carregamento uniaxial de compressão.

Como será visto em item posterior, a curva descrita pelo diagrama tensãodeformação do concreto revela um comportamento não-linear deste material. Por conta disto, MEHTA \& MONTEIRO (1994) descrevem três formas diferentes de se calcular o módulo de deformação, denominando-os como módulos tangente, secante e módulo corda. O primeiro é obtido pela declividade de uma reta tangente à curva tensão-deformação, partindo-se da origem. O segundo é dado pela declividade de uma reta traçada da origem a um ponto da curva correspondente a $40 \%$ da tensão de ruptura. Por fim, o módulo corda corresponde a inclinação de uma reta traçada entre dois pontos da curva tensão-deformação, porém, diferentemente dos módulos anteriores, esta reta parte de um ponto representando uma deformação longitudinal de $0,05 \mathrm{~mm} / \mathrm{m}$ e dirige-se ao ponto que corresponde a $40 \%$ da tensão de ruptura. No Brasil, a NBR 8522 (1984) define como deve ser feita a determinação do módulo de deformação estático do concreto.

$\mathrm{Na}$ falta de determinação experimental, as normas de projeto permitem a utilização de expressões relacionando a resistência à compressão do concreto no cálculo do módulo de deformação longitudinal à compressão. Assim, são apresentadas, a seguir, algumas prescrições de normas conhecidas que valem para os concretos de resistência usual.

a) NBR 6118 (1978)

O módulo de deformação longitudinal à compressão $\left(E_{c}\right)$ deve ser calculado da seguinte forma:

$$
E_{c}=6600 \cdot \sqrt{f_{c j}}(\mathrm{MPa})
$$


onde:

$f_{c j}=f_{c k}+3,5$ é a resistência média do concreto àcompressão, prevista para j dias, em MPa; e

$f_{c k}$ é a resistência característica do concreto àcompressão, em MPa.

O módulo secante, utilizado principalmente na verificação de estados limites de serviço, será considerado igual a 0,9 do módulo na origem $\left(E_{c}\right)$.

As relações apresentadas pela NBR 6118 (1978) são válidas para concretos com resistência característica àcompressão $\left(f_{c k}\right)$ de no máximo 50MPa.

b) Projeto de Revisão da NBR 6118 (2000)

O módulo de elasticidade inicial $\left(E_{c}\right)$, aos vinte e oito dias de idade, deve ser estimado por meio da seguinte expressão:

$$
E_{c}=5600 \cdot \sqrt{f_{c k}}(\mathrm{MPa})
$$

onde:

$f_{c k}$ é a resistência característica do concreto àcompressão, em MPa.

O módulo de elasticidade para uma idade $j \geq 7$ dias pode ser calculado pela mesma relação apresentada, entretanto, deve-se trocar $f_{c k}$ por $f_{c k j}$.

O módulo de elasticidade secante $\left(E_{c s}\right)$, utilizado em análises elásticas de projeto, principalmente na determinação de esforços solicitantes e na verificação de estados limites de serviço, será considerado igual a 0,85 do módulo inicial $\left(E_{c}\right)$.

As relações apresentadas pelo Projeto de Revisão da NBR 6118 (2000) são válidas para concretos com resistência característica à compressão $\left(f_{c k}\right)$ de no máximo 50MPa. 
c) ACI 318 (1995)

O módulo de deformação longitudinal àcompressão $\left(E_{c}\right)$, em concretos com massa específica entre $1442 \mathrm{~kg} / \mathrm{m}^{3}$ e $2483 \mathrm{~kg} / \mathrm{m}^{3}$, deve ser determinado a partir da seguinte equação:

$$
E_{c}=w_{c}^{1,5} \cdot 0,0428 \cdot f_{c}^{1 / 2}(\mathrm{MPa})
$$

onde:

$w_{c}$ é a massa específica do concreto, em $\mathrm{kg} / \mathrm{m}^{3} ; \mathrm{e}$

$f_{c}^{\prime}$ é a resistência àcompressão, aos vinte e oito dias, de corpos-deprova cilíndricos normalizados, em MPa.

A relação apresentada pelo $\mathrm{ACl} 318$ (1992) é válida para concretos com resistência característica àcompressão $\left(f_{c k}\right)$ de no máximo $41 \mathrm{MPa}$.

d) CEB-FIP Model Code (1990)

O módulo de deformação longitudinal àcompressão $\left(E_{c}\right)$, em concretos com massa específica normal, pode ser estimado da seguinte forma:

$$
E_{c}=2,15 \cdot 10^{4} \cdot\left(\frac{f_{c m}}{10}\right)^{1 / 3}(\mathrm{MPa})
$$

onde:

$f_{c m}$ é a resistência média à compressão aos vinte e oito dias. Se a resistência real não for conhecida, $f_{c m}=f_{c k}+8$, sendo que $f_{c k}$ é a resistência característica àcompressão. O valor do $f_{c k}$ é limitado em 80MPa.

A relação apresentada pelo CEB-FIP Model Code (1990) considerou concretos com agregados a base de quartzo. No entanto, para concretos com 
outros agregados, a tabela 2.9 apresenta o coeficiente $\alpha_{e}$ que, multiplicado por $E_{c}$, resulta no módulo de deformação correspondente.

Tabela 2.9. Efeito do tipo de agregado sobre o módulo de deformação, CEBFIP Model Code (1990).

\begin{tabular}{cc}
\hline Tipos de Agregados & $\alpha_{e}$ \\
\hline Basalto, calcário denso & 1,2 \\
Quartzítico & 1,0 \\
Calcário & 0,9 \\
Arenito & 0,7 \\
\hline
\end{tabular}

A porosidade das fases constituintes do concreto é tida como a maior responsável por afetar o módulo de elasticidade deste material. MEHTA \& MONTEIRO (1994) apresentam algumas formas pelas quais o módulo de deformação pode variar. São elas:

- porosidade do agregado - quanto mais denso o agregado, maior seu módulo de deformação e, portanto, a maior quantidade deste material na composição do concreto irá resultar em maior módulo de deformação do concreto. Vale dizer que propriedades do agregado como a dimensão máxima, a forma, a textura superficial, a granulometria e a composição mineralógica podem influenciar na microfissuração da zona de transição e, assim, afetar o formato da curva tensãodeformação;

- porosidade da pasta de cimento - tal como ocorre com o agregado, a maior porosidade da pasta de cimento resulta em menor módulo de elasticidade do concreto. Assim, fatores como a relação água/cimento, o conteúdo de ar, as adições minerais e o grau de hidratação do cimento são importantes, pois estão ligados diretamente com a porosidade da pasta;

- porosidade e composição da zona de transição - na zona de transição, além da maior porosidade diminuir o valor do módulo de deformação, microfissuras e cristais orientados de hidróxido de cálcio desempenham papel importante na determinação do comportamento das relações tensão-deformação no concreto; e 
- parâmetros de ensaio - foi observado que corpos-de-prova ensaiados em condições úmidas apresentaram módulos de elasticidade $15 \%$ maior do que aqueles testados em condições secas (rever o item 2.9.1). Este fato é curioso, pois sob as mesmas condições, os corpos-de-prova secos apresentaram resistências $15 \%$ maiores do que aqueles testados em condições úmidas. Além das condições de cura, a taxa de carregamento também influi na determinação do módulo de elasticidade. Assim, para carga instantânea, ocorre uma pequena deformação antes da ruptura e, portanto, o módulo de elasticidade apresenta-se bastante alto. Em contrapartida, em ensaios conduzidos em tempos de 2 a 5 minutos, a deformação de ruptura é aumentada em 15\% a 20\% e, portanto, o módulo de deformação diminui na mesma proporção. Já para taxas muito lentas de carregamento, as deformações elásticas e de fluência somam-se resultando em menores módulos de deformação.

Para encerrar, é de conhecimento geral que a resistência à compressão e o módulo de elasticidade do concreto são diretamente proporcionais, ou seja, quanto maior a resistência do concreto, maior o módulo de deformação longitudinal.

\subsubsection{Relação Tensão-Deformação}

Segundo MEHTA \& MONTEIRO (1994), a relação tensão-deformação, do ponto de vista do nível de tensão e da microfissuração no concreto, apresenta quatro estágios no comportamento do concreto sob compressão simples (ver a figura 2.5).

Para se compreender o primeiro estágio, deve-se partir do pressuposto que existem microfissuras na zona de transição entre a matriz e o agregado graúdo do concreto, antes da aplicação do carregamento. Deste modo, estas fissuras irão permanecer estáveis até que se alcance o nível de tensão de $30 \%$ da carga última, resultando em uma relação tensão-deformação linear até este ponto. O segundo estágio está compreendido entre $30 \%$ e $50 \%$ da carga última de ruptura. Nesta fase, na medida em que as tensões aumentam, as microfissuras da zona de transição começam a aumentar em comprimento, largura e número. Porém, o sistema de microfissuras ainda é considerado estável e a relação tensãodeformação começa a se desviar sensivelmente de uma reta. De 50\% a 75\% da 
carga última de ruptura se desenvolvem as fissuras na matriz, antes desprezíveis no segundo estágio, e o sistema de fissuras na zona de transição torna-se instável. Com isso, a curva tensão-deformação inclina-se mais ainda na direção horizontal, caracterizando o terceiro estágio. O quarto estágio dá-se com os níveis de tensão entre $75 \%$ e $80 \%$ da carga última. A partir de então, a taxa de liberação de energia de deformação atinge um nível crítico necessário para o crescimento espontâneo das fissuras sob tensão constante. Desta forma, desenvolvem-se grandes deformações até a ruptura do material.

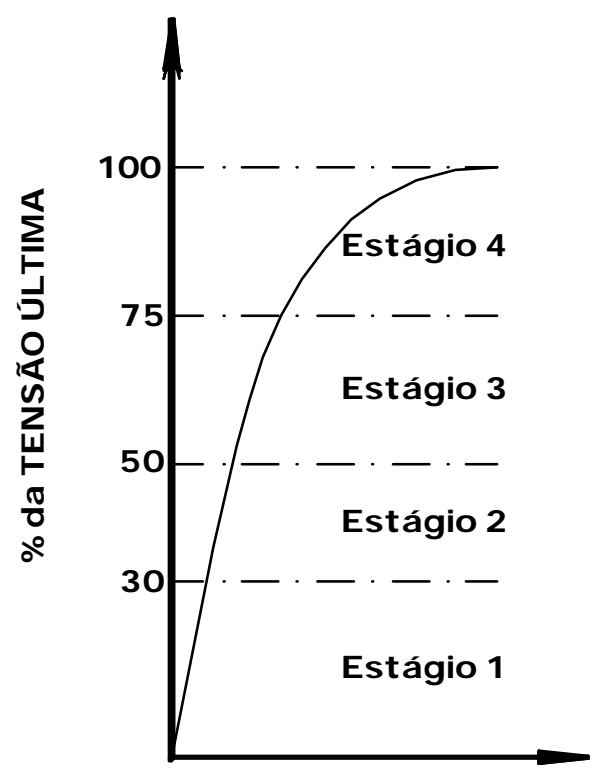

DEF ORMAÇÃ O

Figura 2.5. Representação dos estágios na relação tensão-deformação do concreto sob carregamento uniaxial, MEHTA \& MONTEIRO (1994).

COLLINS et al. (1993) demonstraram que a forma da curva tensãodeformação do concreto sob carregamento de compressão uniaxial é bastante afetada pela resistência à compressão deste concreto (ver a figura 2.6). Assim, verificou-se um comportamento mais elasto-plástico e dúctil nos concretos de resistência usual do que nos concretos de alta resistência. 


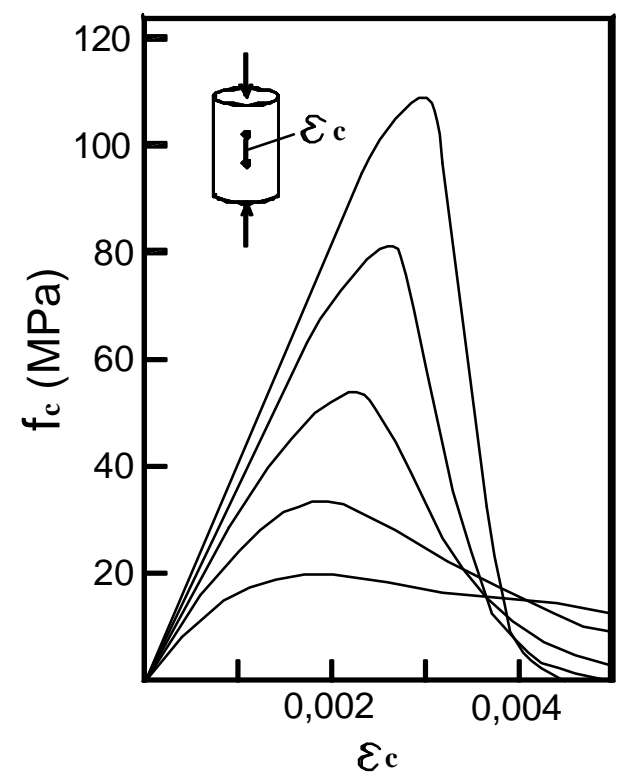

Figura 2.6. Influência da resistência do concreto àcompressão uniaxial na forma da curva tensão-deformação, COLLINS et al. (1993).

Visando ajustar uma expressão matemática que represente a curva tensãodeformação do concreto sob carregamento uniaxial, tanto na parte ascendente como na descendente, NEVILLE (1982) apresenta as expressões propostas por DESAYI \& KRISHNAN ${ }^{1}$ e SAENZ ${ }^{2}$, em 1964. Assim, têm-se:

a) DESAYI \& KRISHNAN

$$
\sigma=\frac{E \cdot \varepsilon}{1+\left(\frac{\varepsilon}{\varepsilon_{o}}\right)^{2}}
$$

onde:
$\sigma$ é a tensão;
$\varepsilon$ é a deformação;
$\varepsilon_{o}$ é a deformação àtensão máxima; e

\footnotetext{
1 DESAYI, P.; KRISHNAN, S. (1964). Equation for stress-strain curve of concrete. Journal American Concrete Institute, n.61, p.345-350, Mar.

2 SAENZ, L. P. (1964). Discussion of reference 1. Journal American Concrete Institute, n.61, p.1229-1235, Sept.
} 
$E$ é o módulo de deformação tangente inicial, admitido como sendo igual ao dobro do módulo secante àtensão máxima $\sigma_{\text {máx }}$, ou seja, $E=\frac{2 \cdot \sigma_{\text {máx }}}{\varepsilon_{o}}$.

b) SAENZ

$$
\sigma=\frac{\varepsilon}{A+B \cdot \varepsilon+C \cdot \varepsilon^{2}+D \cdot \varepsilon^{3}}
$$

onde, além das notações utilizadas anteriormente, têm-se:

$$
\begin{aligned}
& A=\frac{1}{E} ; \\
& B=\frac{R_{E}+R-2}{R_{E} \cdot \sigma_{\text {máx }}} \\
& C=\frac{1-2 \cdot R}{R_{E} \cdot \sigma_{\text {máx }} \cdot \varepsilon_{o}} ; \\
& D=\frac{R}{R_{E} \cdot \sigma_{\text {máx }} \cdot \varepsilon_{o}^{2}} ; \\
& R=\frac{R_{E} \cdot\left(R_{\sigma}-1\right)}{\left(R_{\varepsilon}-1\right)^{2}}-\frac{1}{R_{E}} ; \\
& R_{E}=\frac{E}{E_{m}} ; \\
& R_{\sigma}=\frac{\sigma_{\text {máx }}}{\sigma_{\mu}} ; \\
& R_{\varepsilon}=\frac{\varepsilon_{\text {máx }}}{\varepsilon_{o}} \\
& E_{m}=\frac{\sigma_{\text {máx }}}{\varepsilon_{o}} ; \mathrm{e}
\end{aligned}
$$

$q$ é a tensão de ruptura.

Para análises no estado limite último, tanto a NBR 6118 (1978) como o Projeto de Revisão da NBR 6118 (2000) propõem a relação tensão-deformação 
mostrada na figura 2.7 para concretos com resistência característica àcompressão $\left(f_{c k}\right)$ de até 50MPa.

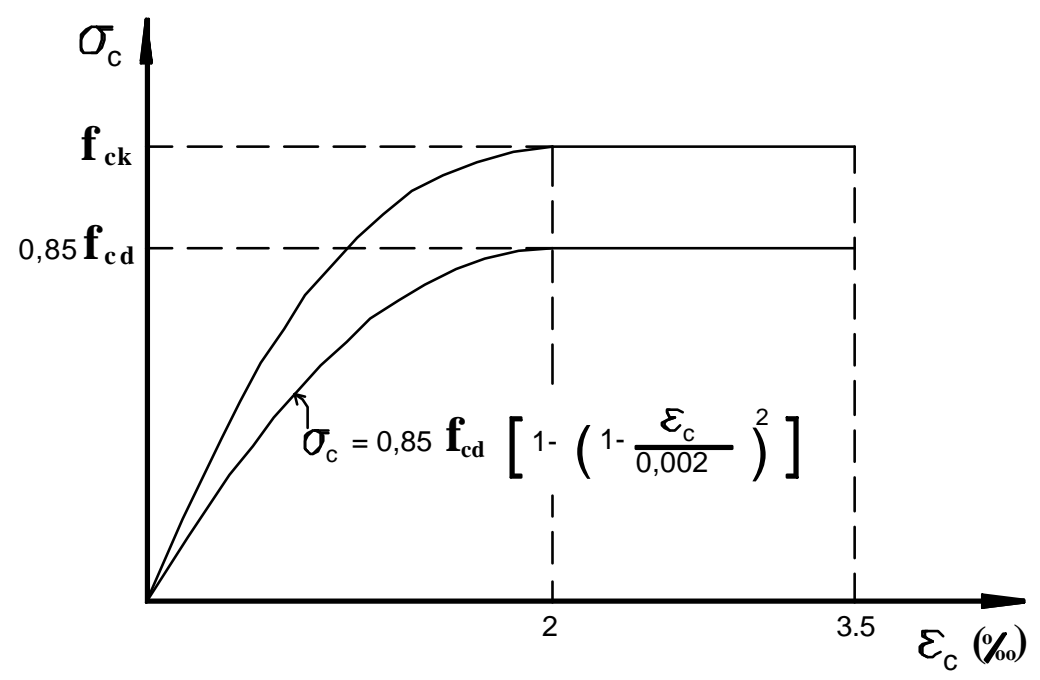

Figura 2.7. Diagrama tensão-deformação do concreto à compressão para análises no estado limite último, NBR 6118 (2000).

\subsubsection{Coeficiente de Poisson}

O coeficiente de Poisson é a relação entre a deformação transversal e a deformação axial resultantes de um carregamento uniaxial dentro de um intervalo elástico. De acordo com MEHTA \& MONTEIRO (1994), apesar desta relação poder estar entre 0,11 e 0,21, em geral, ela se apresenta entre 0,15 e 0,20. A NBR 6118 (1978) e o Projeto de Revisão da NBR 6118 (2000) fixam o coeficiente de Poisson em 0,20 para concretos com resistência característica à compressão $\left(f_{c k}\right)$ de até $50 \mathrm{MPa}$.

MEHTA \& MONTEIRO (1994) e NEVILLE (1982) concordam ao afirmarem que não há uma relação consistente entre o coeficiente de Poisson e as características do concreto, tais como a relação água/cimento, o tempo de cura e a granulometria do agregado. No entanto, tudo indica que o coeficiente de Poisson é inversamente proporcional àresistência àcompressão do concreto. 


\subsubsection{Aderência Concreto-Armadura}

A aderência é um fenômeno decorrente, basicamente, do atrito e da adesão entre o concreto e a armadura que, em geral, é de aço. Assim, fica claro que a aderência não depende somente do concreto, mas também das propriedades mecânicas do aço e a sua posição nos elementos de concreto.

No que tange ao concreto, NEVILLE (1982) afirma que a aderência depende da qualidade do concreto e a resistência de aderência é, aproximadamente, proporcional à resistência à compressão até a casa dos $20 \mathrm{MPa}$. Todavia, para resistências mais elevadas o aumento da resistência de aderência torna-se cada vez menor.

No caso de se utilizar armadura galvanizada, NEVILLE (1982) mostra que os resultados obtidos pelo Building Research Establishement indicam para uma aderência tão boa quanto a aderência de barras e fios de aço comum. Além do mais, a utilização de armadura galvanizada apresenta grande vantagem em relação a não-galvanizada quando a carbonatação pode alcançar a armadura dos concretos leves ou de resistência baixa.

O comportamento eficiente do concreto armado depende em muito da aderência entre o concreto estrutural e a armadura. $O$ cálculo da tensão de aderência, feito a partir da NBR 6118 (1978) e do Projeto de Revisão da NBR 6118 (2000), é apresentado a seguir:

a) NBR 6118 (1978)

Em situação de boa aderência:

$\mathrm{Na}$ ancoragem e nas emendas por transpasse

$$
\begin{gathered}
\tau_{b u}=0,28 \cdot \sqrt{f_{c d}}(\mathrm{MPa}) \text { para } \eta_{b} \leq 1,0 \\
\tau_{b u}=0,42 \cdot \sqrt[3]{f_{c d}^{2}}(\mathrm{MPa}) \text { para } \eta_{b} \geq 1,5
\end{gathered}
$$


Para escorregamento

$$
\begin{gathered}
\tau_{b u}=0,51 \cdot \sqrt{f_{c d}}(\mathrm{MPa}) \text { para } \eta_{b} \leq 1,0 \\
\tau_{b u}=0,74 \cdot \sqrt[3]{f_{c d}^{2}}(\mathrm{MPa}) \text { para } \eta_{b} \geq 1,5
\end{gathered}
$$

Interpolando-se linearmente para $1,0 \leq \eta_{b} \leq 1,5$ e não considerando-se $\eta_{b}$ maior que 1,5 .

onde:

$\tau_{b u}$ é a tensão de aderência de cálculo, em MPa;

$f_{c d}=\frac{f_{c k}}{\gamma_{c}}$ é a resistência de cálculo do concreto à compressão, em MPa, sendo que $f_{c k}$ e $\gamma_{c}$ são, respectivamente, a resistência característica do concreto àcompressão e o coeficiente de minoração da resistência do concreto; e

$\eta_{b}$ é o coeficiente de conformação superficial das barras da armadura (suposto igual a 1,0 para barras lisas).

Em situação de má aderência:

Os valores de $\tau_{b u}$ indicados acima serão divididos por 1,5.

b) Projeto de Revisão da NBR 6118 (2000)

$$
f_{b d}=\eta_{1} \cdot \eta_{2} \cdot \eta_{3} \cdot f_{c t d}
$$

onde:

$f_{b d}$ é a tensão de aderência de cálculo da armadura passiva;

$$
f_{c t d}=\frac{f_{c t k i n f}}{\gamma_{c}} \text { é o valor de cálculo da resistência àtração do concreto, }
$$

sendo que $f_{c t k, i n f}$ foi definido no item 2.9.2 e $\gamma_{c}$ é o coeficiente de minoração da resistência do concreto; 
$\eta_{1}=1,0$ para barras lisas;

$\eta_{\mathbf{l}}=1,4$ para barras dentadas;

$\eta_{1}=2,25$ para barras nervuradas;

$\eta_{2}=1,0$ para situações de boa aderência;

$\eta_{2}=0,7$ para situações de má aderência;

$\eta_{3}=1,0$ para $\phi<32 \mathrm{~mm} ; \mathrm{e}$

$\eta_{\mathrm{b}}$ é igual a $\frac{132-\phi}{100}(\phi$ em $\mathrm{mm})$ para $\phi>32 \mathrm{~mm}$.

No caso de escorregamento da armadura de peças fletidas, adotam-se os valores da tensão de aderência apresentados acima multiplicados por 1,75. 


\section{PILARES DE CONCRETO DE RESISTÊNCIA USUAL}

\subsection{Considerações Iniciais}

Este capítulo procura abordar o tema "pilares de concreto armado" de um modo bastante amplo, porém, respeitando a proposta de trabalho enunciada no capítulo introdutório. Assim sendo, dém de um levantamento histórico sobre os tipos de pilares e as pesquisas realizadas ao longo do século $X X$, também são apresentadas as ferramentas teóricas utilizadas na análise dos resultados dos modelos de pilares ensaiados neste trabalho.

\subsection{Definição e Tipos}

LANGENDONK (1944) define os pilares como peças alongadas em que predominam os esforços de compressão, tendo a armadura as funções de auxiliar o concreto na sua resistência àcompressão, permitindo reduzir suas dimensões, e de resistir a esforços secundários, quer provenham de defeitos locais no interior da massa, quer da ação de possíveis forças cortantes ou momentos fletores.

A armadura longitudinal dos pilares tem sempre função resistente, enquanto que, a transversal, quando muito espaçada, servirá apenas para evitar a flambagem das barras longitudinais e mantê-las na distância prevista pelo projeto durante a execução. Todavia, se a armadura transversal apresentar-se pouco espaçada, ela terá função resistente, pois irá impedir a deformação transversal do concreto e, com isso, confinar o concreto. Esta última constatação foi feita por MÖRSCH (1952) depois das análises de uma série de ensaios de pilares de concreto armado conduzidos por instituições européias, no início do século XX. O referido autor tanto reportou como comentou estes ensaios. 
CUSSON \& PAULTRE (1994) verificaram que uma maior quantidade e melhor distribuição da armadura longitudinal e, principalmente, da transversal contribuem muito para a ductilização e o cintamento do concreto. KERSTEN (1927), MÖRSCH (1952), AGOSTINI (1992), CUSSON \& PAULTRE (1994) e CLAESON et al. (1996) verificaram que o efeito do confinamento no concreto é mais sensível em pilares com concretos de menor resistência.

Hoje em dia, com os avanços na tecnologia de obtenção de concretos de alta resistência, o aumento da resistência do pilar por conta do cintamento não é mais tão almejado, exceto em casos de reforço estrutural. Porém, quando se utiliza CAR ou a estrutura está localizada em zona sísmica, uma maior ductilidade nos elementos estruturais é exigida, com o propósito de se evitar a ruptura brusca da estrutura. Nestes casos, o aumento das taxas de armadura longitudinal e transversal, tanto em pilares de concreto de resistência usual como naqueles de alta resistência, irá conferir maior ductilidade aos pilares e, portanto, maior segurança àestrutura como um todo (redistribuição de esforços).

Ao longo dos anos, vários tipos de seções transversais foram utilizados pelos projetistas de estruturas. O que chama a atenção é a diferença entre as seções transversais mais utilizadas no passado e àquelas empregadas em tempos recentes. Não somente a forma da seção, mas também as configurações da armadura transversal.

SEGURADO (1921) relata um tipo de pilar que recebeu a denominação de Hennebique. Sua armadura transversal aguça a curiosidade, pois é composta por anéis formados por barras de ferro ou aço de seção retangular (2mm a $5 \mathrm{~mm}$ de espessura) perfuradas que se enfiam nas barras longitudinais (ver a figura 3.1). 0 problema na utilização deste pilar estava no fato dos anéis interromperem a continuidade do concreto, originando a aparição de fendas se o pilar fosse sujeito à flexo-compressão.

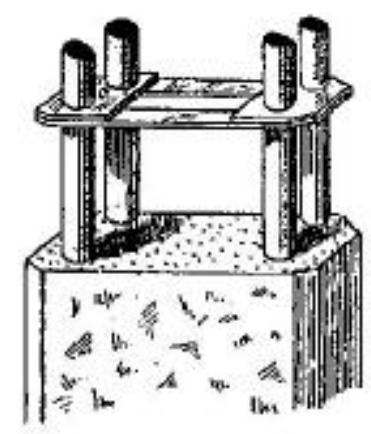

Figura 3.1. Pilar de seção retangular constituído por armadura transversal em forma de anéis formados por barras chatas, FANTI (1917). 
As figuras 3.2 e 3.3 foram extraídas de SEGURADO (1921) e MÖRSCH (1952), respectivamente, e apresentam as seções transversais e vistas laterais dos pilares executados com mais freqüência na primeira metade do século $X X$.

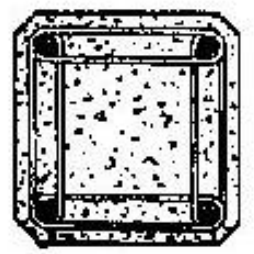

(a)

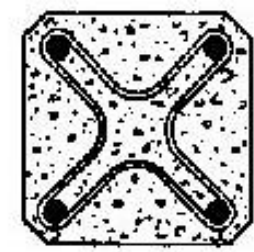

(b)

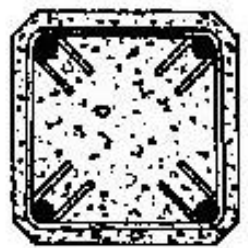

(c)

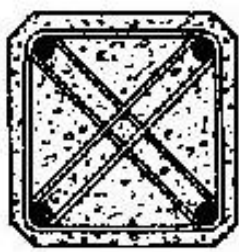

(d)

Figura 3.2. Seções transversais de pilares de concreto armado, SEGURADO (1921).

$\mathrm{Na}$ figura 3.2, o desenho a mostra as barras longitudinais sendo ligadas por barras transversais duplas; em $\mathbf{b}$ a ligação é feita por barras em forma de estrela, o que, segundo SEGURADO (1921), permite o bom adensamento do concreto; em c há quatro barras transversais abraçando as longitudinais, ficando as pontas dobradas para o interior, disposição esta que não oferece dificuldade ao adensamento; por fim, em d, além das barras transversais que ligam as barras longitudinais externamente, há outras que se cruzam na diagonal, configuração esta que dificulta o adensamento do concreto.
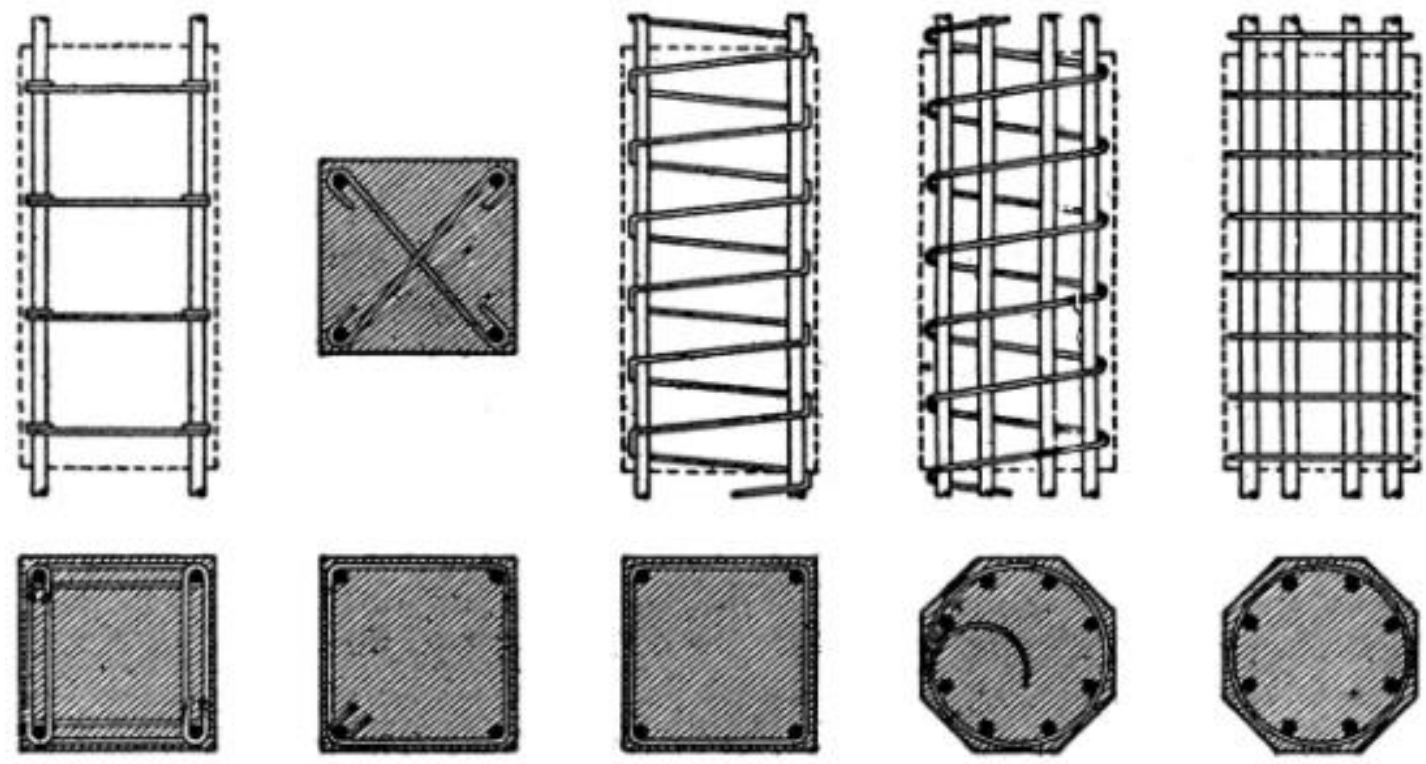

Figura 3.3. Seções transversais e vistas laterais de pilares de concreto armado, MÖRSCH (1952). 
Referente a figura 3.3, MÖRSCH (1952) afirma que os estribos diagonais só podem ser utilizados se forem alternados com estribos quadrados. Nesta mesma figura, chamam atenção as armaduras transversais em forma de hélice quadrada ou redonda.

Tanto KERSTEN (1927) como MÖRSCH (1952) citam que a seção transversal de pilar mais utilizada na primeira metade do século XX era a quadrada. Contudo, sabe-se que os pilares de seção circular e octogonal também foram bastante utilizados, pois aliavam a possibilidade de cintamento do concreto com um cálculo mais simples à flexo-compressão do que em qualquer outro tipo de seção. KERSTEN (1927), inclusive, justifica o fato de se evitar as seções retangulares em função da dificuldade de cálculo destes pilares mediante esforços de flexocompressão, oriundos de cargas excêntricas.

Principalmente com os avanços na área da informática e na tecnologia de obtenção de concretos de maior resistência, a forma da seção transversal dos pilares deixou de ser um fator de grande relevância durante a fase de concepção e cálculo estrutural. Com isso, as seções circulares e octogonais perderam sua "popularidade", pois a dificuldade na execução e montagem de suas fôrmas fez com que somente alguns projetistas e arquitetos optassem por estas seções por questões estéticas ou em casos especiais, como por exemplo em pilares de pontes sobre rios. Na figura 3.4, apresentam-se seções transversais quadradas e retangulares com as configurações de armaduras mais empregadas nos dias de hoje.
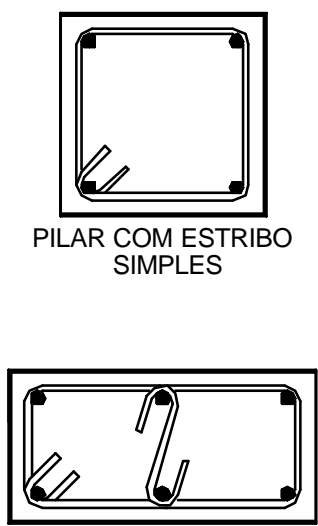

PILAR COM ESTRIBO ADICIONAL

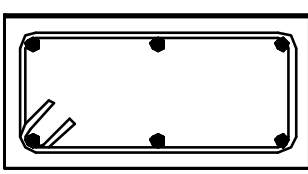

PILAR COM ESTRIBO SIMPLES

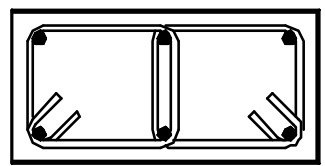

PILAR COM DOIS ESTRIBOS PRINCIPAIS

Figura 3.4. Seções transversais quadradas e retangulares com as configurações de armaduras mais empregadas atualmente em pilares de concreto armado. 
Em momento algum o posicionamento vertical das barras da armadura longitudinal foi questionado na maioria das bibliografias pesquisadas pelo autor. Porém, SEGURADO (1921) apresenta algo fora do comum até mesmo para a sua época. Trata-se de um pilar denominado Matrai (ver a figura 3.5). Nele, a armadura é formada por um feixe de barras delgadas de ferro ou aço, reunidas à pequena distância das extremidades, cruzando-se e formando seio a meia altura. As barras ou cabos ficam em planos diametrais irradiantes do pilar e não existem barras de ligação transversal. A curva que se dá às barras longitudinais é parabólica. Quanto ao cálculo destes pilares, para o caso de seção transversal quadrada com quatro barras longitudinais, têm-se:

$$
\begin{gathered}
A_{a}=\frac{150 \cdot L^{2}}{R_{a}} \\
P=R_{b} \cdot A
\end{gathered}
$$

onde:

$P$ é a carga a suportar;

$L$ é a altura do pilar;

$R_{b}$ é o coeficiente de trabalho do concreto que não pode ultrapassar o valor de 2,5MPa;

$R_{a}$ é o coeficiente de trabalho do aço;

$A$ é a área da seção transversal do pilar; e

$A_{a}$ é a seção transversal de uma das barras ou cabos.

Para os pilares que possuem continuidade através dos diversos pisos de um edifício, SEGURADO (1921) propõe que, na passagem de um andar para o outro, a ligação das armaduras seja feita por meio de uniões de tubos de ferro laminado (luvas), nos quais as barras são rosqueadas se o pilar for sujeito à flexocompressão. Caso sofra apenas compressão simples, basta fazer a ligação enfiando uns pequenos tubos de ferro laminado sem rosca (luvas sem rosca) (ver a figura 3.6). 


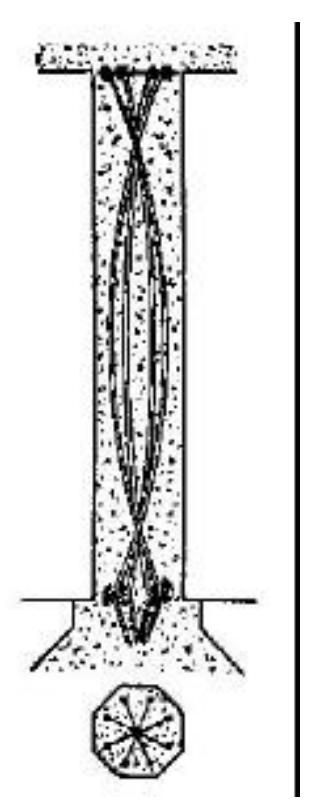

Figura 3.5. Vista lateral e seção transversal do pilar Matrai, SEGURADO (1921).

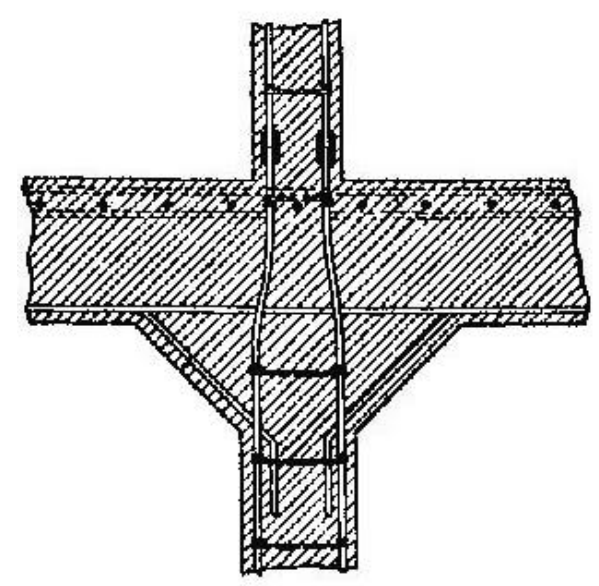

Figura 3.6. Ligação das armaduras de pilares submetidos à compressão simples de um piso a outro, SEGURADO (1921).

Alegando que o sistema mencionado no parágrafo anterior foi abandonado por estar sujeito a defeitos, MÖRSCH (1952) sugere que as barras longitudinais sejam transpassadas acima do nível do pavimento e num comprimento de $60 \mathrm{~cm}$ a $80 \mathrm{~cm}$ (ver a figura 3.7). Além disso, estas barras devem ter suas extremidades dobradas em forma de gancho a fim de poder garantir com segurança a transmissão de eventuais esforços de flexão. Este sistema concorda com o proposto por KERSTEN (1927), onde apenas o comprimento varia de $30 \mathrm{~cm}$ a $50 \mathrm{~cm}$. 


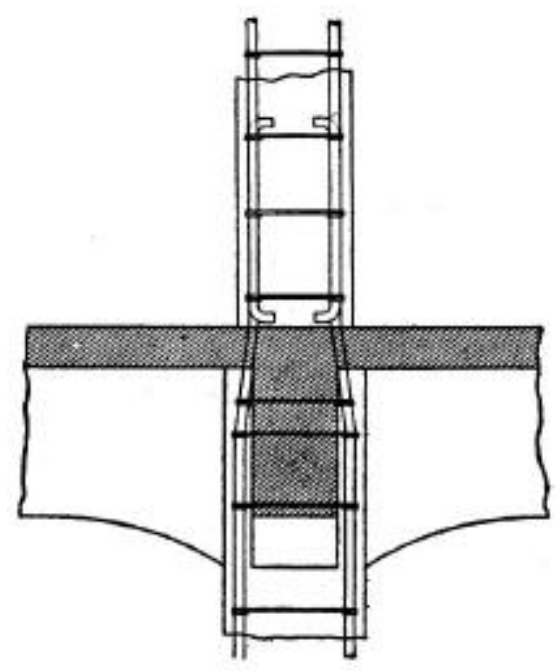

Figura 3.7. Ligação das armaduras de pilares de um piso a outro, MÖRSCH (1952).

Nos dias atuais, a prescrição feita por MÖRSCH (1952) parece ser a mais utilizada. No entanto, o comprimento de transpasse deve ser calculado levando-se em consideração parâmetros como a tensão de aderência entre o concreto e as barras de aço, o diâmetro das barras longitudinais e a tensão de escoamento do aço.

Com o passar dos tempos, o aumento da resistência do concreto e a conseqüente diminuição das dimensões das seções transversais dos pilares fizeram com que as taxas geométricas de armadura longitudinal aumentassem. Contudo, este parâmetro teve de ser limitado, pois nas regiões de transpasse as taxas poderiam dobrar, dificultando o adensamento do concreto. Assim, para os casos em que a taxa limite é ultrapassada quando utilizado o sistema de ligação por transpasse, sugere-se que a continuidade da armadura longitudinal se dê com luvas análogas aos tubos com roscas apresentados por SEGURADO (1921). Estas luvas podem ser acopladas às barras por meio de roscas ou qualquer outro sistema que garanta um efeito semelhante, como por exemplo, por amassamento. O maior problema na utilização das luvas está em se garantir o cobrimento mínimo das armaduras na região do transpasse. Deste modo, outras formas de ligação como as soldas de topo podem ser empregadas com o mesmo propósito sem que haja este inconveniente.

Por fim, quanto ao cobrimento das armaduras, os valores empregados no passado não diferem muito dos atuais. MÖRSCH (1952) sugere que para qualquer um dos pilares da figura 3.3 sejam empregados no mínimo $20 \mathrm{~mm}$ de cobrimento. A 
NBR 6118 (1978) prescreve um cobrimento mínimo de 15mm, porém, apresenta valores superiores em função das condições de exposição e geometria dos elementos estruturais.

\subsection{Histórico das Pesquisas}

Dentre os primeiros ensaios conhecidos com pilares de concreto armado, MÖRSCH (1952) apresenta e comenta alguns deles. Estes ensaios foram realizados no início do século XX por instituições européias como o Laboratório da Universidade Industrial de Stuttgart e o Laboratório Oficial de BerlimGrosslichterfelde.

Em meio aos principais objetivos destas pesquisas, destacou-se a observação do comportamento de pilares sob compressão centrada e a criação de subsídios àformulação de um modelo teórico de cálculo de pilares não cintados e cintados.

Antes de apresentar os ensaios, MÖRSCH (1952) faz questão de alertar para o fato de que mesmo um ensaio de pilar submetido à compressão simples está sujeito a influências perturbadoras, as quais podem tornar contraditórios e incompreensíveis os resultados obtidos. Deste modo, o referido autor descreve os seguintes cuidados que devem ser tomados com o objetivo de minimizar estas influências:

- as superfícies de compressão dos modelos devem estar totalmente planas e o mais paralelas possíveis para que se permita uma transmissão uniforme dos esforços de compressão e, assim, se evite a ruptura prematura da cabeça;

- as placas de pressão da máquina de ensaio devem ficar apoiadas em rótulas, de tal modo que não ocorra solicitação de momento fletor;

- o pilar deve estar posicionado de modo que a máquina de ensaio aplique uma ação completamente centrada sobre ele; 
- as barras da armadura longitudinal devem estar totalmente retas e seus eixos paralelos ao eixo axial do pilar. Esta medida irá contribuir para que o esforço solicitante esteja centrado na seção transversal;

- devem ser evitadas as seções transversais demasiadamente pequenas e, em especial, com armadura longitudinal de diâmetros entre $4 \mathrm{~mm}$ e $10 \mathrm{~mm}$. A justificativa está no fato de que os golpes do pistão da máquina de ensaio produzem flexão lateral nas barras longitudinais delgadas que, por sua vez, apresentarão uma convexidade entre os estribos na direção exterior do pilar. Tendo isto ocorrido, desenvolve-se uma pressão lateral sobre o cobrimento de concreto das armaduras que levará ao descolamento deste cobrimento e, conseqüentemente, àruptura prematura do pilar; $\mathrm{e}$

- devem ser tomados cuidados nos processos de dosagem, cura, lançamento e adensamento do concreto e desforma dos pilares. Isto irá permitir que os modelos previamente especificados para uma mesma resistência do concreto apresentem ao menos valores próximos.

De acordo com MÖRSCH (1952), no ano de 1905 efetuaram-se ensaios em comemoração ao 25. Aniversário da Indústria Alemã. Estes ensaios foram conduzidos no Laboratório Oficial de Stuttgart com modelos de seção transversal de $250 \mathrm{~mm} \times 250 \mathrm{~mm}$ e altura de $1000 \mathrm{~mm}$. A tabela 3.1 e a figura 3.8 exemplificam os dados de cada um dos pilares. Vale dizer que também foi ensaiado um modelo sem armadura alguma.

Tabela 3.1. Dados das armaduras dos pilares ensaiados, MÖRSCH (1952).

\begin{tabular}{ccccc}
\hline \multirow{2}{*}{$\begin{array}{c}\text { Modelo } \\
\text { de }\end{array}$} & \multicolumn{2}{c}{ Armadura Longitudinal } & \multicolumn{2}{c}{ Armadura Transversal } \\
\cline { 2 - 5 } Pilar & Número & $\begin{array}{c}\text { Diâmetro } \\
(\mathbf{m m})\end{array}$ & $\begin{array}{c}\text { Diâmetro } \\
(\mathbf{m m})\end{array}$ & $\begin{array}{c}\text { Espaçamento } \\
(\mathbf{m m})\end{array}$ \\
\hline A & 4 & 15 & 7 & 250 \\
B & 4 & 15 & 7 & 125 \\
C & 4 & 15 & 7 & 62,5 \\
D & 4 & 20 & 7 & 250 \\
E & 4 & 30 & 7 & 250 \\
\hline
\end{tabular}



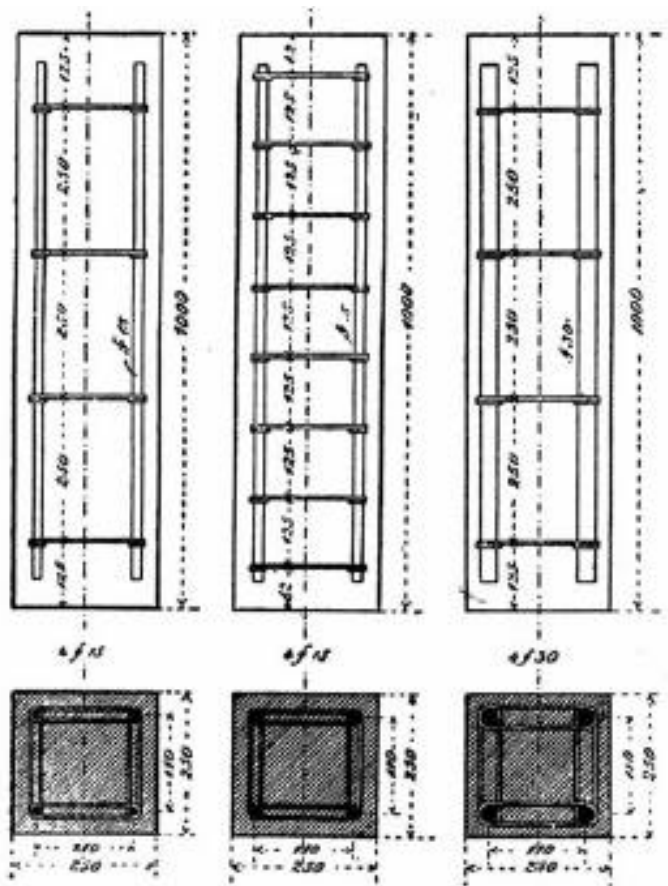

Figura 3.8. Seção transversal e vista lateral dos modelos de pilares, MÖRSCH (1952).

MÖRSCH (1952) analisou os resultados obtidos nos modelos de pilares partindo do pressuposto que a resistência do pilar é o resultado da soma isolada das resistências do concreto e do aço em seu escoamento. A partir de então, pôde concluir que a maior força de ruína do pilar $\mathrm{C}$, em relação ao esperado, ocorreu por conta do cintamento do concreto provocado pelo pequeno espaçamento da armadura transversal. Já para os pilares $\mathrm{D}$ e E, com barras longitudinais de maiores diâmetros, verificou-se que suas capacidades resistentes ficaram abaixo do esperado em função da ruptura prematura de suas cabeças (ver a figura 3.9).

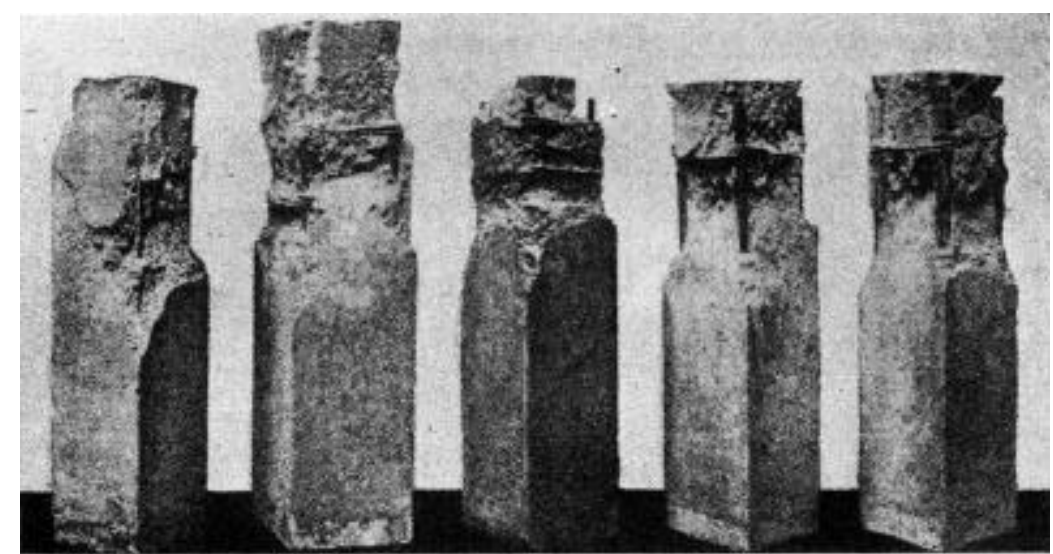

Figura 3.9. Modelos rompidos em comemoração ao $25 .^{\circ}$ Aniversário da Indústria Alemã, MÖRSCH (1952). 
Unindo os resultados destes ensaios com os de ensaios mais antigos, MÖRSCH (1952) sugere a seguinte explicação para o rompimento prematuro das cabeças dos modelos fortemente armados: com as grandes pressões exercidas sobre o concreto localizado entre a superfície de contato da placa de apoio e as barras longitudinais, imagina-se a formação de um cilindro de tensões acima de cada barra longitudinal; assim, o alargamento transversal deste cilindro resulta no rompimento do concreto que o rodeia. Aliado a isto, a desigualdade nos esforços de compressão causam altos esforços de cisalhamento na cabeça do pilar, fato este que contribui para o rompimento prematuro dos modelos (ver a figura 3.10).

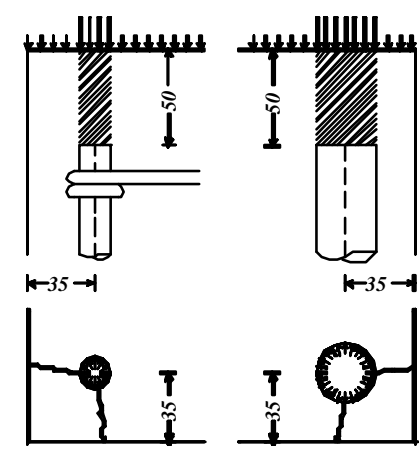

Figura 3.10. Distribuição de tensões nas extremidades de pilares com barras longitudinais de pequeno e grande diâmetro, MÖRSCH (1952).

Os ensaios dos pilares da Comissão Alemã de Concreto Armado foram realizados no Laboratório de Grosslichterfelde. Os resultados foram publicados nos Cadernos 5, 21, 28 e 34 da Comissão Alemã pelo conselho Rudeloff.

O Caderno 5 apresenta duas séries de pilares ensaiados. No entanto, a série I, com pilares de seção transversal $300 \mathrm{~mm} \times 300 \mathrm{~mm}$ e altura de $2000 \mathrm{~mm}$, foi considerada inválida. Segundo MÖRSCH (1952), os motivos que levaram a esta decisão foram: falta de homogeneidade nos procedimentos de cura; os estribos não estavam ligados adequadamente æ̀ barras longitudinais e, por isso, acabaram deslizando dentro do concreto; a distância de 200mm entre os estribos foi demasiadamente grande e, portanto, incapaz de proteger as barras longitudinais contra a flambagem prematura.

A série II apresentou pilares com mesma seção transversal da série I e altura de $900 \mathrm{~mm}$. Além disso, os estribos de $7 \mathrm{~mm}$ de diâmetro foram espaçados de $150 \mathrm{~mm}$. A armadura longitudinal foi composta por quatro barras de diâmetro de $16 \mathrm{~mm}$. A figura 3.11 apresenta as seções transversais e configurações das armaduras empregadas nesta série. 

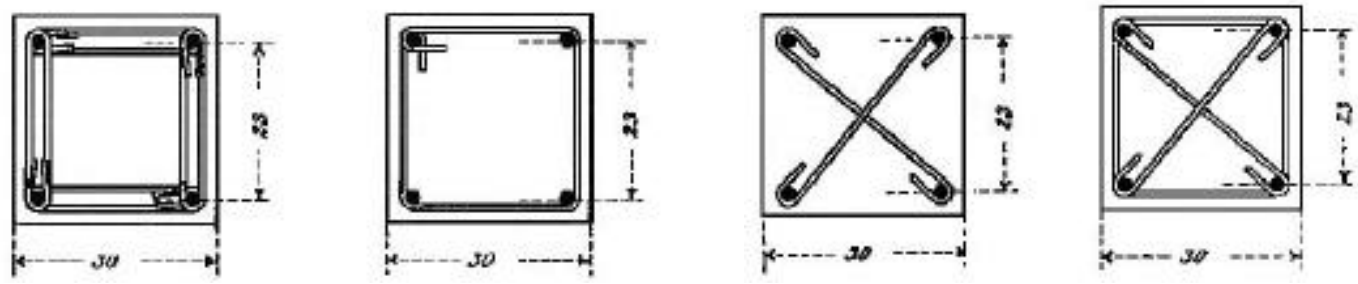

Figura 3.11. Seções transversais e configurações das armaduras empregadas na série II, MÖRSCH (1952).

Dentre as conclusões obtidas com os resultados dos ensaios, podem ser citadas as seguintes:

- modelos com armadura apresentaram menores deformações do que aqueles não armados, como era de se esperar;

- caso não se esteja buscando o cintamento do concreto, então, os estribos quadrados são a melhor opção para compor a armadura transversal, pois são simples de executar, facilitam o adensamento do concreto nas fôrmas e consomem menor quantidade de aço; e

- verificação da concordância entre a capacidade resistente experimental e a capacidade resistente teórica, esta última baseada na soma da resistência do concreto com a resistência do aço em seu escoamento.

Como nestes ensaios foi novamente observado que a maior parte dos modelos rompeu em suas extremidades superiores, MÖRSCH (1952) apresenta alguns motivos que podem explicar este fenômeno:

- resistência menor da extremidade superior do pilar em virtude do mau adensamento do concreto nesta região;

- ação rompedora de um cilindro de concreto altamente comprimido que se encontra na continuação das armaduras longitudinais (ver a figura 3.10); e

- modelo de pilar não centrado na máquina de ensaio. 
Os ensaios reportados no Caderno 21 trazem a preocupação em se evitar a ruptura prematura da cabeça dos pilares. Por meio da figura 3.12, pode-se observar o detalhamento das extremidades dos pilares que, agora, apresentam-se reforçadas.
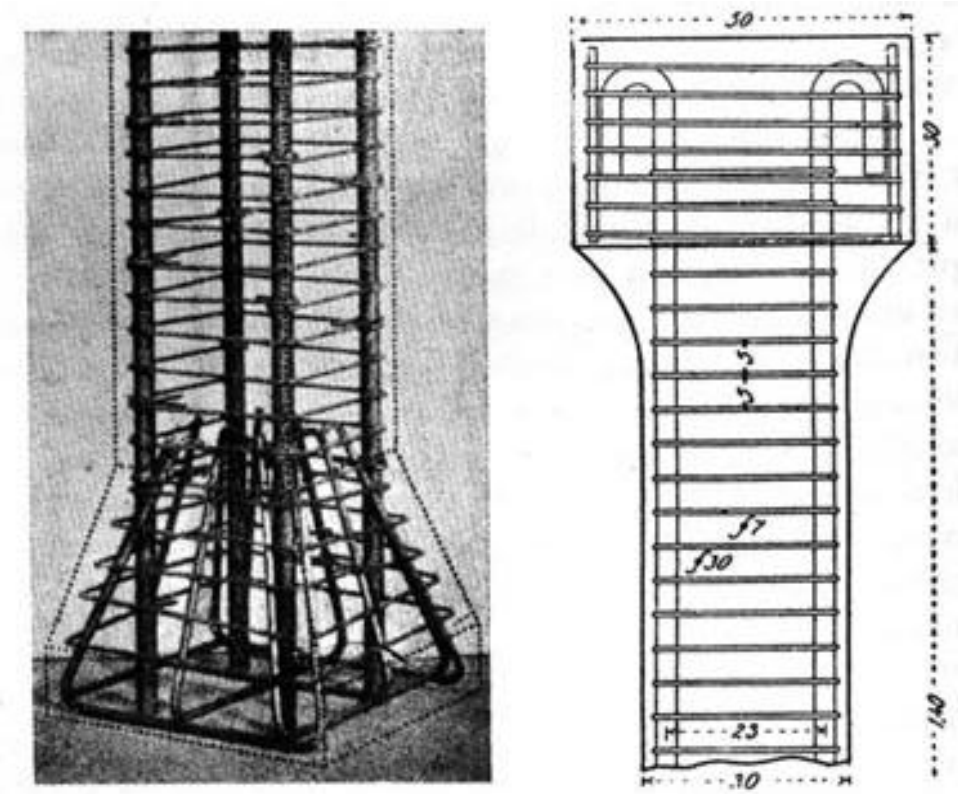

Figura 3.12. Da esquerda para a direita, cabeça de pilar desenvolvida pela Comissão Austríaca de Concreto Armado e cabeça de pilar proposta e descrita por MÖRSCH (1952).

Após os ensaios destes pilares, verificou-se que a proposta austríaca de reforço das extremidades não correspondeu ao esperado. Como os pilares executados com a proposta de Mörsch romperam na região desejada, supôs-se que a descontinuidade na transição do fuste poderia ser a culpada pelo fracasso da cabeça austríaca.

Ainda no Caderno 21, alguns pilares tiveram a espessura do concreto de cobrimento das armadura, no topo dos pilares, diminuída. Esta medida permitiu minimizar a ação rompedora do cilindro de concreto altamente comprimido (ver a figura 3.10) e, assim, evitar a ruptura prematura da cabeça dos pilares. Isto pôde ser verificado, pois nos modelos com igualdades de geometria e armaduras, aqueles com maiores espessuras do cobrimento mencionado acima apresentaram menores capacidades de carga. 
Por fim, MÖRSCH (1952) apresenta as seguintes conclusões obtidas com os resultados dos ensaios do Caderno 21:

- comprovação da validade da fórmula de cálculo da capacidade resistente de um pilar não cintado

$$
P=\Omega \cdot k_{h}+F \cdot \sigma_{s}
$$

onde:

$P$ é a capacidade resistente do pilar não cintado;

$k_{h}$ é a resistência prismática do concreto;

$\sigma_{s}$ é a tensão de escoamento do aço da armadura longitudinal;

$\Omega$ é a área de concreto da seção transversal; e

$F$ é a área da seção transversal da armadura longitudinal.

- para se evitar a ruptura prematura da cabeça do pilar, deve-se reforçar esta região conforme o detalhamento proposto por Mörsch (ver a figura 3.12) ou então, executar o cobrimento de concreto, localizado entre a prensa e as barras longitudinais, com poucos milímetros; e

- para seção transversal quadrada de $300 \mathrm{~mm} \times 300 \mathrm{~mm}$, com estribos de $7 \mathrm{~mm}$ de diâmetro espaçados a cada $50 \mathrm{~mm}$, não ocorreu nenhuma ação de cintamento do concreto.

Os ensaios de pilares relatados no Caderno 28 tiveram como um dos principais objetivos verificar a ação de cintamento provocada por uma armadura transversal cerrada. No caso dos modelos quadrados de dimensões $300 \mathrm{~mm} x$ $300 \mathrm{~mm} \times 1300 \mathrm{~mm}$, a armadura transversal de $5 \mathrm{~mm}$ e $7 \mathrm{~mm}$ de diâmetro era composta por estribos ou hélices quadradas com espaçamento de $50 \mathrm{~mm}$, enquanto que, a armadura longitudinal era formada por quatro barras com diâmetro de $20 \mathrm{~mm}$. Nos pilares octogonais com área da seção transversal de $900 \mathrm{~cm}^{2}$ e altura de $1300 \mathrm{~mm}$, foi empregada armadura transversal circular de $7 \mathrm{~mm}$ e $12 \mathrm{~mm}$ em forma de estribos ou espirais espaçadas de $30 \mathrm{~mm}$ e $40 \mathrm{~mm}$. 
As seguintes observações puderam ser feitas a partir dos resultados obtidos com os ensaios:

- as deformações dos pilares armados foram maiores do que nos similares não armados. Isto contradiz as leis da elasticidade e poderia ser explicado por uma diferente constituição do concreto dos pilares armados;

- nos pilares de seção retangular, as armaduras transversais com diâmetros de $5 \mathrm{~mm}$ ou $7 \mathrm{~mm}$ e espaçadas de $50 \mathrm{~mm}$ não produziram nenhum efeito de cintamento no concreto;

- nos pilares de seção octogonal, verificou-se o cintamento do concreto pela armadura transversal cerrada;

- com os ensaios de pilares circulares, sem cobrimento de concreto e com mesma armadura que os octogonais, obtiveram-se capacidades de carga muito próximas aos de seção octogonal. Assim, concluiu-se que, em pilares suficientemente cintados, o cobrimento de concreto das armaduras pode ser desconsiderado no cálculo da capacidade de carga destes pilares;

- nos pilares cintados, o concreto da seção transversal delimitada pelos eixos dos estribos constituiu um núcleo resistente que, mesmo após o descolamento do cobrimento das armaduras, conservou sua coesão e apresentou uma resistência crescente às deformações progressivas; e

- a relação entre as deformações transversais e longitudinais, conhecida como coeficiente de Poisson, foi menor nos pilares com maiores resistências.

MÖRSCH (1952) apresenta também os ensaios da Casa Wayss \& Freitag A. G., a partir dos quais fica confirmada a dificuldade para se obter um eficiente cintamento em pilares de concreto armado com seções transversais quadradas e retangulares. Enquanto isso, nos ensaios da Comissão Francesa de Cimento Armado, verificou-se que o cintamento do concreto é mais sensível em pilares com concretos de menor resistência à compressão. Por fim, os ensaios do Laboratório de Stuttgart trazem pilares submetidos à compressão centrada e excêntrica. Os 
resultados dos ensaios à compressão simples permitiram validar a fórmula de cálculo de pilares não cintados (ver a página 51). Além disso, o detalhamento dos modelos de pilares chama a atenção, pois, pela primeira vez, observam-se estribos complementares, em forma de barra reta com ganchos nas extremidades, ligados æ̀ barras longitudinais localizadas fora dos cantos (ver a figura 3.13).

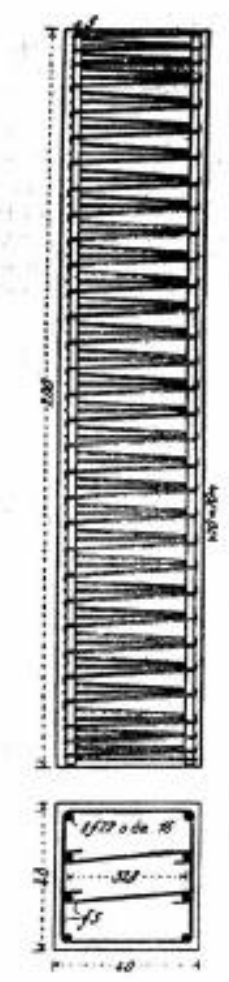

Figura 3.13. Seção transversal e vista lateral de um dos modelos de pilares ensaiados pelo Laboratório de Stuttgart, MÖRSCH (1952).

Em suma, depois dos diversos ensaios reportados e apresentados por MÖRSCH (1952), foram elaboradas as seguintes conclusões gerais:

- no caso de pilar não cintado, sua capacidade de carga é resultante da soma da resistência do concreto com a resistência do aço em seu limite de escoamento. Todavia, para o pilar cintado, a resistência do elemento compõe-se da resistência do concreto do núcleo (superfície delimitada pelos eixos dos estribos) somada a resistência das barras da armadura longitudinal e a um aumento na resistência do núcleo de concreto. Esta última parcela de resistência é proporcional àquantidade e ao limite de escoamento da armadura transversal.

Para os pilares não cintados, a armadura transversal com diâmetro entre $5 \mathrm{~mm}$ e $7 \mathrm{~mm}$ mostrou-se a mais conveniente funcional e economicamente; 
- para o cintamento de pilares, os estribos circulares com pequeno espaçamento e as hélices circulares ou espirais mostraram-se mais eficientes. Porém, as hélices quadradas apresentaram pouco ou quase nenhum efeito de cintamento sobre o núcleo de concreto dos pilares;

- nos ensaios de pilares com armadura transversal em forma de espirais, verificou-se que nos elementos com menor resistência àcompressão do concreto o efeito do cintamento foi maior;

- o aumento da resistência nos pilares cintados, em relação aos não cintados, é resultante de um estado multiaxial de tensões. Ocorre que a força de compressão axial aplicada ao pilar conduz à deformação transversal do elemento que, por sua vez, solicita a armadura transversal criando uma pressão lateral sobre o núcleo de concreto. Deste modo, a maior quantidade de armadura transversal e o maior limite de escoamento desta armadura farão com que a pressão lateral exercida sobre o núcleo de concreto aumente e, com isso, a resistência do pilar na direção axial cresça;

- independente do diâmetro do núcleo de concreto, o fenômeno do cintamento é diretamente proporcional à tensão de escoamento da armadura transversal e inversamente proporcional àresistência do concreto àcompressão; e

- o modo como a armadura transversal é solicitada, em pilares cintados, cria esforços que resultam no descolamento do cobrimento de concreto das armaduras (ver a figura 3.14).

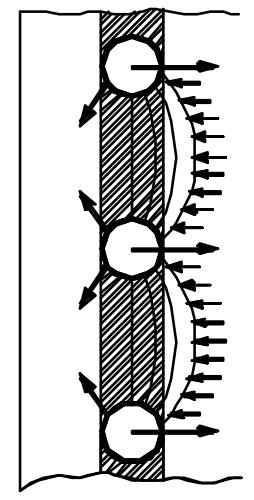

Figura 3.14. Análise estática das forças que envolvem a armadura transversal dos pilares, MÖRSCH (1952). 
A busca pelo confinamento do concreto de resistência usual bi um dos principais objetivos das pesquisas realizadas ao longo dos anos com pilares de concreto armado submetidos à compressão centrada. Na tabela 3.2, elaborada por SHEIKH \& UZUMERI (1982), apresentam-se os principais trabalhos desenvolvidos até $O$ ano de 1980. As pesquisas mais recentes sobre o assunto foram realizadas por MANDER et al. (1988), RAZVI \& SAATCIOGLU (1989) e CLAESON et al. (1996). No Brasil, as referências são AGOSTINI (1992) e PAIVA (1994), os quais apresentaram estudos comparativos entre pilares de concreto de resistências usual e alta.

Segundo SHEIKH \& UZUMERI (1982), os modelos mais antigos não apresentaram ganhos significativos de resistência, após o descolamento do cobrimento, pois a relação entre a área do núcleo delimitado pelos eixos dos estribos e a área da seção transversal era pequena (ver a tabela 3.2). Este, talvez, tenha sido o principal motivo pelo qual diversos pesquisadores, inclusive MÖRSCH (1952), não chegaram a um acordo sobre os efeitos benéficos da armadura transversal retilínea utilizada com o objetivo de cintar o concreto. Além disso, variáveis como o espaçamento entre a armadura transversal, quantidade e distribuição da armadura longitudinal e as características dos aços empregados nas armaduras, não teriam sido arranjadas, convenientemente, visando o ganho de ductilidade e resistência nos modelos de pilares.

Como indicado na tabela 3.2, SHEIKH \& UZUMERI (1980) conduziram um programa experimental que envolveu um total de 24 pilares curtos de concreto armado com seção transversal quadrada e dimensões de $305 \mathrm{~mm} \times 305 \mathrm{~mm} \times$ $1960 \mathrm{~mm}$. Nestes modelos, foram variadas as taxas e configurações das armaduras, todavia, utilizou-se somente concreto de resistência usual.

A figura 3.15 apresenta o detalhamento dos modelos e revela a preocupação com a possibilidade de ruptura prematura das extremidades expressa com 0 alargamento da seção nas extremidades. 
Tabela 3.2. Principais pesquisas sobre confinamento do concreto em pilares submetidos à compressão centrada, SHEIKH \& UZUMERI (1982).

\begin{tabular}{|c|c|c|c|c|}
\hline \multirow[b]{2}{*}{ Pesquisador } & \multicolumn{4}{|c|}{ Detalhes dos Modelos } \\
\hline & $\begin{array}{l}\text { Número } \\
\text { de } \\
\text { Modelos }\end{array}$ & $\begin{array}{c}\text { Seção } \\
\text { Transversal } \\
\text { (in } x \text { in) }\end{array}$ & Área núcleo/Área seção & $\begin{array}{c}\text { Armadura } \\
\text { Longitudinal } \\
\text { (n. }{ }^{\circ} \text { de barras) }\end{array}$ \\
\hline KING (1946) & 164 & $3,5 \times 3,5$ & $0,54-0,61$ & 4 \\
\hline KING (1946) & 18 & $10 \times 10$ & $0,34-0,66$ & 4 \\
\hline \multirow{3}{*}{ CHAN (1955) } & 9 & $6 \times 6$ & $0,63-0,92$ & 4 \\
\hline & 7 & $6 \times 3^{5 / 8}$ & $0,92-0,96$ & 4 \\
\hline & 7 & 6in de diâmetro & 0,97 & 4 \\
\hline BRESLER \& & 2 & $8 \times 8$ & 0,61 & 6 \\
\hline GILBERT (1961) & 2 & $8 \times 8$ & 0,61 & 8 \\
\hline \multirow{3}{*}{ PFISTER (1964) } & 4 & $12 \times 12$ & $0,42-0,53$ & 12 \\
\hline & 3 & $8 \times 18$ & $0,36-0,49$ & 12 \\
\hline & 4 & $10 \times 12$ & 0,49 & 6 \\
\hline $\begin{array}{c}\text { ROY \& SOZEN } \\
(1964)\end{array}$ & 45 & $5 \times 5$ & $0,86-0,90$ & 4 \\
\hline \multirow{4}{*}{$\begin{array}{c}\text { BERTERO \& } \\
\text { FELIPPA (1964) }\end{array}$} & 2 & $3 \times 3$ & & 0 \\
\hline & 5 & $3 \times 3$ & & 4 \\
\hline & 2 & $4^{1 / 4} \times 4^{1 / 4}$ & & 0 \\
\hline & 6 & $4^{1 / 4} \times 4^{1 / 4}$ & & 4 \\
\hline \multirow{2}{*}{ HUDSON (1966) } & 32 & $4 \times 4$ & $0,46-0,47$ & 8 \\
\hline & 28 & $6 \times 6$ & $0,63-0,66$ & 8 \\
\hline \multirow{4}{*}{$\begin{array}{c}\text { SOLIMAN \& YU } \\
\text { (1967) }\end{array}$} & 3 & $6 \times 4$ & $0,92-1,00$ & 2 \\
\hline & 11 & $6 \times 4$ & $0,44-0,92$ & 4 \\
\hline & 1 & $6 \times 3$ & 0,91 & 4 \\
\hline & 1 & $6 \times 5$ & 0,93 & 4 \\
\hline $\begin{array}{c}\text { SHAH \& RANGAN } \\
(1970)\end{array}$ & 11 & $2 \times 2$ & 0,83 & 0 \\
\hline SOMES (1970) & 42 & $4 \times 4$ & $0,88-0,92$ & 0 \\
\hline SARGIN (1971) & 41 & $5 \times 5$ & $0,65-0,96$ & 0 \\
\hline BURDETTE \& & 16 & $5 \times 5$ & $0,72-1,00$ & 0 \\
\hline HILSDORF (1971) & 4 & 5in de diâmetro & 1,00 & 0 \\
\hline \multirow{2}{*}{ BUNNI (1975) } & 4 & $5 \times 5$ & $0,88-0,90$ & 0 \\
\hline & 50 & $5 \times 5$ & $0,88-0,95$ & 4 \\
\hline KAAR, et al. & 13 & $10 \times 16$ & $0,68-0,72$ & 4 \\
\hline (1977) & 6 & $5 \times 8$ & 0,70 & 4 \\
\hline \multirow{4}{*}{$\begin{array}{c}\text { VALLENAS; } \\
\text { BERTERO \& } \\
\text { POPOV (1977) }\end{array}$} & 3 & $10 \times 10$ & 0,78 & 8 \\
\hline & 3 & $9 \times 9$ & 0,96 & 8 \\
\hline & 3 & $10 \times 10$ & 0,78 & 0 \\
\hline & 3 & $9 \times 9$ & 0,96 & 0 \\
\hline $\begin{array}{c}\text { SHEIKH \& } \\
\text { UZUMERI (1980) }\end{array}$ & 24 & $12 \times 12$ & 0,78 & 8,12 e 16 \\
\hline
\end{tabular}



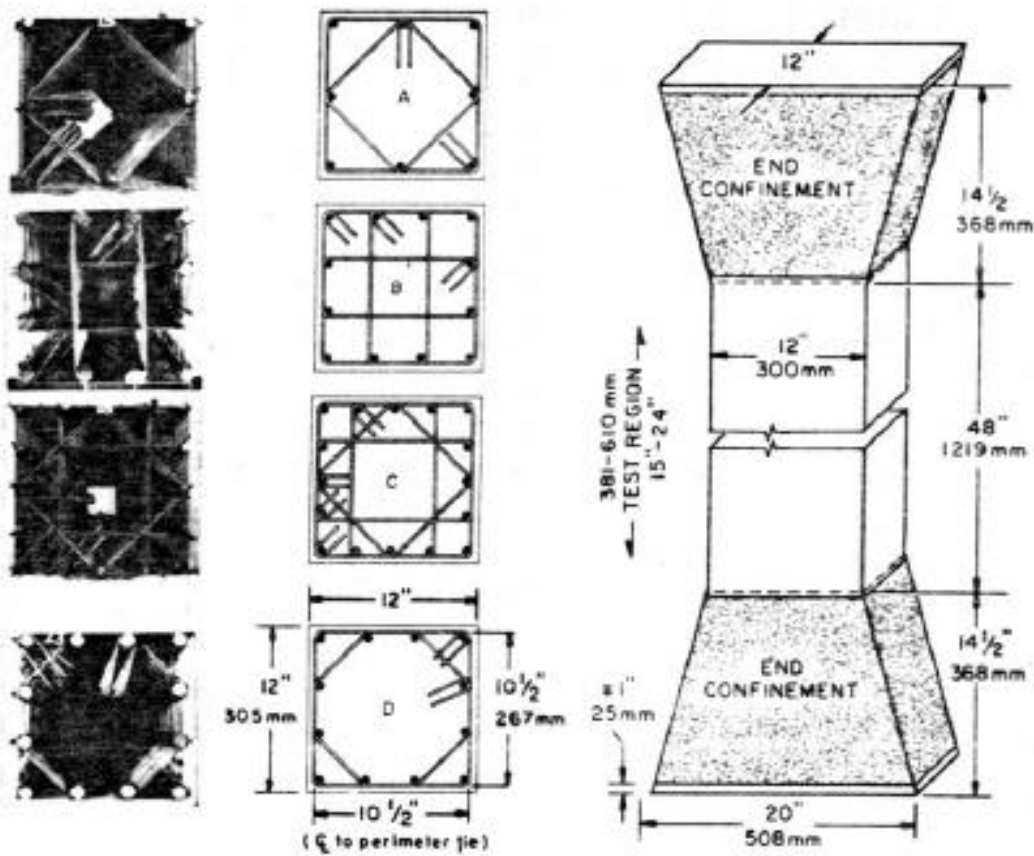

Figura 3.15. Detalhamento dos modelos de pilares, SHEIKH \& UZUMERI (1980).

As seguintes conclusões foram elaboradas mediante os resultados obtidos com os ensaios dos pilares àcompressão simples:

- o concreto confinado com armadura transversal retilínea e uma adequada distribuição das barras longitudinais apresentou ganhos significativos de resistência (até $70 \%$ ) e ductilidade;

- a área de concreto efetivamente confinado é menor do que a área de concreto contida entre os eixos dos estribos. Além disso, a determinação desta área depende da distribuição das barras longitudinais e da configuração e espaçamento das barras transversais;

- o reduzido espaçamento entre as armaduras, em ambas as direções longitudinal e transversal, aumentou a eficiência do confinamento. Mesmo com a redução dos diâmetros das barras transversais, mantidas as taxas volumétricas de armadura transversal, a diminuição do espaçamento entre os estribos conduziu a grandes aumentos na resistência e na ductilidade do concreto; 
- a maior quantidade de armadura lateral teve um efeito bastante significativo no comportamento do concreto confinado. Porém, o aumento da resistência do aço que compunha a armadura transversal resultou em menores incrementos de resistência e ductilidade do que o esperado;

- a utilização de armadura transversal composta por aço com patamar de escoamento conduziu a menores ganhos de resistência e ductilidade no concreto confinado; e

- dentro da esfera dos valores usados nos ensaios, a quantidade de armadura longitudinal pareceu ter pequeno efeito sobre o comportamento do concreto confinado.

MANDER et al. (1988a) apresentam um estudo experimental sobre o comportamento da relação tensão-deformação do concreto confinado em pilares de concreto de resistência usual submetidos àcompressão centrada. Para isso, foram ensaiados trinta e um modelos com seções transversais circulares, quadradas e retangulares, dotados de diversos arranjos de armadura transversal e longitudinal. A figura 3.16 exemplifica o detalhamento geral de alguns destes modelos de pilares.

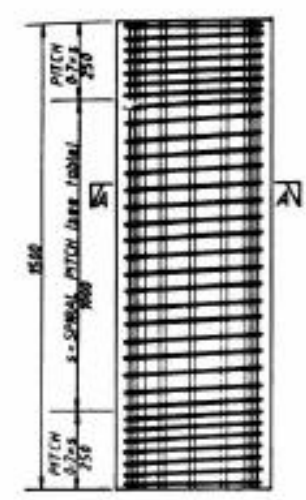

ELEVATION

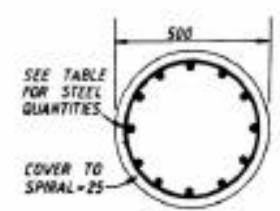

SECTION A-A

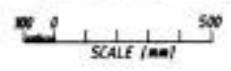

(a) 


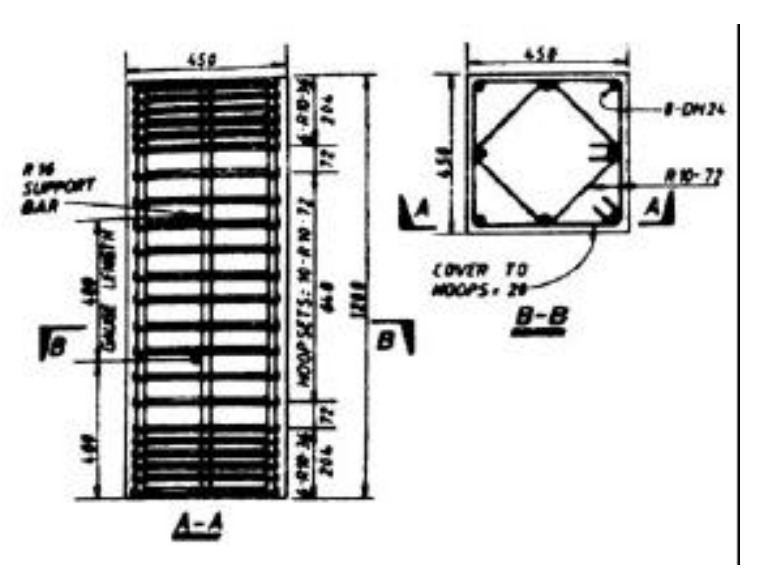

(b)

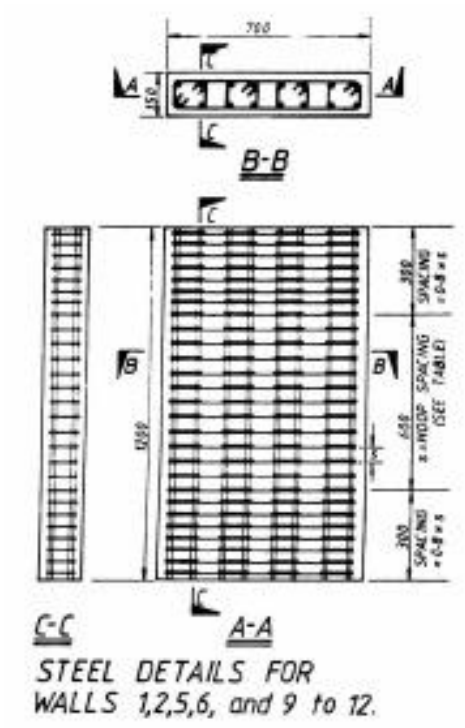

\section{0 \\ WALL 3 \\ 000000 \\ WALL 4 \\ \begin{tabular}{lll}
\hline 1003 \\
WALLS 13 and 14
\end{tabular}}

(c)

Figura 3.16. Seções transversais e vistas laterais dos pilares de seção circular (a), quadrada (b) e retangular (c), MANDER et al. (1988a).

Os resultados experimentais foram comparados com valores teóricos obtidos por meio de um modelo teórico que foi desenvolvido por MANDER et al. (1988b) para representar a relação tensão-deformação no concreto de resistência usual confinado. Este modelo teórico de confinamento será apresentado no item 3.5 deste trabalho. 
Dentre as conclusões de MANDER et al. (1988a), enumeram-se as seguintes:

- independente do tipo de seção transversal, o parâmetro que mais afetou a forma da curva tensão-deformação do concreto confinado foi a quantidade de armadura de confinamento. Assim, o aumento da taxa volumétrica de armadura transversal resultou em acréscimo na resistência àcompressão axial dos modelos, diminuição da inclinação da parte descendente da curva tensão-deformação e aumento da deformação longitudinal no instante da ruptura dos estribos;

- a influência da configuração da armadura transversal pode ser predita com a utilização do coeficiente de confinamento efetivo $K_{e}$. Nos pilares de seção transversal quadrada e retangular, $K_{e}$ variou de 0,40 a 0,70 , enquanto que, naqueles com seção circular, foi de 0,89 a 1,00. Este coeficiente será definido mais adiante junto do modelo teórico de confinamento proposto por MANDER et al. (1988b);

- como era de se esperar, os pilares confinados com armadura transversal em forma de espiral apresentaram melhor performance que os pilares de seção transversal quadrada e retangular. Isto foi verificado com a medida de parâmetros como a resistência à compressão dos pilares e a deformação última de compressão, ambos para uma mesma taxa de armadura transversal; e

- o modelo teórico de confinamento proposto por MANDER et al. (1988b) descreveu de forma satisfatória a relação tensão-deformação de pilares de seção circular, quadrada e retangular, com diferentes configurações de armaduras (ver a figura 3.17). 

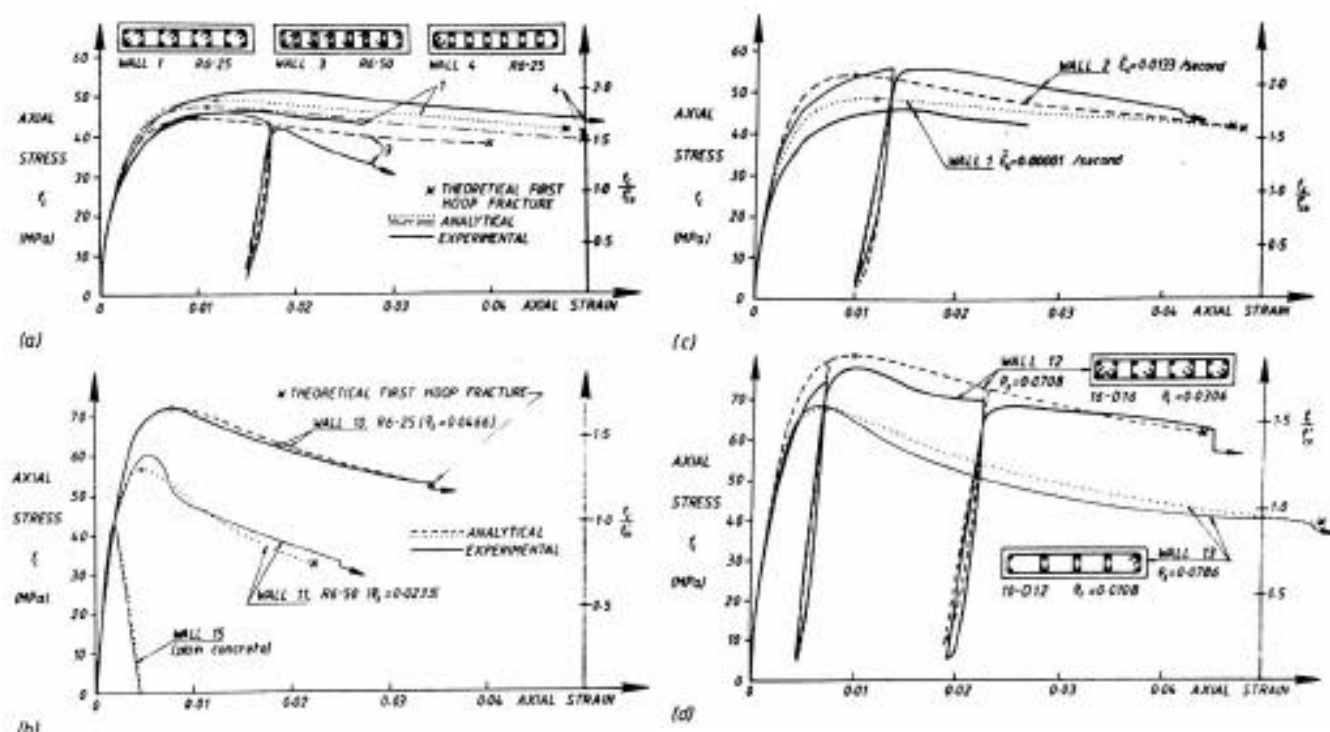

Figura 3.17. Comparação entre as relações de tensão-deformação teórica e experimental de pilares variando-se os seguintes aspectos: a) configuração da armadura transversal (a simbologia R6-25 significa: armadura transversal com $6 \mathrm{~mm}$ de diâmetro e espaçada de $25 \mathrm{~mm}$ ); b) espaçamento da armadura transversal; c) taxa de deformação aplicada no ensaio; e d) distribuição da armadura longitudinal (a simbologia 10-D12 significa: armadura longitudinal composta por 10 barras de diâmetro 12mm). Figura extraída de MANDER et al. (1988a).

CLAESON et al. (1996) fizeram uma análise experimental e numérica de pilares de concreto com resistências alta e usual. Para os pilares curtos de concreto com resistência usual foram observadas as seguintes particularidades:

- até $90 \%$ da carga última não foi verificada fissuração no pilar;

- os modelos sem nenhuma armadura apresentaram ruptura brusca, enquanto que, nos modelos armados a ruptura se deu de forma mais gradual em função dos efeitos benéficos da armadura;

- o cobrimento separou-se do núcleo de concreto delimitado pelos eixos dos estribos nos pilares que apresentavam densa armadura transversal. Na verdade, esta armadura criou um plano natural de separação. Este fenômeno ocorreu de 
forma gradual ao longo do tempo, permitindo a obtenção de um trecho significativo no pós-pico da curva força-deslocamento (ver a figura 3.18);

- o aumento das taxas de armadura transversal resultou em aumento na ductilidade e resistência dos pilares; e

- o confinamento dado pela armadura transversal foi mais sensível nos pilares com concretos de menor resistência àcompressão.

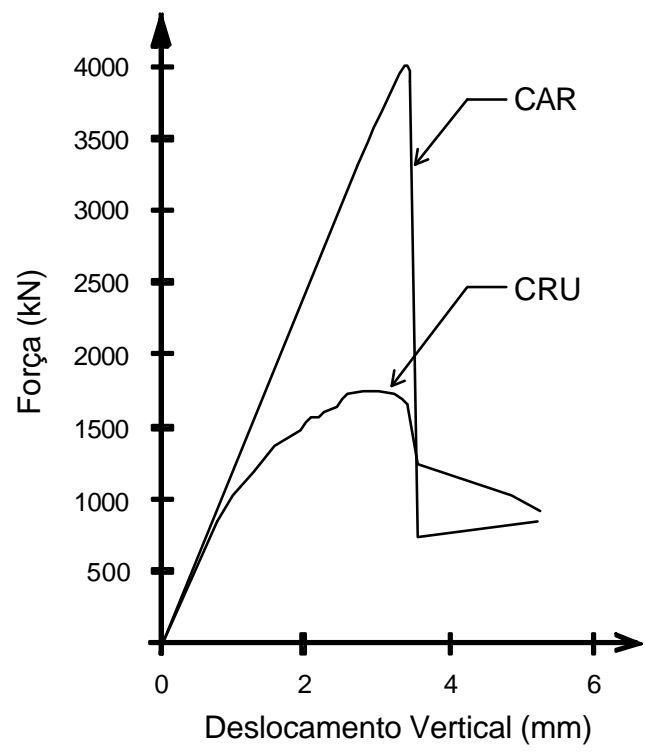

Figura 3.18. Relação força-deslocamento em pilares com resistência à compressão do concreto alta (CAR) e usual (CRU), CLAESON et al. (1996).

Para que a ruptura dos pilares ocorresse na região instrumentada, CLAESON et al. (1996) reforçaram as extremidades dos modelos com a utilização de pequenos espaçamentos entre os estribos da ordem de $50 \mathrm{~mm}$ ou menos.

No Brasil, AGOSTINI (1992), PAIVA (1994), LIMA (1997) e QUEIROGA (1999) realizaram estudos sobre pilares de concreto de alta resistência, todavia, os dois primeiros ensaiaram alguns pilares com concreto de resistência usual para fins de observação e comparação.

AGOSTINI (1992) verificou o efeito diferenciado causado pelo emprego de armadura transversal helicoidal com pequeno passo em pilares de dimensões de $100 \mathrm{~mm} \times 100 \mathrm{~mm} \times 400 \mathrm{~mm}$, com concretos de resistência usual e alta. Assim, concluiu que nos pilares de resistência usual a armadura de confinamento permitiu um acréscimo de tensão de 1,75 vez em relação aos valores obtidos nos ensaios 
dos corpos-de-prova cilíndricos aos 28 dias. Enquanto isso, nos pilares de alta resistência, a mesma armadura apenas confinou o núcleo impedindo uma ruptura frágil.

Os ensaios conduzidos por PAIVA (1994) em quatro pilares de dimensões de $80 \mathrm{~mm} \times 100 \mathrm{~mm} \times 480 \mathrm{~mm}$, com concreto de resistência usual, revelaram que toda a seção transversal, ńclusive o cobrimento, participa como seção resistente. Isto pôde ser afirmado, pois as deformações médias nos dois pilares armados, na fase elástica, foram coincidentes àquelas dos dois pilares não armados. Esta mesma análise foi feita em quatro pilares de concreto de alta resistência com as mesmas dimensões e armaduras daqueles com concreto de resistência usual. Assim, a partir do momento em que as deformações médias dos pilares armados, na fase elástica, foram maiores que àquelas dos pilares não armados, concluiu-se que a seção resistente não é a seção transversal total, mas sim uma região delimitada pelos eixos dos estribos.

É interessante observar a preocupação demonstrada por PAIVA (1994) quanto à possibilidade de ruptura prematura dos pilares, pelo efeito de ponta das barras da armadura longitudinal. Desta forma, foram colocadas nas extremidades dos pilares duas placas de aço de $5 \mathrm{~mm}$ de espessura.

$\mathrm{Na}$ presente pesquisa, a prevenção contra a ruptura prematura dos pilares foi feita com o reforço das extremidades dos modelos utilizando-se uma armadura de fretagem pouco espaçada. Anteriormente, LIMA et al. (1997) e QUEIROGA et al. (1999) empregaram e verificaram a validade desta medida em ensaios de pilares de concreto de alta resistência.

\subsection{Cálculo da Capacidade Resistente}

Nesta fase do trabalho será apresentado o cálculo da capacidade resistente de pilares cintados e não cintados. Porém, este cálculo levará em conta as seguintes particularidades:

- as dimensões do pilar o caracterizam como pilar curto;

- a força de compressão sobre o pilar é perfeitamente centrada; e 
- em função das duas primeiras particularidades, os efeitos de segunda ordem e as excentricidades acidentais podem ser desprezados.

Com o objetivo claro de se fazer um levantamento histórico sobre o cálculo de pilares àcompressão centrada, são apresentados, a seguir, os métodos de cálculo descritos por alguns dos autores mais respeitados no Brasil. Vale salientar que foram mantidas as notações adotadas por estes autores em suas publicações.

\subsubsection{LANGENDONCK, T. (1944)}

a) Pilares não cintados

LANGENDONCK (1944) parte do pressuposto que a resistência do pilar é igual àsoma das resistências isoladas do concreto e do aço.

Tendo o aço doce, no qual se refere LANGENDONCK (1944), encurtamento de escoamento menor que o de ruptura do concreto, a ruína do pilar se dará com a ruptura do concreto e a armadura longitudinal em escoamento.

A formulação apresentada por LANGENDONCK (1944) prevê a utilização de um coeficiente de flambagem $\omega$, o qual irá multiplicar a carga axial atuante, para que o pilar possa ser calculado sem perigo de flambagem. Nos pilares com índice de esbeltez $\lambda$ menor que 50, correspondente a situação em estudo, o coeficiente de flambagem $\omega$ é tomado igual a 1.

Assim sendo, a capacidade resistente do pilar não cintado é dada pela seguinte equação:

$$
P_{o}=\omega \cdot P=\omega \cdot\left\{\sigma_{c} \cdot\left(S_{c}-S_{f}\right)+\sigma_{f} \cdot S_{f}\right\}
$$

onde:

$$
\begin{aligned}
& P_{o} \text { é a capacidade resistente do pilar; } \\
& P \text { é a capacidade resistente do pilar sem flambagem; } \\
& \omega \text { é o coeficiente de flambagem que, para o caso, é igual a 1; } \\
& \sigma_{c} \text { é a tensão de ruptura do concreto do pilar; } \\
& \sigma_{f} \text { é a tensão de escoamento do aço da armadura longitudinal; }
\end{aligned}
$$


$S_{c}$ é a área da seção transversal do pilar; e

$S_{f}$ é a área da seção transversal da armadura longitudinal.

b) Pilares cintados

LANGENDONCK (1944) apresenta o cálculo de pilares que estejam cintados por armadura transversal composta por espirais ou estribos circulares.

Tal como no caso dos pilares não cintados, os pilares cintados são calculados a partir da soma das resistências do concreto e do aço, mas considerando-se agora o acréscimo de resistência proveniente do cintamento. Este acréscimo de tensões é calculado da seguinte forma:

$$
\Delta \boldsymbol{\sigma}_{c}=\frac{S_{s}}{S_{n}} \cdot \boldsymbol{\sigma}_{e}
$$

onde:

$\Delta \sigma_{c}$ é o acréscimo de tensões no concreto localizado entre os eixos das barras de cintamento;

$$
S_{s}=\frac{\pi^{2} \cdot d^{\prime} \cdot \delta^{\prime 2}}{4 \cdot t} \text { é a área fictícia do cintamento (volume de armadura }
$$
de cintamento, por unidade de comprimento do pilar);

$S_{n}=\frac{\pi \cdot d^{\prime 2}}{4}$ é a área da seção transversal do núcleo;

$\sigma_{e}$ é o limite de escoamento do aço da armadura de cintamento;

$d^{\prime}$ é o diâmetro do núcleo, medido de eixo a eixo das barras de cintamento;

$\delta$ 'é o diâmetro da barra de cintamento; e

$t$ é o passo da hélice de cintamento ou o espaçamento entre cs estribos circulares.

O cobrimento de concreto não deve ser considerado no cálculo do pilar cintado e, além disso, a capacidade de carga do pilar cintado não deverá exceder o dobro da capacidade de carga, quando se despreza o cintamento. 
A flambagem deverá ser levada em conta a partir do coeficiente de flambagem $\omega$, como no caso dos pilares não cintados. Porém, a seção transversal a ser considerada deverá ser aquela contida entre os eixos dos estribos, a qual é chamada de núcleo. Deste modo, para núcleos cilíndricos, o índice de esbeltez é igual a

$$
\lambda=4 \cdot \frac{l}{d^{\prime}}
$$

onde, além das notações utilizadas anteriormente, têm-se:

$\lambda$ é o índice de esbeltez do núcleo cilíndrico; e

$l$ é o comprimento do pilar.

Por fim, a capacidade resistente do pilar cintado é estimada pela seguinte fórmula:

$$
P_{o}=\omega \cdot P=\omega \cdot\left\{\sigma_{n} \cdot\left(S_{n}-S_{f}\right)+\sigma_{f} \cdot S_{f}\right\}
$$

Porém, esta previsão de força última só será valida quando for obedecida a seguinte condição:

$$
P \leq 2 \cdot \frac{\sigma_{c} \cdot\left(S_{c}-S_{f}\right)+\sigma_{f} \cdot S_{f}}{\omega_{c}}
$$

onde, além das notações já utilizadas, têm-se:

$P_{o}$ é a capacidade resistente do pilar cintado;

$P$ é a capacidade resistente do pilar cintado sem flambagem;

$\omega$ é o coeficiente de flambagem correspondente à seção do núcleo que, para o caso, é igual a 1;

$\omega_{c}$ é o coeficiente de flambagem correspondente à seção total que, para o caso, é igual a 1;

$$
\sigma_{n}=\sigma_{c}+\Delta \sigma_{c}=\sigma_{c}+\frac{S_{s}}{S_{n}} \cdot \sigma_{e} \text { é a tensão de ruptura do concreto }
$$
localizado no núcleo; 
$\sigma_{c}$ é a tensão de ruptura do concreto;

$\sigma_{f}$ é a tensão de escoamento do aço da armadura longitudinal;

$S_{c}$ é a área da seção transversal do pilar; e

$S_{f}$ é a área da seção transversal da armadura longitudinal.

\subsubsection{MÖRSCH, E. (1952)}

a) Pilares não cintados

Segundo MÖRSCH (1952), ensaios com pilares de concreto armado demonstraram que antes que se alcançasse a capacidade de carga dos pilares, suas deformações foram suficientemente grandes para que o aço das barras longitudinais entrasse em escoamento.

Observando-se o comportamento dos aços considerados por LANGENDONCK (1944) e MÖRSCH (1952), fica claro que se tratavam de aços com limites de escoamento inferiores ao apresentado pelo aço CA-50, o mais empregado hoje em dia no Brasil. Atualmente, a NBR 7480 (1996) especifica apenas o aço CA-25, com baixo limite de escoamento, e os aços CA-50 e CA-60, com altos limites de escoamento, como aços destinados às armaduras para concreto armado. Contudo, a NBR 6118 (1978) permite a utilização de aços com outra qualidade desde que suas propriedades sejam suficientemente estudadas por laboratório nacional idôneo.

Supondo a utilização de aços com baixo limite de escoamento, MÖRSCH (1952) apresenta a capacidade de carga de pilares não cintados, prescrita pela norma alemã de 1932, como sendo igual a:

$$
P_{\text {máx }}=k_{h} \cdot \Omega+\sigma_{s} \cdot F
$$

onde:

$$
\begin{aligned}
& P_{m a ́ x} \text { é a capacidade resistente do pilar não cintado; } \\
& k_{h} \text { é a resistência prismática do concreto; } \\
& \sigma_{s} \text { é a tensão de escoamento do aço da armadura longitudinal; }
\end{aligned}
$$


$\Omega$ é a área da seção transversal do pilar; e

$F$ é a área da seção transversal da armadura longitudinal.

Como se pode observar, não foi descontada a área de aço da armadura longitudinal no cálculo da contribuição do concreto na capacidade resistente do pilar. De acordo com MÖRSCH (1952), este erro perde importância visto que o limite de escoamento do aço é variável e a área da armadura longitudinal representa uma porção muito pequena da seção transversal do pilar.

Para finalizar, o emprego da equação que define a capacidade resistente de pilares não cintados só era permitido nos pilares com taxa geométrica de armadura longitudinal compreendida entre $0,8 \%$ e $3 \%$.

b) Pilares cintados

MÖRSCH (1952) define os pilares cintados como sendo aqueles com armadura transversal em hélice ou estribos circulares. $O$ valor do passo da hélice ou o espaçamento entre os estribos circulares devem ser limitados em $80 \mathrm{~mm}$. Além disso, a relação entre o passo ou o espaçamento da armadura transversal e o diâmetro da seção transversal do núcleo não pode ser menor do que 1/5.

Assim sendo, a capacidade de carga de pilares cintados é dada pela seguinte fórmula:

$$
P_{\text {máx }}=k_{h} \cdot \Omega_{n}+\sigma_{s} \cdot F+m \cdot k_{h} \cdot F_{Z}
$$

onde:

$P_{m a ́ x}$ é a capacidade resistente do pilar cintado;

$k_{h}$ é a resistência prismática do concreto;

$\sigma_{s}$ é a tensão de escoamento do aço da armadura longitudinal;

$\Omega_{n}$ é a área da seção transversal do núcleo;

$F$ é a área da seção transversal da armadura longitudinal; 


$$
F_{Z}=\frac{\pi \cdot D}{s} \cdot f \text { é a área fictícia do cintamento (volume de armadura de }
$$
cintamento, por unidade de comprimento do pilar), sendo que $F_{z}$ não pode ser menor que $\frac{\Omega-\Omega_{n}}{m}$;

$\Omega$ é a área da seção transversal do pilar;

$D$ é o diâmetro do núcleo, medido de eixo a eixo das barras de cintamento;

$f$ é a área da seção transversal da barra da armadura de cintamento;

$s$ é o passo da hélice de cintamento ou o espaçamento entre os estribos circulares; e

$m$ é um coeficiente obtido em ensaios. Sabe-se que $m$ é independente de $F_{z}$ e diretamente proporcional ao limite de escoamento da armadura transversal e inversamente proporcional à resistência à compressão do concreto. Todavia, a norma alemã permitia o emprego de $m$ com o valor de 45. Isto pois, imaginava-se, na época, a utilização de concretos com resistências baixas e situadas numa faixa de valores suficientemente próximos tal que a variação de $m$ em torno de 45 pudesse ser considerada pequena e, então, desprezada.

Analisando-se a equação exposta, percebe-se que a influência da armadura transversal na capacidade de carga do pilar é considerada com um aumento na área de concreto, representada pelo produto $m \cdot k_{h}$.

A validade da formulação para a capacidade resistente de pilares cintados só ocorrerá quando a área da seção transversal ideal $\Omega_{i}$ obedecer a seguinte limitação:

$$
\Omega_{i}=\Omega_{n}+n \cdot F+m \cdot F_{Z} \leq 2 \cdot \Omega
$$

onde, além das notações utilizadas anteriormente, têm-se:

$\Omega_{i}$ é a área da seção transversal ideal; e

$n=\frac{E_{f}}{E_{h}}$ é a relação entre o módulo de elasticidade do aço da armadura longitudinal $E_{f}$ e o módulo de elasticidade do concreto $E_{h}$. 
Além disso, todo equacionamento descrito para pilares cintados só era válido nos casos em que a área da armadura longitudinal fosse pelo menos $1 / 3$ de $F_{z}$, não menor que $0,8 \%$ de $\Omega_{n}$ e nem maior que $8 \%$ de $\Omega_{n}$.

\subsubsection{ROCHA, A. M. (1970)}

a) Pilares não cintados

ROCHA (1970) apresenta o cálculo de pilares não cintados dotados de armadura longitudinal com baixo ou alto limite de escoamento. Como foi visto anteriormente, LANGENDONCK (1944) e MÖRSCH (1952) somente consideraram a utilização de aços com baixos limites de escoamento.

Dentre os aços padronizados pela NBR 7480 (1996), somente o CA-25 possui baixo limite de escoamento, enquanto que, os aços CA-50 e CA-60 possuem altos limites de escoamento. A diferença de se empregar um ou outro aço na armadura longitudinal dos pilares está na possibilidade de ocorrer ou não o escoamento desta armadura antes da ruptura do concreto.

Desta forma, os ensaios com barras de aço doce CA-25 isoladas demonstraram que seu encurtamento de escoamento é menor que o encurtamento de ruptura do concreto $(2 \mathrm{~mm} / \mathrm{m})$ e, portanto, a ruptura do concreto do pilar se dará com o aço em escoamento. Sendo assim, a capacidade resistente de um pilar não cintado, composto por armadura longitudinal de baixo limite de escoamento, será dada pela soma das resistências do concreto na ruptura e do aço em seu escoamento.

$$
N_{R}=S_{c}^{\prime} \cdot \sigma_{R}+S_{f} \cdot \sigma_{e}
$$

onde:

$N_{R}$ é a capacidade resistente de pilares não cintados;

$\sigma_{R}$ é a tensão de ruptura do concreto;

$\sigma_{e}$ é a tensão de escoamento do aço da armadura longitudinal;

$S_{c}^{\prime}$ é a área de concreto da seção transversal; e 
$S_{f}$ é a área da seção transversal da armadura longitudinal.

Nos ensaios em pilares com armadura longitudinal dotada de barras de aço com altos limites de escoamento (CA-50 e CA-60), verificou-se que a ruptura do concreto ocorreu antes do escoamento do aço. Com isso, a capacidade resistente do pilar não cintado passa a ser:

$$
N_{R}=S_{c}^{\prime} \cdot \sigma_{R}+S_{f} \cdot \sigma_{e}^{\prime}
$$

onde:

$N_{R}$ é a capacidade resistente de pilares não cintados;

$\sigma_{R}$ é a tensão de ruptura do concreto;

$\sigma_{e}^{\prime}$ é a tensão no aço da armadura longitudinal correspondente ao encurtamento de $2 \mathrm{~mm} / \mathrm{m}$;

$S_{c}^{\prime}$ é a área de concreto da seção transversal; e

$S_{f}$ é a área da seção transversal da armadura longitudinal.

Por fim, ROCHA (1970) afirma que, para fins práticos, pode-se adotar no lugar da área de concreto $S_{c}^{\prime}$ o valor da área da seção transversal do pilar $S_{c}$.

b) Pilares cintados

Verificou-se, a partir de ensaios, que a capacidade resistente de um pilar cintado é dada pela fórmula:

$$
N_{R}=S_{n}^{\prime} \cdot \sigma_{R}+S_{f} \cdot \sigma_{e}+2 \cdot S_{s} \cdot \sigma_{e s}
$$

onde:

$N_{R}$ é a capacidade resistente de pilares cintados;

$\sigma_{R}$ é a tensão de ruptura do concreto;

$\sigma_{e}$ é a tensão de escoamento do aço da armadura longitudinal; 
$\sigma_{e s}$ é a tensão de escoamento do aço da armadura transversal;

$S_{n}^{\prime}$ é a área de concreto do núcleo;

$S_{f}$ é a área da seção transversal da armadura longitudinal;

$S_{s}=\frac{\pi \cdot d^{\prime} \cdot S_{1}}{t}$ é o volume de aço da armadura transversal por unidade de comprimento do pilar (chamado seção de cintamento);

$d$ ' é o diâmetro do núcleo;

$S_{1}$ é a seção transversal da barra da armadura transversal; e

$t$ é o passo da espiral de cintamento ou o espaçamento entre os estribos circulares.

Como pode ser observado, a influência do cintamento na definição da capacidade de carga do pilar é representada pelo terceiro membro da equação $\left(2 \cdot S_{s} \cdot \sigma_{e s}\right)$, o qual é chamado de força que provoca o escoamento dos estribos.

Segundo ROCHA (1970), a parcela $2 \cdot S_{s} \cdot \sigma_{e s}$ provém de ensaios, dos quais se concluiu que a pressão lateral $p$ exercida em uma peça cilíndrica de concreto é equivalente a uma tensão normal longitudinal aproximadamente igual a $5 \cdot p$ na seção transversal, onde 5 representa o inverso do coeficiente de Poisson. No entanto, em virtude da pressão lateral não ser contínua, adota-se o coeficiente 4 ao invés de 5 (ver a figura 3.19).

Chamando-se de $S_{s}^{\prime}=\frac{S_{1}}{t}$ a seção transversal das espirais por metro linear, a força no cintamento durante o escoamento será $F=S_{s}^{\prime} \cdot \sigma_{e s}$. Assim, tem-se a seguinte pressão lateral (ver a figura 3.19):

$$
p=\frac{F}{R}
$$

onde:

$R$ é o raio da armadura de cintamento. 
Substituindo-se o valor de $F$, tem-se:

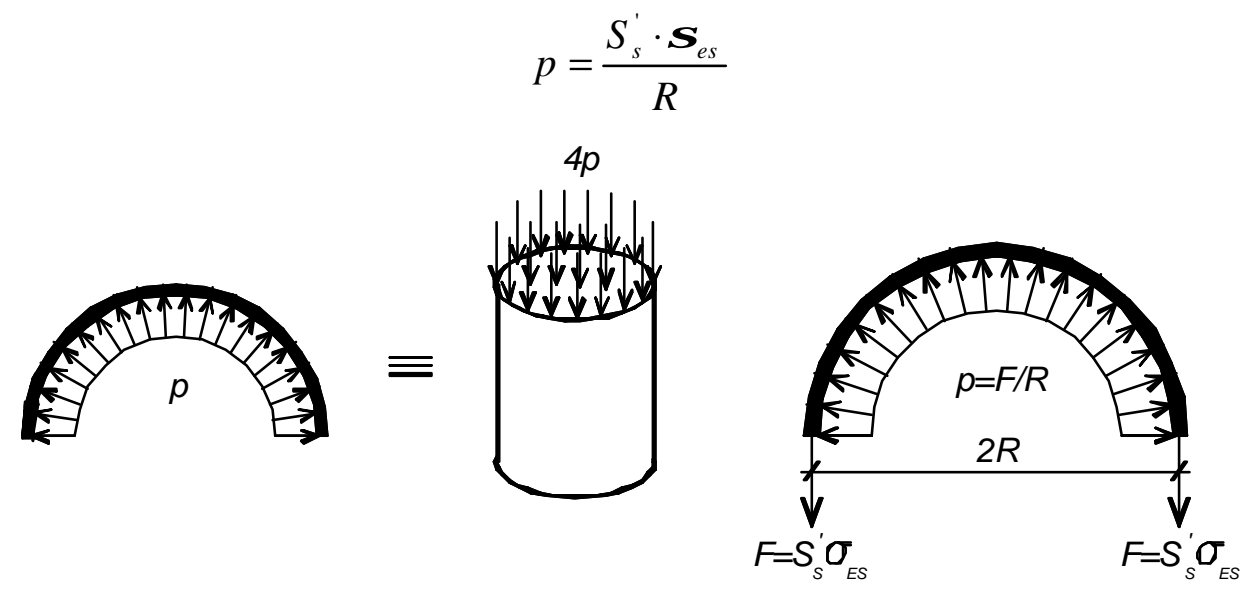

Figura 3.19. Pressões oriundas do cintamento da armadura transversal, ROCHA (1970).

Correspondendo esta pressão $p$ a uma pressão longitudinal de

$$
4 \cdot \frac{S_{s}^{\prime} \cdot \sigma_{e s}}{R}
$$

que, por sua vez, dá lugar a uma força longitudinal sobre o concreto do núcleo igual a

$$
F_{n}=4 \cdot \frac{S_{s}^{\prime} \cdot \sigma_{e s}}{R} \cdot S_{n}^{\prime}=4 \cdot \frac{S_{s}^{\prime} \cdot \sigma_{e s}}{R} \cdot \pi \cdot R^{2}=2 \cdot\left(2 \cdot \pi \cdot R \cdot S_{s}^{\prime}\right) \cdot \sigma_{s e}
$$

Se o valor $2 \cdot \pi \cdot R \cdot S_{s}^{\prime}=\pi \cdot d^{\prime} \cdot \frac{S_{1}}{t}=S_{s}$, então, a parcela de força que determina a influência do cintamento é dada pela seguinte fórmula:

$$
F_{n}=2 \cdot S_{s} \cdot \sigma_{s e}
$$

Alerta-se que a fórmula que define a capacidade de carga de pilares cintados não deverá ser maior do que 1,65 vez a resistência do pilar calculada sem o cintamento. Portanto: 


$$
N_{R} \leq 1,65 \cdot\left(S_{c} \cdot \sigma_{R}+S_{f} \cdot \sigma_{e}^{\prime}\right)
$$

onde, além das notações já utilizadas, têm-se:

$S_{c}$ é a área da seção transversal do pilar; e

$\sigma_{e}^{\prime}$ é a tensão no aço da armadura longitudinal correspondente ao encurtamento de $2 \mathrm{~mm} / \mathrm{m}$.

Por fim, ROCHA (1970) afirma que, para fins práticos, pode-se adotar no lugar da área de concreto do núcleo $S_{n}^{\prime}$ o valor da área da seção total do núcleo $S_{n}$.

3.4.4 PFEIL, W. (1983) e FUSCO, P. B. (1986)

Apesar destes autores apresentarem métodos de cálculo semelhantes e de acordo com as prescrições da NBR 6118 (1978), ambos adotaram simbologias diferentes entre si e em relação à norma brasileira. Assim, para tornar a apresentação mais familiar, será aqui utilizada a notação disposta na NBR 6118 (1978).

a) Pilares não cintados

A capacidade resistente de pilares não cintados é dada pela seguinte fórmula:

$$
F_{\text {teor }}=A_{c c} \cdot f_{c}+A_{s}^{\prime} \cdot \sigma_{s, 2}
$$

onde:

$F_{\text {teor }}$ é a capacidade resistente do pilar não cintado;

$f_{c}$ é a resistência àcompressão do concreto;

$\sigma_{s, 2}$ é a tensão no aço da armadura longitudinal correspondente ao encurtamento de $2 \mathrm{~mm} / \mathrm{m}$. Portanto, supõe-se o emprego de aço com alto limite de escoamento; 
$A_{c c}=A_{c}-A_{s}^{\prime}$ é a área de concreto da seção transversal;

$A_{s}^{\prime}$ é a área da seção transversal da armadura longitudinal; e

$A_{c}$ é a área da seção transversal do pilar.

b) Pilares cintados

PFEIL (1983) define os pilares cintados como sendo aqueles que possuem armadura em espiral ou estribos circulares capaz de provocar um estado de tensão tridimensional no concreto localizado dentro da armadura transversal.

No cálculo dos pilares cintados, não se considera o concreto que serve de cobrimento æ̀s armaduras, pois quando o pilar entra em carga, sua deformação provoca a ruptura deste cobrimento.

Assim sendo, a capacidade de carga de pilares cintados é dada pela seguinte equação:

$$
F_{\text {teor }}=\left(A_{c i}-A_{s}^{\prime}\right) \cdot f_{c, \text { aparente }}+A_{s}^{\prime} \cdot \sigma_{s, 2}
$$

onde:

$N$ é a capacidade resistente do pilar cintado;

$f_{c, \text { aparente }}=f_{c}+2 \cdot \frac{A_{t}}{A_{c i}} \cdot f_{y}$ é a resistência à compressão do concreto cintado;

$f_{c}$ é a resistência àcompressão do concreto;

$\sigma_{s, 2}$ é a tensão no aço da armadura longitudinal correspondente ao encurtamento de $2 \mathrm{~mm} / \mathrm{m}$. Portanto, supõe-se o emprego de aço com alto limite de escoamento;

$f_{y}$ é a resistência de escoamento do aço da armadura transversal;

$A_{s}^{\prime}$ é a área da seção transversal da armadura longitudinal;

$A_{t}=\frac{\pi \cdot d_{i} \cdot A_{t 1}}{s_{t}}$ é o volume de armadura transversal por unidade de comprimento do pilar;

$d_{i}$ é o diâmetro do núcleo; 
$A_{t 1}=\frac{\pi \cdot \phi_{t}^{2}}{4}$ é a área da seção transversal da barra de cintamento;

$\phi_{t}$ é o diâmetro da barra da armadura de cintamento;

$s_{t}$ é o espaçamento da armadura de cintamento; e

$A_{c i}=\frac{\pi \cdot d_{i}^{2}}{4}$ é a área da seção do núcleo.

Para fins práticos, pode-se adotar no lugar da área de concreto do núcleo $\left(A_{c i}-A_{s}^{\prime}\right)$ o valor da área da seção total do núcleo $A_{c i}$.

Para finalizar, os pilares cintados devem atender æ̀s seguintes condições para que seu emprego esteja dentro de uma faixa de eficácia comprovada experimentalmente:

- o índice de esbeltez da peça $\lambda$ deve ser menor ou igual a 40;

- as extremidades da armadura de cintamento devem estar bem ancoradas no núcleo de concreto;

- o diâmetro mínimo da armadura de cintamento deve ser maior ou igual a $5 \mathrm{~mm}$;

- os espaçamentos limites entre as espirais ou estribos circulares devem ser maiores ou iguais ao diâmetro da armadura transversal somado ao valor de $3 \mathrm{~cm}$. Além disso, não poderão ser superiores à $8 \mathrm{~cm}$ e nem maiores que o diâmetro do núcleo dividido 5;

- a seção fictícia da armadura de cintamento $A_{t}$ deve estar compreendida entre os valores

$$
0,5 \% \cdot A_{c i} \leq A_{t} \leq 3 \cdot A_{s}^{\prime}
$$


- a armadura longitudinal não pode ter diâmetro inferior à $10 \mathrm{~mm}$. Além do mais, a área da seção transversal da armadura longitudinal $A_{s}^{\prime}$ deve estar compreendida entre os seguintes valores:

$$
\text { 6. Área do } \phi 10 m m \leq A_{s}^{\prime} \leq 0,08 \cdot A_{c i}
$$

- a capacidade resistente do pilar cintado não deve ser superior a 1,7 vez 0 valor calculado como se não houvesse cintamento.

\subsection{Modelos Teóricos de Confinamento do Concreto}

Independente da referência bibliográfica apresentada no cálculo da capacidade de carga de pilares, o fenômeno do cintamento foi tratado somente nos casos em que a armadura transversal era composta por espirais ou estribos circulares pouco espaçados. Todavia, admitindo-se que uma adequada armadura longitudinal e transversal retilínea, para variadas seções de pilares, seja capaz de confinar o núcleo de concreto, então, poderia ocorrer a ductilização e até mesmo o aumento da capacidade resistente deste pilar.

No caso do confinamento do concreto, pelas armaduras, apenas ductilizar o pilar, este poderia ser calculado como se fosse um pilar não cintado, com o detalhe de que sua seção resistente não contaria com a área de concreto de cobrimento das armaduras. Desta forma, ter-se-ia, por exemplo, a seguinte formulação:

$$
F_{\text {teor }, n}=A_{c c n} \cdot f_{c}+A_{s}^{\prime} \cdot \sigma_{s, 2}
$$

onde, de acordo com a notação adotada na NBR 6118 (1978), têm-se:

$F_{\text {teor,n }}$ é a capacidade resistente do pilar tendo-se apenas o núcleo como seção resistente;

$f_{c}$ é a resistência àcompressão do concreto;

$\sigma_{s, 2}$ é a tensão no aço da armadura longitudinal correspondente ao encurtamento de $2 \mathrm{~mm} / \mathrm{m}$. Portanto, supõe-se a utilização de armadura com alto limite de escoamento; 
$A_{c c n}=A_{c n}-A_{s}^{\prime}$ é a área da seção de concreto do núcleo;

$A_{s}^{\prime}$ é a área da seção transversal da armadura longitudinal; e $A_{c n}$ é a área da seção do núcleo do pilar.

No entanto, a precisão desta proposta de cálculo não é das melhores. Trabalhando com pilares de seções quadradas e retangulares e concretos de alta resistência, LIMA et al. (1997) e QUEIROGA et al. (1999) verificaram relações entre a resistência experimental e a resistência teórica do núcleo variando de 1,11 a 1,41.

Visando melhorar a previsão da relação tensão-deformação e, por conseguinte, da ductilidade e da capacidade resistente de pilares, foram desenvolvidos modelos teóricos de confinamento do concreto. Para os casos de pilares com concretos de resistência usual e variadas taxas e configurações das armaduras e das seções transversais destacam-se os modelos de SHEIKH \& UZUMERI (1982), MANDER et al. (1988b) e SAATCIOGLU \& RAZVI (1992). Assim sendo, neste trabalho, serão apresentadas as propostas destes autores, além de um índice criado por CUSSON \& PAULTRE (1993) para medir a eficiência do confinamento em termos de ductilidade e cintamento.

\subsubsection{SHEIKH \& UZUMERI (1982)}

A partir de resultados experimentais obtidos pelos autores em 1980, foi desenvolvido um modelo analítico para representar o fenômeno do confinamento do concreto, pelas armaduras, em pilares de concreto armado.

Para representar a relação tensão-deformação no concreto confinado, foi proposta a curva ilustrada na figura 3.20. Assim sendo, o trecho inicial, que vai do ponto $\mathrm{O}$ até o $\mathrm{A}$, é definido por meio de uma parábola do segundo grau, onde as coordenadas do ponto A são $\varepsilon_{s 1}$ e $f_{c c}$. A seguir, tem-se um trecho reto e horizontal entre os pontos $\mathrm{A}$ e $\mathrm{B}$, onde as coordenadas do ponto $\mathrm{B}$ são $\varepsilon_{s 2}$ e $f_{c c}$. A terceira parte da curva liga, por meio de uma reta inclinada, os pontos $B$ e $C$, tendo $C$ as coordenadas $\varepsilon_{s 85}$ e $0,85 \cdot f_{c c}$. A quarta parte da curva é uma continuação da reta anterior que, assim, segue até o ponto $\mathrm{D}$, o qual representa $30 \%$ de $f_{c c}$. A partir do 
ponto $\mathrm{D}$, o comportamento do concreto passa a ser descrito por uma linha reta e horizontal.

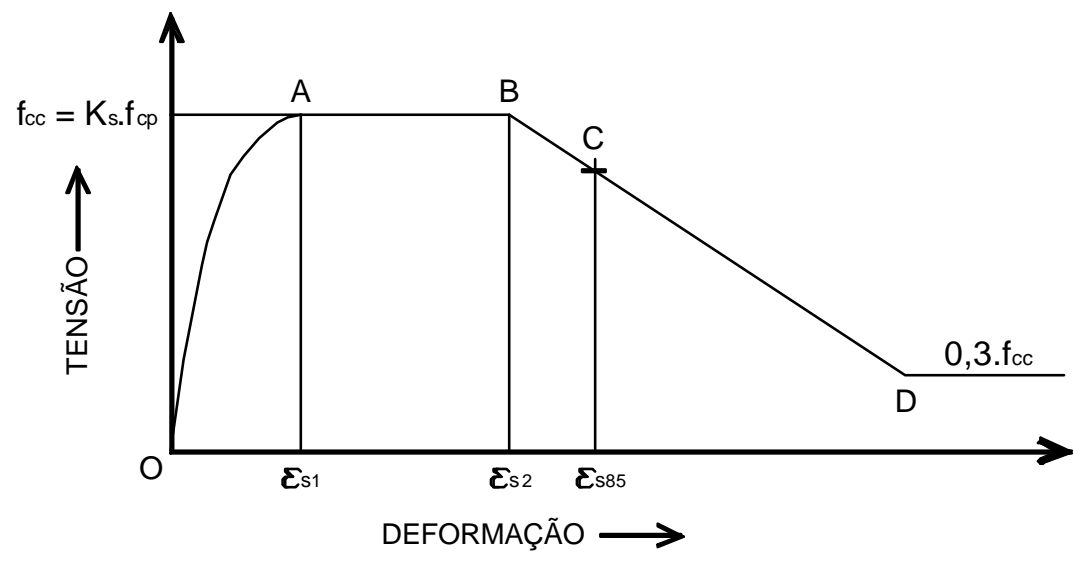

Figura 3.20. Proposta de relação tensão-deformação do concreto confinado, SHEIKH \& UZUMERI (1982).

O valor da máxima resistência à compressão do concreto confinado é dado pela seguinte fórmula:

$$
f_{c c}=K_{s} \cdot f_{c p}
$$

onde:

$f_{c c}$ é a máxima resistência àcompressão do concreto confinado;

$f_{c p}$ é a máxima resistência àcompressão do concreto não confinado; e $K_{s}$ é o fator que representa o ganho de resistência no concreto confinado em relação ao não confinado.

Quanto aos termos $\varepsilon_{s 1}$ e $\varepsilon_{s 2}$, são eles, respectivamente, a mínima e a máxima deformação correspondentes a máxima resistência do concreto confinado $f_{c c}$. Enquanto isso, $\boldsymbol{\varepsilon}_{s 85}$ representa a deformação referente a $85 \%$ da máxima resistência do concreto confinado $f_{c c}$, ou seja, $0,85 \cdot f_{c c}$.

Para se determinar os parâmetros relacionados acima, partiu-se do pressuposto que a máxima resistência do concreto confinado também pode ser estimada com a seguinte expressão: 


$$
f_{c c}=f_{c p}+f\left(\boldsymbol{\rho}_{s}, s, f_{s}^{\prime}, \lambda, \eta\right)
$$

onde, além das notações já descritas anteriormente, têm-se:

$\rho_{s}$ é a relação entre o volume total da armadura transversal e o volume do núcleo;

$s$ é o espaçamento entre a armadura transversal;

$f_{s}^{\prime}$ é a tensão na armadura transversal;

$\lambda$ é um fator que leva em conta a configuração da seção transversal e a distribuição das barras longitudinais no perímetro do núcleo de concreto; e

$\eta$ representa o efeito do tamanho da seção transversal.

Nos modelos confinados por armadura retilínea, verificou-se que a pressão lateral sobre o núcleo, ocasionada pela solicitação da armadura transversal por conta da expansão lateral do concreto sob compressão axial, não é uniformemente distribuída. Deste modo, sob altas deformações, quando o cobrimento de concreto das armaduras descolou-se do núcleo, observou-se que uma parte deste núcleo foi pouco efetiva na resistência à força de compressão aplicada. Esta constatação fez surgir o termo "área de concreto efetivamente confinado".

A determinação da área de concreto efetivamente confinado depende de fatores como o espaçamento entre a armadura transversal e a configuração desta armadura, bem como, a distribuição das barras da armadura longitudinal no perímetro do núcleo. Para todos os casos práticos, esta área é menor do que a área do núcleo de concreto delimitado pela projeção dos eixos dos estribos.

Ao nível dos estribos, a configuração da armadura transversal e a distância entre as barras da armadura longitudinal determinam a superfície de concreto não confinado. Isto pode ser visto na figura 3.21, onde as regiões hachuradas representam as áreas de concreto não confinadas dentro do núcleo de concreto.
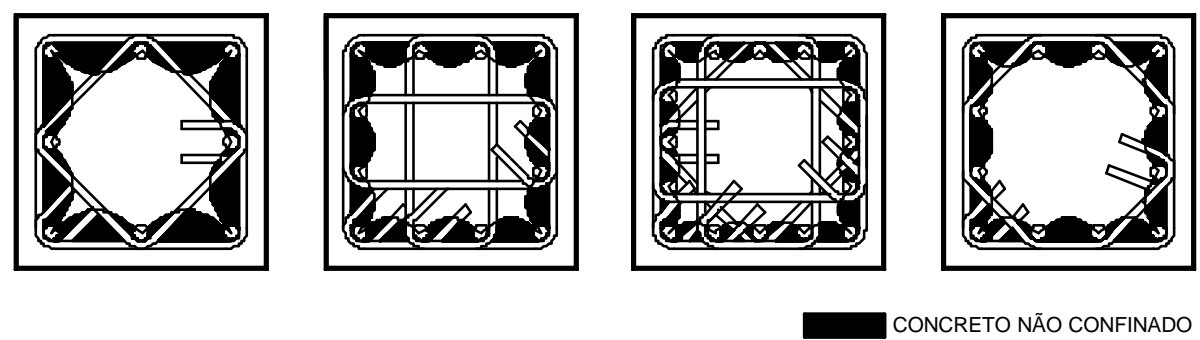

CONCRETO NÃO CONFINADO

Figura 3.21. Área de concreto não confinado ao nível dos estribos, SHEIKH \& UZUMERI (1982). 
A área de concreto não confinado, ao nível dos estribos, pode ser estimada conforme mostrado na figura 3.22. Assim, é assumido que a separação entre o concreto não confinado e o confinado dá-se por meio de uma série de arcos entre as barras da armadura longitudinal. Estes arcos, por sua vez, podem estar localizados entre um triângulo e uma parábola do segundo grau, com ângulo $\theta$ entre a reta tangente àcurva e a reta horizontal. Assim sendo, para o caso de uma parábola, tem-se a área sob a curva igual a $\frac{c^{2}}{6} \cdot \cot \theta$ e, para o caso de um triângulo, tem-se o valor de $\frac{c^{2}}{4} \cdot \cot \theta$, sendo $c$ a distância entre as barras da armadura longitudinal. Como não se sabe a forma exata do arco, assumiu-se que a área de concreto não confinado, entre as barras longitudinais, pode ser calculada pela expressão $\frac{c^{2}}{\alpha}$, onde $\alpha$ é uma constante.

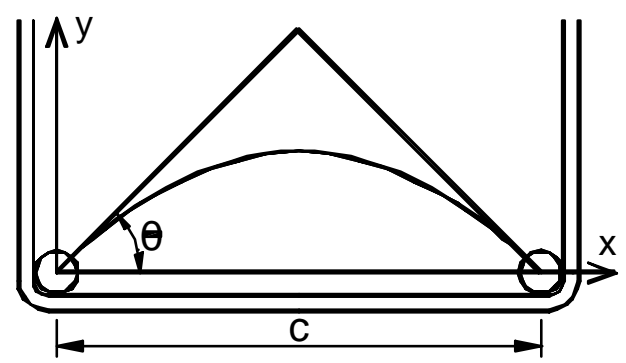

Figura 3.22. Estimativa da área de concreto não confinado ao nível dos estribos, SHEIKH \& UZUMERI (1982).

Enfim, a área de concreto efetivamente confinado, ao nível dos estribos, pode ser estimada com a seguinte expressão:

$$
A_{c o}-\sum_{i=1}^{n} \frac{c_{i}^{2}}{\alpha}
$$

onde, além das notações já descritas anteriormente, têm-se:

$A_{c o}$ é a área da seção transversal delimitada pelos eixos dos estribos (núcleo); e

$n$ é o número de arcos, calculado conforme sugere a figura 3.21. 
Se for definido um fator $\lambda$ que relaciona a área de concreto efetivamente confinado com a área do núcleo, ambas ao nível dos estribos, então

$$
\lambda=\frac{A_{c o}-\sum_{i=1}^{n} \frac{c_{i}^{2}}{\alpha}}{A_{c o}}=1-\frac{\sum_{i=1}^{n} c_{i}^{2}}{\boldsymbol{\alpha} \cdot A_{c o}}
$$

$\mathrm{Na}$ direção longitudinal e quanto mais distante dos estribos tem-se uma diminuição na área de concreto efetivamente confinado, conforme mostrado na figura 3.23. Neste caso, a forma exata da curva entre o concreto confinado e o não confinado não tem grande importância, podendo, assim, ser assumida uma parábola do segundo grau. Deste modo, a resistência do pilar será definida pela menor área de concreto confinado localizada entre os estribos, a qual foi chamada de seção crítica.

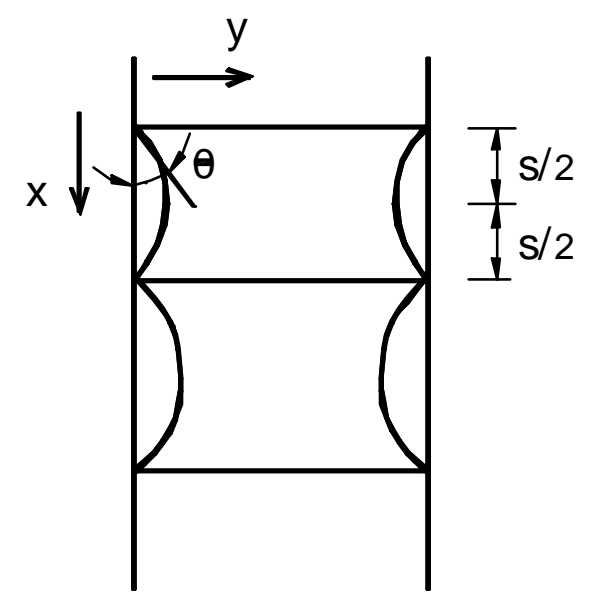

Figura 3.23. Estimativa da área de concreto não confinado entre os estribos, SHEIKH \& UZUMERI (1982).

Como pôde ser observada, a determinação do volume de concreto confinado deverá ser feita sobre uma superfície tridimensional (ver a figura 3.24) e, portanto, a definição exata da seção crítica irá depender do conhecimento dos perfis das curvas entre o concreto confinado e o não confinado. 


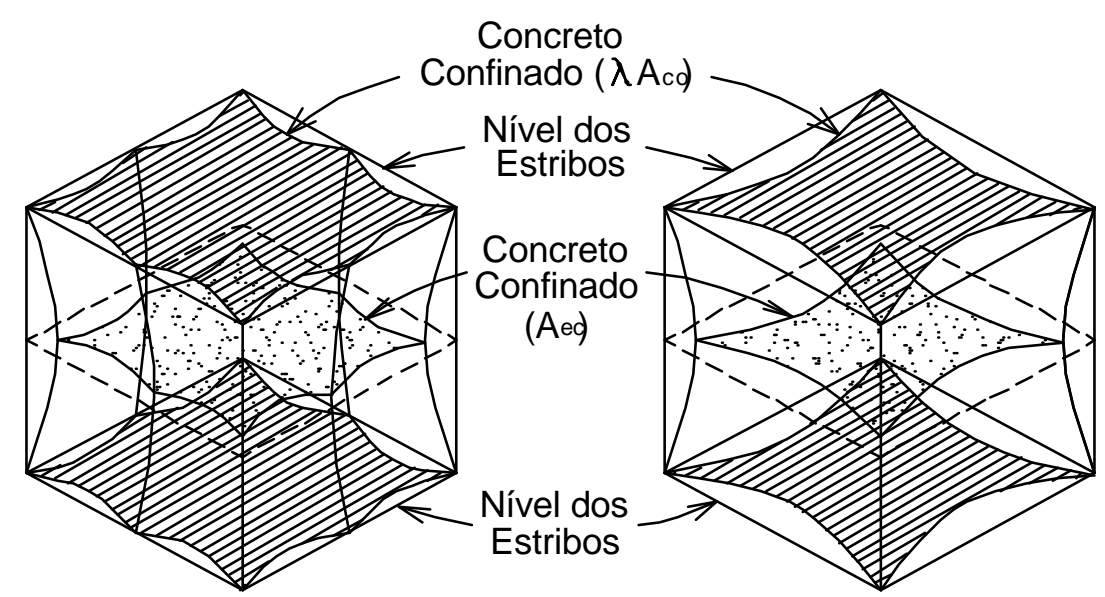

Figura 3.24. Determinação da seção crítica - uma visão tridimensional do concreto confinado e não confinado, SHEIKH \& UZUMERI (1982).

SHEIKH \& UZUMERI (1982) sugerem a seguinte metodologia de cálculo da seção crítica de concreto localizada entre os estribos:

$$
A_{c o}=B \cdot H
$$

onde:

$A_{c o}$ é a área da seção transversal delimitada pelos eixos dos estribos (núcleo); e

$B$ e $H$ são as dimensões do núcleo de concreto.

Assim, a área de concreto efetivamente confinado, ao nível dos estribos, será

$$
\lambda \cdot A_{c o}
$$

Desprezando-se a redução de $A_{c o}$, ao nível dos estribos, a área de concreto efetivamente confinado, entre os estribos, pode ser calculada da seguinte forma:

$$
\left(B-2 \cdot y_{m}\right) \cdot\left(H-2 \cdot y_{m}\right)
$$


onde, além das notações já utilizadas, têm-se:

$y_{m}$ é o máximo valor de $y$, entre os estribos, conforme a figura 3.23.

Ainda de acordo com esta figura, $y_{m}$ pode ser calculado pelo produto $0,25 \cdot s \cdot \tan \theta$.

Por fim, a seção crítica será estimada por meio da seguinte expressão:

$$
A_{e c}=\lambda \cdot\left(B-2 \cdot y_{m}\right) \cdot\left(H-2 \cdot y_{m}\right)
$$

Além de substituir-se o valor de $y_{m}$, pode-se relacionar a área de concreto efetivamente confinado, na seção crítica, com a área do núcleo, por meio da seguinte equação:

$$
A_{e c}=\lambda \cdot(B-0,5 \cdot s \cdot \tan \theta) \cdot(H-0,5 \cdot s \cdot \tan \theta)=\lambda^{*} \cdot A_{c o}
$$

onde, além das notações utilizadas anteriormente, têm-se:

$\lambda^{*}$ é a relação entre a área de concreto efetivamente confinado, na seção crítica $\left(A_{e c}\right)$, e a área do núcleo $\left(A_{c o}\right)$.

Como $\lambda$ considera somente o efeito da configuração dos estribos, a introdução do termo $\lambda^{*}$ permite que se leve em conta, ao mesmo tempo, os efeitos da configuração da armadura transversal e do espaçamento entre os estribos.

Após estudos de vários pesquisadores, verificou-se que o acréscimo de resistência no concreto confinado por armadura transversal retilínea é proporcional a seguinte expressão:

$$
\beta \cdot\left(\rho_{s} \cdot f_{s}^{\prime}\right)^{\gamma}
$$

onde:

$\beta$ é uma constante;

$\rho_{s}$ é a relação entre o volume total da armadura transversal e o volume do núcleo, também chamada de taxa volumétrica de armadura transversal; 
$f_{s}^{\prime}$ é a tensão na armadura transversal no instante em que se atinge a capacidade última do concreto confinado; e

$\gamma$ é uma constante com valor menor do que 1,00.

Assim sendo, o ganho de capacidade resistente no concreto confinado, expresso em termos de força, pode ser calculado pela seguinte fórmula:

$$
P_{a d d}=A_{e c} \cdot \boldsymbol{\beta} \cdot\left(\rho_{s} \cdot f_{s}^{\prime}\right)^{\gamma}
$$

Com isso, o fator $K_{s}$ será igual a:

$$
K_{s}=1,0+\frac{P_{a d d}}{P_{o c c}}=1,0+\frac{A_{e c}}{P_{o c c}} \cdot \boldsymbol{\beta} \cdot\left(\boldsymbol{\rho}_{s} \cdot f_{s}^{\prime}\right)^{\gamma}
$$

onde, além das notações utilizadas anteriormente, tem-se:

$P_{o c c}$ é a capacidade resistente do concreto não confinado localizado na área delimitada pelos eixos dos estribos, expressa em termos de força.

Substituindo-se a expressão de cálculo da seção crítica e arranjando-se os termos, tem-se:

$$
K_{s}=1,0+\frac{1}{P_{o c c}} \cdot\left(1-\frac{\sum_{i=1}^{n} c_{i}^{2}}{\alpha \cdot A_{c o}}\right) \cdot\left(1-\frac{0,5 \cdot s}{B} \cdot \tan \boldsymbol{\theta}\right) \cdot\left(1-\frac{0,5 \cdot s}{H} \cdot \tan \boldsymbol{\theta}\right) \cdot B \cdot H \cdot \boldsymbol{\beta} \cdot\left(\boldsymbol{\rho}_{s} \cdot f_{s}^{\prime}\right)^{\gamma}
$$

Para o caso de seções transversais quadradas e armadura longitudinal uniformemente distribuída, a mesma expressão pode ser escrita da seguinte forma:

$$
K_{s}=1,0+\frac{1}{P_{o c c}} \cdot\left(1-\frac{n \cdot c^{2}}{\boldsymbol{\alpha} \cdot B^{2}}\right) \cdot\left(1-\frac{0,5 \cdot s}{B} \cdot \tan \boldsymbol{\theta}\right)^{2} \cdot B^{2} \cdot \boldsymbol{\beta} \cdot\left(\boldsymbol{\rho}_{s} \cdot f_{s}^{\prime}\right)^{\gamma}
$$


Utilizando da regressão dos dados experimentais obtidos por SHEIKH \& UZUMERI (1980), chegou-se aos seguintes valores de $\alpha=5,5, \theta=45^{\circ}, \gamma=0,5$, $\beta=2,73$. Deste modo, sendo $f_{s}^{\prime}$ expresso em MPa e $P_{o c c}$ em $\mathrm{kN}$, a equação final para o cálculo de $K_{s}$ será:

$$
K_{s}=1,0+\frac{B^{2}}{140 \cdot P_{o c c}} \cdot\left[\left(1-\frac{n \cdot c^{2}}{5,5 \cdot B^{2}}\right) \cdot\left(1-\frac{s}{2 \cdot B}\right)^{2}\right] \cdot \sqrt{\rho_{s} \cdot f_{s}^{\prime}}
$$

A figura 3.25 apresenta as curvas $\lambda^{*} \times s / B$ referentes aos pilares de seção quadrada ensaiados por SHEIKH \& UZUMERI (1980) (ver a figura 3.15). A partir delas, pode-se verificar que quando o espaçamento entre os estribos $(s)$ excede duas vezes a dimensão do núcleo $(B)$, o confinamento não é efetivo no aumento da resistência do concreto.

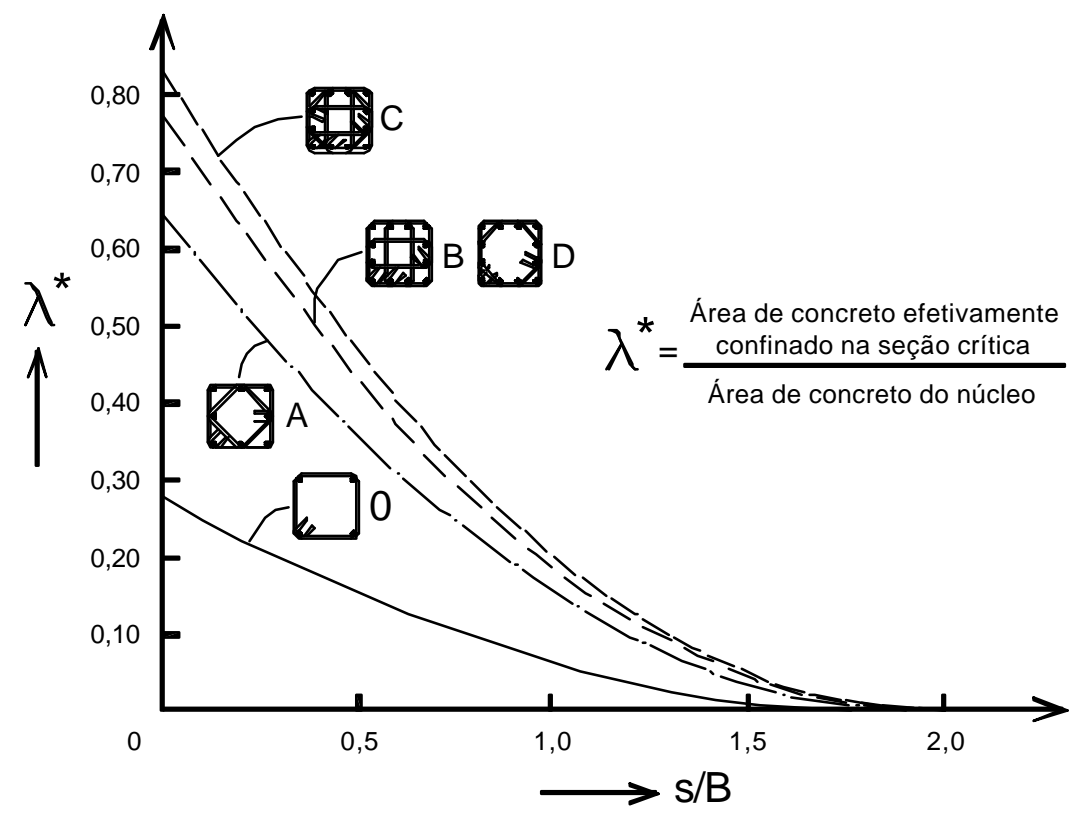

Figura 3.25. Coeficiente $\lambda^{*}$ em função da relação entre o espaçamento entre estribos $(s)$ e a dimensão do núcleo de concreto $(B)$,

SHEIKH \& UZUMERI (1982). 
Definido o cálculo do coeficiente $K_{s}$, pode-se determinar os parâmetros $\varepsilon_{s 1}$, $\varepsilon_{s 2}$ e $\varepsilon_{s 85}$, necessários à construção da relação tensão-deformação do concreto confinado.

Modificando-se a equação sugerida por SOLIMAN \& YU ${ }^{3}$, para $\varepsilon_{s 1}$, tem-se:

$$
\varepsilon_{s 1}=80 \cdot K_{s} \cdot f_{c}^{\prime} \cdot 10^{-6}
$$

onde:

$f_{c}^{\prime}$ é a resistência à compressão de corpos-de-prova cilíndricos com dimensões de $152 \mathrm{~mm} \times 305 \mathrm{~mm}$ [6in. $\times$ 12in.], expressa em MPa.

Enquanto isso, o cálculo de $\varepsilon_{s 2}$ deve ser feito com a seguinte expressão:

$$
\frac{\varepsilon_{s 2}}{\varepsilon_{\infty}}=1+\frac{248}{c} \cdot\left[1-5,0 \cdot\left(\frac{s}{B}\right)^{2}\right] \cdot \frac{\rho_{s} \cdot f_{s}^{\prime}}{\sqrt{f_{c}^{\prime}}}
$$

onde, além das notações utilizadas anteriormente, tem-se:

$\varepsilon_{\infty}$ é a deformação correspondente a máxima resistência do concreto não confinado. Nos ensaios de SHEIKH \& UZUMERI (1980) este valor foi de 0,0022; e

$c$ é expresso em mm e $f_{c}^{\prime}$ e $f_{s}^{\prime}$ em MPa.

Por fim, depois de algumas modificações na equação proposta por KENT \& PARK $^{4}$, tem-se $\varepsilon_{s 85}$ igual a:

\footnotetext{
${ }^{3}$ SOLIMAN, M. T. M.; YU, C. W. (1967). The flexural stress-strain relationship of concrete confined by rectangular transverse reinforced. Magazine of Concrete Research, v.19, n.61, p.223-238, Dec.

${ }^{4}$ KENT, D. C.; PARK, R. (1971). Flexural members with confined concrete. ASCE Journal of the Structural Division, v.97, n.ST7, p.1969-1990, July.
} 


$$
\varepsilon_{s 85}=0,225 \cdot \rho_{s} \cdot \sqrt{\frac{B}{s}}+\varepsilon_{s 2}
$$

O modelo de confinamento do concreto, proposto por SHEIKH \& UZUMERI (1982), não contempla os casos em que a armadura transversal é composta por espirais ou estribos suplementares (em forma de barra reta com ganchos nas extremidades). Contudo, os referidos autores acreditam que, mesmo nestas situações, o modelo analítico pode ser aplicado. Assim sendo, no caso de se utilizarem estribos suplementares, haveriam ganhos de resistência e de ductilidade, porém, desde que estes estribos estivessem ligados às barras longitudinais, pois, se ligados somente aos estribos principais não seriam capazes de desenvolver as forças necessárias ao confinamento do núcleo de concreto. Enquanto isso, nos pilares com armadura transversal em forma de espirais ou anéis circulares, tanto a ductilidade quanto a resistência do concreto seriam aumentadas.

Por fim, de acordo com o modelo analítico, pilares com apenas quatro barras longitudinais seriam pouco eficientes no confinamento do núcleo de concreto.

\subsubsection{MANDER et al. (1988b)}

O modelo de confinamento proposto por MANDER et al. (1988b) depende da relação tensão-deformação do concreto confinado, estabelecida pelos mesmos autores em 1984 (ver a figura 3.26).

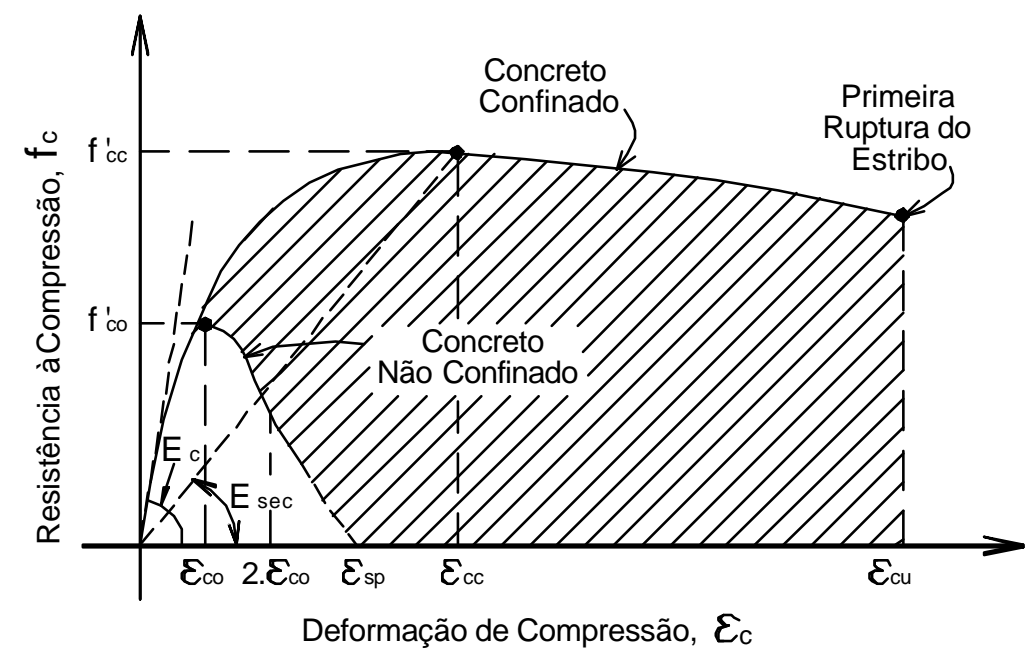

Figura 3.26. Modelo de relação tensão-deformação para concreto confinado e não confinado proposto por MANDER et al. (1984), MANDER et al. (1988b). 
Assim, se $f_{c}$ é a resistência do concreto àcompressão, então:

$$
f_{c}=\frac{f_{c c}^{\prime} \cdot x \cdot r}{r-1+x^{r}}
$$

onde:

$f_{c c}^{\prime}$ é a máxima resistência àcompressão do concreto confinado;

$x=\frac{\boldsymbol{\varepsilon}_{c}}{\boldsymbol{\varepsilon}_{c c}}$, sendo $\boldsymbol{\varepsilon}_{c}$ a deformação longitudinal do concreto à compressão;

$$
\boldsymbol{\varepsilon}_{c c}=\boldsymbol{\varepsilon}_{c o} \cdot\left[1+5 \cdot\left(\frac{f_{c c}^{\prime}}{f_{c o}^{\prime}}-1\right)\right] \text { é a deformação correspondente à máxima }
$$

resistência à compressão do concreto confinado $f_{c c}^{\prime}$, sendo que $f_{c o}^{\prime}$ e $\varepsilon_{c o}$ são a máxima resistência àcompressão do concreto não confinado e sua correspondente deformação, respectivamente (na falta de dados experimentais, $\boldsymbol{\varepsilon}_{c o}=0,002$ );

$$
\begin{aligned}
& r=\frac{E_{c}}{E_{c}-E_{\mathrm{sec}}} ; \\
& E_{c}=5000 \cdot \sqrt{f_{c o}^{\prime}} \text { é o módulo de elasticidade tangente referente ao }
\end{aligned}
$$

concreto não confinado, em MPa; e

$$
E_{\mathrm{sec}}=\frac{f_{c c}^{\prime}}{\varepsilon_{c c}} \text { é o módulo de elasticidade secante do concreto confinado. }
$$

Este modelo faz uma aproximação similar a que foi utilizada por SHEIKH \& UZUMERI (1980) para calcular a pressão lateral efetiva de confinamento do concreto. Assim, uma sucessão de arcos resultante da configuração e espaçamento da armadura transversal define o núcleo de concreto efetivamente confinado. Isto irá fazer com que parte da seção transversal do elemento seja considerada inefetiva no cálculo da resistência à compressão do concreto confinado. Apesar da perda de área resistente, o estado multiaxial de tensões proporcionado pelo confinamento resulta em ganhos de ductilidade e até mesmo de resistência pelo elemento estrutural em relação àquele sem confinamento do 
concreto. As figuras 3.27 e 3.28 apresentam de forma mais clara a base deste modelo de confinamento.

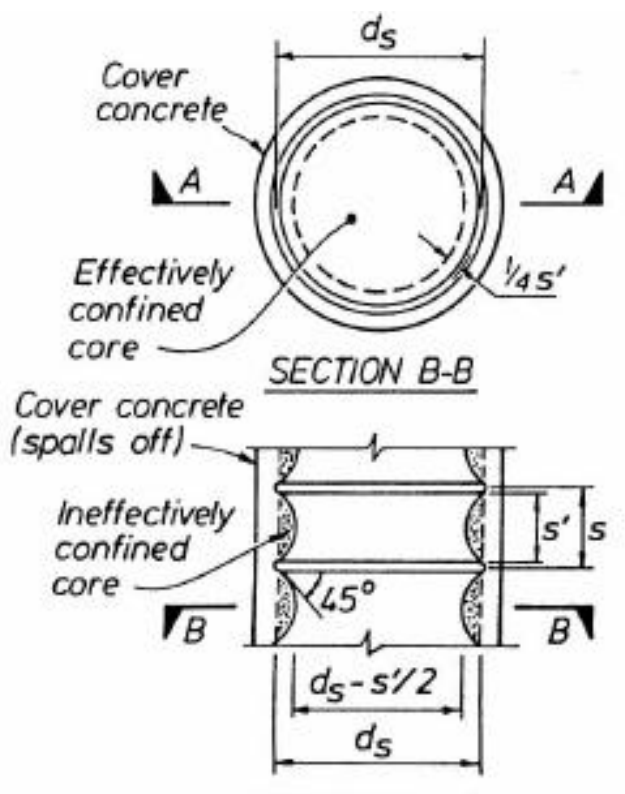

SECTION A-A

Figura 3.27. Núcleo de concreto efetivamente confinado para armadura transversal composta por estribos circulares, MANDER et al. (1988b).

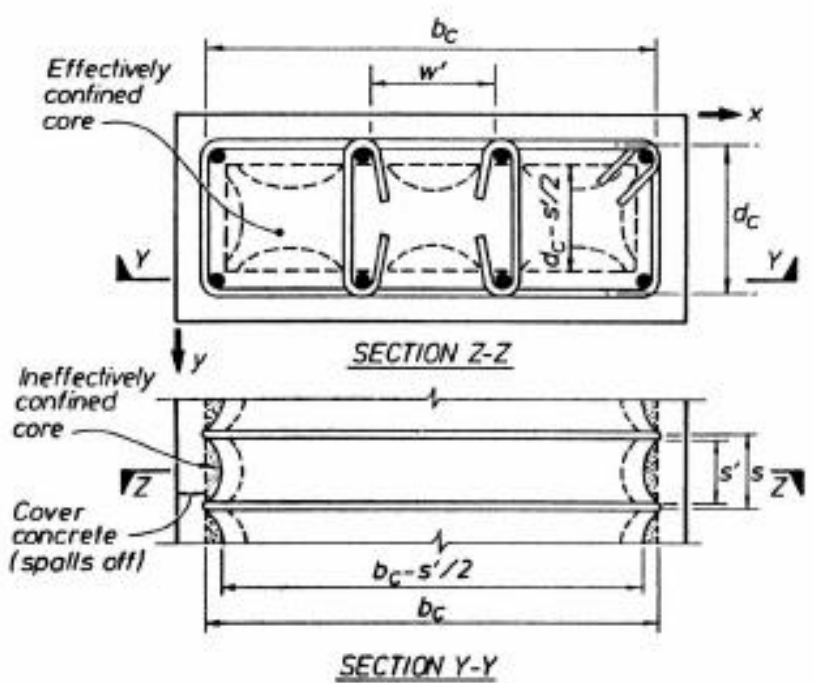

Figura 3.28. Núcleo de concreto efetivamente confinado para armadura transversal composta por estribos retangulares e barras retas com ganchos nas extremidades, MANDER et al. (1988b). 
O equacionamento proposto por MANDER et al. (1988b) para o cálculo da pressão efetiva de confinamento é o seguinte:

$$
f_{l}^{\prime}=f_{l} \cdot k_{e}
$$

onde:

$f_{l}^{\prime}$ é a pressão lateral de confinamento efetivo;

$f_{l}$ é a pressão lateral exercida pela armadura transversal, assumida como uniformemente distribuída sobre toda a superfície do núcleo;

$k_{e}=\frac{A_{e}}{A_{c c}}$ é o coeficiente de confinamento efetivo;

$A_{e}$ é a área do núcleo efetivamente confinado;

$A_{c c}=A_{c} \cdot\left(1-\rho_{c c}\right)$ é a área de concreto delimitada pelos eixos dos estribos ou espirais;

$A_{c}$ é a área da seção transversal delimitada pelos eixos dos estribos ou espirais; e

$\rho_{c c}$ é a relação entre a área da armadura longitudinal e a área do núcleo da seção.

Para o caso de núcleo de concreto efetivamente confinado com armadura transversal composta por estribos retangulares e barras retas com ganchos nas extremidades (ver a figura 3.28), as grandezas relacionadas acima assumem os seguintes valores:

$$
A_{i}=\sum_{i=1}^{n} \frac{\left(w_{i}^{\prime}\right)^{2}}{6} \text { é a área de concreto não confinado, ao nível dos estribos, }
$$

sendo que $w_{i}^{\prime}$ é a distância entre as barras longitudinais adjacentes e $n$ o número de barras longitudinais;

$$
A_{e}=\left(b_{c} \cdot d_{c}-\sum_{i=1}^{n} \frac{\left(w_{i}^{\prime}\right)^{2}}{6}\right) \cdot\left(1-\frac{s^{\prime}}{2 \cdot b_{c}}\right) \cdot\left(1-\frac{s^{\prime}}{2 \cdot d_{c}}\right) \text { é a área do núcleo de }
$$

concreto efetivamente confinado localizado ao nível intermediário das barras da armadura transversal, sendo que $b_{c}$ e $d_{c}$ são as dimensões das linhas de centro 
do perímetro dos estribos, conforme mostrado na figura 3.28, e s' o espaçamento da armadura transversal;

$$
\begin{aligned}
& k_{e}=\frac{\left(1-\sum_{i=1}^{n} \frac{\left(w_{i}^{\prime}\right)^{2}}{6 \cdot b_{c} \cdot d_{c}}\right) \cdot\left(1-\frac{s^{\prime}}{2 \cdot b_{c}}\right) \cdot\left(1-\frac{s^{\prime}}{2 \cdot d_{c}}\right)}{\left(1-\rho_{c c}\right)} ; \\
& \rho_{x}=\frac{A_{s x}}{s \cdot d_{c}}, \text { sendo que } A_{s x} \text { é a soma da área da armadura transversal na }
\end{aligned}
$$

direção x; e

$$
\rho_{y}=\frac{A_{s y}}{s \cdot b_{c}}, \text { sendo que } A_{s y} \text { é a soma da área da armadura transversal na }
$$
direção y.

A tensão de escoamento na armadura transversal exerce uma pressão lateral assumida como uniforme sobre o núcleo de concreto. Isto permite que seja feito o seguinte equilíbrio de forças nas direções x e y, respectivamente:

$$
\begin{aligned}
& f_{l x}=\frac{A_{s x}}{s \cdot d_{c}} \cdot f_{y h}=\rho_{x} \cdot f_{y h} \\
& f_{l y}=\frac{A_{s y}}{s \cdot b_{c}} \cdot f_{y h}=\rho_{y} \cdot f_{y h}
\end{aligned}
$$

onde, além das notações utilizadas anteriormente, têm-se:

$f_{l x}$ e $f_{l y}$ são as pressões laterais nas direções x e y, respectivamente, exercidas pela armadura transversal, e adotadas como sendo uniformemente distribuídas sobre o núcleo de concreto; e

$f_{y h}$ é a resistência de escoamento do aço da armadura transversal.

Por fim, as pressões de confinamento efetivo nas direções $x$ e y serão:

$$
\begin{aligned}
& f_{l x}^{\prime}=k_{e} \cdot \boldsymbol{\rho}_{x} \cdot f_{y h} \\
& f_{l y}^{\prime}=k_{e} \cdot \boldsymbol{\rho}_{y} \cdot f_{y h}
\end{aligned}
$$


Para se calcular a máxima resistência à compressão do concreto confinado $\left(f_{c c}^{\prime}\right)$, utiliza-se de um modelo que envolve a resistência última em condição de tensões de compressão multiaxial. Assim, para o caso em que ocorre pressão de confinamento efetiva em duas direções, conforme sugere a figura 3.28, o gráfico da figura 3.29 irá possibilitar a obtenção da máxima resistência à compressão do concreto confinado $\left(f_{c c}^{\prime}\right)$.

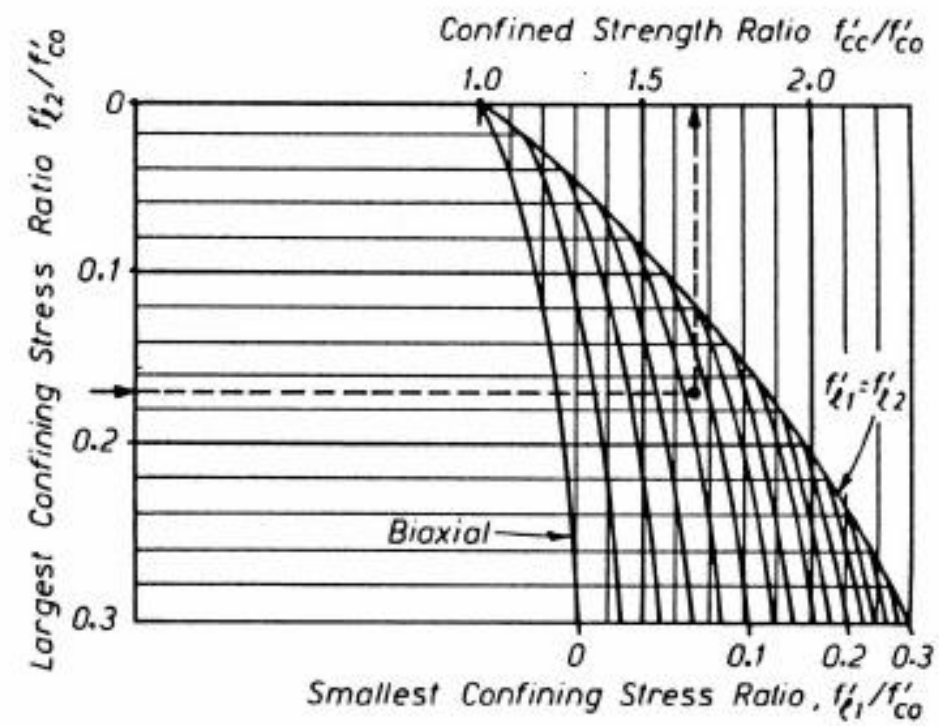

Figura 3.29. Determinação da resistência à compressão do concreto confinado em função das pressões de confinamento efetivas em seções retangulares, MANDER et al. (1988b).

Como forma de facilitar o entendimento do processo, utiliza-se um exemplo numérico em que a máxima resistência à compressão do concreto não confinado $f_{c o}^{\prime}$ é igual a 30MPa. Além disso, $f_{l y}^{\prime}=2,7 \mathrm{MPa}$ e $f_{l x}^{\prime}=5,1 \mathrm{MPa}$. Com isso, a partir da figura 3.29, tem-se $\frac{f_{c c}^{\prime}}{f_{c o}^{\prime}}=1,65$ e, portanto, $f_{c c}^{\prime}=1,65 \times 30=49,5 \mathrm{MPa}$.

As relações tensão-deformação determinadas pelas equações apresentadas foram obtidas de ensaios realizados sob taxas de deformações baixas (carregamento quase-estático). Para o caso de taxas de deformações altas (carregamento dinâmico), as mesmas equações podem ser utilizadas desde que se façam modificações nos parâmetros $f_{c o}^{\prime}, E_{c}$ e $E_{c o}$ do concreto não confinado. Estas modificações se resumem na multiplicação destes parâmetros por um fator dinâmico majorador. Isto deve ser feito, pois foi verificado que o carregamento 
dinâmico aumenta a rigidez e a resistência àcompressão do concreto, como pode ser visto na figura 3.30. Assim sendo, têm-se:

$$
\left(f_{c o}^{\prime}\right)_{d y n}=D_{f} \cdot f_{c o}^{\prime} \text { é a máxima resistência à compressão do concreto não }
$$

confinado sob carregamento dinâmico, sendo $f_{c o}^{\prime}$ a máxima resistência à compressão do concreto não confinado sob carregamento quase-estático, expressa em MPa;

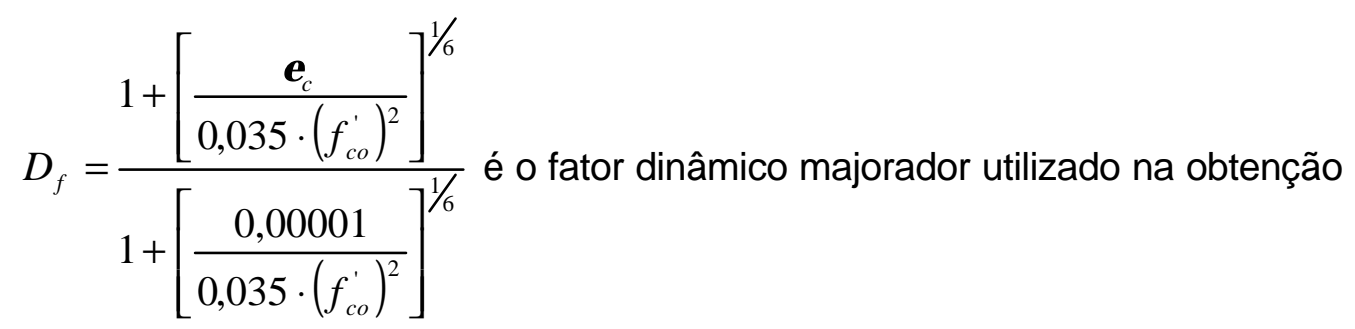

da máxima resistência do concreto não confinado para o caso de carregamento dinâmico, sendo $\varepsilon_{c}$ a taxa de deformação, expressa em $s^{-1}$;

$$
\left(E_{c}\right)_{d y n}=D_{E} \cdot E_{c} \text { é o módulo de elasticidade tangente do concreto não }
$$
confinado sob carregamento dinâmico, sendo $E_{c}$ o módulo de elasticidade tangente do concreto não confinado sob carregamento quase-estático, expresso em $\mathrm{MPa}$;

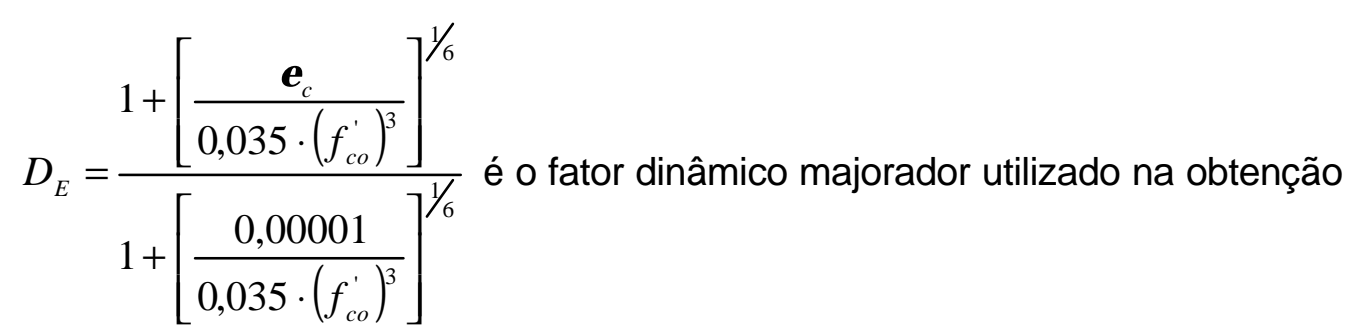

do módulo de elasticidade tangente do concreto não confinado para o caso de carregamento dinâmico, sendo $\varepsilon_{c}$ a taxa de deformação, expressa em $s^{-1}$;

$\left(\varepsilon_{c o}\right)_{d y n}=D_{\varepsilon} \cdot \varepsilon_{c o}$ é a deformação correspondente à máxima resistência à compressão do concreto não confinado sob carregamento dinâmico, sendo $\varepsilon_{c o}$ a deformação correspondente à máxima resistência à compressão do concreto não confinado sob carregamento quase-estático; e 


$$
D_{\varepsilon}=\frac{1}{3 \cdot D_{f}} \cdot\left(1+\sqrt{1+\frac{3 \cdot D_{f}^{2}}{D_{E}}}\right) \text { é o fator dinâmico utilizado na obtenção da }
$$

deformação correspondente à máxima resistência à compressão do concreto não confinado sob carregamento dinâmico.

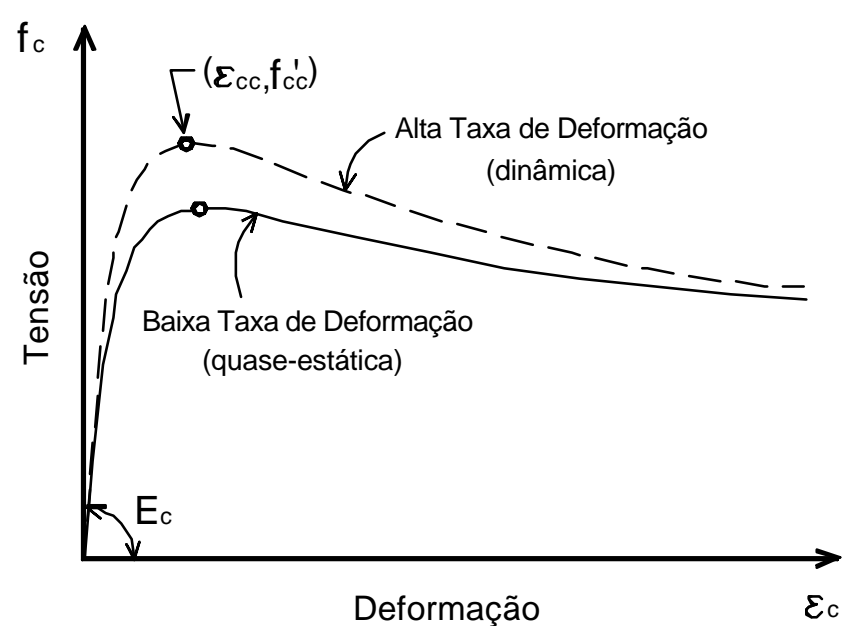

Figura 3.30. Efeito da taxa de deformação na relação tensão-deformação do concreto, MANDER et al. (1988b).

\subsubsection{SAATCIOGLU \& RAZVI (1992)}

O modelo analítico de confinamento proposto por SAATCIOGLU \& RAZVI (1992) depende da relação tensão-deformação do concreto confinado e não confinado, estabelecida pelos mesmos em 1992 (ver a figura 3.31). Assim, se $f_{c}$ é a resistência àcompressão do concreto confinado, então:

$$
f_{c}=f_{c c}^{\prime} \cdot\left[2 \cdot\left(\frac{\varepsilon_{c}}{\varepsilon_{1}}\right)-\left(\frac{\varepsilon_{c}}{\varepsilon_{1}}\right)^{2}\right]^{1 /(1+2 \cdot K)} \leq f_{c c}^{\prime}
$$

onde:

$f_{c}$ é a resistência àcompressão do concreto confinado;

$f_{c c}^{\prime}$ é a máxima resistência àcompressão do concreto confinado; 


$$
\varepsilon_{1}=\varepsilon_{01} \cdot(1+5 \cdot K) \text { é a deformação correspondente à máxima }
$$

resistência à compressão do concreto confinado, sendo $\varepsilon_{01}$ a deformação correspondente àmáxima resistência àcompressão do concreto não confinado (na falta de dados experimentais e para baixas taxas de deformação, $\varepsilon_{01}=0,002$ );

$$
\begin{aligned}
& K=\frac{k_{1} \cdot f_{l e}}{f_{c o}^{\prime}} ; \\
& k_{1}=6,7 \cdot\left(f_{l}\right)^{-0,17} \text { é um coeficiente obtido de dados experimentais, como }
\end{aligned}
$$

pode ser visto na figura 3.32, sendo que $f_{l}$ é a pressão lateral de confinamento, expressa em MPa;

$f_{l e}$ é a pressão lateral de confinamento efetivo, a qual varia com o tipo de armadura transversal;

$f_{c o}^{\prime}$ é a máxima resistência àcompressão do concreto não confinado;

$\varepsilon_{85}=260 \cdot \rho \cdot \varepsilon_{1}+\varepsilon_{085}$ é a deformação pós-pico do concreto confinado correspondente à $85 \%$ da máxima resistência àcompressão do concreto confinado;

$$
\mathbf{\rho}=\frac{\sum A_{s}}{s \cdot\left(b_{c x}+b_{c y}\right)} ;
$$

$A_{s}$ é a área da seção da barra da armadura transversal;

$s$ é o espaçamento entre a armadura transversal;

$b_{c x}$ e $b_{c y}$ são as dimensões da seção transversal do núcleo do pilar nas direções x e y, respectivamente ( ver a figura 3.37); e

$\varepsilon_{085}$ é a deformação pós-pico do concreto não confinado correspondente à $85 \%$ da máxima resistência à compressão do concreto não confinado (na falta de dados experimentais e para baixas taxas de deformação, $\left.\varepsilon_{085}=0,0038\right)$. 


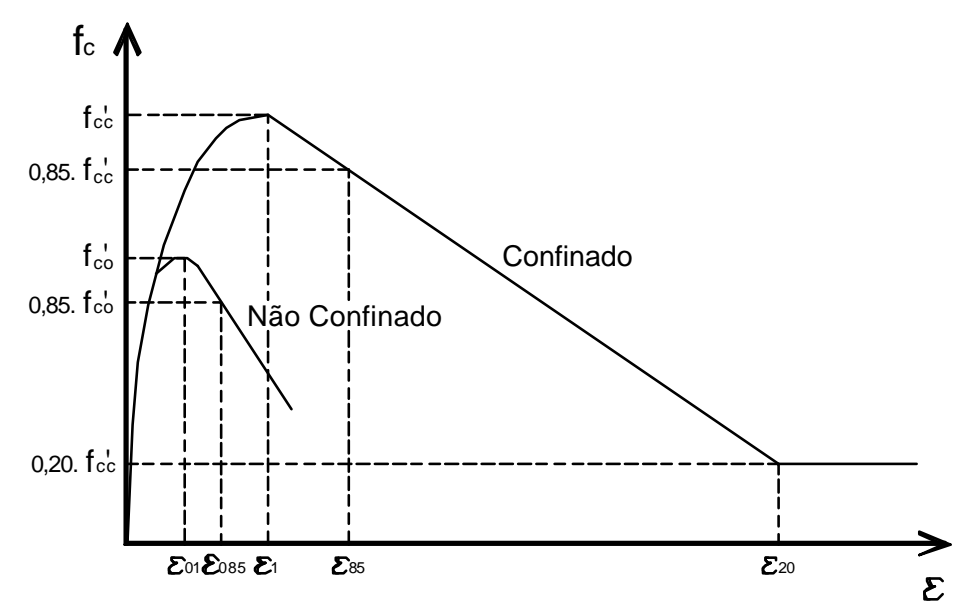

Figura 3.31. Modelo de relação tensão-deformação para concreto confinado e não confinado proposto por SAATCIOGLU \& RAZVI (1992),

SAATCIOGLU \& RAZVI (1992).

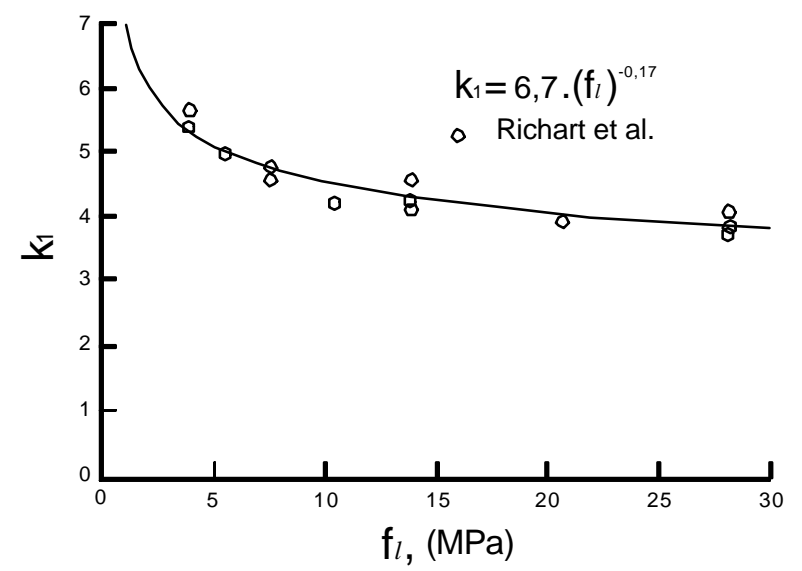

Figura 3.32. Variação do coeficiente $k_{1}$ com a pressão lateral de confinamento, SAATCIOGLU \& RAZVI (1992).
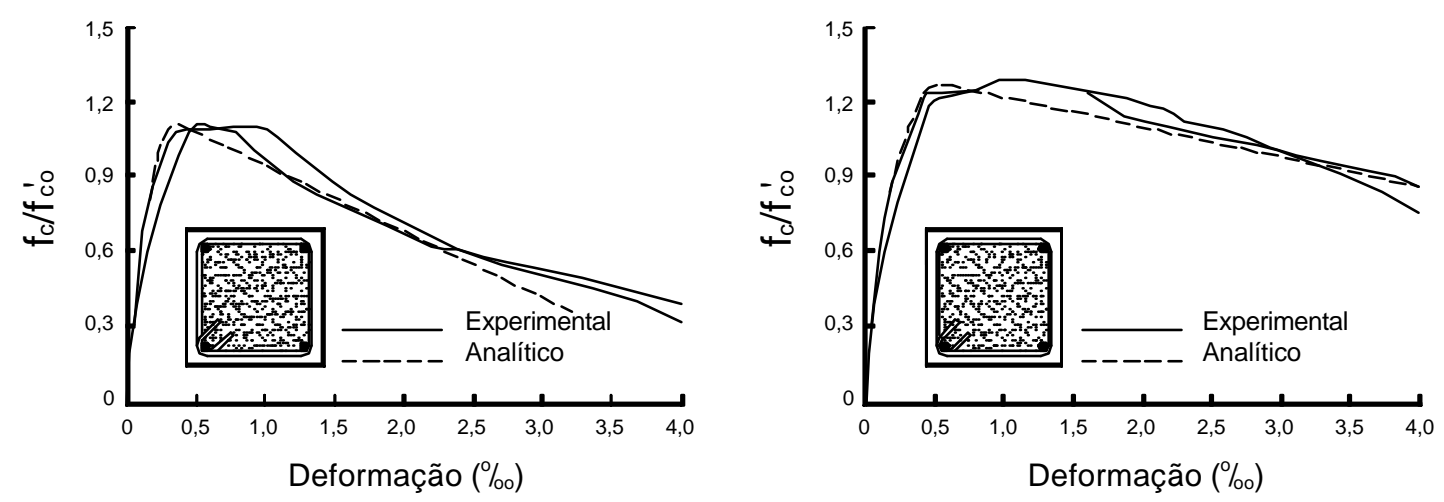

Figura 3.33. Ensaios comprovaram a concordância entre os resultados experimentais e o modelo analítico, SAATCIOGLU \& RAZVI (1992). 
O cálculo da máxima resistência à compressão do concreto confinado $\left(f_{c c}^{\prime}\right)$, ou seja, sob estado triaxial de tensões, pode ser expresso em termos da máxima resistência do concreto à compressão uniaxial $\left(f_{c o}^{\prime}\right)$ e da pressão lateral de confinamento $\left(f_{l}\right)$ :

$$
f_{c c}^{\prime}=f_{c o}^{\prime}+k_{1} \cdot f_{l}
$$

O coeficiente $k_{1}$ depende do coeficiente de Poisson e assumirá valor baixo quando o coeficiente de Poisson for alto. A determinação de $k_{1}$, para o concreto, foi feita em 1928 por RICHART et al. ${ }^{5}$, a partir de dados experimentais. A figura 3.32 apresenta a curva que relaciona $k_{1}$ e a pressão lateral de confinamento $f_{l}$, obtida com a regressão dos dados experimentais.

Tendo-se $f_{c o}^{\prime}$ e $k_{1}$, o segredo do modelo desenvolvido por SAATCIOGLU \& RAZVI (1992) está no cálculo da pressão lateral de confinamento $\left(f_{l}\right)$, a qual depende do tipo de armadura transversal empregada nos pilares.

Para pilares com armadura transversal circular ou em espiral pouco espaçada, a pressão lateral de confinamento pode ser considerada uniforme sobre o perímetro do núcleo e, portanto, calculada conforme sugere a figura 3.34.

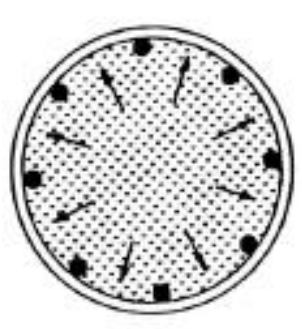

(a)

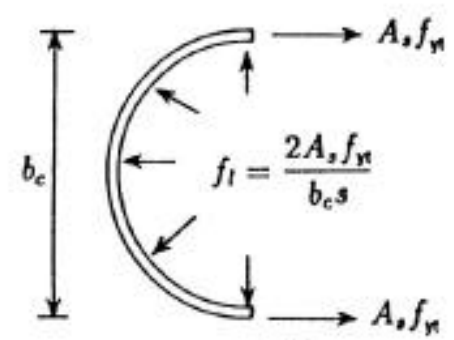

(b)

Figura 3.34. Pressão lateral de confinamento em pilares de seção circular, SAATCIOGLU \& RAZVI (1992).

5 RICHART, F. E.; BRANDTZAEG, A.; BROWN, R. L. (1928). A study of the failure of concrete under combined compressive stress. Bulletin n.185, Univ. of Illinois Engrg. Experimental Station, Urbana, III. 
Para pilares com armadura transversal quadrada, a pressão de confinamento exercida pelos estribos depende da força de contenção gerada por estes estribos. Deste modo, nos pontos nodais de suporte dos estribos são desenvolvidas altas forças de contenção, pois estas dependem da rigidez elástica da armadura transversal. Enquanto isso, nas regiões intermediárias ocorrem baixas forças de contenção por conta da pequena rigidez à flexão da armadura transversal (ver a figura 3.35).
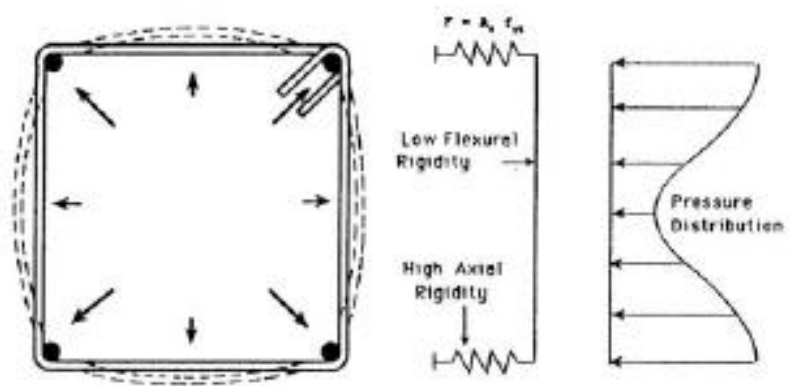

(a)
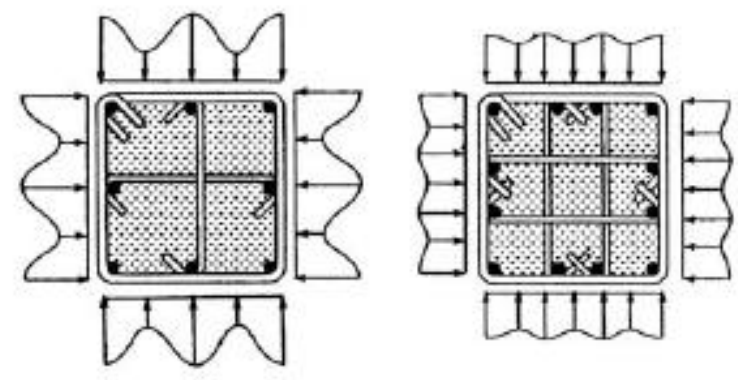

(b)

Figura 3.35. Pressão lateral em pilares quadrados, SAATCIOGLU \& RAZVI (1992).

O confinamento do concreto é um fenômeno tridimensional e, portanto, não pode ser reduzido ao nível da seção. Assim, deve-se considerar a variação da pressão lateral ao longo do comprimento do pilar. $\mathrm{Na}$ figura 3.36 (a), pode-se observar a redução da pressão lateral entre os níveis dos estribos.

Quando se tem armadura transversal pouco espaçada e barras longitudinais próximas suportadas lateralmente por estribos, permite-se admitir que a pressão lateral de confinamento possui distribuição uniforme e pode ser calculada da seguinte forma:

$$
f_{l}=\frac{\sum A_{s} \cdot f_{y t} \cdot \operatorname{sen}(\boldsymbol{\alpha})}{s \cdot b_{c}}
$$


onde:

$f_{l}$ é a pressão lateral uniforme média;

$A_{s}$ é a área da seção da barra da armadura transversal;

$f_{y t}$ é a resistência de escoamento do aço da armadura transversal;

$\alpha$ é o ângulo entre a armadura transversal e $b_{c}$. Este ângulo será de $90^{\circ}$ quando a armadura transversal for perpendicular à $b_{c}$;

$b_{c}$ é a dimensão da seção transversal quadrada do núcleo; e

$s$ é o espaçamento entre a armadura transversal.

No entanto, em casos em que o pilar possui barras longitudinais apenas nas quinas do estribo quadrado e o espaçamento da armadura transversal é grande, a redução de pressão ao longo da direção longitudinal entre os estribos é bastante pronunciada. Nestas situações, o valor da pressão de confinamento, determinado conforme descrito no parágrafo anterior, torna-se superestimado em relação ao da pressão real. Pensando nestes casos, SAATCIOGLU \& RAZVI (1992) propõem o cálculo de uma pressão lateral de confinamento equivalente que produza os mesmos efeitos da pressão lateral real não uniforme. Na figura 3.36 (b), apresentam-se as distribuições das pressões laterais real, média e equivalente sobre pilares de seção quadrada. O cálculo da pressão lateral equivalente $f_{l e}$ é estabelecido pela redução da pressão lateral média por meio do coeficiente $k_{2}$ :

$$
f_{l e}=k_{2} \cdot f_{l}
$$

onde, além das notações já utilizadas, têm-se:

$$
k_{2}=0,26 \cdot \sqrt{\left(\frac{b_{c}}{s}\right) \cdot\left(\frac{b_{c}}{s_{l}}\right) \cdot\left(\frac{1}{f_{l}}\right)} \leq 1,0 \text { desde que a flambagem prematura }
$$

da armadura longitudinal seja prevenida com a limitação do espaçamento máximo entre estribos de acordo com prescrições contidas em normas como o ACI 318 (1989) ${ }^{6}$. A inserção de $f_{l}$ deverá ser feita em MPa. A equação que define $k_{2}$ foi

\footnotetext{
${ }^{6}$ American Concrete Institute (1989). ACI 318 - Building code requeriments for reinforced concrete and commentary. Detroit, $\mathrm{ACl}$.
} 
obtida mediante a regressão de dados experimentais de diversos pesquisadores (SCOTT et al. ${ }^{7}$;RAZVI \& SAATCIOGLU (1989) e SHEIKH \& UZUMERI (1980)); e

$s_{l}$ é a distância livre entre as barras longitudinais adjacentes (ver a figura $3.36(b))$.
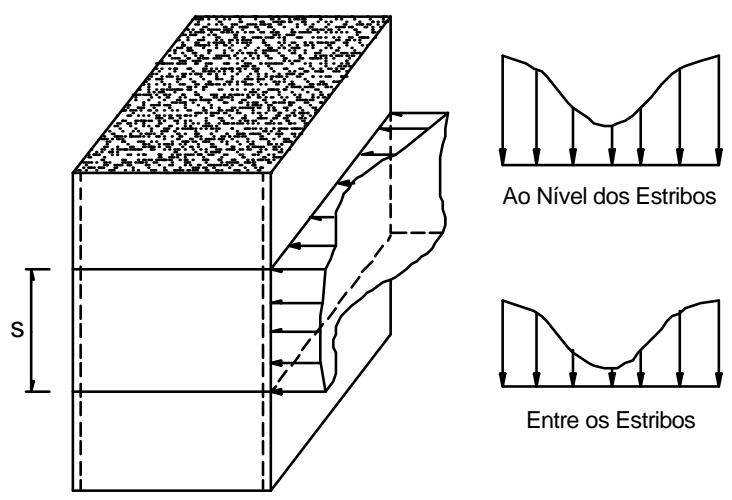

Ao Nível dos Estribos

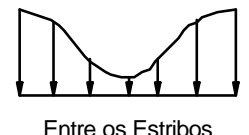

(a)

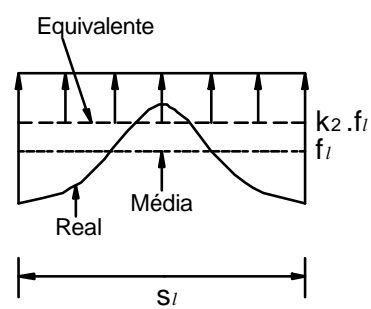

(b)

Figura 3.36. Distribuição das pressões laterais nos pilares: a) Distribuição da pressão lateral ao longo do pilar; e b) Pressões laterais real, média e equivalente no pilar, SAATCIOGLU \& RAZVI (1992).

Para os pilares de seção transversal retangular, tem-se a armadura de confinamento diferente nas duas direções ortogonais. Com isto, diferentes pressões de confinamento irão agir nas laterais dos pilares. Entretanto, o mesmo procedimento de cálculo da pressão de confinamento equivalente para pilares quadrados deverá ser usado nestes casos, apenas com algumas adaptações. A figura 3.37 ilustra a distribuição de pressões ao longo das laterais de pilares com seção transversal retangular.

7 SCOTT, B. D.; PARK, R.; PRIESTLEY, M. J. N. (1982). Stress-strain behavior of concrete confined by overlapping hoops at high and low strain rates. ACI Structural Journal, v.79, n.1, p.13-27. 


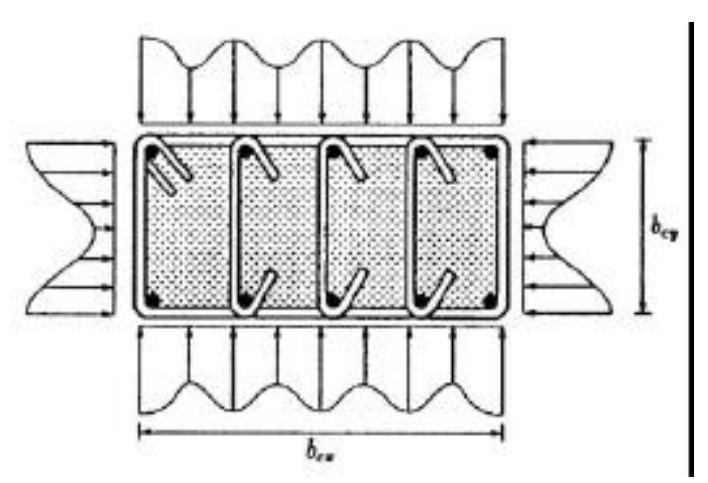

Figura 3.37. Distribuição das pressões laterais em pilares de seção retangular, SAATCIOGLU \& RAZVI (1992).

Assim sendo, o cálculo da pressão lateral equivalente, em pilares de seção retangular, deve ser feito por meio da seguinte expressão:

$$
f_{l e}=\frac{f_{l e x} \cdot b_{c x}+f_{l e y} \cdot b_{c y}}{b_{c x}+b_{c y}}
$$

onde, além das notações utilizadas anteriormente, têm-se:

$f_{\text {lex }}$ e $f_{\text {ley }}$ são as pressões de confinamento lateral efetivas agindo perpendicularmente às dimensões $b_{c x}$ e $b_{c y}$, respectivamente.

Cabe dizer que o modelo analítico de confinamento apresentado foi desenvolvido a partir da análise de dados experimentais de pilares ensaiados sob baixas e altas taxas de deformação. Além disso, este modelo permite o cálculo da resistência à compressão do concreto que esteja confinado por diferentes tipos de armaduras transversais, podendo isto ser realizado com a superposição dos efeitos do confinamento causado pelas armaduras empregadas, embora, sem considerar a possível interação entre estes efeitos.

\subsubsection{CUSSON \& PAULTRE (1993)}

Estes autores desenvolveram um modelo analítico para representar o fenômeno do confinamento do concreto em pilares executados com concreto de alta resistência. Embora a atual pesquisa contemple apenas pilares de resistência 
usual, um fruto interessante do trabalho de CUSSON \& PAULTRE (1993), denominado Índice de Eficiência do Confinamento (I.E.C.), foi aqui empregado com o objetivo de avaliar o grau de confinamento dado ao núcleo de concreto pela ação da armadura transversal. Assim sendo, apresenta-se, a seguir, a formulação deste índice:

$$
\text { I.E.C. }=\frac{f_{l e}}{f_{c o}^{\prime}}
$$

onde:

$f_{l e}$ é a pressão lateral equivalente que age sobre o núcleo; e

$f_{c o}^{\prime}$ é a máxima resistência àcompressão do concreto não confinado.

Os valores do I.E.C. permitem identificar três classes de eficiência do confinamento, conforme mostrado na tabela 3.3.

Tabela 3.3. Classes de eficiência do confinamento de acordo com os valores do I.E.C., CUSSON \& PAULTRE (1993).

\begin{tabular}{cc}
\hline I.E.C. $(\%)$ & Classe \\
\hline $0<$ I.E.C. $<5$ & 1 \\
$5<$ I.E.C. $<20$ & 2 \\
I.E.C. $>20$ & 3 \\
\hline
\end{tabular}

Pilares com pequena ductilidade e nenhum ganho de resistência enquadramse na Classe 1. A Classe 2 identifica pilares que obtiveram ganhos de resistência e comportamento dúctil na fase de pós-pico. Por fim, pilares pertencentes àClasse 3 apresentam grandes acréscimos de resistência e ductilidade.

Apesar do I.E.C. ter sido formulado com base nos ensaios de pilares de concreto de alta resistência e no modelo teórico de confinamento do concreto de alta resistência, neste trabalho, ele foi aplicado utilizando-se as pressões laterais efetivas calculadas de acordo com o modelo de confinamento de SAATCIOGLU \& RAZVI (1992) para pilares de resistência usual. Em sua dissertação de mestrado, TAKEUTI (1999) lança mão disso fazendo o cálculo do I.E.C. a partir das pressões laterais obtidas por SAATCIOGLU \& RAZVI (1992) e CUSSON \& PAULTRE (1993). 


\subsection{Avaliação da Ductilidade}

LIMA JÚNIOR \& GIONGO (2001) propõem um critério de avaliação da ductilidade do concreto à compressão, o qual pode ser estendido para elementos de concreto armado como os pilares desta pesquisa.

Partindo da definição de ductilidade, como sendo a medida de deformação que indica a capacidade de um corpo deformar-se inelasticamente sem perder de maneira brusca a sua capacidade resistente, os autores sugerem que sejam calculados índices que relacionem as deformações elástica e plástica com a deformação de pico, em ambas as fases ascendente e descente do diagrama tensão-deformação. Isto permitirá saber o quanto as deformações plásticas e elástica são maiores ou menores que a deformação registrada na força máxima e, assim, ter-se-á uma idéia da ductilidade apresentada pelo elemento estrutural.

Para facilitar a exposição do critério, sua formulação foi dividida nas fases pré e pós-pico. Assim, têm-se:

\section{a) Pré-pico}

A partir da figura 3.38, observa-se que a Energia Total de Pré-Pico ( $\left.E_{t-p r e ́}\right)$ foi manipulada de forma a se obter uma Deformação Elástica $\left(\varepsilon_{t-e l a}\right)$ que pudesse representar o somatório da Deformação Elástica do Elemento $\left(\varepsilon_{\text {ela }}\right)$ com a Deformação Plástica de Pré-Pico $\left(\varepsilon_{p-p r e ́}\right)$. Assim, calculando-se $E_{t-p r e ́}, \varepsilon_{t-e l a} \mathrm{e}$ $\varepsilon_{\text {ela }}$, chega-se facilmente ao valor de $\varepsilon_{p-p r e}$.

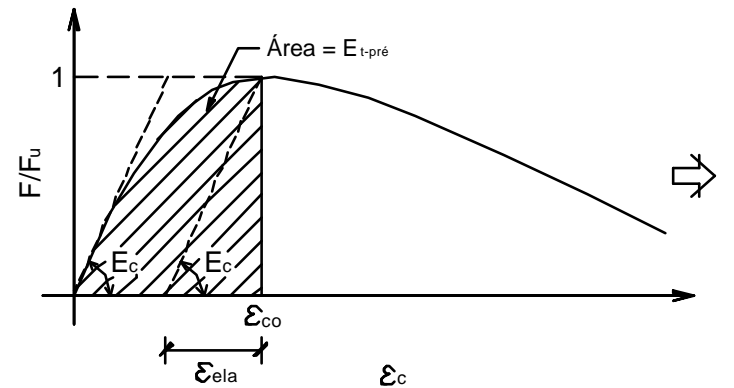

a)

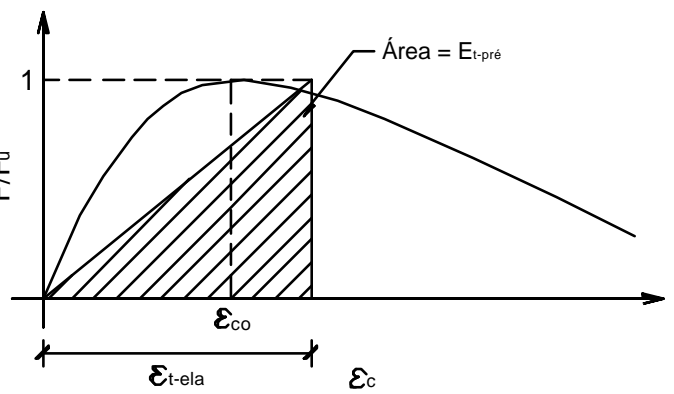

b)

Figura 3.38. Manipulação gráfica utilizada para se calcular as deformações elástica e plástica de pré-pico. 
Em seguida apresentam-se as etapas matemáticas empregadas para se determinar as grandezas relacionadas no parágrafo anterior:

$$
\begin{aligned}
& E_{t-p r e ́}=\text { Área da Figura 3.38.a = Área da Figura 3.38.b } \\
& \int_{0}^{\varepsilon_{c o}} \frac{F}{F_{u}}\left(\varepsilon_{c}\right) \cdot d \varepsilon_{c}=\frac{\varepsilon_{t-e l a} \cdot 1}{2}
\end{aligned}
$$

onde:

$\varepsilon_{c o}$ é deformação registrada na força última;

$\varepsilon_{t-e l a}=\varepsilon_{e l a}+\varepsilon_{p-p r e ́} ;$

$\varepsilon_{\text {ela }}=\frac{1}{E_{c}}$ é a deformação elástica do elemento, sendo $E_{c}$ o módulo de elasticidade tangente na origem;

$\varepsilon_{p-p r e ́}$ é a deformação plástica de pré-pico;

$F$ é a força de compressão aplicada; e

$F_{u}$ é a força última do elemento estrutural.

Portanto:

$$
\boldsymbol{\varepsilon}_{p-p r e ́}=2 \cdot \int_{0}^{\varepsilon_{c o}} \frac{F}{F_{u}}\left(\boldsymbol{\varepsilon}_{c}\right) \cdot d \boldsymbol{\varepsilon}_{c}-\frac{1}{E_{c}}
$$

Tendo-se $\varepsilon_{p-p r e ́}$, pode-se calcular o Índice de Deformação Plástica de PréPico ( $\left.I D_{p-p r e ́ ~}\right)$ como sendo igual a:

$$
I D_{p-p r e ́}=\frac{\varepsilon_{p-p r e ́}}{\varepsilon_{c o}}
$$

onde:

$I D_{p-p r e ́}$ irá variar de 0 (comportamento elástico-linear) a 2 (comportamento plástico-perfeito). 
Pode-se também calcular o Índice de Deformação Elástica $\left(I D_{\text {ela }}\right)$ com a seguinte fórmula:

$$
I D_{\text {ela }}=\frac{\varepsilon_{\text {ela }}}{\varepsilon_{c o}}
$$

onde:

$I D_{\text {ela }}$ irá variar de 1 (comportamento elástico-linear) a 0 (comportamento plástico-perfeito).

b) Pós-pico

A partir da figura 3.39, observa-se que a Energia Total de Pós-Pico $\left(E_{t-p o ́ s}\right)$ foi manipulada de forma a se obter uma Deformação Plástica de Pós-Pico $\left(\varepsilon_{p-p o ́ s}\right)$ correspondente a um comportamento plástico-perfeito no trecho descendente do diagrama $F / F_{u}-\varepsilon_{c}$. Assim, calculando-se $E_{t-p o ́ s}$, chega-se facilmente ao valor de $\varepsilon_{p-p o ́ s}$.

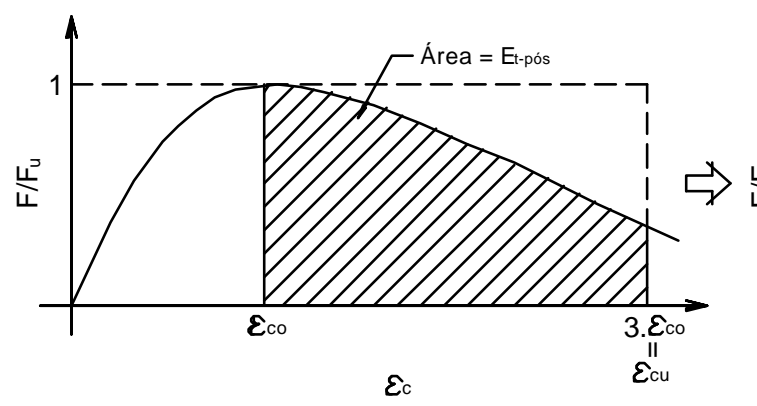

a)

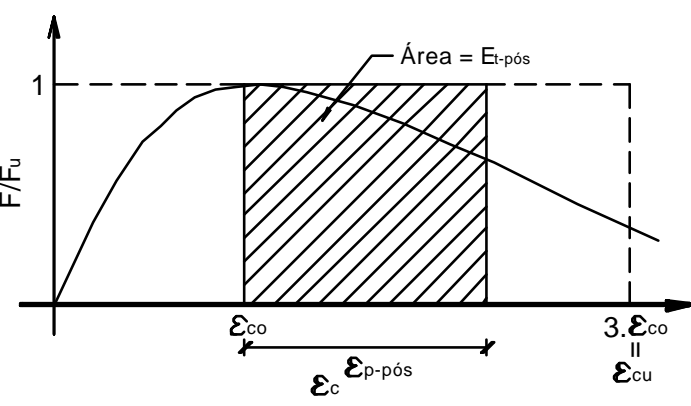

b)

Figura 3.39. Consideração gráfica utilizada para o cálculo da deformação plástica de pós-pico.

As etapas matemáticas utilizadas para se determinar as grandezas relacionadas são apresentadas a seguir: 


$$
\begin{gathered}
E_{t-p o ́ s}=\text { Área da Figura 3.39.a }=\text { Área da Figura 3.39.b } \\
\qquad \int_{\varepsilon_{c o}}^{3 . \varepsilon_{c o}} \frac{F}{F_{u}}\left(\varepsilon_{c}\right) \cdot d \varepsilon_{c}=\varepsilon_{p-p o ́ s} .1
\end{gathered}
$$

Portanto:

$$
\boldsymbol{\varepsilon}_{p-p o ́ s}=\int_{\varepsilon_{c o}}^{3 . \varepsilon_{c o}} \frac{F}{F_{u}}\left(\boldsymbol{\varepsilon}_{c}\right) \cdot d \boldsymbol{\varepsilon}_{c}
$$

Tendo-se $\varepsilon_{p-p o ́ s}$, pode-se calcular o Índice de Deformação Plástica de PósPico $\left(I D_{p-p o ́ s}\right)$ como sendo igual a:

$$
I D_{p-p o ́ s}=\frac{\boldsymbol{\varepsilon}_{p-p o ́ s}}{\boldsymbol{\varepsilon}_{c o}}
$$

onde:

$I D_{p-p o ́ s}$ irá variar de 0 (comportamento frágil-perfeito) a 2 (comportamento plástico-perfeito). 


\section{MATERIAIS, MODELOS E EQUIPAMENTOS}

\subsection{Considerações Iniciais}

Neste capítulo, são apresentados, além de outros tópicos, os estudos de dosagem realizados para se obter resistência média àcompressão do concreto de $25 \mathrm{MPa}$ e $40 \mathrm{MPa}$, aos quatorze dias de idade. A dosagem de concreto de resistência média àcompressão de 40MPa foi pesquisada com o objetivo de que os resultados possam ser úteis para futuras pesquisas. Ainda, são apresentadas as caracterizações dos materiais utilizados para produzir o concreto e as armaduras dos pilares, os conceitos empregados na definição dos modelos de pilares, a instrumentação utilizada nas medidas das deformações e, por fim, os equipamentos aplicados na realização dos ensaios.

\subsection{Estudo de Dosagem}

Utilizando-se o roteiro prático de dosagem experimental do concreto de SILVA (1983) e alguns dados e recomendações de HELENE \& TERZIAN (1992), pôde-se, após algumas tentativas, chegar na resistência média à compressão do concreto de $25 \mathrm{MPa}$, aos quatorze dias. Para tanto, o traço em massa seca foi de 1 : 2,369: 3,547: $a / c=0,65$. O lançamento dos materiais na betoneira basculante teve a seguinte ordem: $100 \%$ da pedra britada; $100 \%$ da areia; $80 \%$ da água; $100 \%$ do cimento; $20 \%$ da água. $O$ tempo de mistura foi de $5 \mathrm{~min}$, à contar da última fração de água inserida na betoneira. A medida do abatimento do tronco de cone, para esta dosagem, foi de $70 \mathrm{~mm} \pm 5 \mathrm{~mm}$. Quanto à caracterização dos materiais empregados nesta dosagem, a mesma será apresentada mais adiante. 
Para a dosagem de 40MPa de resistência média àcompressão do concreto, aos quatorze dias, o traço encontrado, em massa seca, foi de $1: 1,800: 2,827:$ a/c $=0,55$. A ordem e o tempo de mistura dos materiais na betoneira basculante foram iguais ao da dosagem anterior. A medida do abatimento do tronco de cone, para esta dosagem, foi de $110 \mathrm{~mm} \pm 5 \mathrm{~mm}$. Da mesma forma que na primeira dosagem, a caracterização dos materiais aqui empregados será descrita adiante.

Nas tabelas 4.1 e 4.2, são apresentados os consumos de materiais por metro cúbico de concreto fresco para as duas dosagens estudadas. Na tabela 4.3, têm-se os resultados dos ensaios de compressão de corpos-de-prova cilíndricos de concreto, com seção transversal de diâmetro de $150 \mathrm{~mm}$ e altura de $300 \mathrm{~mm}$, para as dosagens em estudo. Estes ensaios foram realizados de acordo com a NBR 5739 (1980).

Tabela 4.1. Consumo de materiais por metro cúbico de concreto fresco para a dosagem de 25MPa.

\begin{tabular}{cc}
\hline Material & Consumo $\left(\mathbf{k g} / \mathbf{m}^{\mathbf{3}}\right)$ \\
\hline Cimento & 319,8 \\
Areia & 757,6 \\
Pedra Britada & 1134,3 \\
Água & 207,9 \\
Total & $\mathbf{2 4 1 9 , 6}$ \\
\hline
\end{tabular}

Tabela 4.2. Consumo de materiais por metro cúbico de concreto fresco para a dosagem de 40MPa.

\begin{tabular}{cc}
\hline Material & Consumo $\left(\mathbf{k g} / \mathbf{m}^{\mathbf{3}}\right)$ \\
\hline Cimento & 391,4 \\
Areia & 704,4 \\
Pedra Britada & 1106,3 \\
Água & 215,2 \\
Total & $\mathbf{2 4 1 7 , 3}$ \\
\hline
\end{tabular}


Tabela 4.3. Resistência à compressão do concreto dos corpos-de-prova aos 14 dias.

\begin{tabular}{ccccc}
\hline \multirow{2}{*}{ Dosagem } & \multicolumn{4}{c}{ Resistência à compressão (MPa) } \\
\cline { 2 - 5 } & CP-1 & CP-2 & CP-3 & Média \\
\hline $25 \mathrm{MPa}$ & 26,7 & 24,8 & 25,6 & 25,7 \\
$40 \mathrm{MPa}$ & 45,1 & 44,3 & 44,9 & 44,8 \\
\hline
\end{tabular}

Na figura 4.1, apresenta-se a evolução da resistência à compressão do concreto, para as duas dosagens estudadas. É interessante observar como a dosagem de 40MPa apresentou uma taxa de crescimento da resistência bastante alta nas primeiras idades. Isto decorreu da utilização do cimento CP $\vee A R I-32$, conhecido como cimento de Alta Resistência Inicial (ARI), na respectiva dosagem. Mas por que se utilizou o cimento $A R I$ e não o $C P \| F-32$, da dosagem de $25 \mathrm{MPa}$ ? $\mathrm{O}$ motivo foi a necessidade de se alcançar $40 \mathrm{MPa}$ de resistência à compressão, aos 14 dias, sem o emprego de aditivos ou adições. Assim, o cimento ARI tornou-se imprescindível nessa ocasião.

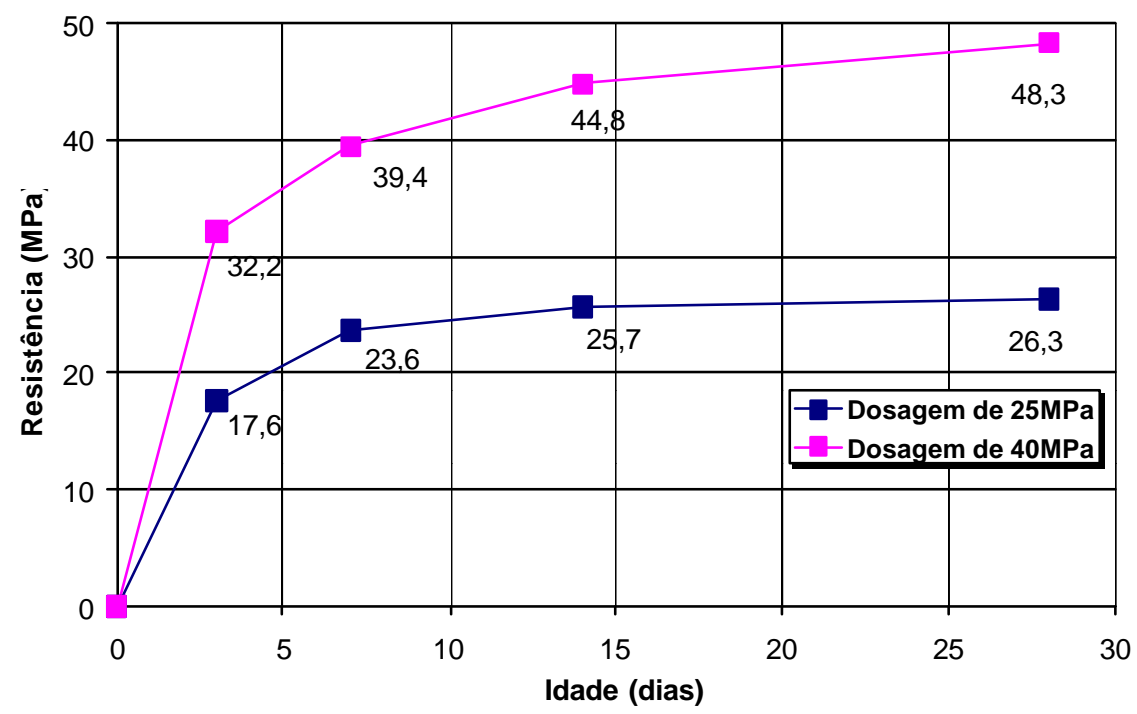

Figura 4.1. Evolução da resistência à compressão com o tempo para as dosagens de 25MPa e 40MPa. 


\subsection{Caracterização dos Materiais}

\subsubsection{Cimento}

Como especificado anteriormente, o cimento utilizado na dosagem referente aos concretos com resistência média àcompressão de $25 \mathrm{MPa}$, aos quatorze dias, foi o CP II F - 32, da marca Cauê. Este cimento permitiu alcançar valores de resistência próximos do necessário, como visto na tabela 4.3. Segundo o fabricante, sua massa específica é de $3,12 \mathrm{~g} / \mathrm{cm}^{3}$.

Para a dosagem de 40MPa, foi empregado o cimento CP V ARI-32, também da marca Cauê e com massa específica fornecida pelo fabricante de $3,12 \mathrm{~g} / \mathrm{cm}^{3}$.

O cimento utilizado em toda a pesquisa foi fornecido mediante doação pela empresa Camargo Corrêa Cimentos S/A.

\subsubsection{Agregado Miúdo}

O agregado miúdo empregado na pesquisa foi areia do tipo quartzosa, proveniente do rio Mogi-Guaçu. Todos os ensaios para caracterizar este material foram realizados no Laboratório de Construção Civil do Departamento de Arquitetura e Urbanismo da EESC-USP.

A granulometria da areia foi determinada segundo a NBR 7217 (1987). Ainda por esta norma, o módulo de finura foi de 2,19 e sua dimensão máxima característica de $2,4 \mathrm{~mm}$.

De acordo com a NBR 7211 (1983), a areia se enquadrou nos limites granulométricos da areia fina, conforme pode ser visto na figura 4.2.

Quanto à massa específica e unitária, seguindo -se as NBR 9776 (1987) e NBR 7251 (1982), obtiveram-se, respectivamente, $2,615 \mathrm{~g} / \mathrm{cm}^{3}$ e $1,5 \mathrm{~kg} / \mathrm{dm}^{3}$. 


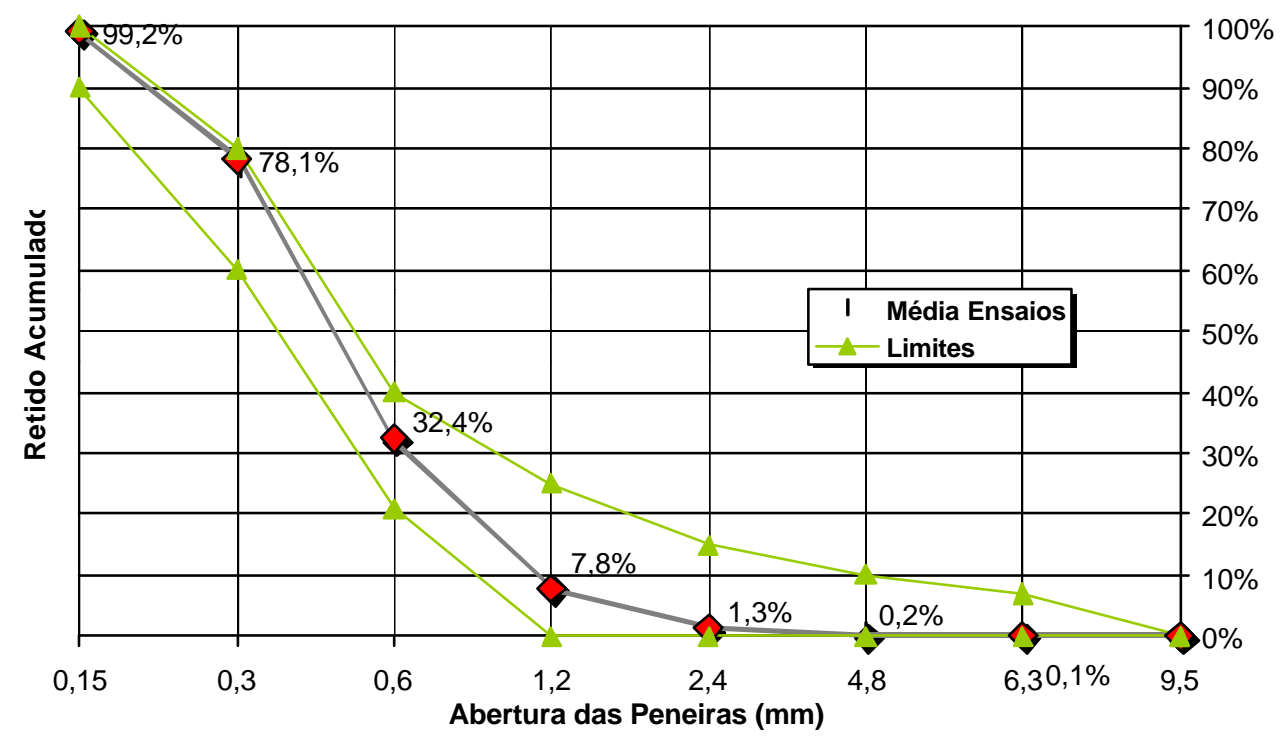

Figura 4.2. Limites granulométricos para a areia fina de acordo com a NBR 7211 (1983).

\subsubsection{Agregado Graúdo}

Como agregado graúdo, utilizou-se pedra britada de origem basáltica da região de São Carlos. Tal como para o agregado miúdo, os ensaios para caracterizar este material foram realizados no Laboratório de Construção Civil do Departamento de Arquitetura e Urbanismo da EESC-USP.

A granulometria da pedra britada foi determinada segundo a NBR 7217 (1987). Ainda por essa norma, o módulo de finura foi de 6,49 e sua dimensão máxima característica de 19,0mm.

A pedra britada não se enquadrou nos limites granulométricos estipulados pela NBR 7211 (1983), conforme pode ser visto na tabela 4.4. Contudo, durante a fase de determinação da dosagem, não foram observadas anormalidades nas propriedades (resistência e plasticidade) dos concretos executados com este agregado. Assim sendo, esta pedra britada foi empregada sem maiores preocupações com sua curva granulométrica.

Quanto à massa específica e unitária, seguindo -se as NBR 9776 (1987) e NBR 7251 (1982), obtiveram-se, respectivamente, $2,837 \mathrm{~g} / \mathrm{cm}^{3}$ e $1,52 \mathrm{~kg} / \mathrm{dm}^{3}$. 
Tabela 4.4. Limites granulométricos da pedra britada segundo a NBR 7211 (1983).

\begin{tabular}{|c|c|c|c|c|c|c|c|c|c|c|c|c|}
\hline \multicolumn{13}{|c|}{ Porcentagem Retida Acumulada, em massa } \\
\hline \multirow{2}{*}{$\begin{array}{l}\text { Peneira } \\
\#(\mathrm{~mm})\end{array}$} & \multicolumn{11}{|c|}{ Valores da NBR 7211 (1987) para as graduações } & \multirow{2}{*}{$\begin{array}{c}\text { Média dos } \\
\text { Ensaios }\end{array}$} \\
\hline & & 0 & & 1 & & 2 & & 3 & & 4 & 5 & \\
\hline 152 & - & - & - & - & - & - & - & - & - & - & - & 0,0 \\
\hline 76 & - & - & - & - & - & - & - & - & 0 & 0 & - & 0,0 \\
\hline 64 & - & - & - & - & - & - & - & - & 0 & 30 & - & 0,0 \\
\hline 50 & - & - & - & - & - & - & 0 & 0 & 75 & 100 & - & 0,0 \\
\hline 38 & - & - & - & - & - & - & 0 & 30 & 90 & 100 & - & 0,0 \\
\hline 32 & - & - & - & - & 0 & 0 & 75 & 100 & 95 & 100 & - & 0,0 \\
\hline 25 & - & - & 0 & 0 & 0 & 25 & 87 & 100 & - & - & - & 0,0 \\
\hline 19 & - & - & 0 & 10 & 75 & 100 & 95 & 100 & - & - & - & 0,0 \\
\hline 12,5 & 0 & 0 & - & - & 90 & 100 & - & - & - & - & - & 13,7 \\
\hline 9,5 & 0 & 10 & 80 & 100 & 95 & 100 & - & - & - & - & - & 55,4 \\
\hline 6,3 & - & - & 92 & 100 & - & - & - & - & - & - & - & 90,9 \\
\hline 4,8 & 80 & 100 & 95 & 100 & - & - & - & - & - & - & - & 97,3 \\
\hline 2,4 & 95 & 100 & - & - & - & - & - & - & - & - & - & 99,3 \\
\hline 1,2 & - & - & - & - & - & - & - & - & - & - & - & 99,3 \\
\hline 0,6 & - & - & - & - & - & - & - & - & - & - & - & 99,3 \\
\hline 0,3 & - & - & - & - & - & - & - & - & - & - & - & 99,3 \\
\hline 0,15 & - & - & - & - & - & - & - & - & - & - & - & 99,3 \\
\hline Fundo & - & - & - & - & - & - & - & - & - & - & - & $100,0 \%$ \\
\hline
\end{tabular}

\subsection{4 Água}

No amassamento do concreto, foi utilizada água da rede pública de abastecimento da cidade de São Carlos.

\subsubsection{Armaduras}

Os pilares tiveram armadura longitudinal composta por barras de diâmetro nominal de $10 \mathrm{~mm}$ ou $12,5 \mathrm{~mm}$, enquanto que a armadura transversal foi de diâmetro nominal de $5,0 \mathrm{~mm}$ ou $6,3 \mathrm{~mm}$. A caracterização destas armaduras foi feita a partir de ensaios de tração simples em três amostras de aço para cada diâmetro. 
Os ensaios para caracterizar as barras transversais foram realizados no Laboratório de Madeiras e Estruturas de Madeira da EESC - USP, e os referentes æ̀ barras longitudinais foram feitos no Laboratório de Estruturas da EESC - USP. Apresentam-se, nas figuras 4.3 e 4.4 , os diagramas de tensão-deformação resultantes dos ensaios realizados.
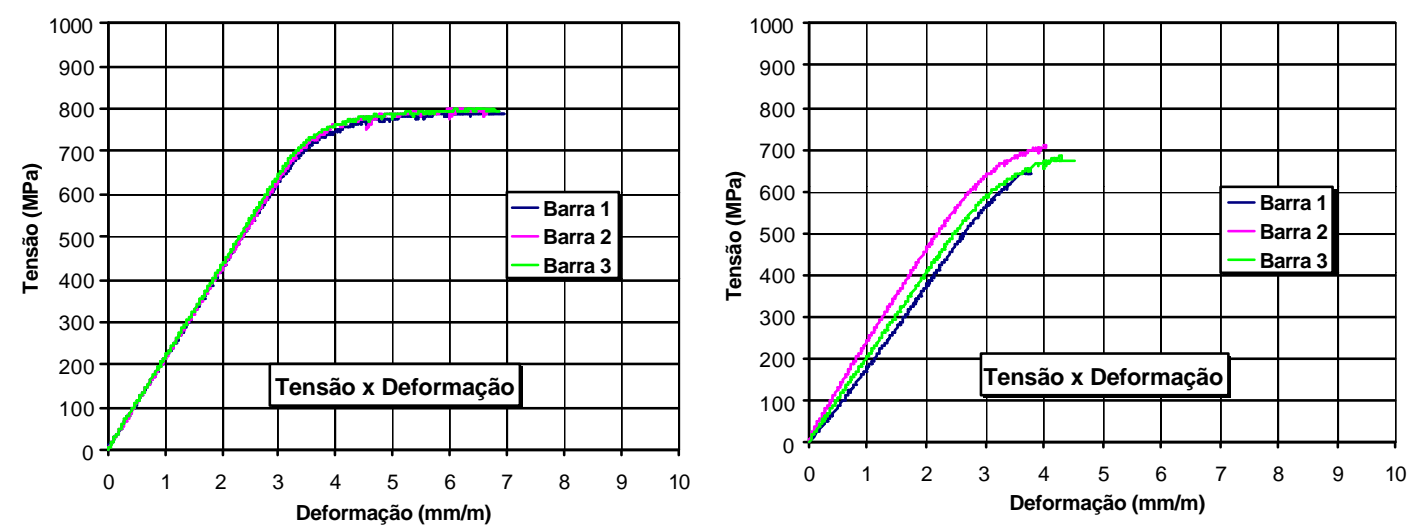

Figura 4.3. Da esquerda para a direita, diagramas tensão-deformação das barras de diâmetro nominal de 5,0mm e $6,3 \mathrm{~mm}$, respectivamente.
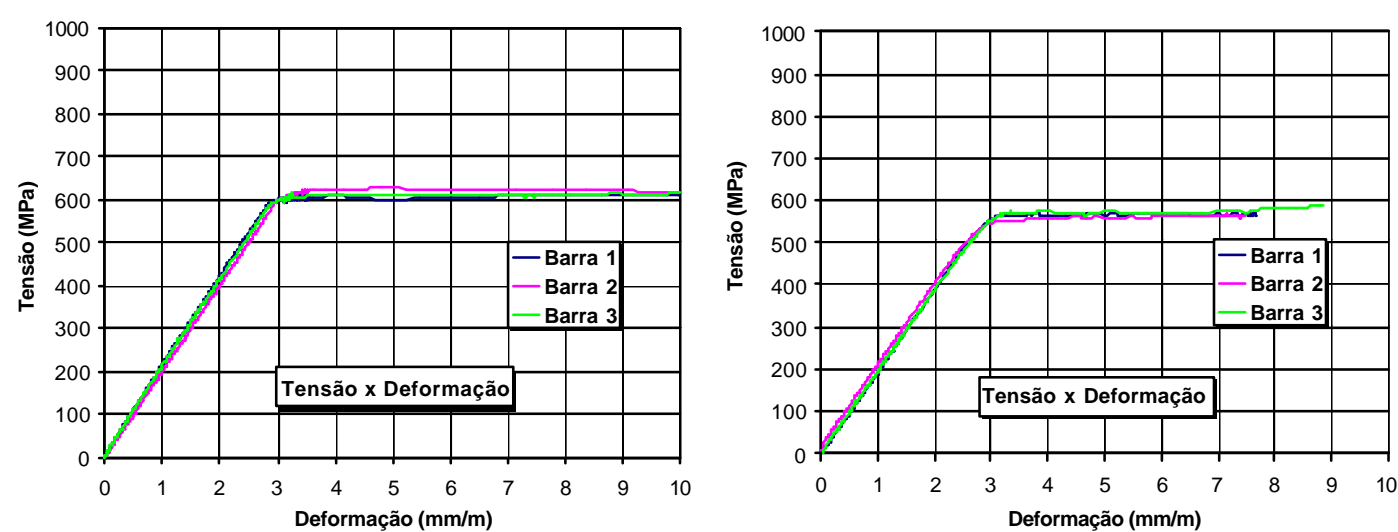

Figura 4.4. Da esquerda para a direita, diagramas tensão-deformação das barras de diâmetro nominal de 10,0 mm e 12,5mm, respectivamente.

Observando-se os diagramas tensão-deformação das amostras de diâmetro nominal de 5,0mm e 6,3mm, percebe-se que seus resultados destoam dos demais. Isto permitiu classificar estas amostras como fios de categoria CA-60. Em contrapartida, as amostras de diâmetro nominal de $10,0 \mathrm{~mm}$ e $12,5 \mathrm{~mm}$ podem ser classificadas como barras de aço de categoria CA-50.

Tendo-se medido o comprimento e a massa das amostras antes dos ensaios, pôde-se calcular o diâmetro efetivo e, portanto, a área efetiva das amostras 
considerando-se a massa específica do aço igual a $7850 \mathrm{~kg} / \mathrm{m}^{3}$, conforme prescreve a NBR 7480 (1996).

De posse dos diagramas de tensão-deformação e das características geométricas das amostras, as propriedades das armaduras puderam ser resumidas na tabela 4.5. É importante que se diga que esta tabela apresenta a média dos valores das três amostras ensaiadas para cada diâmetro nominal especificado.

Tabela 4.5. Propriedades das armaduras.

\begin{tabular}{cccccccc}
\hline $\begin{array}{c}\text { Diâmetro } \\
\text { Nominal } \\
(\mathbf{m m})\end{array}$ & $\begin{array}{c}\text { Diâmetro } \\
\text { Efetivo } \\
(\mathbf{m m})\end{array}$ & $\begin{array}{c}\text { Area } \\
\text { Efetiva } \\
\left(\mathbf{c m}^{2}\right)\end{array}$ & $\begin{array}{c}\mathbf{E}_{\mathbf{s}} \\
(\mathbf{G P a})\end{array}$ & $\begin{array}{c}\mathbf{f}_{\mathbf{y}} \\
(\mathbf{M P a})\end{array}$ & $\begin{array}{c}\mathbf{e}_{\mathbf{y}} \\
(\mathbf{m m} / \mathbf{m})\end{array}$ & $\begin{array}{c}\mathbf{f}_{\mathrm{u}} \\
(\mathbf{M P a})\end{array}$ & $\begin{array}{c}\mathbf{e}_{\mathrm{u}} \\
(\mathbf{m m} / \mathbf{m})\end{array}$ \\
\hline 5,0 & 5,00 & 0,197 & 213 & 787 & 5,7 & 809 & 12 \\
6,3 & 6,30 & 0,311 & 207 & 702 & 5,4 & 908 & 19 \\
10,0 & 9,97 & 0,781 & 205 & 611 & 3,4 & 726 & 20 \\
12,5 & 12,33 & 1,195 & 193 & 561 & 3,2 & 895 & 21 \\
\hline
\end{tabular}

\subsection{Definição dos Modelos de Pilares}

A definição dos modelos de pilares de concreto armado dependeu de parâmetros como a resistência à compressão do concreto, as dimensões dos pilares, a categoria e o diâmetro nominal das armaduras e o detalhamento destas armaduras. Sendo assim, este item foi dividido em subitens que descrevem como foram fixados estes parâmetros.

\subsubsection{Resistência à Compressão do Concreto}

Como já comentado no capítulo de introdução, os modelos de pilares tiveram resistência média à compressão do concreto de 25MPa, aos 14 dias. Com isso, pretendeu-se ampliar os resultados de outras pesquisas realizadas no Departamento de Engenharia de Estruturas da EESC - USP, pois, análises teórica e experimental de pilares de concreto armado sob ação centrada com modelos de dimensões semelhantes, variando o detalhamento das armaduras e a resistência média à compressão do concreto para $60 \mathrm{MPa}$ e $80 \mathrm{MPa}$, foram realizadas por QUEIROGA et al. (1999) e LIMA et al. (1997), respectivamente. Por fim, como fruto 
dessa seqüência de trabalhos, foi disposto à comunidade científica um estudo abrangente sobre pilares de concreto armado submetidos à força de compressão centrada em uma faixa considerável de resistência do concreto.

\subsubsection{Dimensões dos Pilares}

As dimensões dos pilares foram definidas como iguais æ̀ dimensões dos pilares ensaiados por LIMA et al. (1997) e QUEIROGA et al. (1999) (ver a figura 4.5). Assim, objetivou-se aproximar as dimensões dos modelos desta pesquisa das usualmente adotadas em pilares de edifícios. Além disso, com essas dimensões, os pilares puderam ser calculados de forma simplificada, conforme prescreve a NBR 6118 (1978), ou seja, sem a consideração dos efeitos de segunda ordem (deformações e excentricidades acidentais), pois a força era suposta centrada e o índice de esbeltez $\lambda$ menor ou igual a 40 (os dois tipos de pilares possuem índice de esbeltez igual a 20,8$)$.
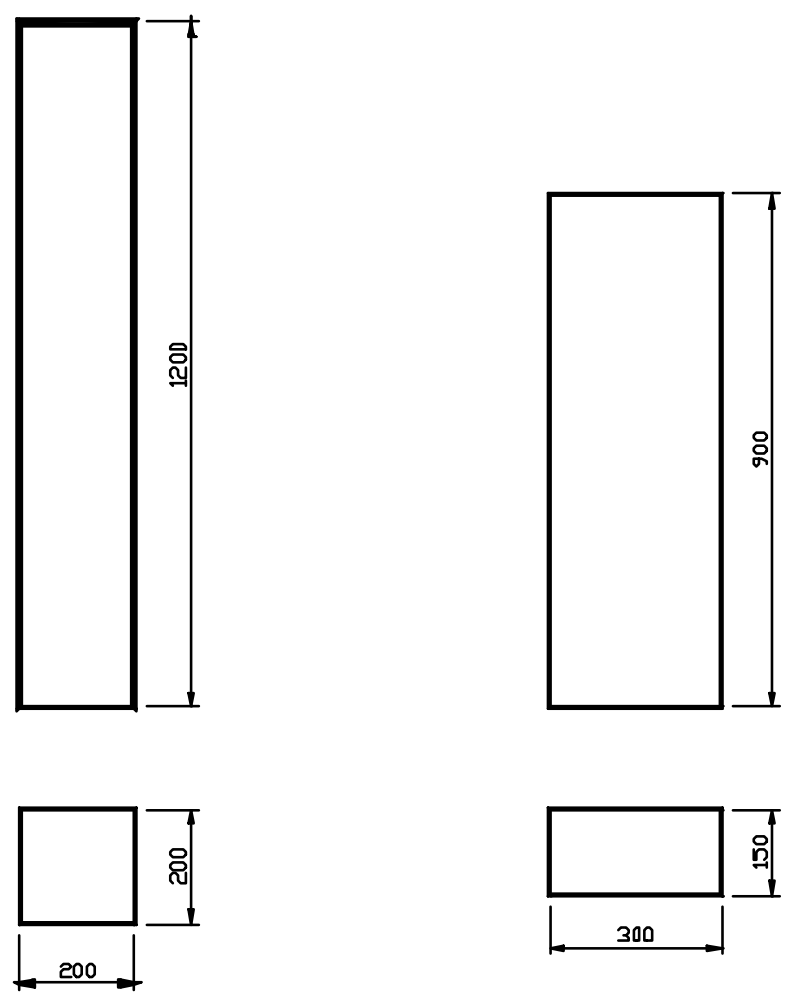

Figura 4.5. Dimensões dos modelos de pilares.

Quanto æ̀ dimensões mínimas das seções transversais dos dois tipos de pilares, a NBR 6118 (1978) permite a execução de pilar que não suporte laje 
cogumelo com largura $b$ menor que $20 \mathrm{~cm}$, desde que se aumente o coeficiente de segurança utilizado no dimensionamento de 1,4 para 1,8, e a largura da seção retangular não seja inferior a $12 \mathrm{~cm}$ e o comprimento não superior a $60 \mathrm{~cm}$. Assim, as larguras de $200 \mathrm{~mm}$ e $150 \mathrm{~mm}$ dos modelos quadrado e retangular, respectivamente, ficaram dentro dos valores prescritos.

\subsubsection{Categoria e Diâmetro Nominal das Armaduras}

Adotaram-se para as armaduras longitudinais os diâmetros nominais de $10,0 \mathrm{~mm}$ e $12,5 \mathrm{~mm}$, enquanto que, nas armaduras transversais se utilizaram diâmetros de 5,0mm e 6,3mm.

De acordo com a NBR 6118 (1978), o diâmetro nominal mínimo das barras longitudinais deve ser de 10,0mm. LEONHARDT \& MÖNNIG (1978) propõem diâmetro mínimo de 10,0mm e diâmetro máximo limitado ao valor da menor dimensão da seção transversal $b$ dividida por oito, desde que a menor dimensão da seção $b$ esteja entre $10 \mathrm{~cm}$ e $20 \mathrm{~cm}$. Assim, para o trabalho em questão, as prescrições de LEONHARDT \& MÖNNIG (1978) resultam em diâmetro mínimo de 10,0 mm e diâmetro máximo de $18,75 \mathrm{~mm}$ e $25 \mathrm{~mm}$ para as seções retangular e quadrada, respectivamente. Desta forma, os diâmetros das barras longitudinais de $10,0 \mathrm{~mm}$ e $12,5 \mathrm{~mm}$, adotados para os pilares da presente pesquisa, atenderam tanto a NBR 6118 (1978) quanto àsugestão de LEONHARDT \& MÖNNIG (1978).

Confirmados os diâmetros das barras longitudinais, pôde-se calcular 0 cobrimento das armaduras como função dos mesmos. Segundo LEONHARDT \& MÖNNIG (1978), o cobrimento $c$ deve ser no mínimo maior ou igual a 1,2 vez o diâmetro da barra longitudinal. Assim sendo, para os pilares desta pesquisa, o cobrimento mínimo poderia ser de $12 \mathrm{~mm}$ e $15 \mathrm{~mm}$, quando empregados diâmetros de barras longitudinais de $10 \mathrm{~mm}$ e $12,5 \mathrm{~mm}$, respectivamente. Para fins de uniformização, adotou-se cobrimento de $15 \mathrm{~mm}$, independente do diâmetro da armadura longitudinal empregada.

Segundo a NBR 6118 (1978) e FUSCO (1994), o diâmetro mínimo da armadura transversal deve ser maior ou igual a $5 \mathrm{~mm}$ ou o diâmetro da armadura longitudinal dividido por quatro. Com isso, os diâmetros das barras transversais de $5,0 \mathrm{~mm}$ e $6,3 \mathrm{~mm}$, adotados para os pilares da presente pesquisa, atenderam tanto à NBR 6118 (1978) quanto àsugestão de FUSCO (1994). 
Por fim, de acordo com a NBR 7480 (1996), as barras de diâmetro nominal de $10,0 \mathrm{~mm}$ e $12,5 \mathrm{~mm}$ puderam ser classificadas na categoria CA-50, e os fios de aço de diâmetro de 5,0mm e 6,3mm como CA-60.

\subsubsection{Taxa Geométrica de Armadura Longitudinal}

Segundo a NBR 6118 (1978), a armadura longitudinal de um pilar não cintado, que tenha todas as suas barras comprimidas, deve ter seção transversal compreendida entre $0,8 \%$ e $6 \%$ da seção transversal do pilar, com o limite inferior podendo ser $0,5 \%$ desde que o índice de esbeltez $\lambda$ seja menor ou igual a 30 . Enquanto isso, MÖRSCH (1959) recomenda, para o dimensionamento de pilares, a utilização de uma taxa geométrica de armadura longitudinal entre 0,8\% e 1,2\%.

Em função das prescrições levantadas no parágrafo anterior, foram adotados pilares com armadura longitudinal mínima, ou seja, com barras de diâmetro nominal de $10,0 \mathrm{~mm}$ e taxa geométrica próxima de 0,8\%. Além disso, foram propostos modelos de pilares com barras de diâmetro de 12,5mm e taxa geométrica próxima do limite superior recomendado por MÖRSCH (1959).

$\mathrm{Na}$ tabela 4.6, são apresentadas variações da armadura longitudinal nos dois tipos de pilares, enquanto que, na figura 4.6, pode-se visualizar a armadura longitudinal empregada nestes pilares.

Tabela 4.6. Variação da armadura longitudinal nos pilares.

\begin{tabular}{|c|c|c|c|c|}
\hline \multirow{2}{*}{$\begin{array}{c}\text { Número de } \\
\text { Barras }\end{array}$} & \multirow{2}{*}{$\begin{array}{c}\text { Diâmetro } \\
\text { Nominal } \\
(\mathrm{mm})\end{array}$} & \multirow{2}{*}{$\begin{array}{c}\text { Area de } \\
\text { Aço } \\
\left(\mathrm{cm}^{2}\right)\end{array}$} & \multicolumn{2}{|c|}{ Taxa Geométrica (\%) } \\
\hline & & & $\begin{array}{c}20 \times 20 \\
(\mathrm{~cm} \times \mathrm{cm})\end{array}$ & $\begin{array}{c}15 \times 30 \\
(\mathrm{~cm} \times \mathrm{cm})\end{array}$ \\
\hline \multirow{2}{*}{4} & 10,0 & 3,14 & 0,79 & 0,70 \\
\hline & 12,5 & 4,91 & 1,23 & 1,09 \\
\hline \multirow{2}{*}{5} & 10,0 & 3,93 & 0,98 & 0,87 \\
\hline & 12,5 & 6,14 & 1,53 & 1,36 \\
\hline \multirow{2}{*}{6} & 10,0 & 4,71 & 1,18 & 1,05 \\
\hline & 12,5 & 7,36 & 1,84 & 1,64 \\
\hline \multirow{2}{*}{7} & 10,0 & 5,50 & 1,38 & 1,22 \\
\hline & 12,5 & 8,59 & 2,15 & 1,91 \\
\hline \multirow{2}{*}{8} & 10,0 & 6,28 & 1,57 & 1,40 \\
\hline & 12,5 & 9,82 & 2,45 & 2,18 \\
\hline
\end{tabular}



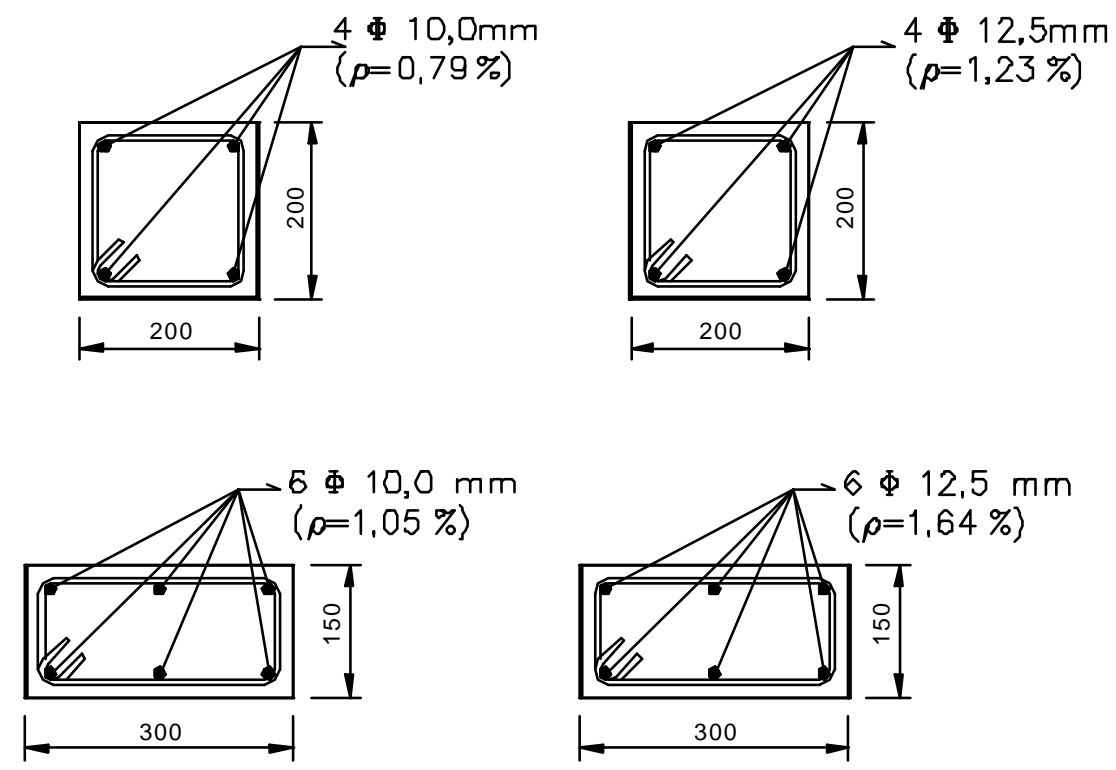

Figura 4.6. Configurações das armaduras (medidas em mm).

As configurações adotadas e descritas na figura 4.6 tiveram como objetivo definir a influência destas no comportamento de pilares executados com Concreto de Resistência Usual e solicitados à compressão axial, no que diz respeito a ductilização do pilar e a formação ou não de núcleo resistente na seção transversal.

\subsubsection{Espaçamento da Armadura Transversal}

A NBR 6118 (1978) define o espaçamento máximo entre estribos como sendo o menor dos valores entre: $30 \mathrm{~cm}$; a menor dimensão do pilar; 12 vezes o diâmetro da armadura longitudinal e 190 vezes o diâmetro do estribo elevado ao quadrado sendo, este valor, dividido pelo diâmetro da barra longitudinal.

Em função da prescrição relacionada acima, o espaçamento máximo dos estribos, o qual resulta em armadura mínima transversal, foi de $15 \mathrm{~cm}$, quando utilizado estribo com diâmetro nominal de $6,3 \mathrm{~mm}$, e $12 \mathrm{~cm}$, quando o diâmetro foi de $5,0 \mathrm{~mm}$, em ambos os pilares. Além destes valores de armadura mínima, foram propostos outros espaçamentos no intuito de verificar a ductilização do pilar e a flambagem das barras longitudinais. Com isso, para a seção quadrada, foram empregados espaçamentos de $20 \mathrm{~cm}$ e $10 \mathrm{~cm}$, enquanto que, para a seção retangular, utilizou-se espaçamentos de $7,5 \mathrm{~cm}$ e $10 \mathrm{~cm}$. 
Apesar de definido o espaçamento entre os estribos dos pilares, deve-se verificar a necessidade de estribo adicional no pilar retangular. Segundo a NBR 6118 (1978), o estribo poligonal garante contra flambagem as barras longitudinais situadas em suas quinas e as por ele abrangidas e situadas no máximo a uma distância de 20 vezes o diâmetro da armadura transversal, se nesse comprimento não houver mais de duas barras.

A figura 4.7 apresenta os espaços entre as barras longitudinais do pilar de seção retangular. Sabendo-se que o valor do espaçamento máximo entre as barras longitudinais $(12,25 \mathrm{~cm})$ é praticamente igual ao valor limite para a não utilização do estribo adicional (12,60cm para estribo de diâmetro de 6,3mm), então, não haveria necessidade do emprego deste estribo. No entanto, como estes valores estão muito próximos, foram sugeridos modelos de pilares com e sem estribos adicionais para que, devidamente instrumentados, fossem verificadas suas influências em fenômenos como a ductilidade e a flambagem das barras longitudinais dos pilares. Assim, foi utilizado estribo adicional em forma de barra reta com gancho nas extremidades, ou então, a armadura transversal do pilar foi composta por dois estribos principais, conforme mostrado na figura 4.8.

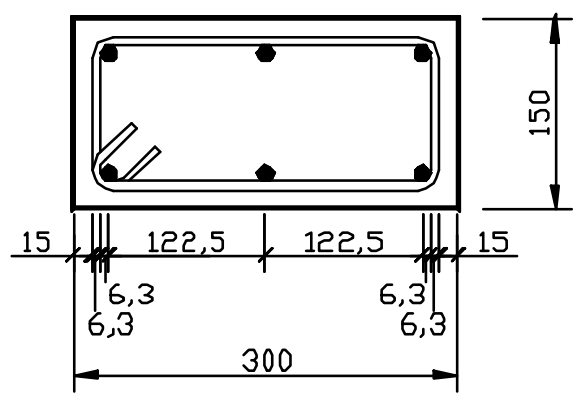

Figura 4.7. Espaços entre as barras longitudinais (medidas em $\mathrm{mm}$ ).

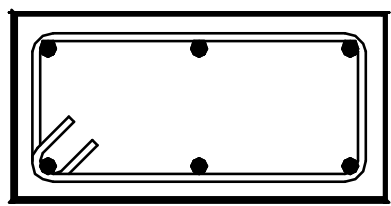

PILAR COM ESTRIBO SIMPLES

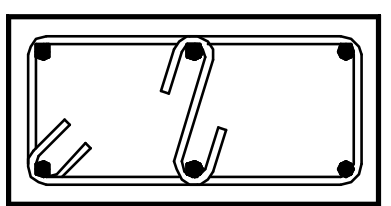

PILAR COM ESTRIBO ADICIONAL

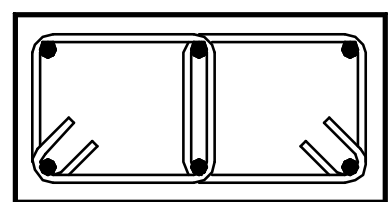

PILAR COM DOIS ESTRIBOS PRINCIPAIS

Figura 4.8. Configurações da armadura transversal. 


\subsubsection{Armadura de Fretagem}

A descontinuidade de tensões junto do ponto de aplicação da força de compressão nos pilares, prevista pelo princípio de Saint-Venant, poderia provocar a ruína prematura dos pilares por efeito de ponta das barras longitudinais. Desta forma, as extremidades dos modelos receberam uma armadura de fretagem de diâmetro de 6,3mm, como pode ser visto na figura 4.9. Com isso, esperava-se que os pilares rompessem na região média da altura dos modelos em função da deformação do concreto e, por conseguinte, perda de capacidade resistente.

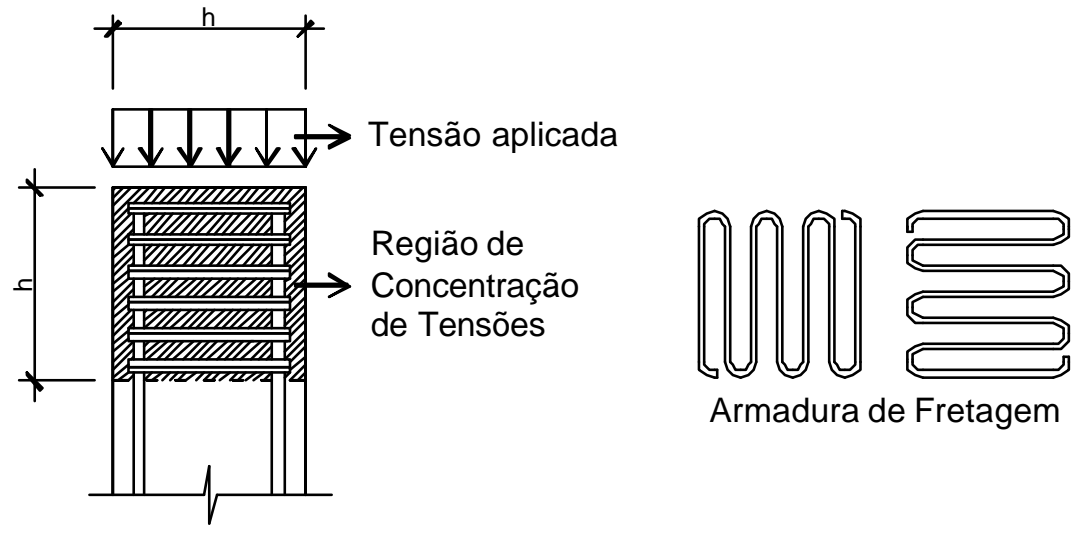

Figura 4.9. Armadura de fretagem nas extremidades dos pilares.

\subsubsection{Detalhamento das Armaduras}

Os detalhamentos das armaduras dos modelos de pilares são apresentados nas figuras 4.10 a 4.25 e tabela 4.7. A identificação dos pilares foi feita com a letra $\mathrm{P}$ seguida de um número que está relacionado aos modelos com mesma configuração da armadura transversal. Além disso, foram utilizados dois números separados por hífen que correspondem, respectivamente, ao diâmetro nominal das barras longitudinais e ao espaçamento da armadura transversal, ambos em milímetros. Algo que pode chamar atenção neste detalhamento é o comprimento dos ganchos dos estribos. Apesar da NBR 6118 (1978) prescrever um valor mínimo de 5 vezes o diâmetro da armadura transversal, ou seja, $25 \mathrm{~mm}$ e $31,5 \mathrm{~mm}$ para barras de 5,0mm e 6,3mm, respectivamente, foi utilizado um tamanho maior e único de $80 \mathrm{~mm}$. A função desta medida foi evitar que as solicitações nos estribos causassem seu escorregamento dentro do concreto. Com isso, eliminou-se a consideração desta variável no momento da análise dos resultados dos ensaios. 

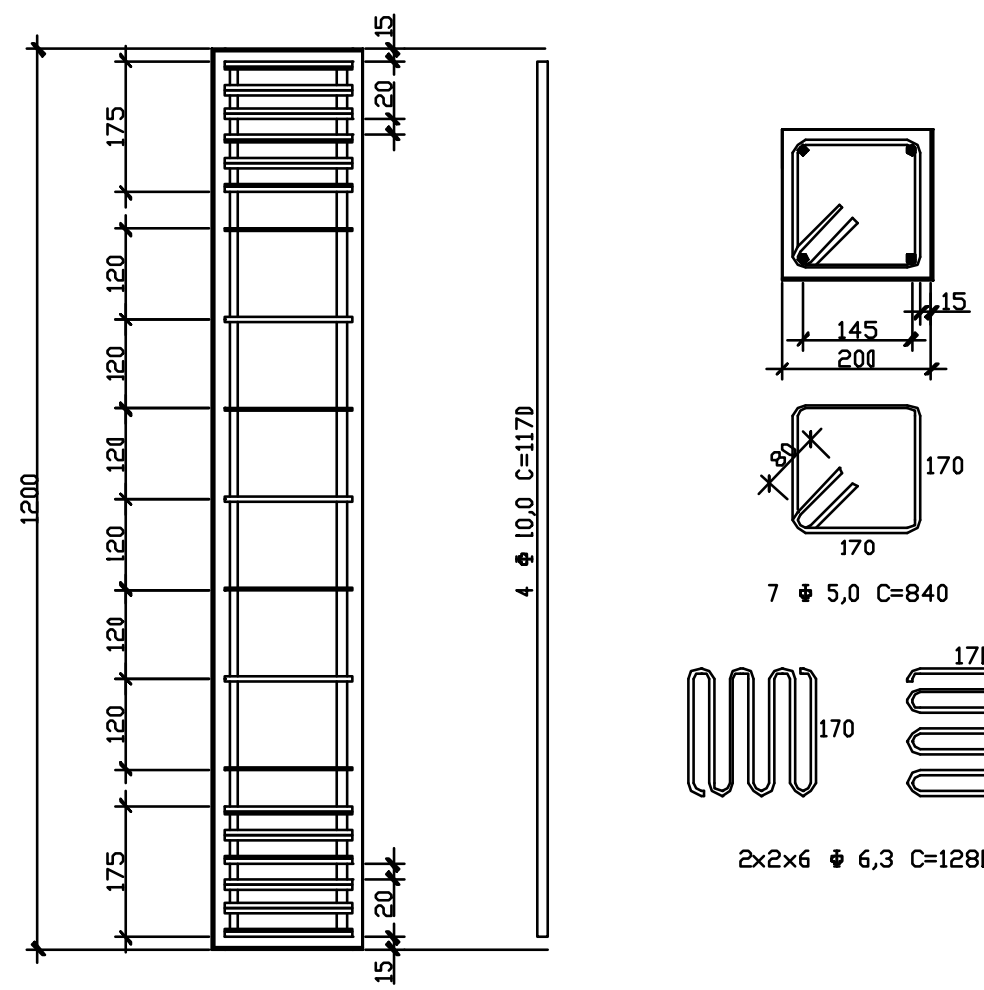

7 \$ $5,0 \quad C=840$

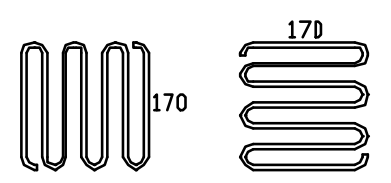

$2 \times 2 \times 6 \quad 6,3 \quad C=1280$

Figura 4.10. Detalhamento da armadura do pilar P1-10,0-120.
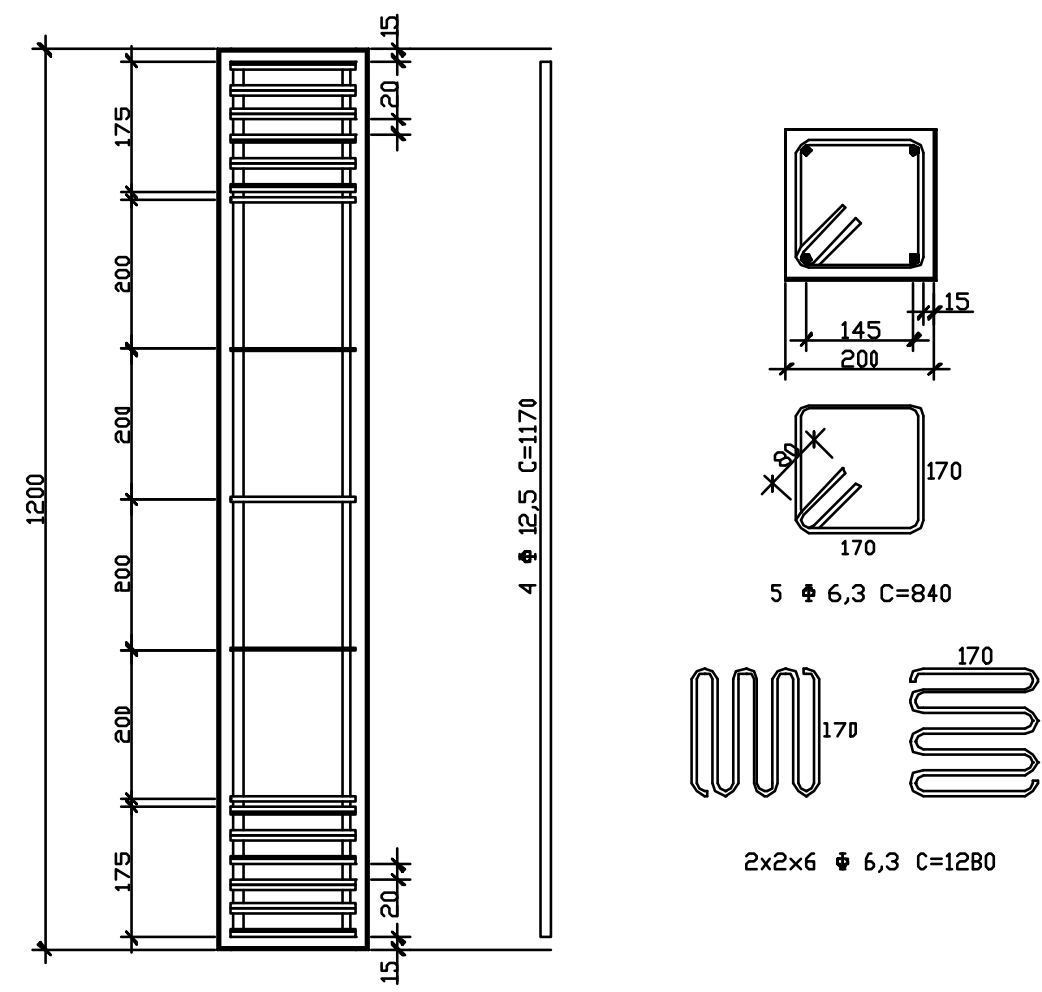

$2 \times 2 \times 6 \quad \$ 6,3 \quad C=12 B 0$

Figura 4.11. Detalhamento da armadura do pilar P1-12,5-200. 

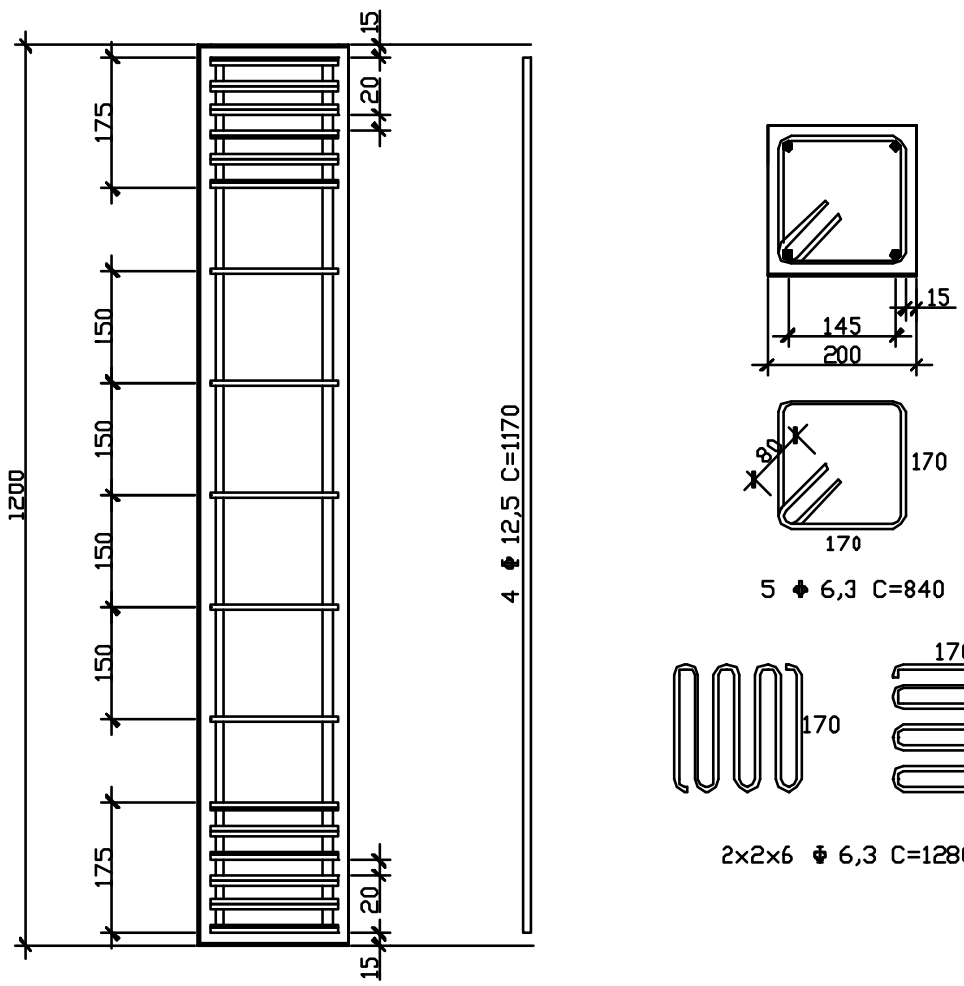

$5+6,3 \quad C=840$

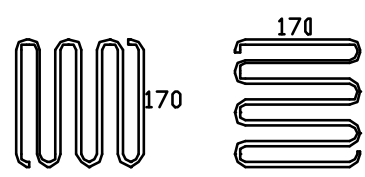

$2 \times 2 \times 6 \Phi 6,3 C=1280$

Figura 4.12. Detalhamento da armadura do pilar P1-12,5-150.
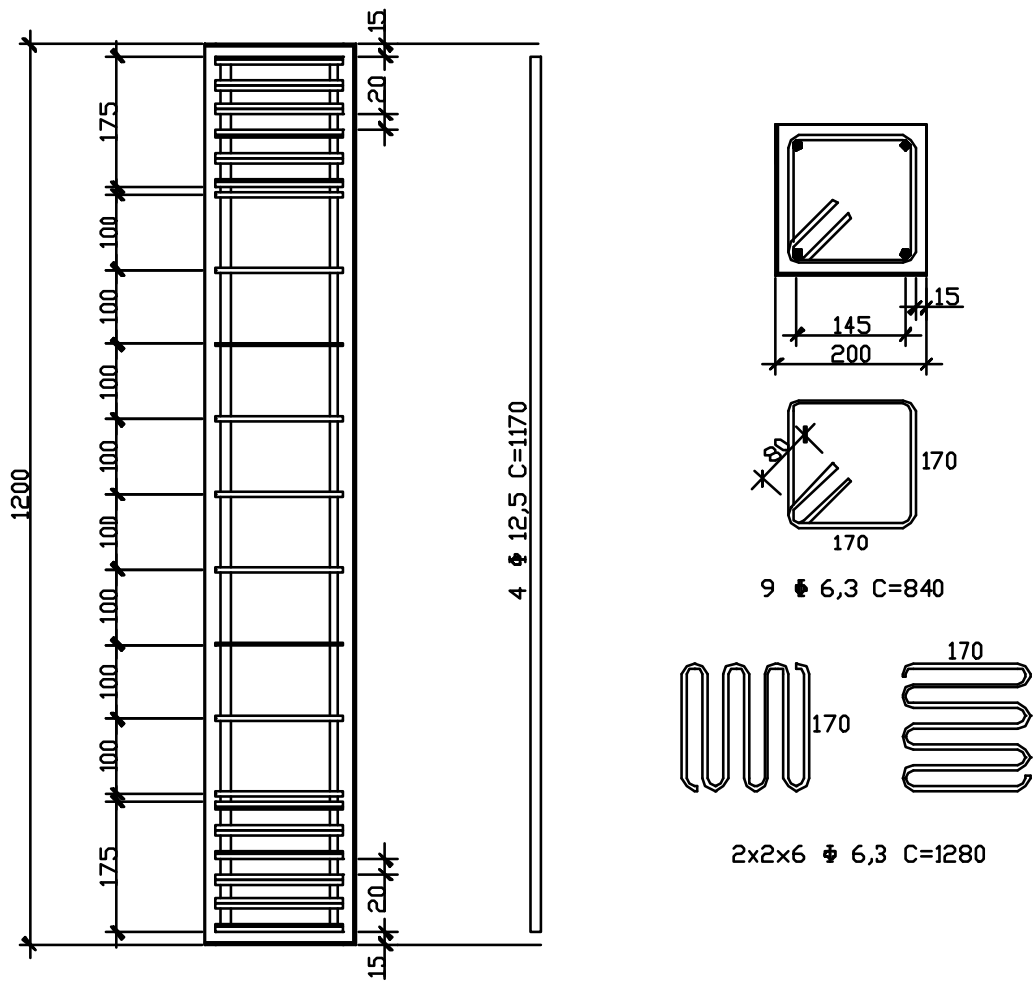

$2 \times 2 \times 6 \quad 6,3 \quad C=1280$

Figura 4.13. Detalhamento da armadura do pilar P1-12,5-100. 

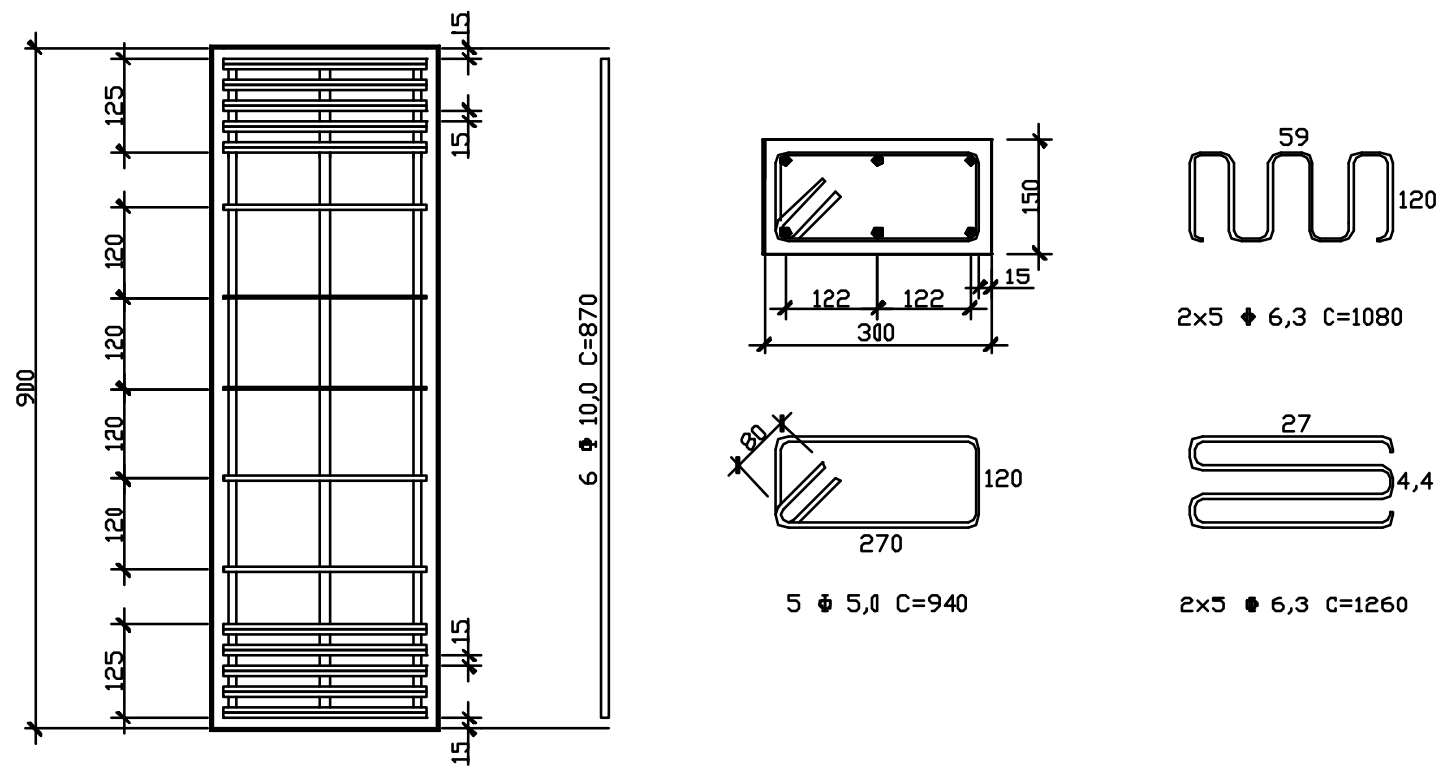

$2 \times 5+6,3 \quad C=1080$

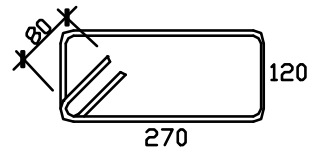

27

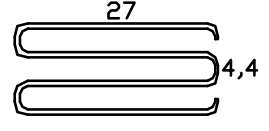

5 Ф $5,0 \quad C=940$

$2 \times 5 \cdot 6,3 \quad c=1260$

Figura 4.14. Detalhamento da armadura do pilar P2-10,0-120.
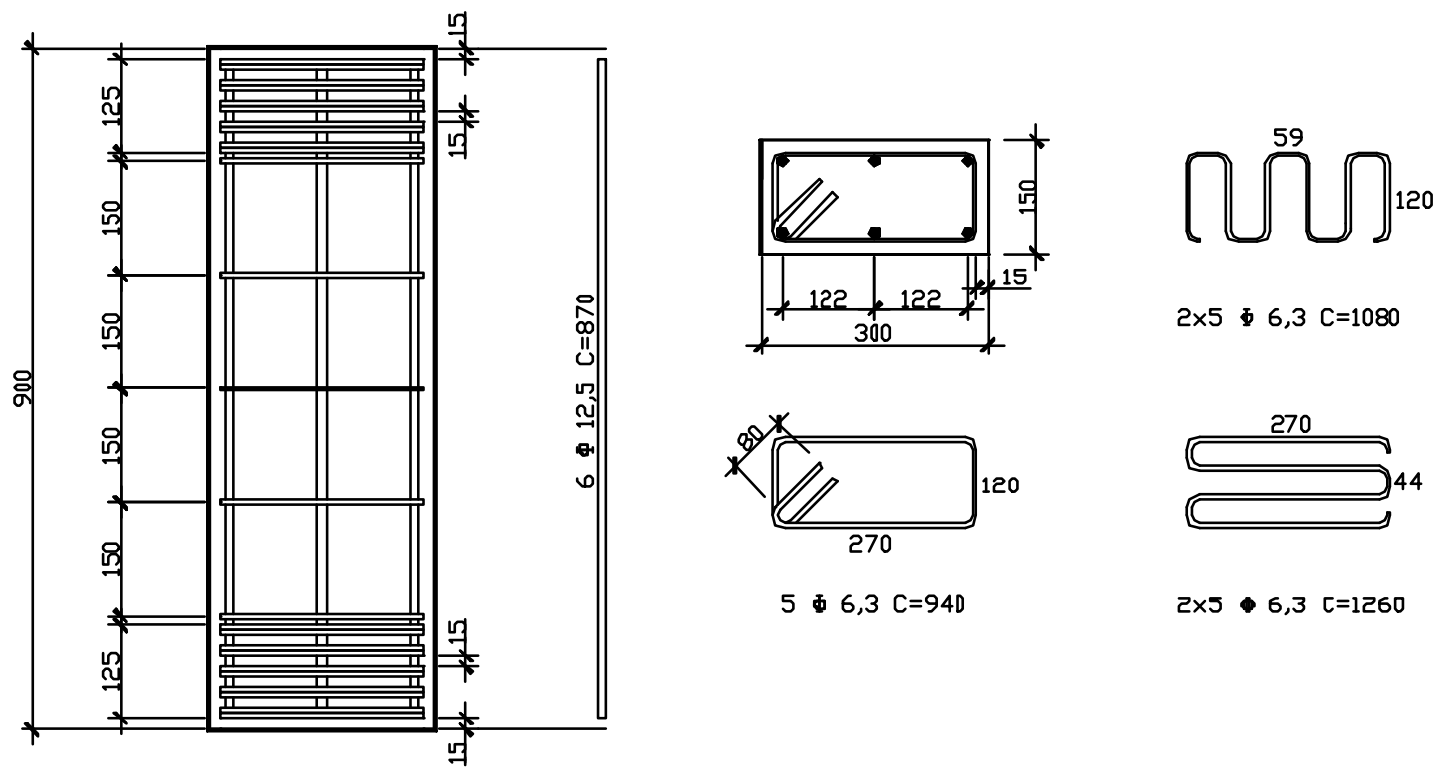

$2 \times 5 \quad 6,3 \quad C=1080$

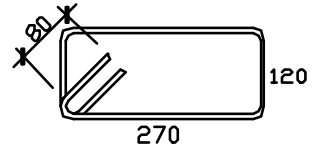

270

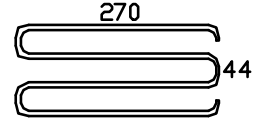

$5 \Phi 6,3 C=940$

$2 \times 5 \bullet 6,3 \quad c=1260$

Figura 4.15. Detalhamento da armadura do pilar P2-12,5-150. 

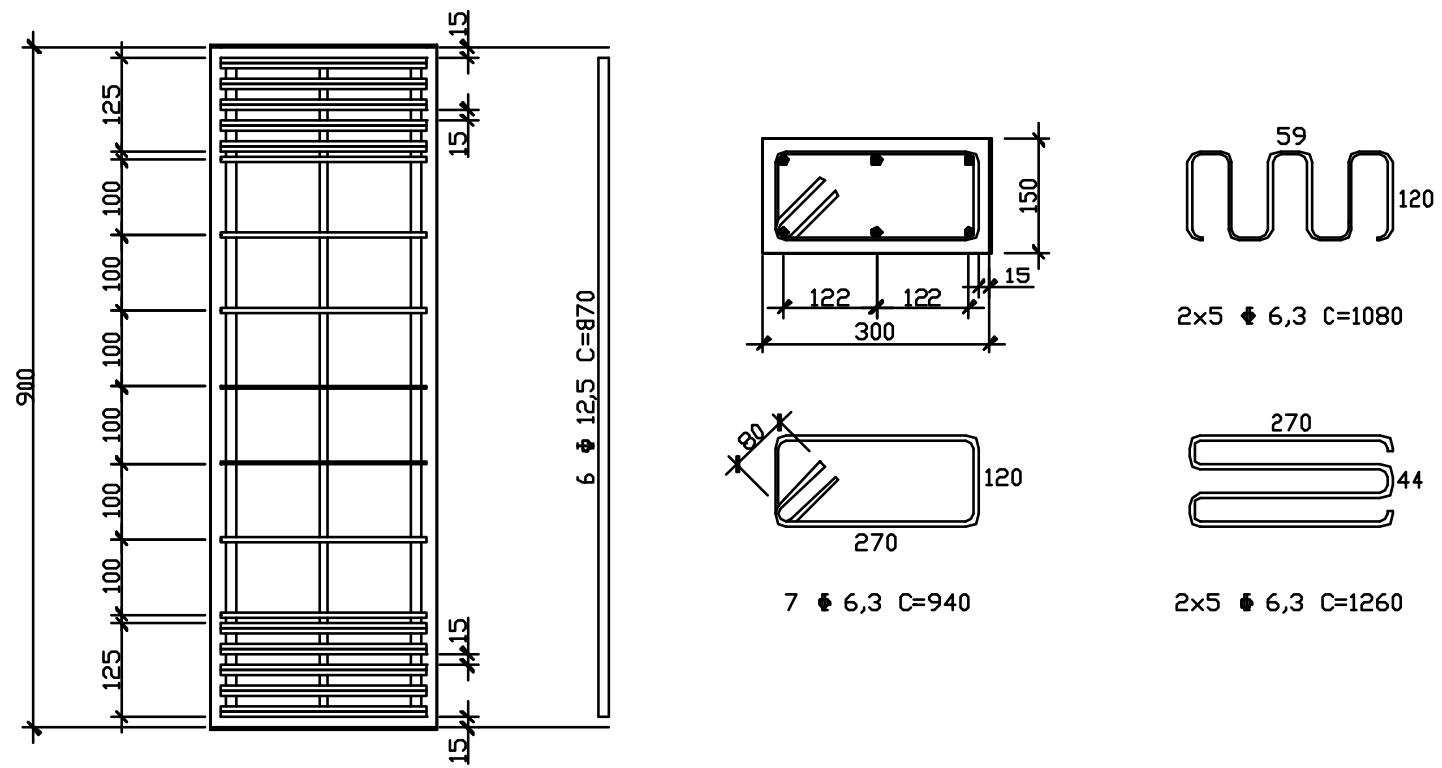

$7 \quad 6,3 \quad C=940$

$2 \times 5-6,3 \quad C=1260$

Figura 4.16. Detalhamento da armadura do pilar P2-12,5-100.
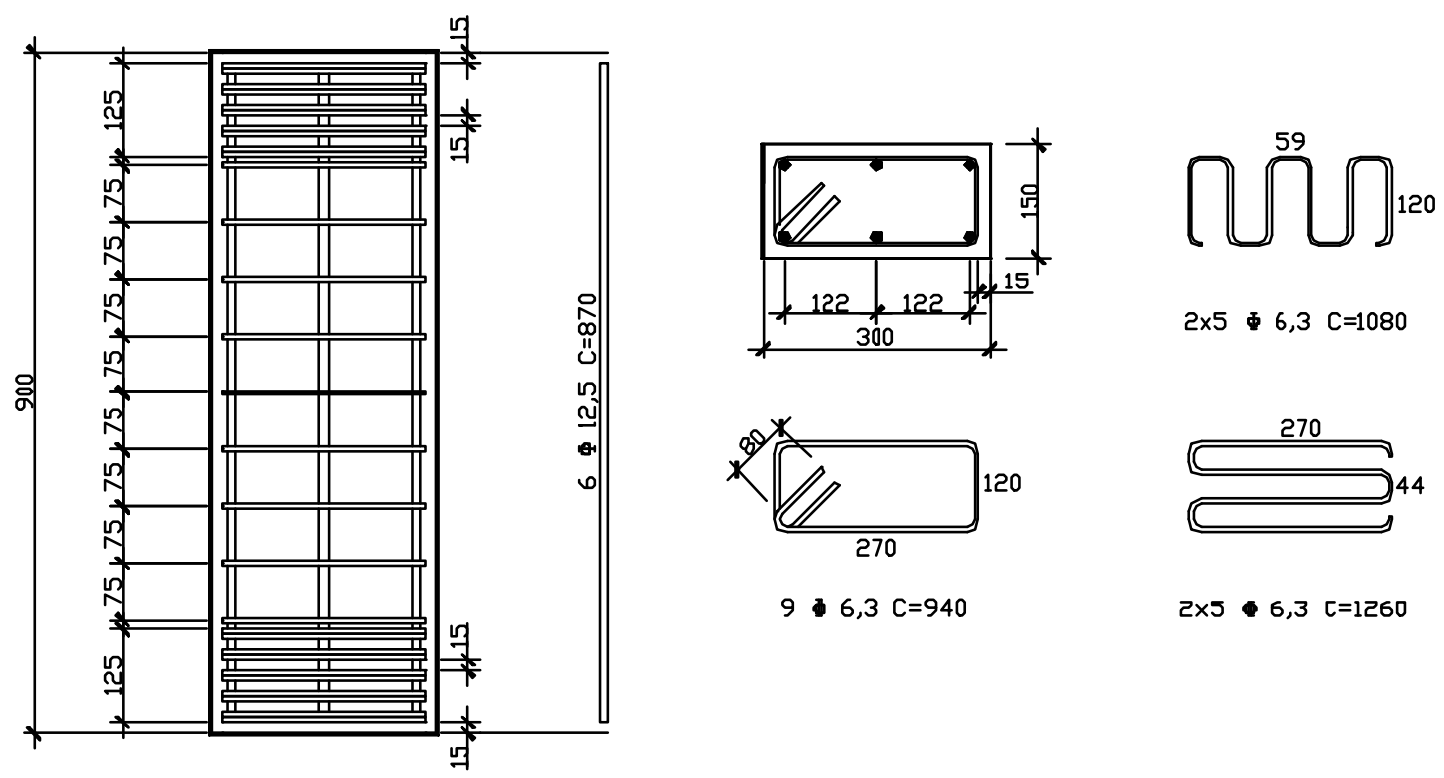

$2 \times 5$ 甲 $6,3 C=1080$

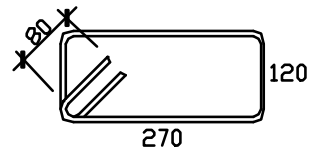

270

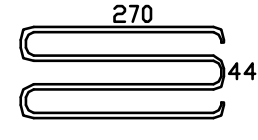

$96,3 \quad C=940$

$2 \times 5 \cdot 6,3 \quad c=1260$

Figura 4.17. Detalhamento da armadura do pilar P2-12,5-75. 

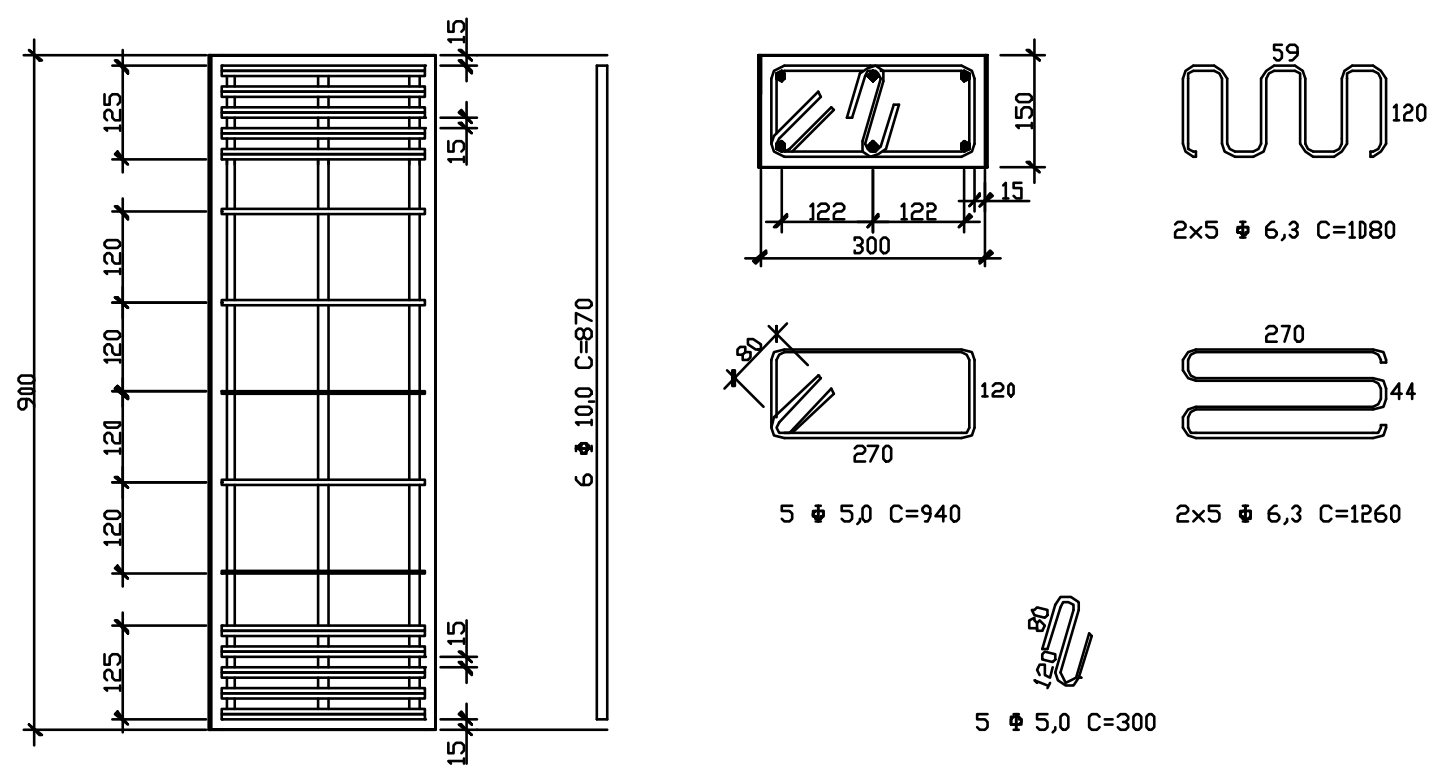

$2 \times 5 \Phi 6,3 \quad C=1260$

Figura 4.18. Detalhamento da armadura do pilar P3-10,0-120.
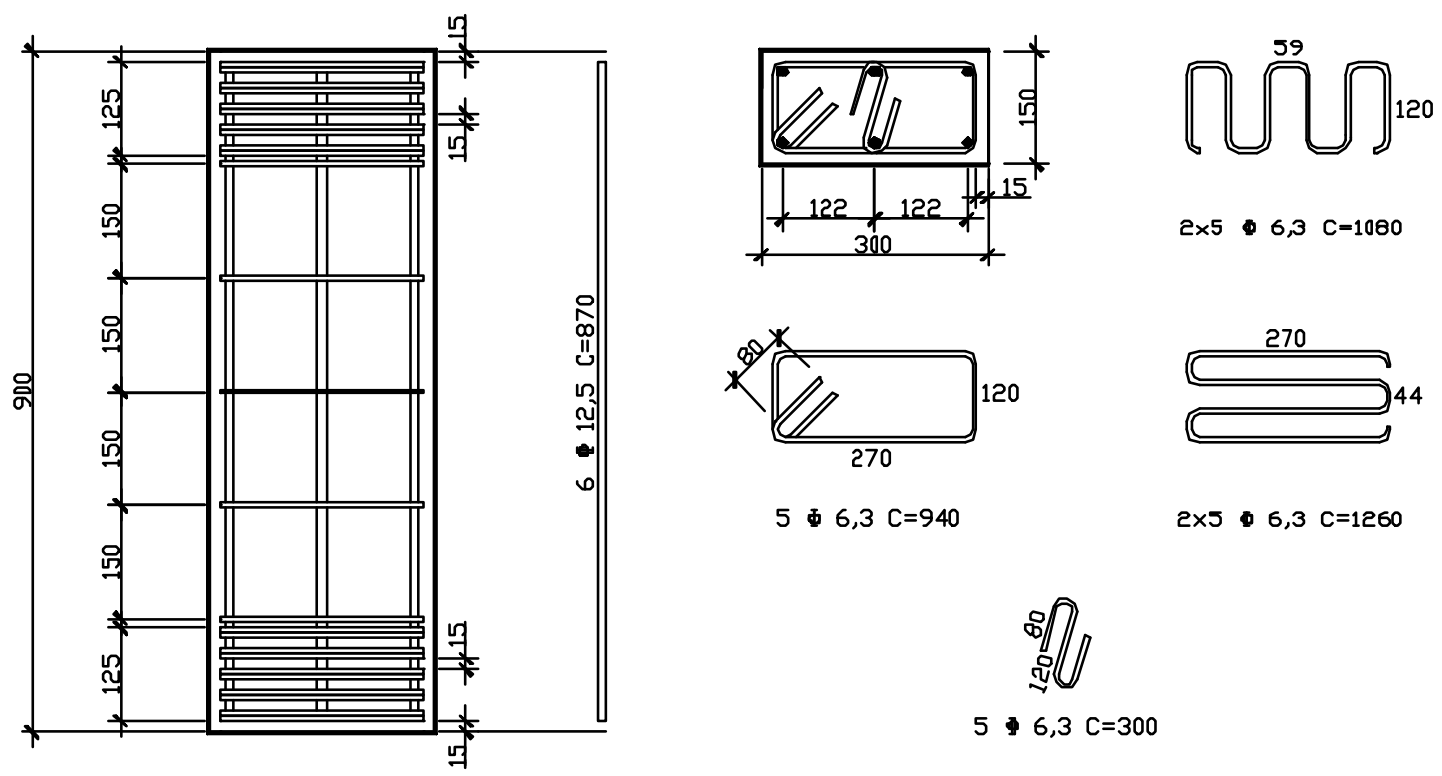

$5 \Phi 6,3 C=940$ $2 \times 5 \bullet 6,3 C=1260$

Figura 4.19. Detalhamento da armadura do pilar P3-12,5-150. 

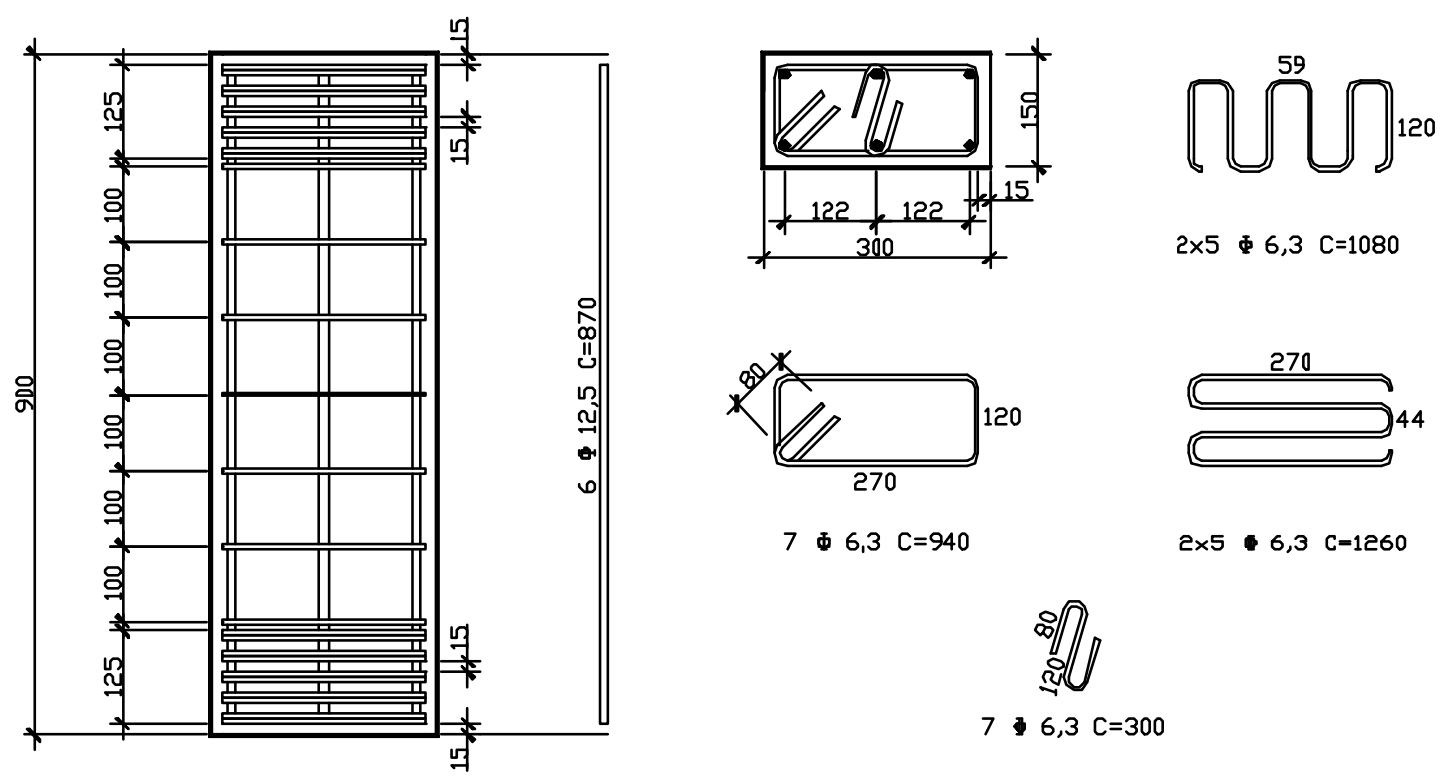

$2 \times 5 \quad \Phi 6,3 \quad C=1080$

Figura 4.20. Detalhamento da armadura do pilar P3-12,5-100.
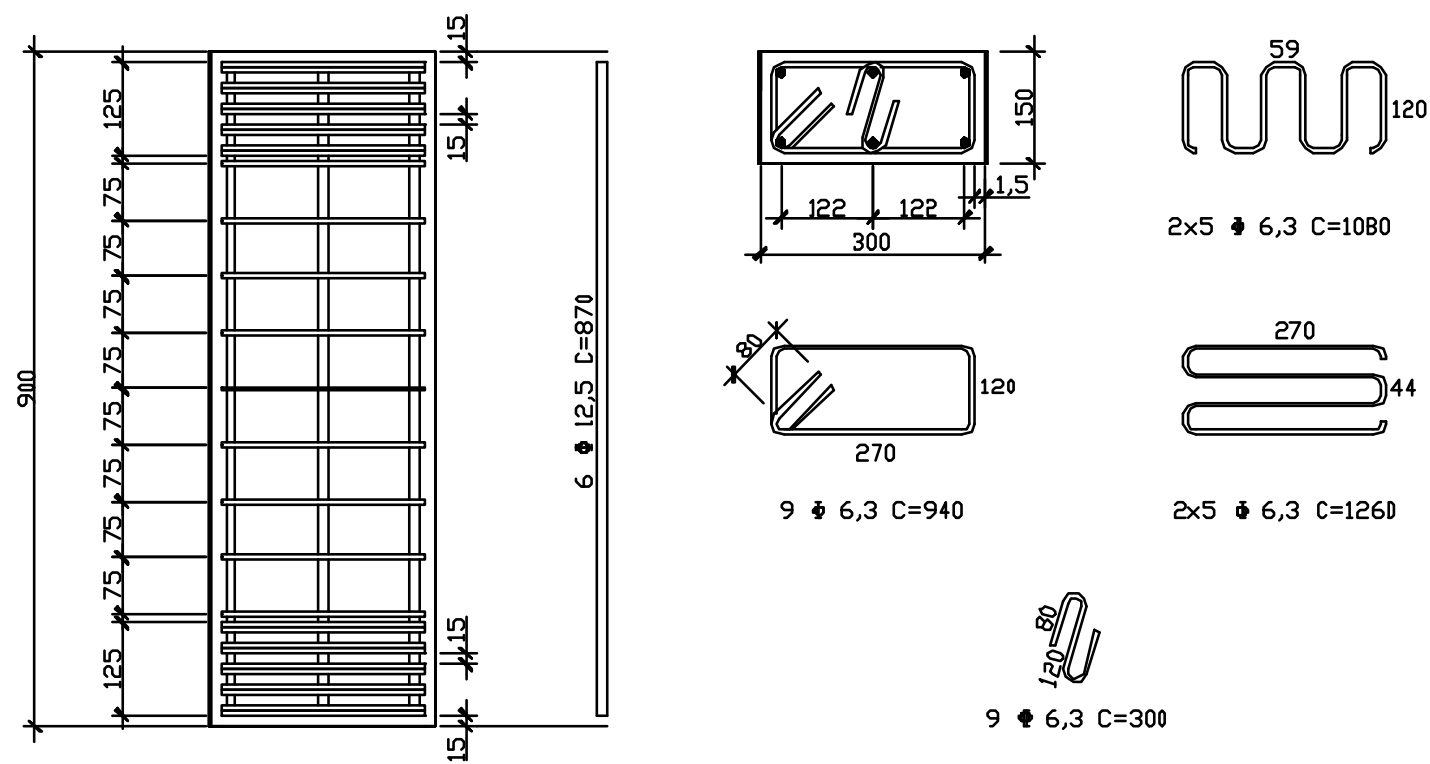

9 \$ $6,3 C=940$

$2 \times 5 \$ 6,3 \quad C=1260$

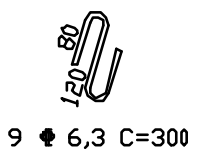

Figura 4.21. Detalhamento da armadura do pilar P3-12,5-75. 

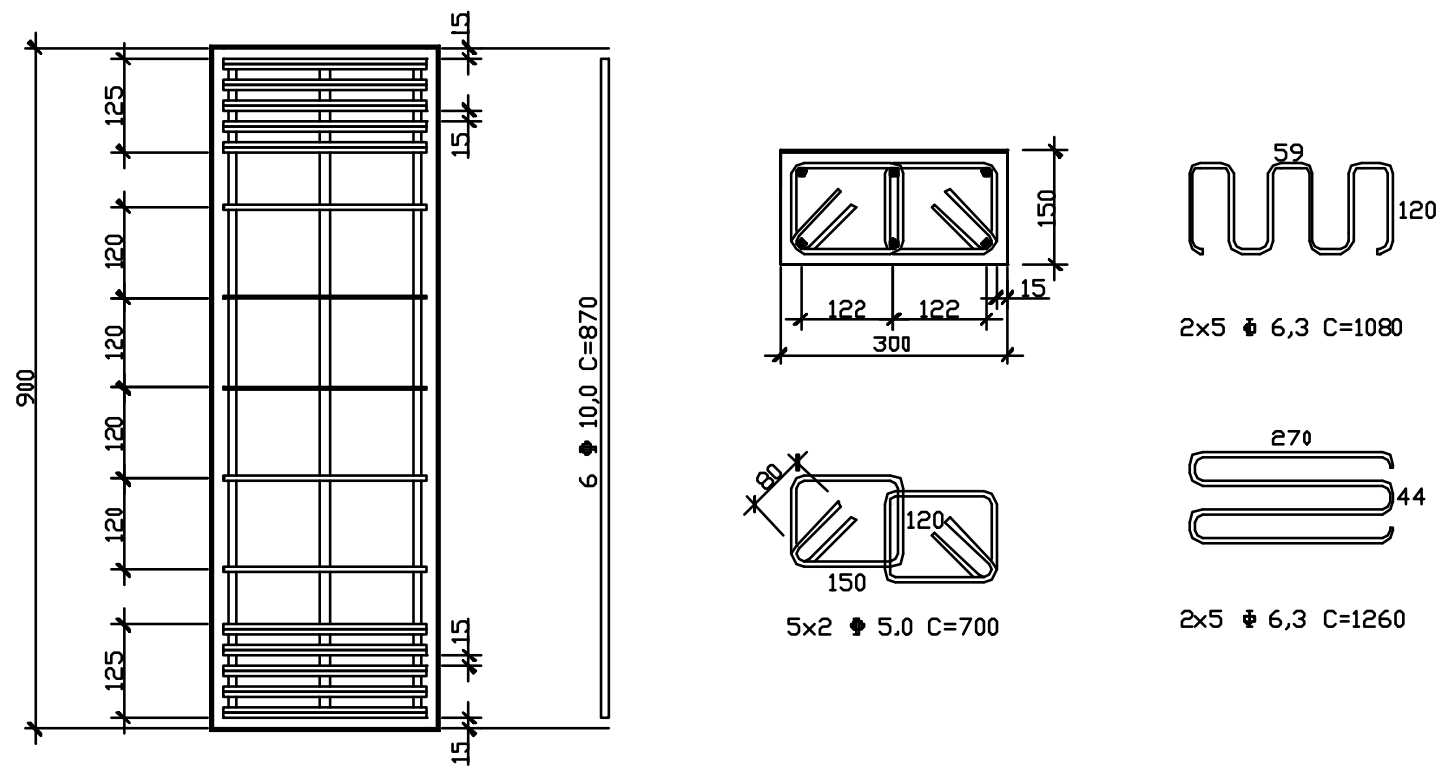

$2 \times 5 \Phi 6,3 \quad C=1260$

Figura 4.22. Detalhamento da armadura do pilar P4-10,0-120.
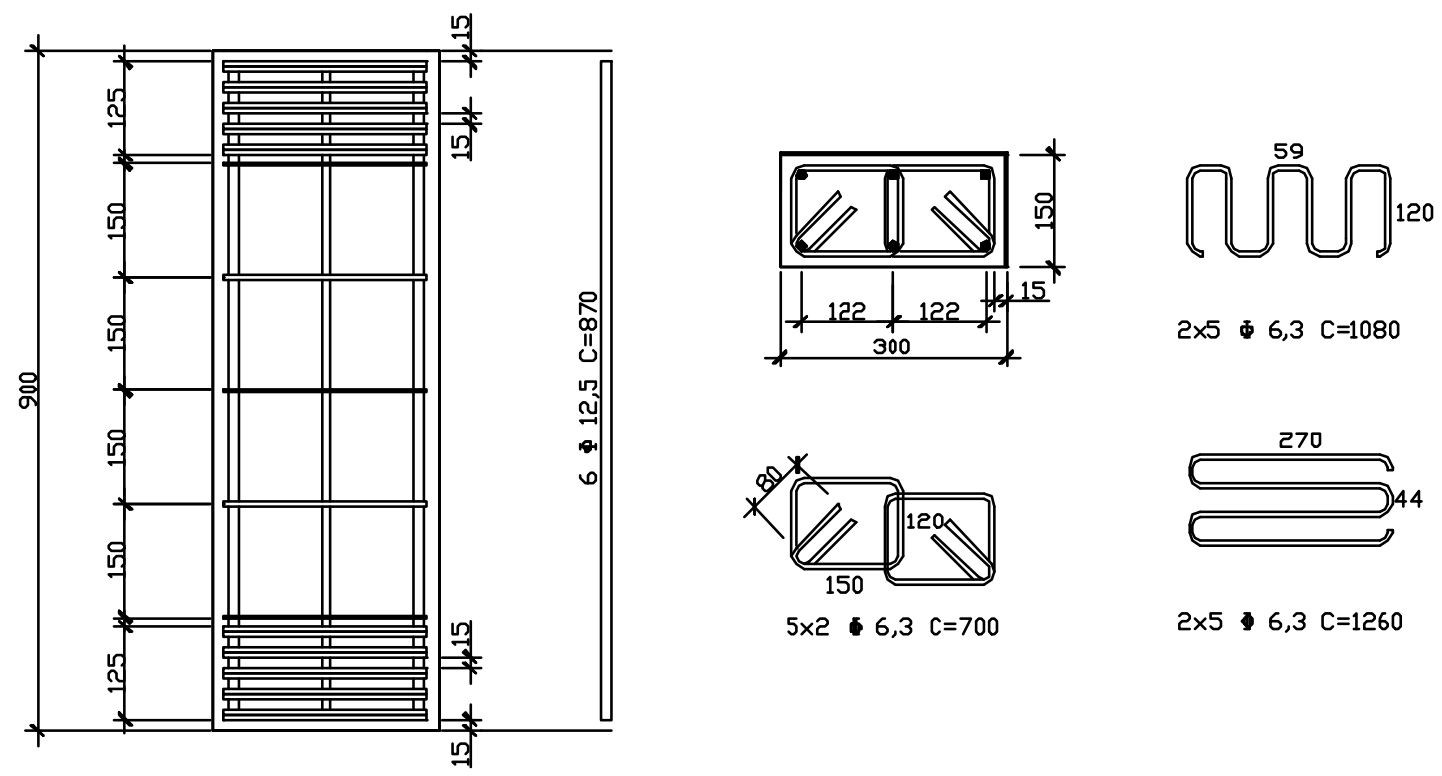

Figura 4.23. Detalhamento da armadura do pilar P4-12,5-150. 

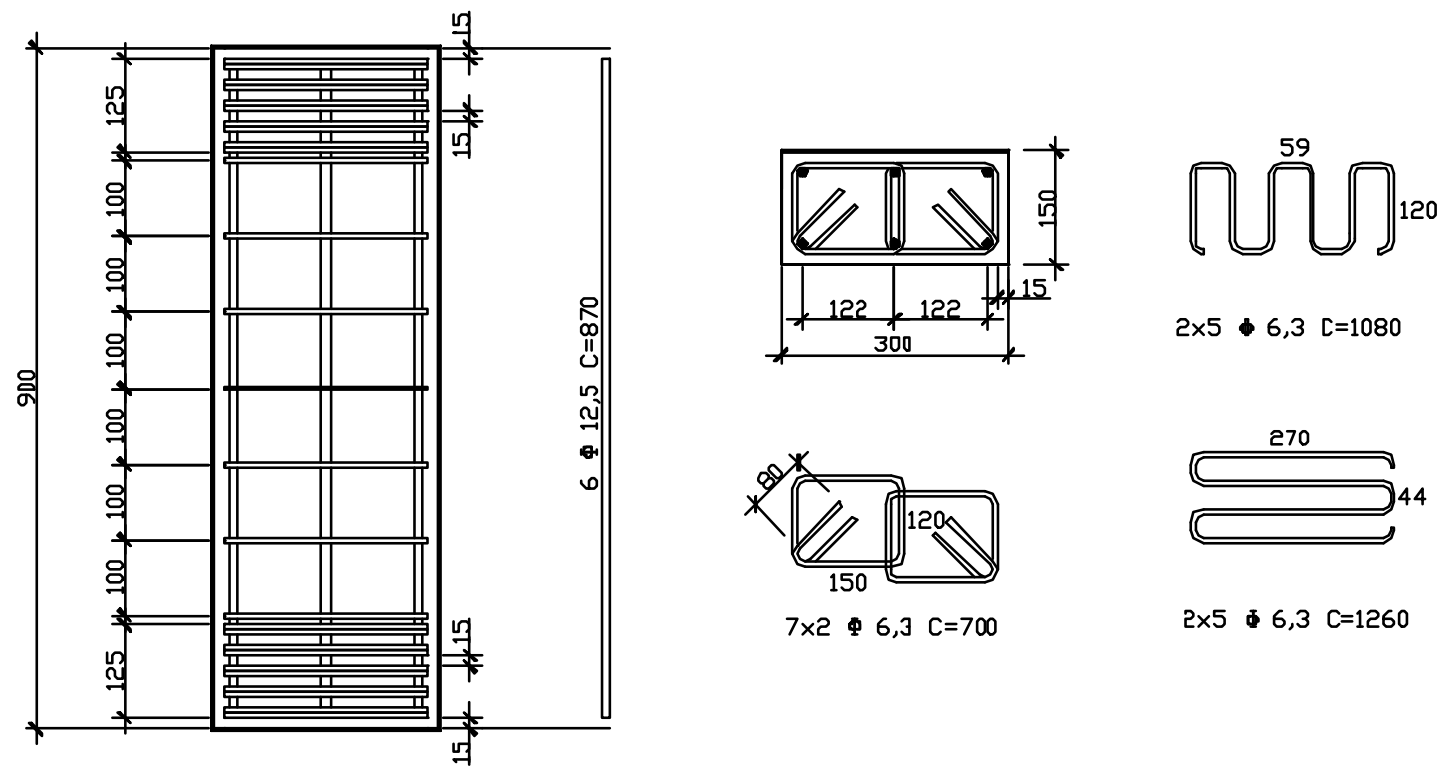

$2 \times 5 \Phi 6,3 \mathrm{C}=1260$

Figura 4.24. Detalhamento da armadura do pilar P4-12,5-100.
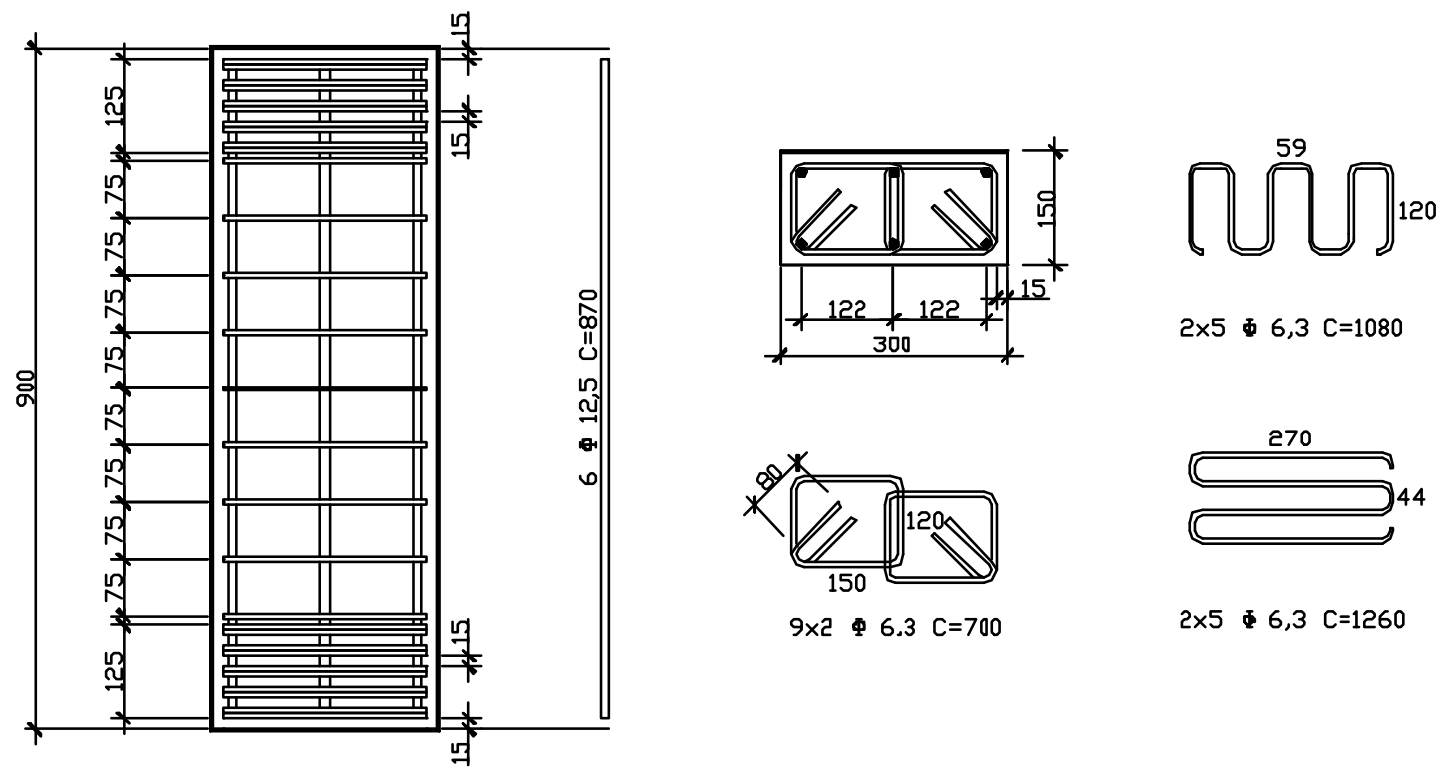

$2 \times 5$ Ф $6,3 \mathrm{C}=1080$
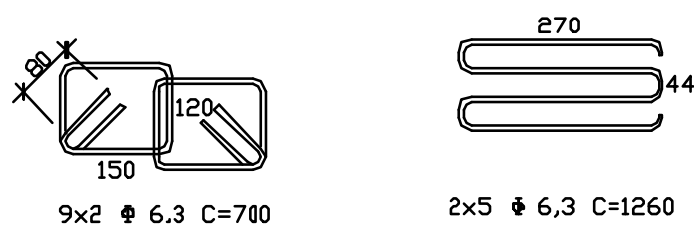

$2 \times 5$ I $6,3 \mathrm{C}=1260$

Figura 4.25. Detalhamento da armadura do pilar P4-12,5-75. 
Tabela 4.7. Características geométricas dos modelos de pilares.

\begin{tabular}{|c|c|c|c|c|c|c|c|}
\hline \multirow[b]{2}{*}{$\begin{array}{c}\text { Modelo } \\
\text { de } \\
\text { Pilar }\end{array}$} & \multirow[b]{2}{*}{$\begin{array}{l}\text { Medidas } \\
\text { da seção } \\
(\mathrm{mm} \times \mathrm{mm})\end{array}$} & \multicolumn{3}{|c|}{ Armadura Transversal } & \multicolumn{3}{|c|}{ Armadura Longitudinal } \\
\hline & & $\begin{array}{l}\text { Diâm. } \\
(\mathrm{mm})\end{array}$ & $\begin{array}{c}\text { Espaç. } \\
(\mathrm{mm})\end{array}$ & $\begin{array}{c}\text { Taxa } \\
\text { Volum. } \\
(\%)\end{array}$ & $\begin{array}{c}\text { Número } \\
\text { de } \\
\text { Barras }\end{array}$ & $\begin{array}{l}\text { Diâm. } \\
(\mathrm{mm})\end{array}$ & $\begin{array}{c}\text { Taxa } \\
\text { Geom. } \\
(\%)\end{array}$ \\
\hline $\mathrm{P} 1-10,0-120$ & $200 \times 200$ & 5,0 & 120 & 0,27 & 4 & 10,0 & 0,79 \\
\hline P1-12,5-200 & $200 \times 200$ & 6,3 & 200 & 0,26 & 4 & 12,5 & 1,23 \\
\hline P1-12,5-150 & $200 \times 200$ & 6,3 & 150 & 0,34 & 4 & 12,5 & 1,23 \\
\hline $\mathrm{P} 1-12,5-100$ & $200 \times 200$ & 6,3 & 100 & 0,51 & 4 & 12,5 & 1,23 \\
\hline P2-10,0-120 & $150 \times 300$ & 5,0 & 120 & 0,28 & 6 & 10,0 & 1,05 \\
\hline P2-12,5-150 & $150 \times 300$ & 6,3 & 150 & 0,35 & 6 & 12,5 & 1,64 \\
\hline P2-12,5-100 & $150 \times 300$ & 6,3 & 100 & 0,52 & 6 & 12,5 & 1,64 \\
\hline$P 2-12,5-75$ & $150 \times 300$ & 6,3 & 75 & 0,70 & 6 & 12,5 & 1,64 \\
\hline P3-10,0-120 & $150 \times 300$ & 5,0 & 120 & 0,32 & 6 & 10,0 & 1,05 \\
\hline P3-12,5-150 & $150 \times 300$ & 6,3 & 150 & 0,40 & 6 & 12,5 & 1,64 \\
\hline P3-12,5-100 & $150 \times 300$ & 6,3 & 100 & 0,60 & 6 & 12,5 & 1,64 \\
\hline P3-12,5-75 & $150 \times 300$ & 6,3 & 75 & 0,80 & 6 & 12,5 & 1,64 \\
\hline P4-10,0-120 & $150 \times 300$ & 5,0 & 120 & 0,36 & 6 & 10,0 & 1,05 \\
\hline P4-12,5-150 & $150 \times 300$ & 6,3 & 150 & 0,45 & 6 & 12,5 & 1,64 \\
\hline P4-12,5-100 & $150 \times 300$ & 6,3 & 100 & 0,68 & 6 & 12,5 & 1,64 \\
\hline P4-12,5-75 & $150 \times 300$ & 6,3 & 75 & 0,91 & 6 & 12,5 & 1,64 \\
\hline
\end{tabular}

\subsubsection{Previsão para Força Última}

Com base na NBR 6118 (1978), foram feitas as previsões das forças últimas dos modelos sem a consideração dos efeitos de segunda ordem (deformações e excentricidades acidentais), pois as forças eram supostas centradas e os índices de esbeltezas $(\lambda)$ menores ou iguais a 40 . Além disso, considerou-se o domínio de deformação descrito pela reta $b$ (ruptura do concreto por compressão uniforme com deformação de $2 \mathrm{~mm} / \mathrm{m}$ ), e o coeficiente de modificação $k_{\text {mod }}$, que correlaciona a resistência à compressão do concreto nos modelo s com aquela ocorrida nos corpos-de-prova, igual a 0,95. O cálculo foi feito levando em conta a seção íntegra (sem perda de cobrimento) $-F_{\text {teór }}$ - e para quando a região delimitada pelos eixos dos estribos define o núcleo resistente na seção transversal - $F_{\text {teór,n. }}$ A tabela 4.8 traz os resultados para a previsão da força última dos pilares. É importante dizer 
que os dados desta tabela, referentes à resistência média à compressão do concreto e à tensão na armadura longitudinal correspondente à deformação de $2 \mathrm{~mm} / \mathrm{m}$, foram obtidos a partir dos estudos de dosagem e caracterização dos materiais.

Tabela 4.8. Previsão da força de ruína dos pilares.

\begin{tabular}{|c|c|c|c|c|c|c|c|c|c|c|}
\hline $\begin{array}{c}\text { Modelo } \\
\text { de } \\
\text { Pilar }\end{array}$ & $\begin{array}{c}b \\
(\mathrm{~cm})\end{array}$ & $\begin{array}{c}\mathrm{h} \\
(\mathrm{cm})\end{array}$ & $\begin{array}{c}A_{c} \\
\left(\mathrm{~cm}^{2}\right)\end{array}$ & $\begin{array}{c}A_{c n} \\
\left(\mathrm{~cm}^{2}\right)\end{array}$ & $\begin{array}{c}\bar{f}_{c, 14} \\
\text { (MPa) }\end{array}$ & $\begin{array}{l}f_{c, p i l a r} \\
\text { (MPa) }\end{array}$ & $\begin{array}{c}A_{s}^{\prime} \\
\left(\mathbf{c m}^{2}\right)\end{array}$ & $\begin{array}{c}\sigma_{s, 2} \\
(\mathrm{MPa})\end{array}$ & $\begin{array}{l}F_{\text {teór }} \\
(\mathrm{kN})\end{array}$ & $\begin{array}{r}F_{\text {teór,r }} \\
(k N)\end{array}$ \\
\hline $\mathrm{P} 1-10,0-120$ & 20 & 20 & 400 & 272,2 & 25,7 & 24,4 & 3,12 & 410 & 1097 & 785 \\
\hline P1-12,5-200 & 20 & 20 & 400 & 268,0 & 25,7 & 24,4 & 4,78 & 395 & 1154 & 831 \\
\hline P1-12,5-150 & 20 & 20 & 400 & 268,0 & 25,7 & 24,4 & 4,78 & 395 & 1154 & 831 \\
\hline P1-12,5-100 & 20 & 20 & 400 & 268,0 & 25,7 & 24,4 & 4,78 & 395 & 1154 & 831 \\
\hline P2-10,0-120 & 15 & 30 & 450 & 304,7 & 25,7 & 24,4 & 4,69 & 410 & 1279 & 925 \\
\hline$P 2-12,5-150$ & 15 & 30 & 450 & 299,8 & 25,7 & 24,4 & 7,17 & 395 & 1364 & 998 \\
\hline P2-12,5-100 & 15 & 30 & 450 & 299,8 & 25,7 & 24,4 & 7,17 & 395 & 1364 & 998 \\
\hline P2-12,5-75 & 15 & 30 & 450 & 299,8 & 25,7 & 24,4 & 7,17 & 395 & 1364 & 998 \\
\hline P3-10,0-120 & 15 & 30 & 450 & 304,7 & 25,7 & 24,4 & 4,69 & 410 & 1279 & 925 \\
\hline P3-12,5-150 & 15 & 30 & 450 & 299,8 & 25,7 & 24,4 & 7,17 & 395 & 1364 & 998 \\
\hline P3-12,5-100 & 15 & 30 & 450 & 299,8 & 25,7 & 24,4 & 7,17 & 395 & 1364 & 998 \\
\hline P3-12,5-75 & 15 & 30 & 450 & 299,8 & 25,7 & 24,4 & 7,17 & 395 & 1364 & 998 \\
\hline P4-10,0-120 & 15 & 30 & 450 & 304,7 & 25,7 & 24,4 & 4,69 & 410 & 1279 & 925 \\
\hline P4-12,5-150 & 15 & 30 & 450 & 299,8 & 25,7 & 24,4 & 7,17 & 395 & 1364 & 998 \\
\hline P4-12,5-100 & 15 & 30 & 450 & 299,8 & 25,7 & 24,4 & 7,17 & 395 & 1364 & 998 \\
\hline P4-12,5-75 & 15 & 30 & 450 & 299,8 & 25,7 & 24,4 & 7,17 & 395 & 1364 & 998 \\
\hline
\end{tabular}

\subsubsection{Medida das Deformações}

a) Nas armaduras

A medida das deformações nas armaduras dos pilares foi feita por meio de extensômetros elétricos fixados nas barras longitudinais e transversais da seção média dos modelos. Nas figuras 4.26 e 4.27, apresentam-se os desenhos referentes àinstrumentação das armaduras. 


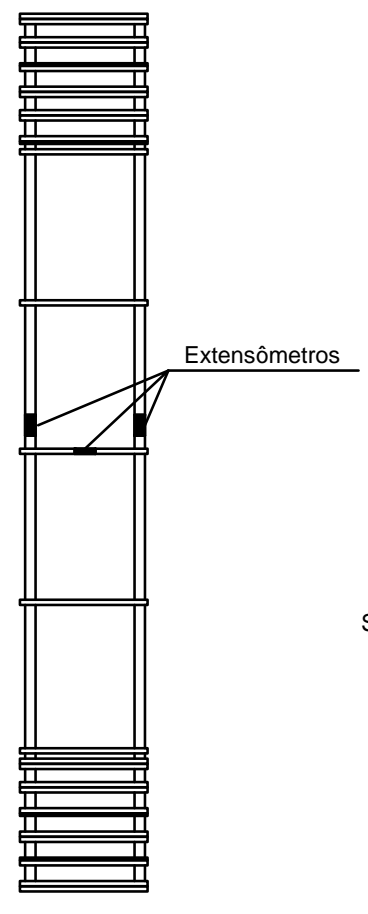

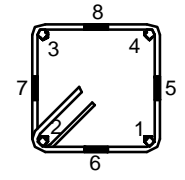

SEÇÃO TRANSVERSAL
Extensômetros de 1 a 4 - Armadura Longitudinal

Extensômetros de 5 a 8 - Armadura Transversal

VISTA LATERAL

Figura 4.26. Instrumentação empregada nas armaduras dos modelos de seção quadrada.

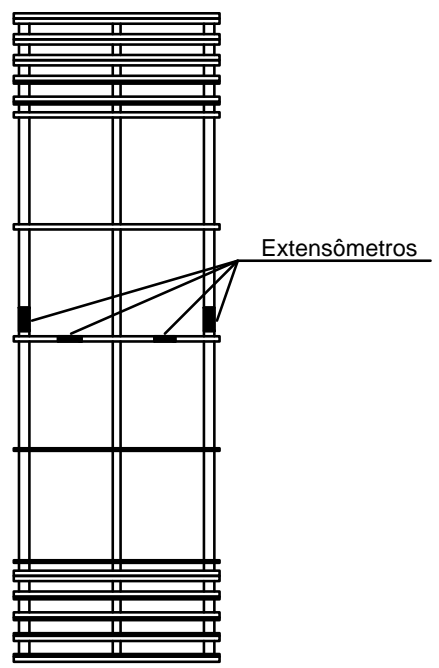

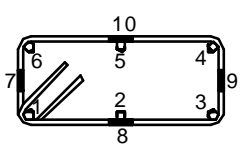

SEÇÃO TRANSVERSAL

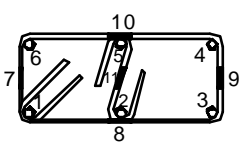

SEÇÃO TRANSVERSAL

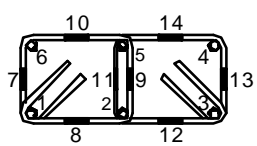

SEÇÃO TRANSVERSAL
Extensômetros de 1 a 6 - Armadura Longitudinal Extensômetros de 7 a 10 - Armadura Transversal

INSTRUMENTAÇÃO

Extensômetros de 1 a 6 - Armadura Longitudinal Extensômetros de 7 a 11 - Armadura Transversal

INSTRUMENTAÇÃO

Extensômetros de 1 a 6 - Armadura Longitudinal Extensômetros de 7 a 14 - Armadura Transversal

INSTRUMENTAÇÃO

VISTA LATERAL

Figura 4.27. Instrumentação empregada nas armaduras dos modelos de seção retangular. 
b) No concreto

A medida das deformações no concreto foi feita com extensômetros elétricos fixados nas quatro faces dos pilares (ver a figura 4.28). Estes extensômetros foram locados na altura da instrumentação das armaduras.

Defletômetros localizados nas faces dos pilares mediram os deslocamentos apresentados pelos mesmos (ver a figura 4.28).

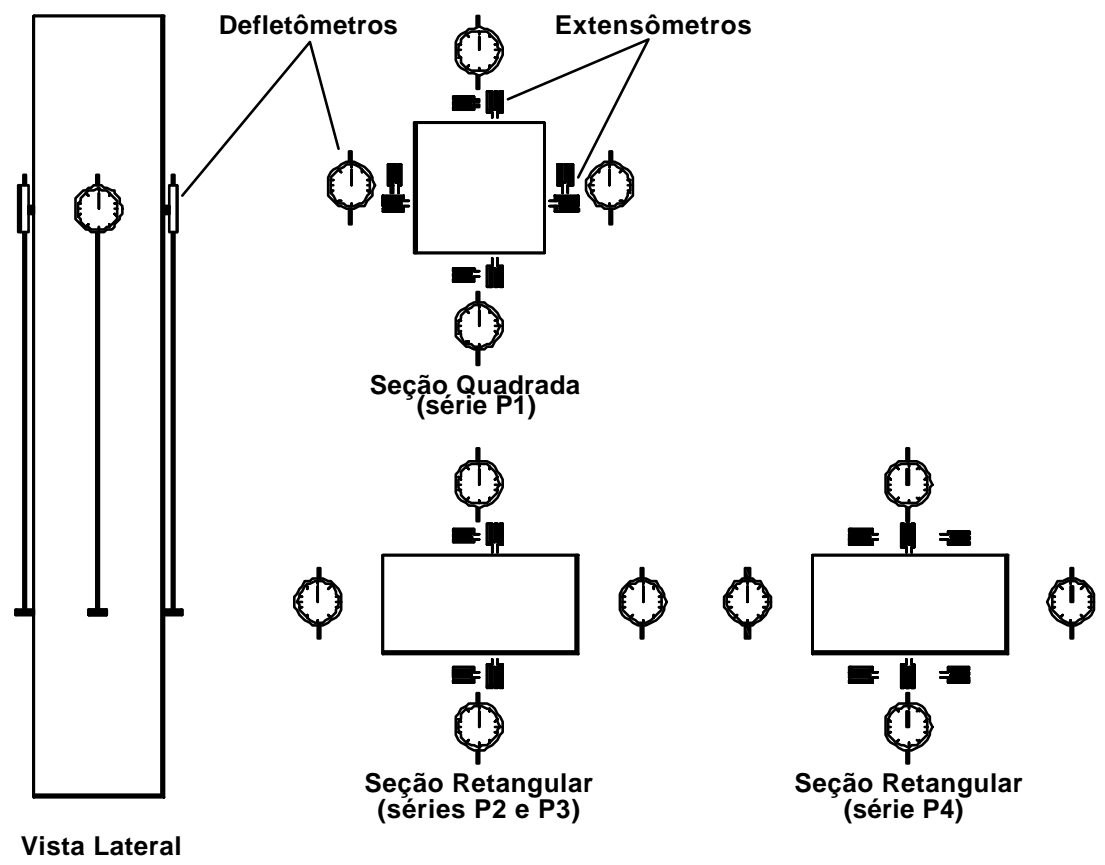

Figura 4.28. Instrumentação das faces dos pilares por meio de extensômetros elétricos colados ao concreto e defletômetros.

\subsection{Moldagem}

\subsubsection{Fôrmas}

As fôrmas empregadas na execução dos pilares eram de madeira e foram produzidas na Oficina de Marcenaria da EESC-USP. Nas figuras 4.29 e 4.30, são apresentados os projetos das fôrmas dos pilares de dimensões $200 \mathrm{~mm} \times 200 \mathrm{~mm} \times$ $1200 \mathrm{~mm}$ e $150 \mathrm{~mm} \times 300 \mathrm{~mm} \times 900 \mathrm{~mm}$. 


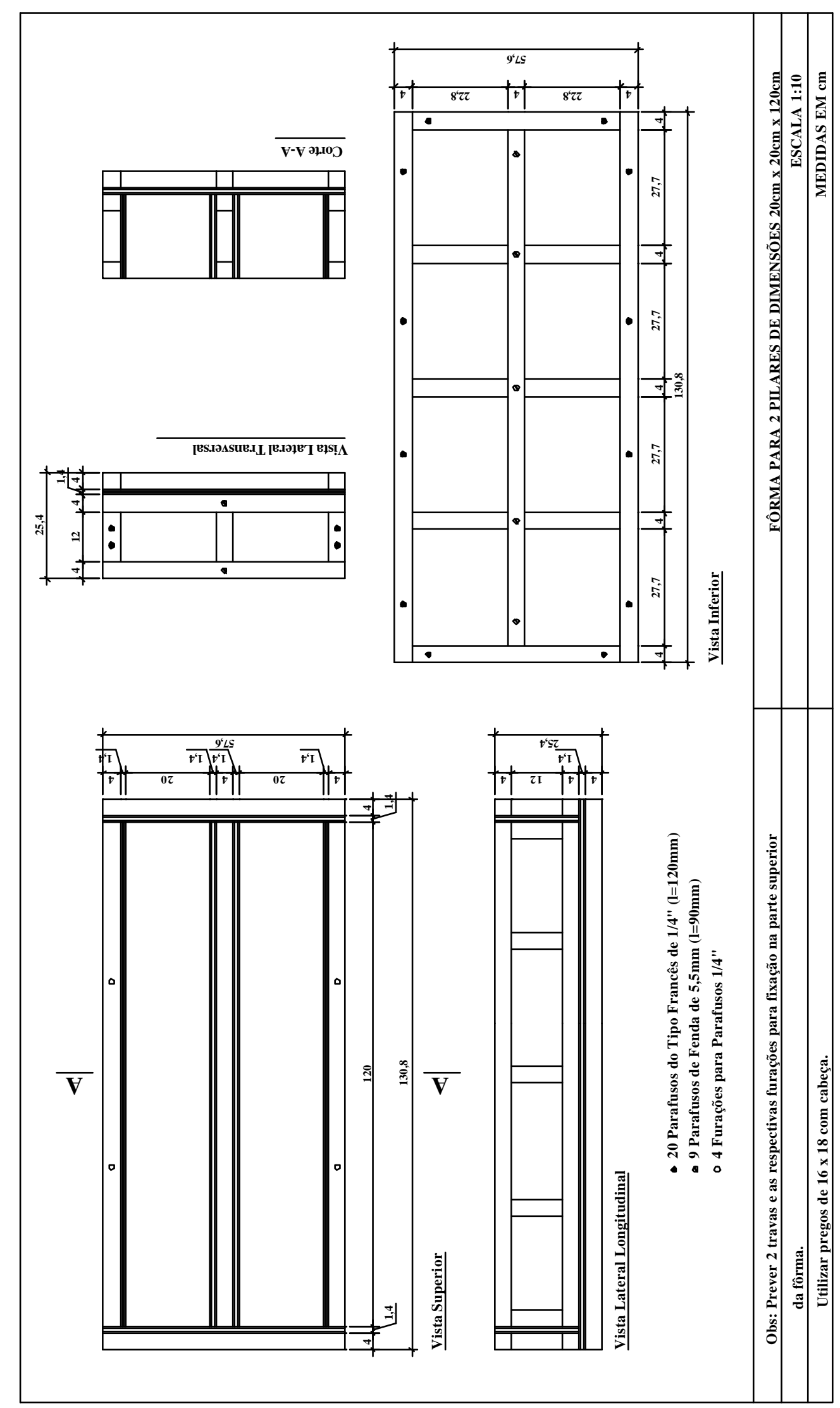

Figura 4.29. Projeto da fôrma dos pilares de $200 \mathrm{~mm}$ x 200mm x 1200mm. 


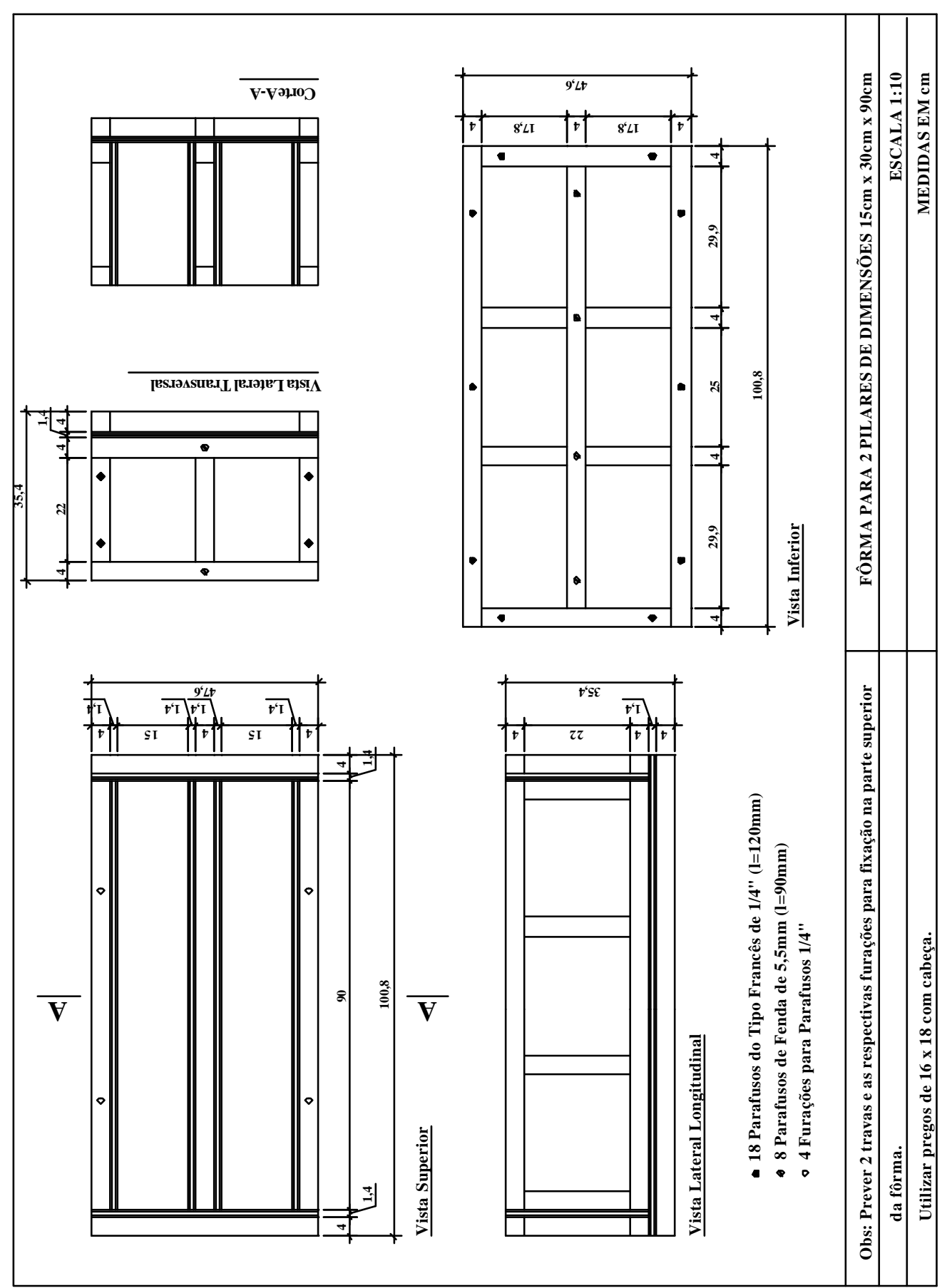

Figura 4.30. Projeto da fôrma dos pilares de $150 \mathrm{~mm} \times 300 \mathrm{~mm} \times 900 \mathrm{~mm}$. 


\subsubsection{Mistura}

A moldagem dos pilares e corpos-de-prova foi feita depois da mistura dos materiais (agregados, cimento e água) na betoneira do Laboratório de Estruturas da EESC-USP, com capacidade para 200 litros, marca CIBI (ver a figura 4.31).

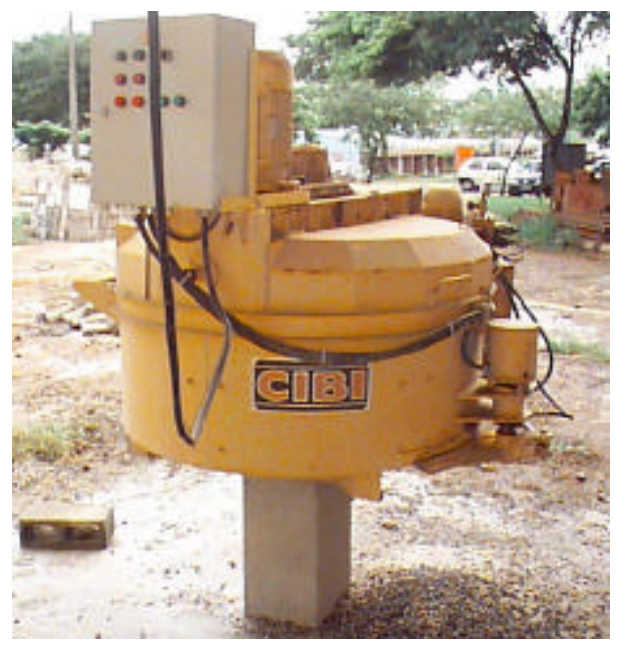

Figura 4.31. Betoneira utilizada no amassamento do concreto.

\subsubsection{Adensamento}

Quanto ao adensamento, tanto os corpos-de-prova como os pilares foram vibrados nas mesas vibratórias do Laboratório de Estruturas da EESC-USP (ver a figura 4.32).

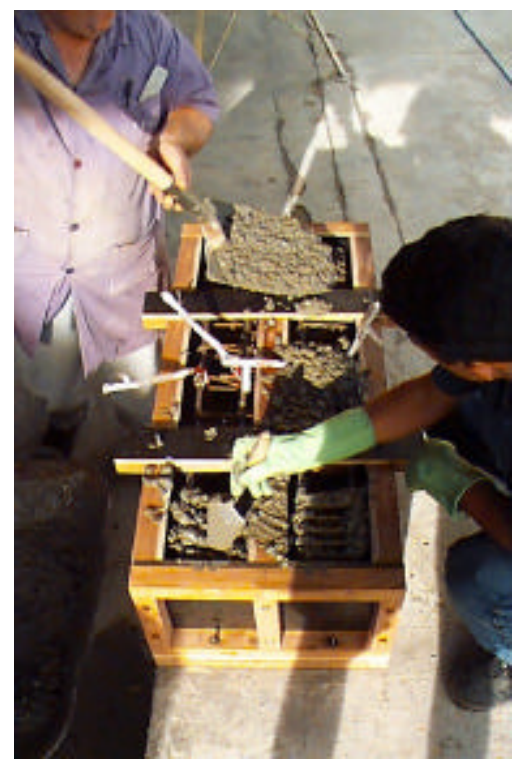

Figura 4.32. Pilares sendo concretados sobre mesa vibratória. 


\subsubsection{Acabamento}

Após o adensamento, foi realizado o acabamento das superfícies expostas dos modelos de pilares e dos corpos-de-prova. Com isso, procurou-se obter superfícies planas e lisas de modo que a aplicação da força de compressão e a colagem dos extensômetros não saíssem prejudicadas por possíveis imperfeições nas mesmas.

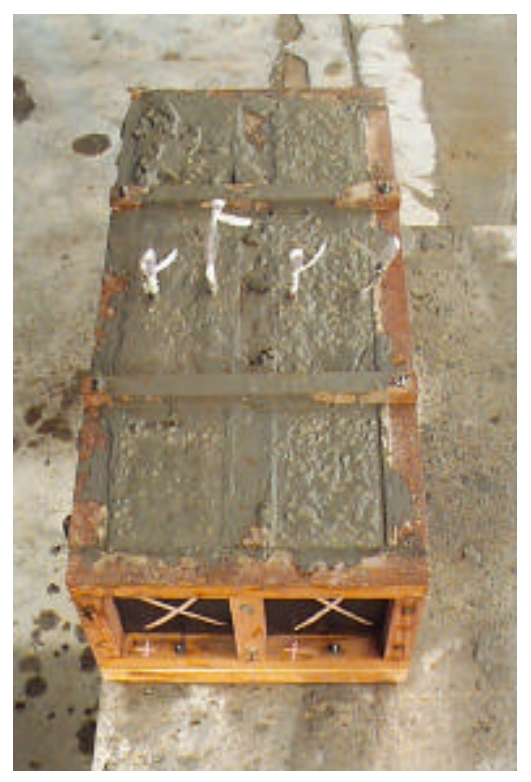

Figura 4.33. Pilares já concretados e àespera do serviço de acabamento.

\subsubsection{Cura}

A menos dos casos em que as concretagens se deram nas sextas-feiras, os pilares e corpos-de-prova foram desmoldados um dia após suas concretagens e, em seguida, colocados na câmara úmida do Laboratório de Estruturas da EESCUSP para serem curados até o $12 .^{\circ}$ dia (ver a figura 4.34). Assim, entre o $12 .^{\circ}$ dia e o $15 .^{\circ}$ dia (data dos ensaios dos pilares), foi feita a instrumentação externa dos modelos (extensômetros colados ao concreto e defletômetros). 


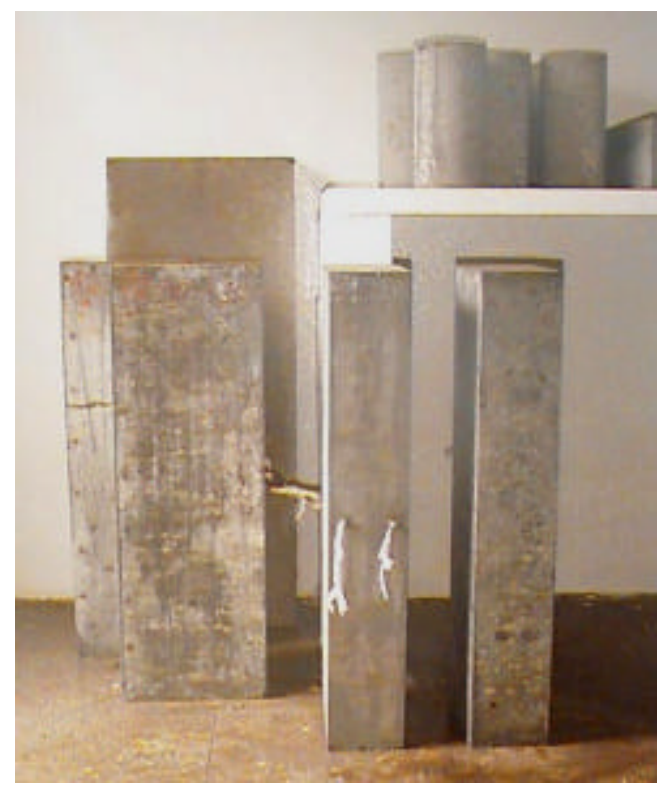

Figura 4.34. Pilares e corpos-de-prova sendo curados em câmara úmida.

\subsection{Equipamentos para os Ensaios dos Pilares}

Para os ensaios dos pilares à compressão centrada foi utilizada a máquina Instron, modelo 8506, do Laboratório de Estruturas da EESC-USP (ver a figura 4.35). Trata-se de um equipamento hidráulico, servo-controlado e computadorizado que permite a realização de ensaios estáticos com força nominal máxima de $2500 \mathrm{kN}$. Além de dispor de um espaço para ensaio de $822 \mathrm{~mm} \times 514 \mathrm{~mm}$ x 4000 $\mathrm{mm}$, a Instron possibilita a aplicação da força sob velocidade de deslocamento constante do pistão ( $\mathrm{mm} / \mathrm{s}$ ou $\mathrm{mm} / \mathrm{min})$.

O sistema de aquisição dos valores dos deslocamentos e deformações que foram fornecidos, respectivamente, pelos transdutores e extensômetros, foi o System 5000, da Measurements Group (ver a figura 4.36). 

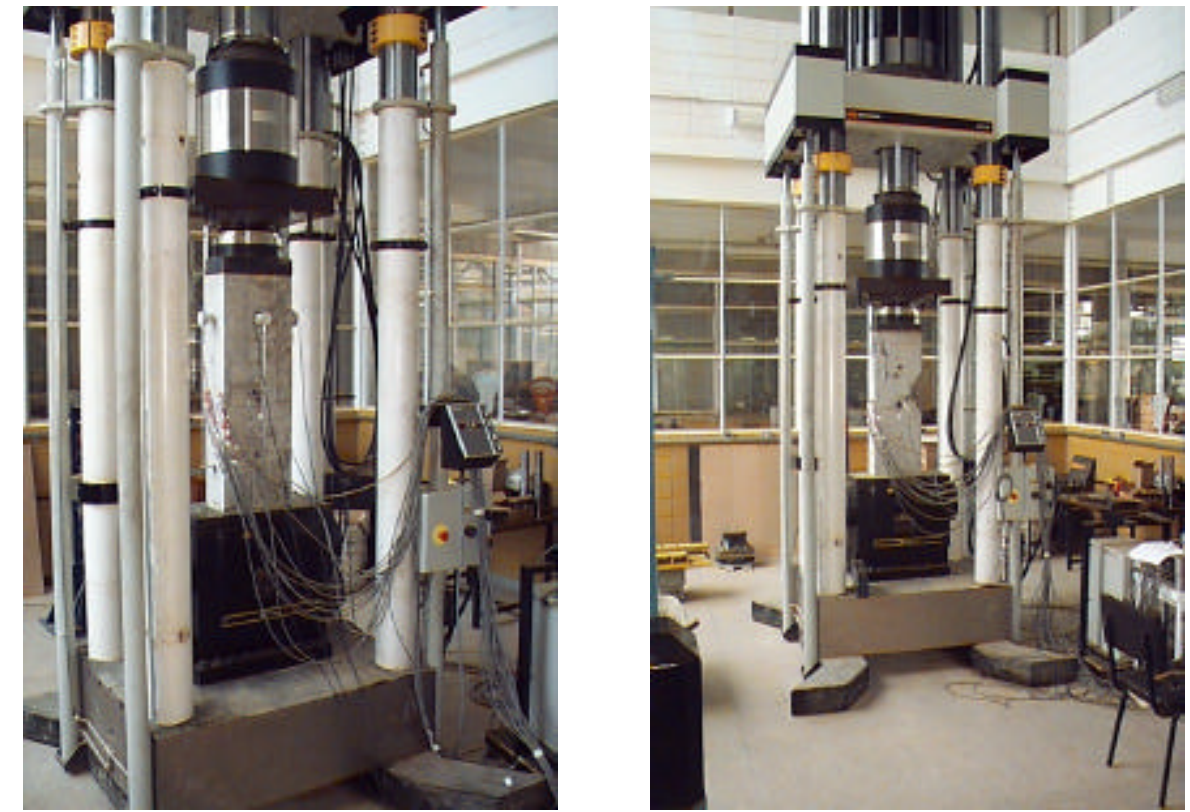

Figura 4.35. Pilares P2-10,0-120 e P3-12,5-75 sendo ensaiados na Instron.

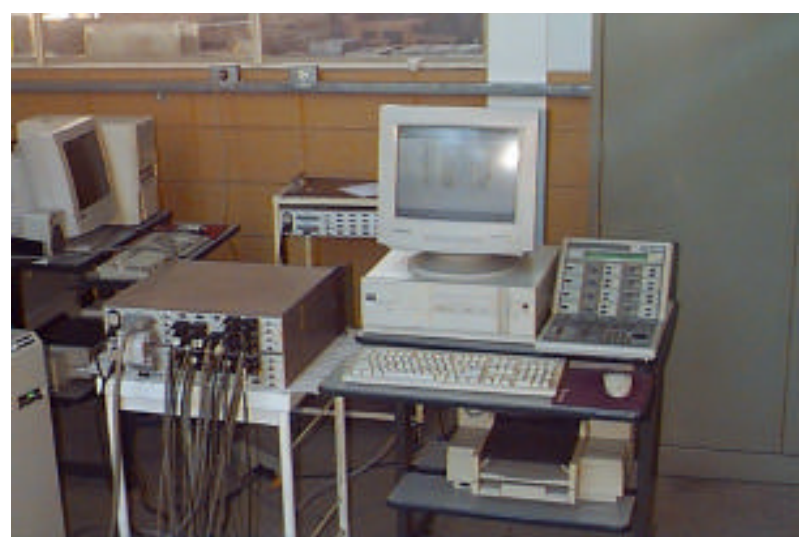

Figura 4.36. Sistema utilizado para a leitura e aquisição de dados. 


\section{ENSAIOS E RESULTADOS}

\subsection{Considerações Iniciais}

Durante a fase experimental, foram realizados ensaios de caracterização dos materiais, dosagem do concreto, ensaios de corpos-de-prova à compressão e à tração, e ensaios dos modelos de pilares. Neste capítulo, apresenta-se a descrição dos ensaios realizados com os modelos de pilares da pesquisa, bem como os resultados obtidos a partir dos mesmos.

\subsection{Descrição dos Ensaios dos Pilares}

Este item narra a maneira como os ensaios foram conduzidos, além das principais observações feitas ao longo dos mesmos. Além disso, o mesmo foi subdividido para apresentar, primeiramente, as condições gerais dos experimentos e, posteriormente, a descrição individual dos ensaios dos pilares.

\subsubsection{Condições Gerais}

Para que se pudesse obter o trecho descendente dos diagramas forçadeformação dos pilares, os ensaios foram realizados com a aplicação da força de compressão com controle da velocidade de deslocamento do pistão da máquina de ensaio. Nos primeiros modelos ensaiados, os quais foram o P1-12,5-100, P1-12,5150, P2-12,5-75 e P2-12,5-100, ainda não se tinha certeza de quais velocidades deveriam ser adotadas. Assim, definiu-se, primeiramente, a aplicação da força a uma velocidade de $0,005 \mathrm{~mm} / \mathrm{s}$ até $80 \%$ da força de ruína estimada (ver a tabela 4.8). Em seguida, $0,002 \mathrm{~mm} / \mathrm{s}$ até a força de ruína experimental e, daí para frente, 
$0,001 \mathrm{~mm} / \mathrm{s}$ até que fosse atingido $60 \%$ da força de ruína experimental. Porém, as velocidades de $0,002 \mathrm{~mm} / \mathrm{s}$ e $0,001 \mathrm{~mm} / \mathrm{s}$ tornaram os experimentos muito lentos e, com isso, quase impediram o cumprimento do cronograma de atividades que previa ensaios de dois modelos por dia. Deste modo, foram sugeridas novas velocidades de deslocamento para os demais pilares, a saber: $0,005 \mathrm{~mm} / \mathrm{s}$ até $80 \%$ da força última estimada (ver a tabela 4.8) e, a partir de então, $0,003 \mathrm{~mm} / \mathrm{s}$ até o final do ensaio. Além disso, mediante a avaliação parcial dos resultados obtidos, verificouse que o fato dos primeiros experimentos terem sido encerrados em função de uma porcentagem da força de ruína não permitiu que fossem feitas análises de ductilidade mais apuradas. Assim, foi proposto, de acordo com LIMA JUNIOR \& GIONGO (2001), que nos demais pilares o ensaio fosse encerrado apenas quando suas deformações longitudinais estivessem no mínimo três vezes maiores que as registradas no momento da força de pico.

Via de regra, em todos os ensaios, conforme a taxa de armadura transversal aumentava, mais dúcteis os pilares se tornavam. Isto era percebido considerando a demora na queda da força aplicada. Além disso, todos os modelos apresentaram poucas fissuras até a força de ruína, inclusive, com o destacamento da camada de cobrimento das armaduras ocorrendo apenas na fase de pós-pico.

\subsubsection{Descrição Individual}

Pois bem, apresentadas as condições gerais dos ensaios dos pilares, partese agora para a descrição individual de cada um deles.

a) Pilar $P 1-10,0-120$

Este pilar foi moldado no dia 24/11/2000 e ensaiado no dia 08/12/2000. Anteriormente ao início do ensaio, foram verificados o perfeito funcionamento dos transdutores, extensômetros e sistema de aquisição de dados. Em seguida, fez-se o ajuste da posição do pilar na máquina de ensaio com o objetivo de eliminar possíveis excentricidades na aplicação da força de compressão (ver a figura 5.1). Para tanto, foi verificada a verticalidade do pilar mediante observação visual e nível de bolha. Além disso, com a aplicação da força de escorvamento, a qual teve como um dos objetivos eliminar pequenas irregularidades nas extremidades do elemento, 
pôde-se perceber a coerência ou não dos deslocamentos e deformações apresentados pelos transdutores e extensômetros, respectivamente. Ou seja, enquanto os deslocamentos nos transdutores apresentassem valores muito desiguais, isto significava que a força aplicada não se encontrava centrada no modelo e, portanto, haveria a necessidade de ser alterada a posição do pilar até que esta desigualdade fosse diminuída. Porém, apesar de tomados estes cuidados, ainda assim ocorreu flexão composta no pilar. Contudo, tal fato é comum quando se tenta obter compressão simples, visto que há outros fatores como a heterogeneidade do concreto que acabam por dificultar a aplicação do carregamento de forma perfeitamente centrada.

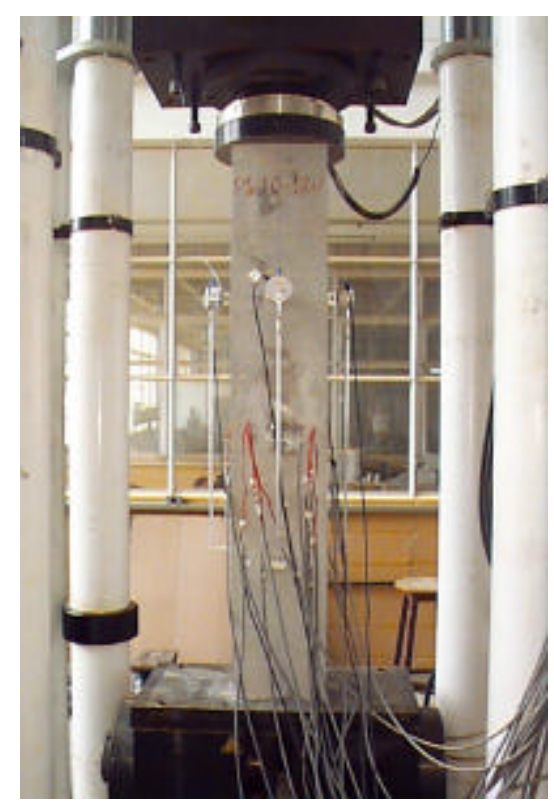

Figura 5.1. Pilar P1-10,0-120 posicionado e pronto para o ensaio.

A primeira fissura no pilar se deu por volta de 1000kN (ver a figura 5.2.a), enquanto que, sua ruína ocorreu com uma força de $1072 \mathrm{kN}$. A partir de $1000 \mathrm{kN}$ do pós-pico foram verificadas fissuras que revelaram a flambagem de duas barras longitudinais (ver a figura 5.2.b). Fissuras inclinadas à $30^{\circ}$ da direção da carga surgiram no pós-pico com uma força de aproximadamente $650 \mathrm{kN}$ (ver a figura 5.2.c). Por fim, durante a execução do ensaio, a observação dos registros dos extensômetros e transdutores, das fissuras inclinadas e da maior deterioração de uma das faces do pilar permitiu concluir que o modelo foi submetido à flexão composta (ver a figura 5.2.d). 


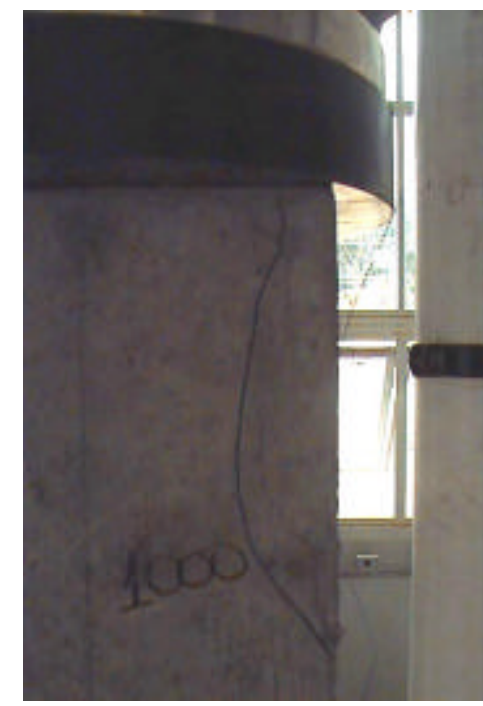

a)

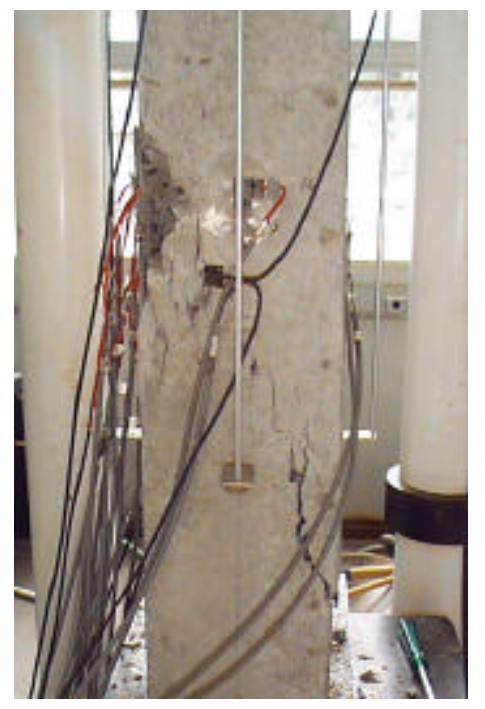

c)

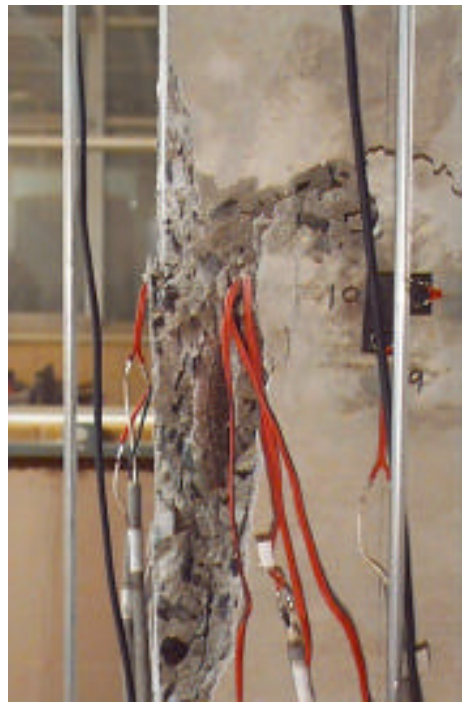

b)

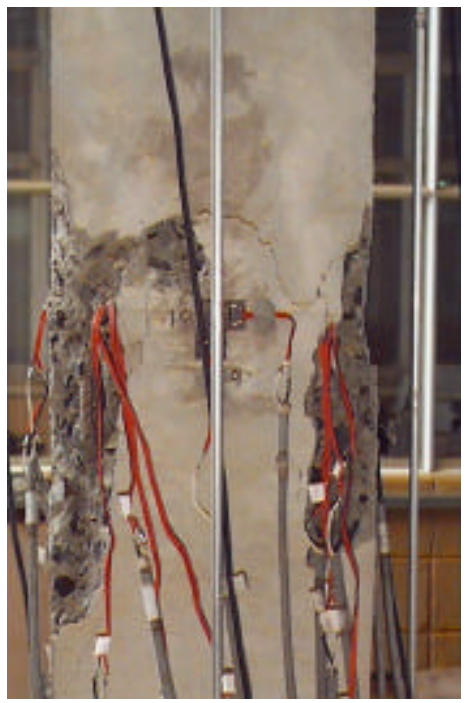

d)

Figura 5.2. Pilar P1-10,0-120. a) Primeira fissura; b) Flambagem de uma das barras longitudinais; c) Fissura inclinada à 30; e d) Detalhe da face mais deteriorada que demonstrou a ação de flexão composta sobre o pilar.

b) Pilar P1-12,5-200

O pilar P1-12,5-200 também foi moldado no dia 24/11/2000 e ensaiado no dia 08/12/2000. Quanto ao funcionamento dos transdutores, extensômetros e sistema de aquisição de dados, foi observada a avaria de um extensômetro da armadura longitudinal em virtude da perda de seu isolamento. Posteriormente, fez-se o ajuste da posição do pilar na máquina de ensaio juntamente com a aplicação da força de escorvamento. Iniciado o ensaio, a primeira fissura no pilar se deu por volta de 
$1075 \mathrm{kN}$ (ver a figura 5.3.a), enquanto que, sua ruína em $1085 \mathrm{kN}$. A partir de $1065 \mathrm{kN}$ do pós-pico foram verificadas fissuras que revelaram a flambagem de duas barras longitudinais (ver a figura 5.3.b). Fissuras inclinadas surgiram no pós-pico com uma força de aproximadamente $1000 \mathrm{kN}$. Durante $\mathrm{o}$ andamento do experimento, com a observação dos dados dos extensômetros e transdutores, das fissuras inclinadas e da maior deterioração de uma das faces do pilar pôde-se concluir que houve flexão composta.

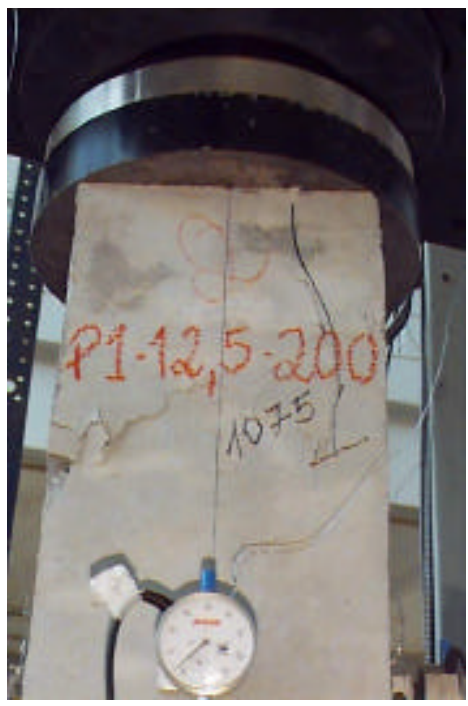

a)

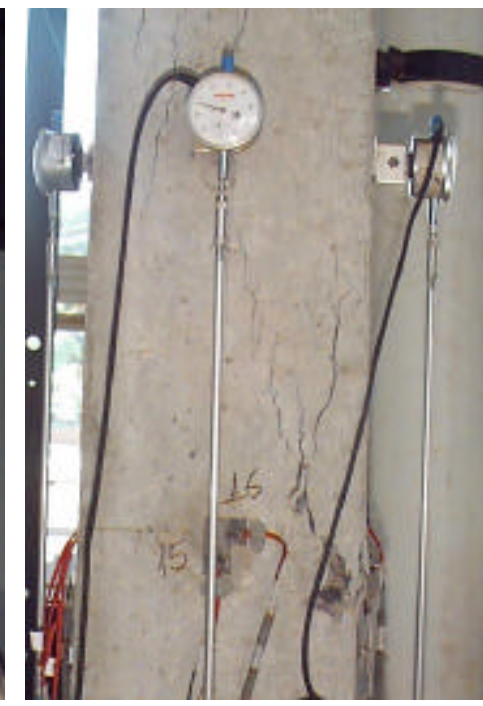

b)

Figura 5.3. Pilar P1-12,5-200. a) Primeira fissura; e b) Fissuras decorrentes da flambagem de uma das barras longitudinais.

c) Pilar P1-12,5-150

Em função do cronograma do Laboratório de Estruturas, este modelo foi moldado no dia 05/10/2000 e ensaiado em 18/10/2000, ou seja, com 13 das de idade. Quanto a instrumentação do mesmo, apenas um extensômetro da armadura transversal apresentou-se danificado. Feito o ajuste da posição do pilar juntamente com a aplicação da força de escorvamento, deu-se início ao ensaio. A primeira fissura se deu por volta de $1100 \mathrm{kN}$ (ver a figura 5.4.a), enquanto que, a ruína do pilar ocorreu com uma força de $1223 \mathrm{kN}$. A flambagem das barras longitudinais (ver a figura 5.4.b) e o surgimento de fissuras inclinadas à30ํ só foram notadas na fase de pós-pico. Por fim, durante a execução do ensaio, a observação dos dados dos extensômetros e transdutores, das fissuras inclinadas e da maior deterioração de uma das faces do pilar permitiu concluir a ocorrência de flexão composta. 


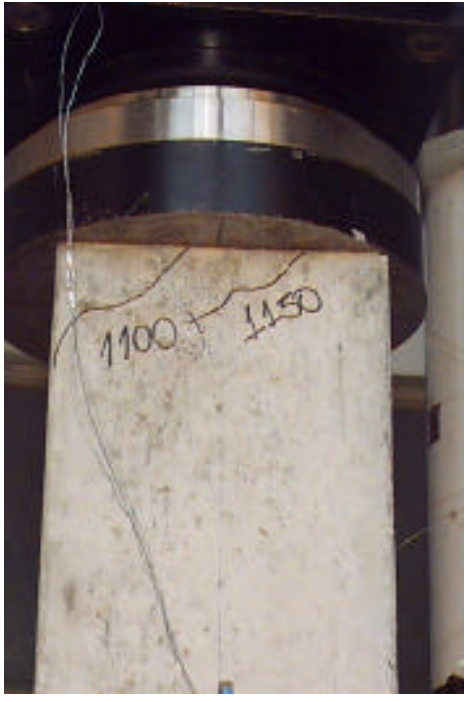

a)

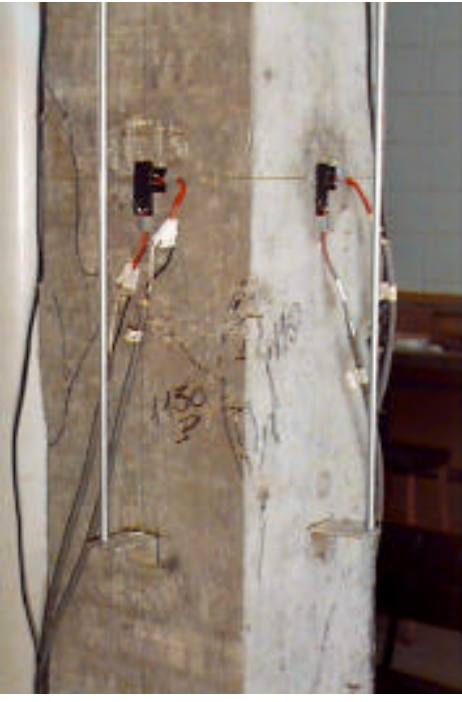

b)

Figura 5.4. Pilar P1-12,5-150. a) Primeira fissura; e b) Configuração de fissuras denuncia a flambagem das barras longitudinais das quinas.

d) Pilar P1-12,5-100

O pilar P1-12,5-100 foi moldado e ensaiado nos mesmos dias que o pilar P1-12,5-150. Quanto a instrumentação, apenas um extensômetro da armadura transversal apresentou-se danificado. Feito o ajuste da posição do pilar juntamente com a aplicação da força de escorvamento, deu-se início ao ensaio. A força de primeira fissura foi em brno de $1200 \mathrm{kN}$ (ver a figura 5.5.a), enquanto que, a de ruína foi de $1292 \mathrm{kN}$. Tanto a flambagem das barras longitudinais como o surgimento de fissuras inclinadas à $30^{\circ}$ ocorreram na fase de pós -pico (ver a figura 5.5.b). Durante o trecho ascendente do diagrama força-deformação a flexão do pilar foi pouco sentida, porém, no pós-pico ela se acentuou. 


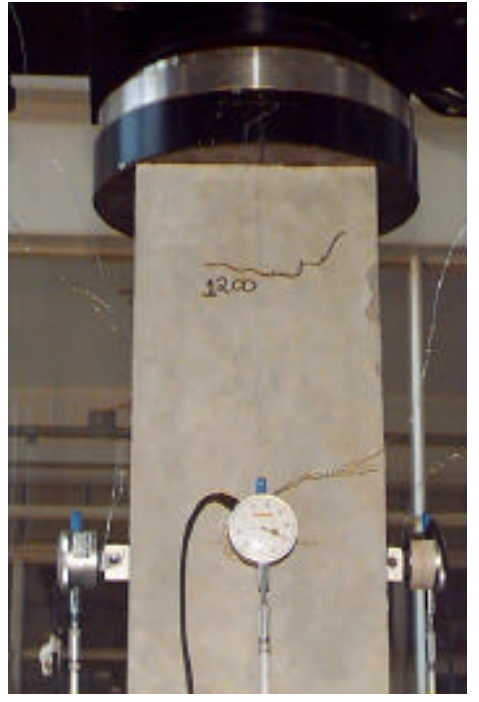

a)

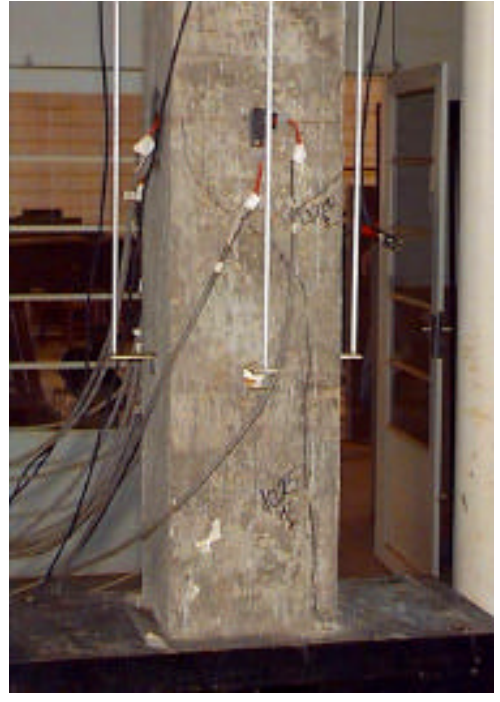

b)

Figura 5.5. Pilar P1-12,5-100. a) Primeira fissura; e b) Fissura inclinada à 30 .

e) Pilar P2-10,0-120

Este pilar foi moldado e ensaiado nos dias 23/11/2000 e 07/12/2000, respectivamente. Dois dos extensômetros da armadura longitudinal apresentaram problemas por falha em seus isolamentos. Após ter sido feito o ajuste da posição do pilar juntamente com a aplicação da força de escorvamento, deu-se início ao ensaio. A força de primeira fissura foi de $1200 \mathrm{kN}$, enquanto que, a de ruína foi de $1325 \mathrm{kN}$. A partir de $1000 \mathrm{kN}$ do pós-pico foram verificadas fissuras que revelaram a flambagem de três barras longitudinais (ver a figura 5.6.a). Fissuras inclinadas surgiram no pós-pico com uma força de aproximadamente $1100 \mathrm{kN}$. Durante o ensaio, pôde-se perceber que o pilar parecia estar submetido à compressão simples (ver a figura 5.6.b), porém, um problema no sistema de leitura e aquisição de dados, o qual resultou na perda de todos os resultados de deslocamentos e deformações no pilar, não permitiu confirmar esta condição. 


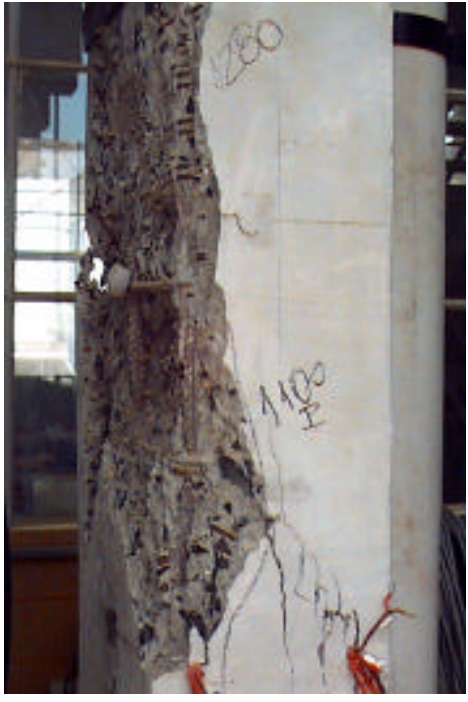

a)

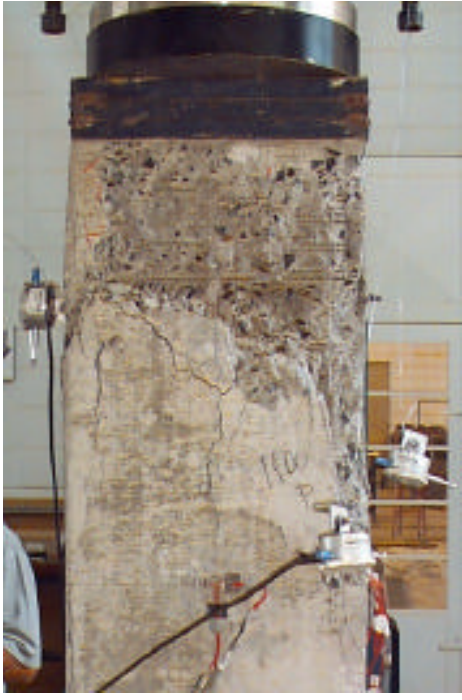

b)

Figura 5.6. Pilar P2-10,0-120. a) Flambagem das barras longitudinais de uma face; e b) Descolamento do cobrimento da parte superior na fase de pós-pico associado ao carregamento centrado que sobre o pilar.

f) Pilar P2-12,5-150

Este modelo foi moldado e ensaiado nos mesmos dias que o pilar P2-10,0-120. Quanto a sua instrumentação, um extensômetro da armadura transversal foi avariado durante a concretagem, e um da armadura longitudinal apresentou-se danificado por falha de isolamento. Após ter sido feito o ajuste da posição do pilar juntamente com a aplicação da força de escorvamento, deu-se início ao ensaio. A primeira fissura ocorreu com uma força de $1390 \mathrm{kN}$, enquanto que, a ruína com $1400 \mathrm{kN}$. Exatamente no instante da força máxima, um dos transdutores caiu por conta de uma fissura formada bem abaixo de sua base. A partir de $1270 \mathrm{kN}$ do pós-pico foram verificadas fissuras nas faces e flambagens de três barras longitudinais (ver a figura 5.7.a). Fissuras inclinadas surgiram no póspico com uma força em torno de $1120 \mathrm{kN}$. Durante o ensaio, pareceu que o modelo foi submetido àcompressão simples (ver a figura 5.7.b). 


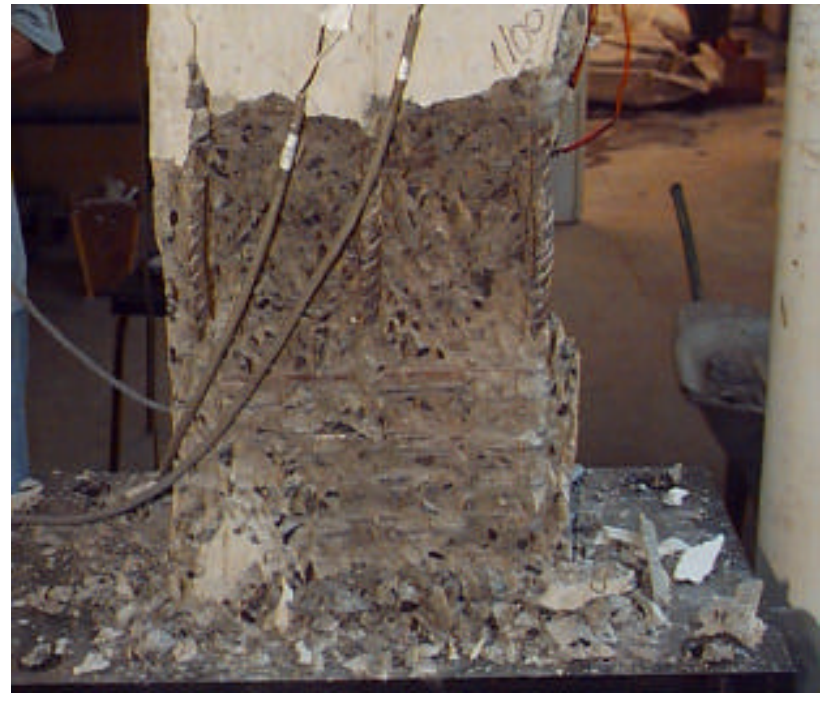

a)

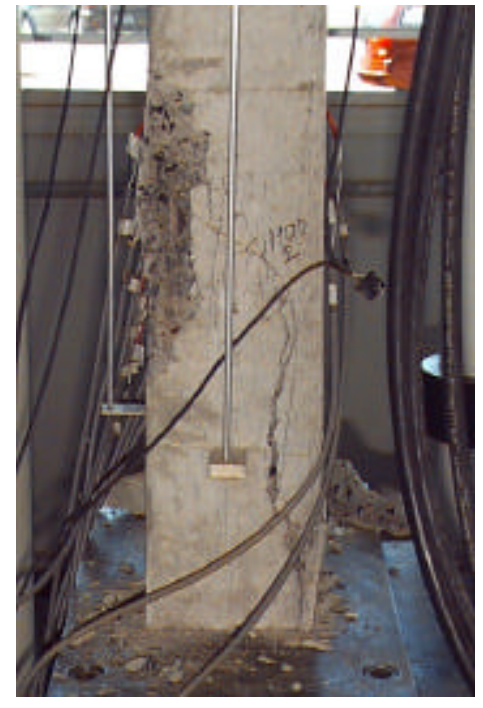

b)

Figura 5.7. Pilar P2-12,5-150. a) Flambagem das barras longitudinais de uma face; e b) Esquema de fissuras característico de elementos submetidos à compressão simples.

g) Pilar P2-12,5-100

A moldagem do P2-12,5-100 se deu no dia 06/10/2000, enquanto que, seu ensaio ocorreu em 20/10/2000. Antes de se iniciar o ensaio, foram verificados o perfeito funcionamento dos transdutores, extensômetros e sistema de aquisição de dados. Em seguida, fez-se o ajuste da posição do pilar juntamente com a aplicação da força de escorvamento. Tendo iniciado o ensaio, a primeira fissura ocorreu com uma força de $1090 \mathrm{kN}$, enquanto que, a ruína com $1175 \mathrm{kN}$. Na fase de pós-pico surgiram fissuras inclinadas à $30^{\circ}$ (ver a figura 5.8.a) e fissuras que indicavam a flambagem das barras longitudinais. Este ensaio foi caracterizado pela presença marcante de esforços de flexão. 


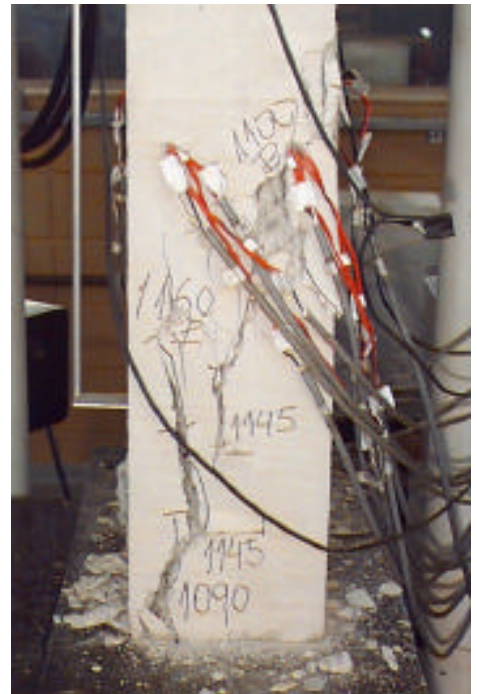

a)

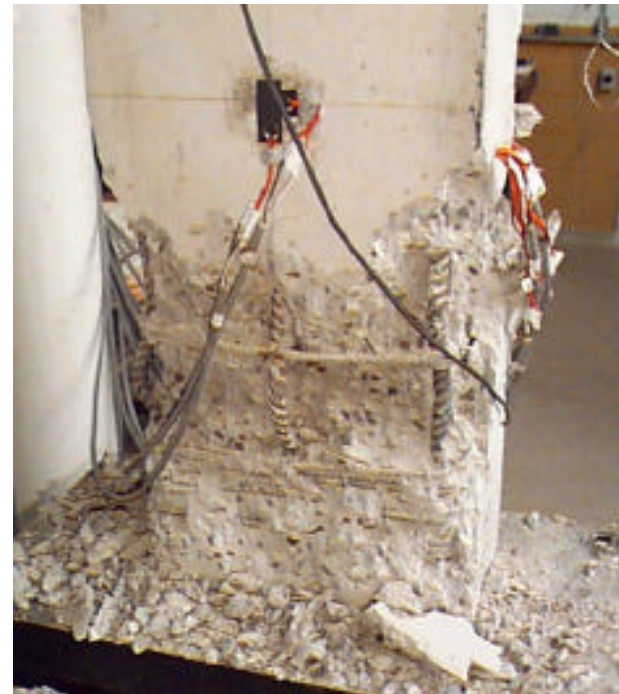

b)

Figura 5.8. Pilar P2-12,5-100. a) Estágio em que o cobrimento está destacando-se e a fissura inclinada mais evidente; e b) Estado de fissuração do pilar ao final do ensaio.

h) Pilar P2-12,5-75

As atividades de moldagem e ensaio deste pilar ocorreram nos mesmos dias que as do P2-12,5-100. Quanto a sua instrumentação, um extensômetro da armadura longitudinal e um longitudinal colado na face do concreto apresentaramse avariados. Após ter sido feito o ajuste da posição do pilar juntamente com a aplicação da força de escorvamento, deu-se início ao ensaio. A primeira fissura ocorreu $\infty \mathrm{m}$ uma força de $1100 \mathrm{kN}$, enquanto que, a ruína se deu na casa dos $1215 \mathrm{kN}$. Tanto a flambagem das barras longitudinais quanto o surgimento de fissuras inclinadas à $30^{\circ}$ ocorreram na fase de pós-pico. Este ensaio foi caracterizado pela presença de esforços de fexão que, inclusive, provocaram a queda precoce do transdutor localizado na face mais comprimida (ver a figura 5.9). 


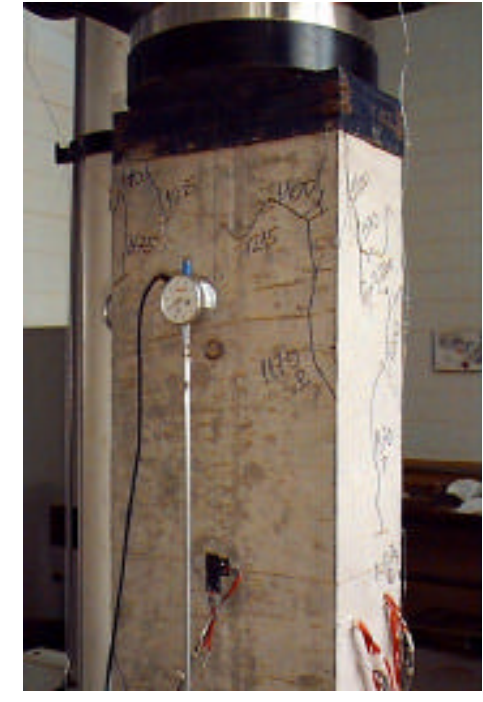

a)

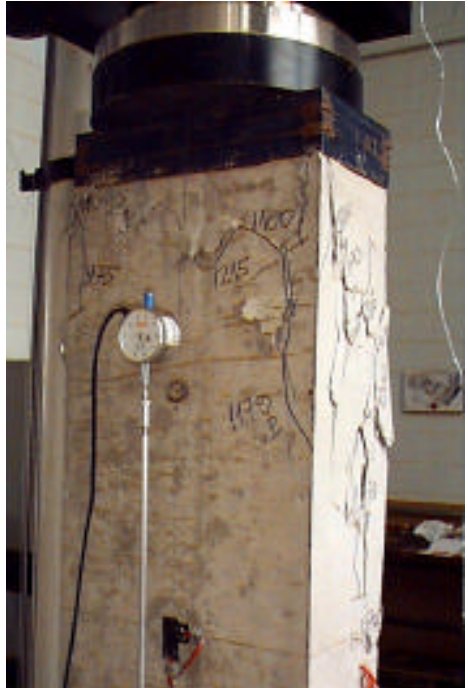

b)

Figura 5.9. As fotos a e b foram tiradas do pilar P2-12,5-75 em diferentes etapas de carregamento, porém, de um mesmo ângulo de visão. Isto permitiu observar a maior fissuração em um dos lados do modelo, fato este que revelou o estado de flexão composta ao qual o pilar foi submetido.

i) Pilar P3-10,0-120

Este modelo foi moldado no dia 01/12/2000 e ensaiado em 15/12/2000. Antes de se iniciar o ensaio, foram verificados o perfeito funcionamento dos transdutores, extensômetros e sistema de aquisição de dados. Por conseguinte, fez-se o ajuste da posição do pilar juntamente com a aplicação da força de escorvamento. Tendo iniciado o ensaio, a primeira fissura ocorreu com uma força de $1200 \mathrm{kN}$ e a ruína com $1265 \mathrm{kN}$. Ainda no pré-pico, exatamente quando se registrou a força de $1050 \mathrm{kN}$, um dos transdutores caiu em virtude de uma fissura formada bem abaixo de sua base. Fissuras inclinadas surgiram no pós-pico com uma força em torno de $550 \mathrm{kN}$. Com a força de $1100 \mathrm{kN}$ do pós-pico puderam ser observadas fissuras que revelaram a flambagem de duas barras longitudinais. Por conta de uma das faces do pilar apresentar-se bem mais deteriorada que as demais, ficou clara a presença de esforços de flexão sobre a peça (ver a figura 5.10.a). 


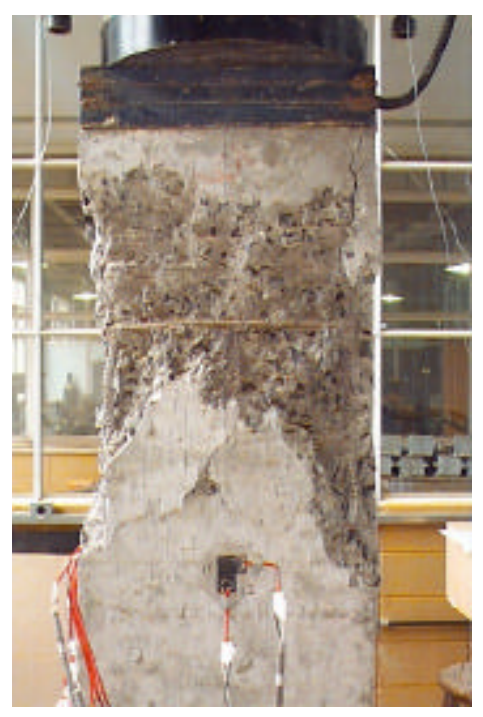

a)

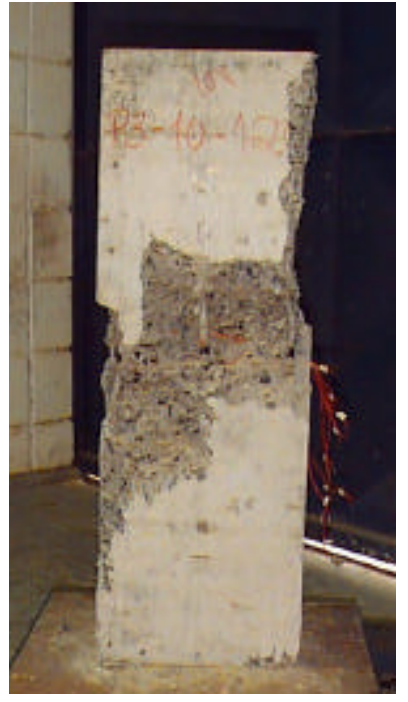

b)

Figura 5.10. Pilar P3-10,0-120. a) Lado esquerdo do pilar mais deteriorado revela a flexão composta que atuou sobre o modelo; e b) Estado de fissuração do pilar ao final do ensaio.

j) Pilar P3-12,5-150

O pilar P3-12,5-150 foi moldado e ensaiado nos mesmos dias que o P3-10,0120. Tendo verificado o perfeito funcionamento dos transdutores, extensômetros e sistema de aquisição de dados, fez-se o ajuste da posição do pilar juntamente com a aplicação da força de escorvamento. Iniciado o ensaio, a primeira fissura surgiu com uma força de $1080 \mathrm{kN}$ e a ruína com $1322 \mathrm{kN}$. Tal como no pilar P3-10,0-120, quando se registrou a força de $1080 \mathrm{kN}$, um dos transdutores caiu em função da formação de fissuras bem abaixo de sua base. A partir de $1000 \mathrm{kN}$ do pós-pico identificaram-se fissuras que revelaram a flambagem de uma barra longitudinal. $A$ presença de esforços de flexão foi característica deste ensaio (ver a figura 5.11.a). 


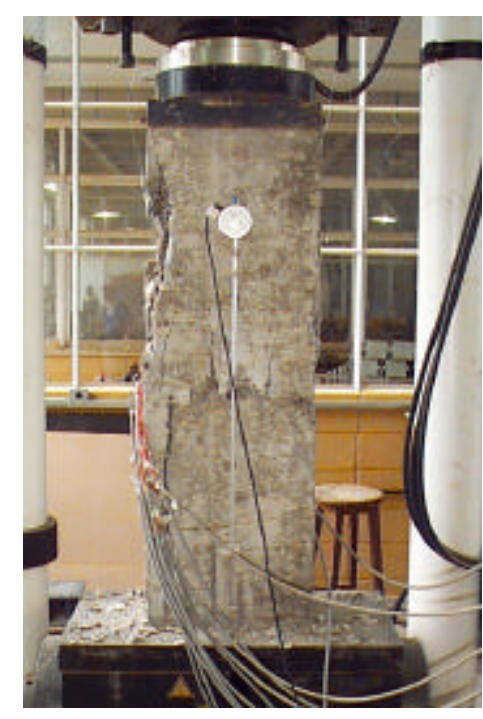

a)

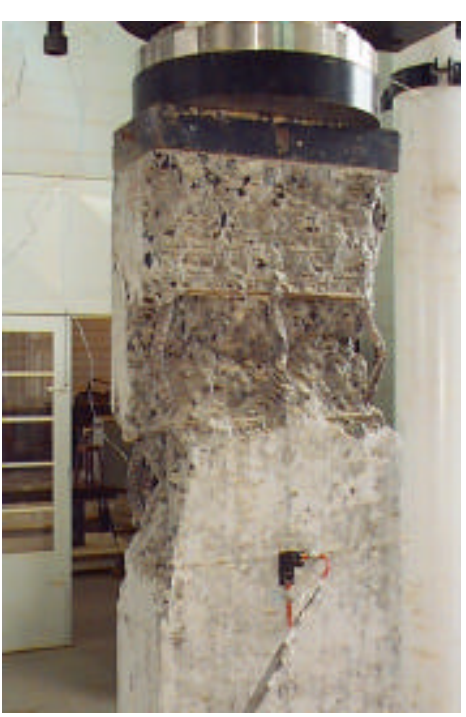

b)

Figura 5.11. Pilar P3-12,5-150. a) Lado esquerdo do pilar mais deteriorado revela a flexão composta que atuou sobre o modelo; e b) Descolamento do cobrimento e flambagem das barras longitudinais do modelo já na fase de pós-pico.

k) Pilar P3-12,5-100

As atividades de moldagem e ensaio deste pilar ocorreram nos dias 30/11/2000 e 14/12/2000, respectivamente. Verificado o funcionamento pleno dos transdutores, extensômetros e sistema de aquisição de dados, partiu-se para o ajuste da posição do pilar juntamente com a aplicação da força de escorvamento. Tendo dado início ao ensaio, a primeira fissura ocorreu com $1330 \mathrm{kN}$ e a ruína com $1468 \mathrm{kN}$. Exatamente no momento da força máxima, um dos transdutores caiu por conta de uma fissura formada bem abaixo de sua base. Logo a 1460kN do pós-pico foi observada a flambagem de duas barras longitudinais. Fissuras inclinadas surgiram por volta de $1220 \mathrm{kN}$ do pós-pico. No decorrer do ensaio, as leituras dos extensômetros da armadura longitudinal e dos transdutores somados a aparência mais deteriorada de uma das faces do pilar demonstraram ter ocorrido flexão composta neste elemento (ver a figura 5.12.a). 


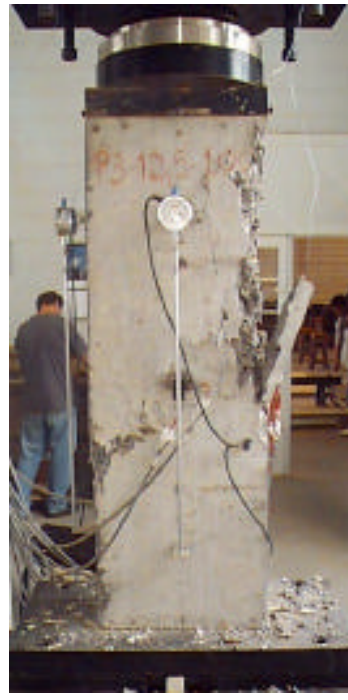

a)

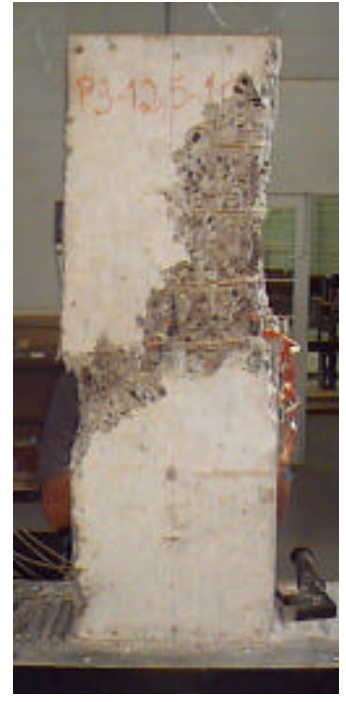

b)

Figura 5.12. Pilar P3-12,5-100. a) Lado esquerdo do pilar mais deteriorado revela a flexão composta que atuou sobre o modelo; e b) Estado de fissuração do pilar ao final do ensaio.

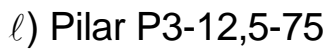

Este pilar foi moldado e ensaiado nos mesmos dias que o pilar P3-12,5-100. Quanto a sua instrumentação, nenhum problema foi observado. No entanto, o ajuste do modelo na máquina de ensaio apresentou problemas, pois durante a aplicação da força de escorvamento, as deformações registradas por dois extensômetros opostos mostravam-se muito diferentes. Assim, com o propósito de diminuir esta excentricidade, deslocou-se o pilar no sentido do transdutor com maior deformação. Dado início ao ensaio, a primeira fissura ocorreu com uma força de $1330 \mathrm{kN}$, enquanto que, a ruína com $1485 \mathrm{kN}$. Quando foi registrada a força de $1450 \mathrm{kN}$, um dos transdutores caiu por conta de uma fissura formada bem abaixo de sua base. A partir de $1450 \mathrm{kN}$ do pós-pico foram verificadas fissuras que revelaram a flambagem de duas barras longitudinais (ver a figura 5.13.a). Fissuras inclinadas surgiram no pós-pico com uma força em torno de $1450 \mathrm{kN}$. Durante o ensaio deste pilar, a leitura dos transdutores e extensômetros e o fato de uma das faces apresentar-se bem mais deteriorada que as demais, revelaram o estado de flexão composta a que o modelo foi submetido. 


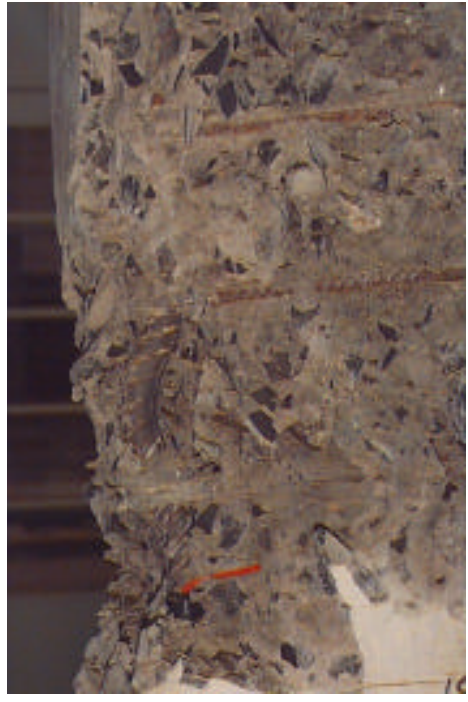

a)

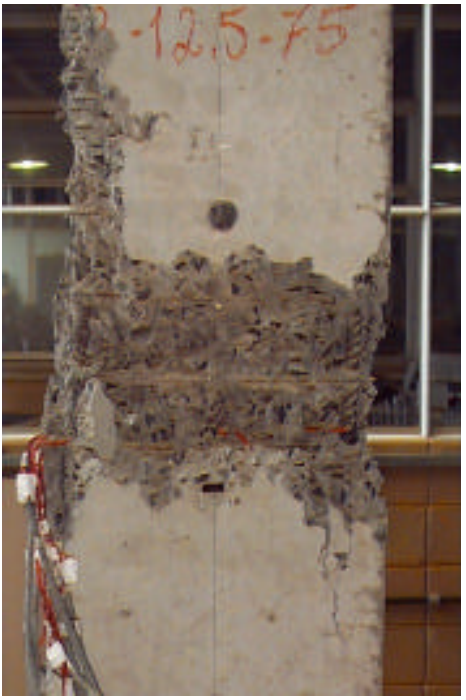

b)

Figura 5.13. Pilar P3-12,5-75. a) Detalhe da barra longitudinal flambada entre os estribos por conta da eficiente contenção lateral imposta por esta armadura transversal; e b) Estado de fissuração do pilar ao final do ensaio.

m) Pilar P4-10,0-120

A moldagem do pilar P4-10,0-120 ocorreu no dia 29/11/2000, enquanto que, sua experimentação se deu no dia 13/12/2000. No que tange a instrumentação do modelo, nenhuma avaria foi detectada. Porém, o mesmo problema de ajuste do pilar na máquina de ensaio, observado no P3-12,5-75, ocorreu neste ensaio. Assim, as mesmas medidas tomadas anteriormente foram empregadas antes de se iniciar o ensaio deste pilar. Iniciado o ensaio, a primeira fissura ocorreu com 1150kN (ver a figura 5.14.a) e a ruína com 1238kN. Quando atuava a força de $1150 \mathrm{kN}$, uma fissura surgida bem abaixo da base de um dos transdutores provocou a sua queda. A flambagem de duas barras longitudinais foi observada quando a força era de aproximadamente $1200 \mathrm{kN}$ do pós-pico. A primeira fissura inclinada do pilar surgiu a $1100 \mathrm{kN}$ da fase de pós-pico. 


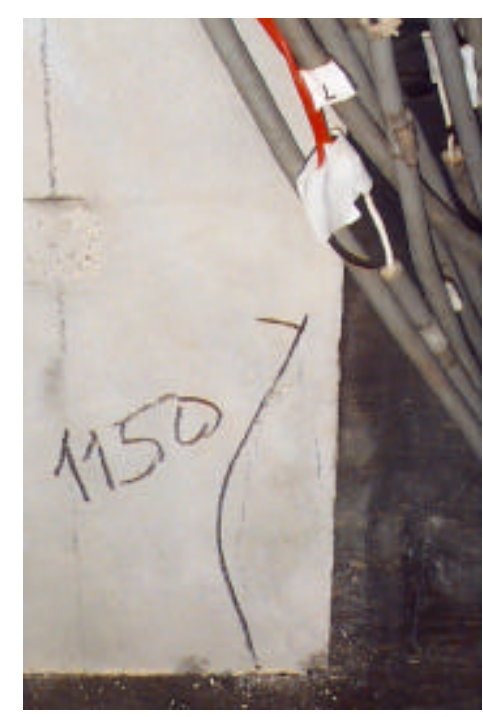

a)

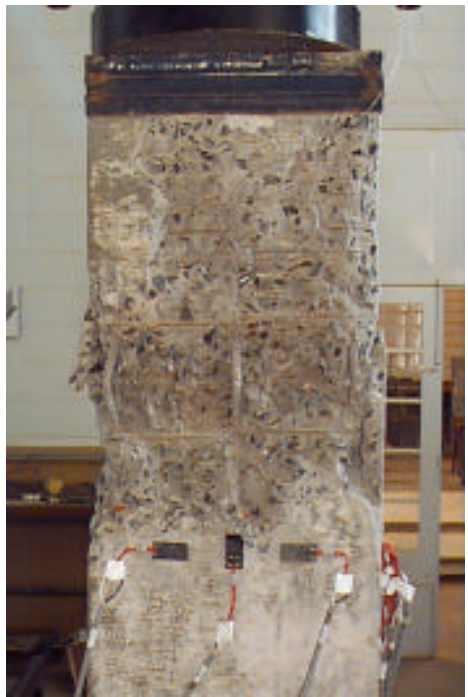

b)

Figura 5.14. Pilar P4-10,0-120. a) Força de primeira fissura; e b) Estado de fissuração do pilar ao final do ensaio.

n) Pilar P4-12,5-150

Este pilar foi moldado e ensaiado nos mesmos dias que o pilar P4-10,0-120. Sua instrumentação não apresentou nenhum problema e, após ter sido feito o ajuste da posição do pilar juntamente com a aplicação da força de escorvamento, deu-se início ao ensaio. A primeira fissura ocorreu com uma força de 1310kN, enquanto que, a ruína com $1340 \mathrm{kN}$. Em virtude de fissuras formadas bem abaixo de sua base, um dos transdutores caiu no instante da força máxima. Com a força de $1200 \mathrm{kN}$ do pós-pico puderam ser observadas fissuras que revelaram a flambagem de quatro barras longitudinais (ver a figura 5.15.a). Quando a força já havia caído para 900kN surgiu a primeira fissura inclinada (ver a figura 5.15.b). Mais uma vez, foi verificado a presença de esforços de flexão no ensaio de um modelo. 


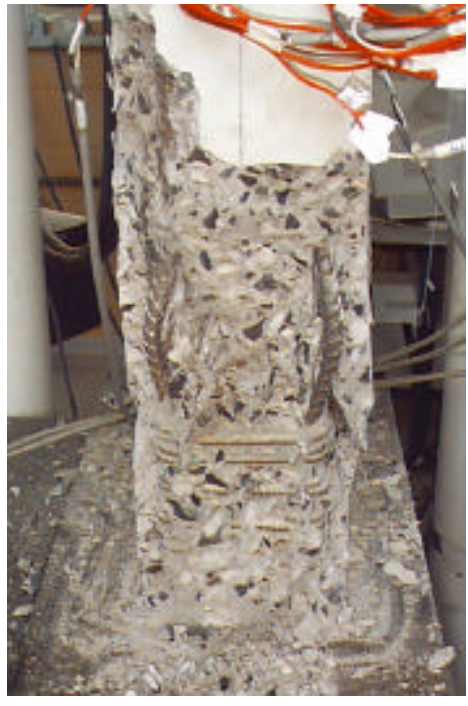

a)

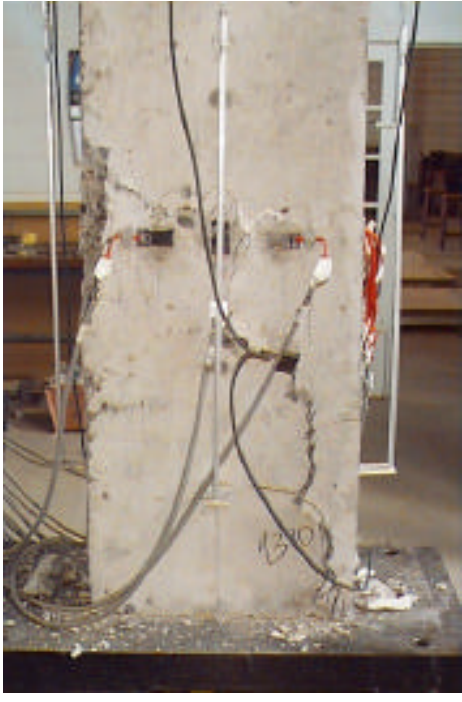

b)

Figura 5.15. Pilar P4-12,5-150. a) Flambagem das barras longitudinais na fase de pós-pico; e b) Descolamento do cobrimento e desenvolvimento da fissura inclinada à $30^{\circ}$.

o) Pilar P4-12,5-100

Este modelo foi moldado no dia $28 / 11 / 2000$ e ensaiado em 12/12/2000. Antes de se iniciar o ensaio, observou-se a avaria de apenas um dos extensômetros da armadura longitudinal. Contudo, após o término do experimento e uma primeira análise dos resultados obtidos, deu-se pela falta das medidas dos extensômetros transversais. Logo em seguida, constatou-se que esta falha se deu por conta da falta de atenção no momento em que foram selecionados os canais a serem registrados pelo sistema de leitura e aquisição de dados. Retomando a descrição do ensaio, como de praxe, fez-se o ajuste da posição do pilar juntamente com a aplicação da força de escorvamento. Com o ensaio em andamento, a primeira fissura ocorreu a $1340 \mathrm{kN}$ e a ruína a $1355 \mathrm{kN}$. Dois dos quatro transdutores caíram quando eram aplicadas as forças de $770 \mathrm{kN}$ e $1350 \mathrm{kN}$. Como já comentado anteriormente, isto se deu provavelmente em virtude da formação de fissuras bem abaixo das bases destes transdutores. Fissuras inclinadas surgiram no pós-pico com uma força em torno de $1100 \mathrm{kN}$. Logo com $1340 \mathrm{kN}$ do pós-pico foram observadas a flambagem de duas barras longitudinais (ver a figura 5.16.a). Pelo fato de uma das faces ter se apresentado bem mais deteriorada que as demais, ficou claro o estado de flexão composta presente neste pilar (ver a figura 5.16.b). 


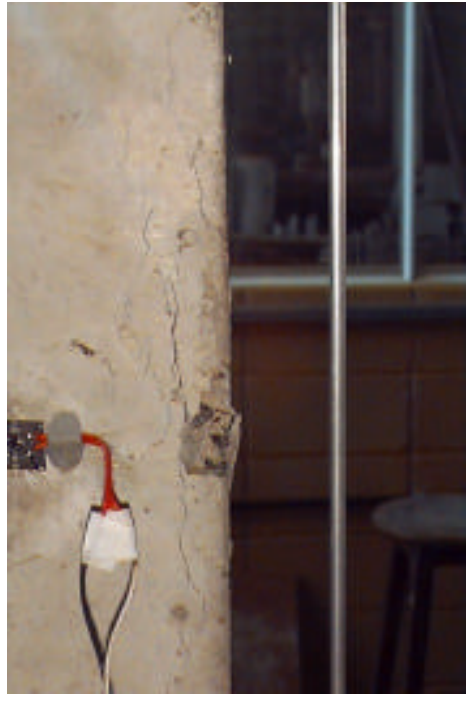

a)

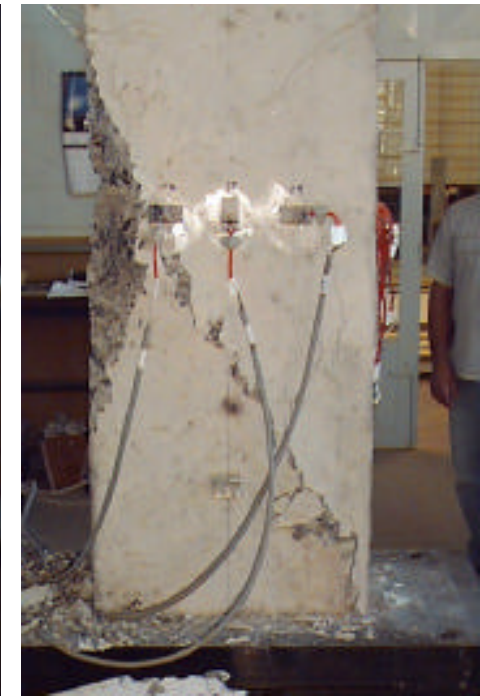

b)

Figura 5.16. Pilar P4-12,5-100. a) Fissura decorrente da flambagem de uma das barras longitudinais das quinas; e b) Lado esquerdo do pilar mais deteriorado revela o estado de flexão composta que atuou sobre o modelo.

p) Pilar P4-12,5-75

As atividades de moldagem e ensaio do pilar P4-12,5-75 se deram nos mesmos dias do pilar P4-12,5-100. Quanto a sua instrumentação, nenhuma falha foi detectada. Mais uma vez, o ensaio teve início após o ajuste da posição do pilar juntamente com a aplicação da força de escorvamento. As forças registradas no momento da primeira fissura e da ruína do modelo foram de $1300 \mathrm{kN}$ e $1365 \mathrm{kN}$, respectivamente. Dois dos quatro transdutores caíram quando era aplicada a força de $1300 \mathrm{kN}$. A flambagem de duas barras longitudinais foi verificada a partir de $1350 \mathrm{kN}$ do pós-pico. Fissuras inclinadas surgiram no pós-pico com uma força de aproximadamente $1200 \mathrm{kN}$. Este experimento teve de ser interrompido em $1000 \mathrm{kN}$ do pós-pico por conta da ameaça do pilar sair lateralmente da máquina de ensaio. Isto foi verificado visualmente por meio da flecha apresentada pelo pilar e do aparecimento de fissuras horizontais em uma de suas faces (ver a figura 5.17.a). Com certeza, a flexão composta atuante sobre este pilar foi a responsável por tal acontecimento. 


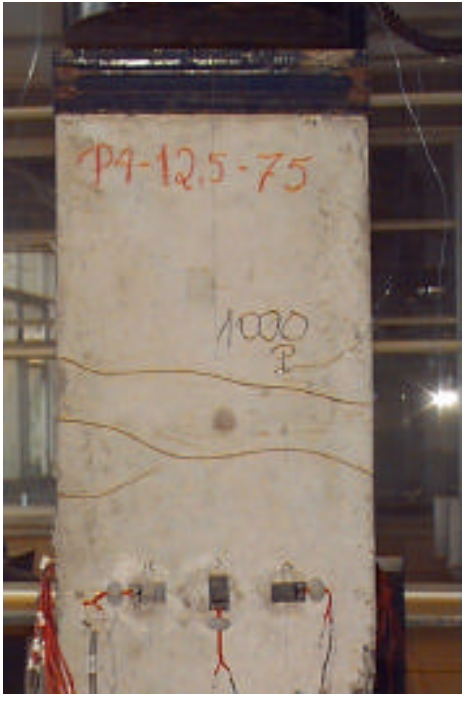

a)

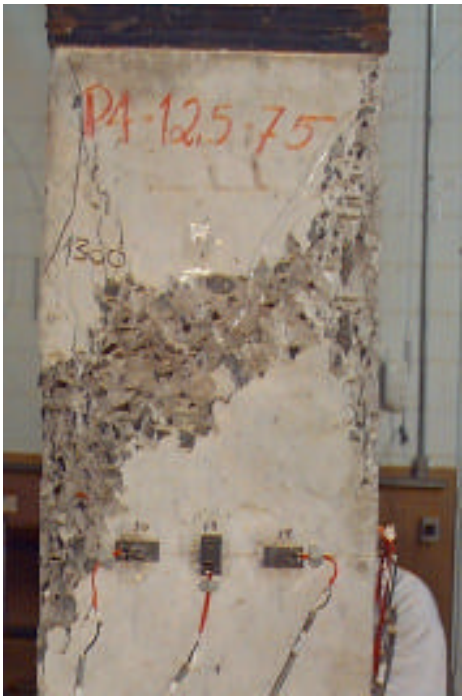

b)

Figura 5.17. Pilar P4-12,5-75. a) Fissuras horizontais na face menos carregada do pilar; e b) Estado de fissuração da face mais carregada do pilar.

\subsection{Resultados dos Ensaios dos Pilares}

Os resultados dos ensaios dos pilares nada mais são do que os deslocamentos dos transdutores e deformações dos extensômetros registradas em função da força aplicada pela máquina de ensaio. Assim sendo, com o intuito de facilitar o estudo destes dados, foram construídos diagramas que relacionam força e deformação. Além disso, quando possível, são apresentadas as deformações obtidas por meio dos transdutores e extensômetros correspondentes à máxima força empregada nos modelos de pilares.

\subsubsection{Diagramas Força-Deformação}

O objetivo deste item é apresentar, por meio de curvas que relacionam força e deformação, a resposta longitudinal e transversal dos pilares àforça aplicada, em termos de deformação. Porém, para tanto, é acompanhada uma figura que ilustra a numeração dos transdutores e extensômetros que aparecem nas legendas dos diagramas. 
a) Pilar $P 1-10,0-120$

$$
\begin{aligned}
& f_{c, \text { pilar }}=23,7 \mathrm{MPa} \\
& \mathrm{F}_{\text {experimental }}=1072 \mathrm{kN}
\end{aligned}
$$

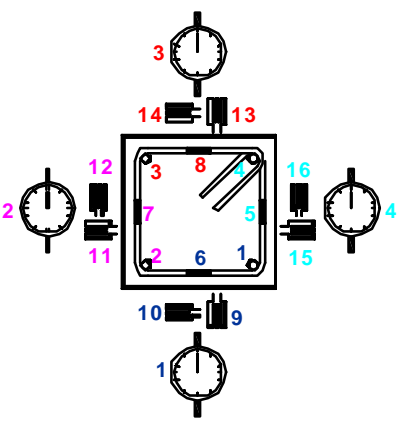

Figura 5.18. Numeração dos transdutores e extensômetros do pilar P1-10,0-120.

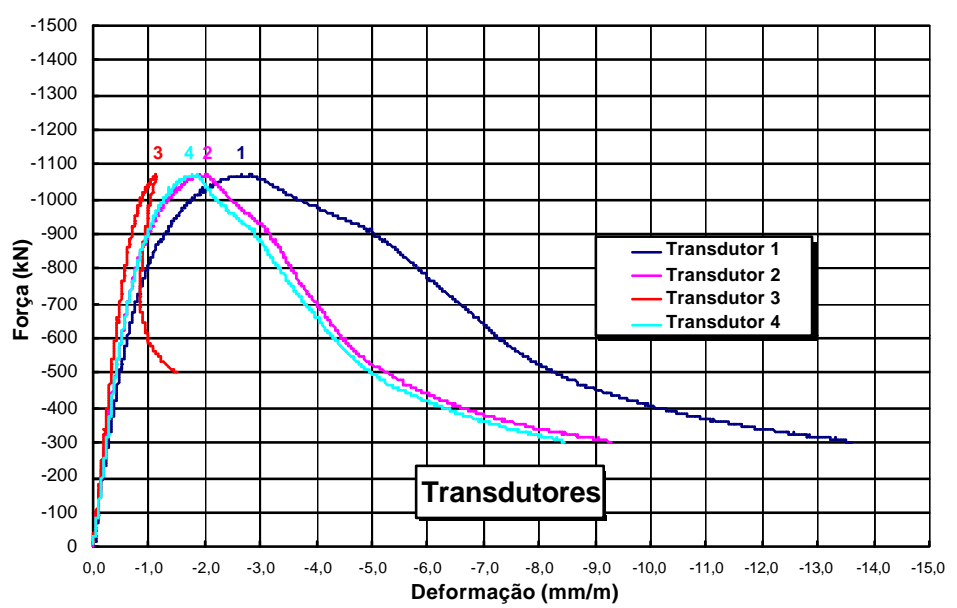

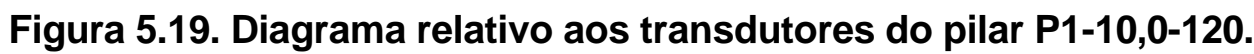

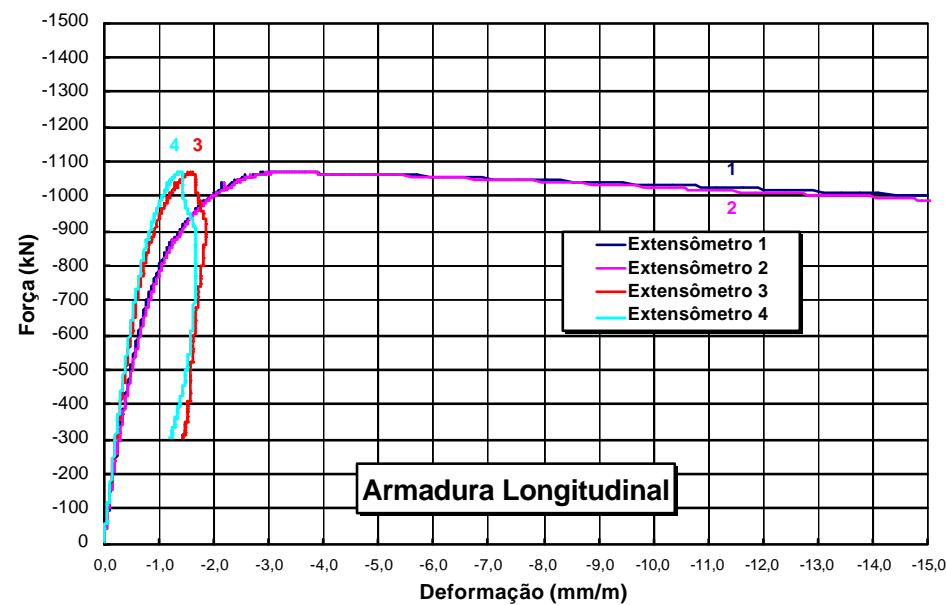

Figura 5.20. Diagrama relativo aos extensômetros da armadura longitudinal do pilar P1-10,0-120. 


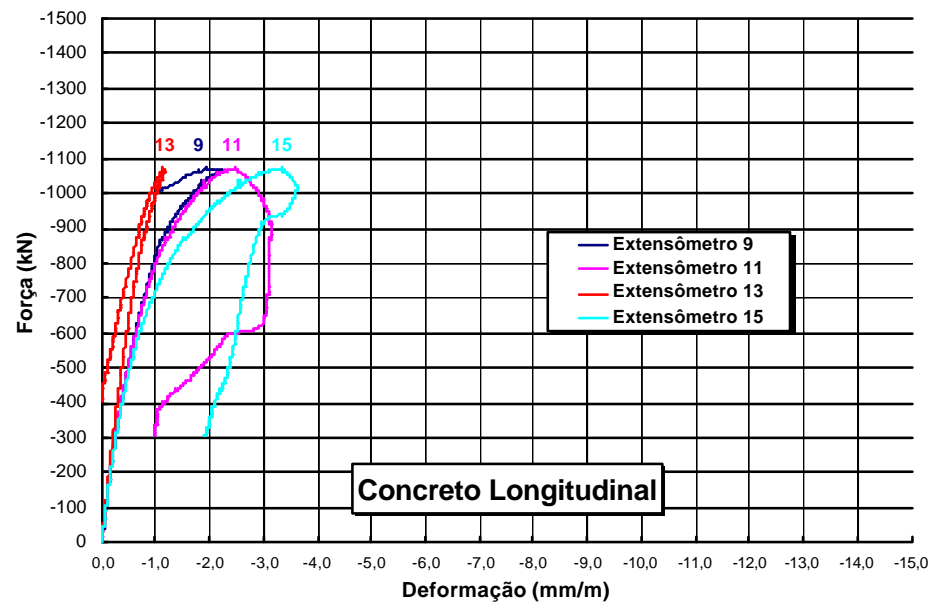

Figura 5.21. Diagrama relativo aos extensômetros dispostos longitudinalmente sobre as faces do pilar P1-10,0-120.

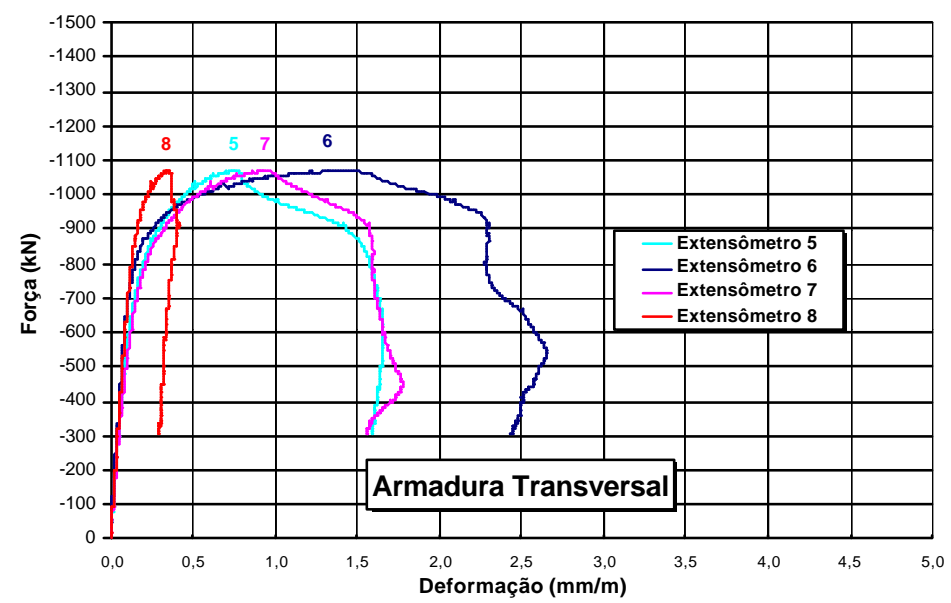

Figura 5.22. Diagrama relativo aos extensômetros da armadura transversal do pilar P1-10,0-120.

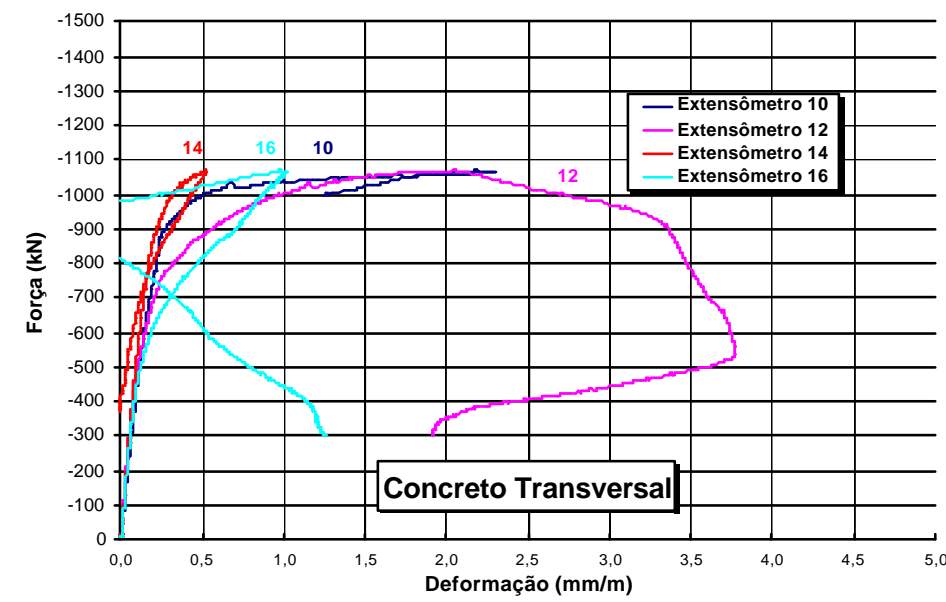

Figura 5.23. Diagrama relativo aos extensômetros dispostos transversalmente sobre as faces do pilar P1-10,0-120. 
b) Pilar P1-12,5-200

$$
\begin{aligned}
& f_{c, \text { pilar }}=23,7 \mathrm{MPa} \\
& \mathrm{F}_{\text {experimental }}=1085 \mathrm{kN}
\end{aligned}
$$

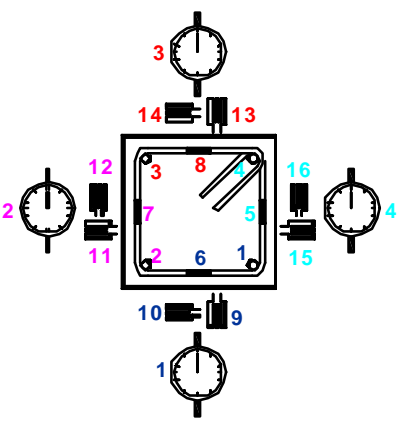

Figura 5.24. Numeração dos transdutores e extensômetros do pilar

P1-12,5-200.

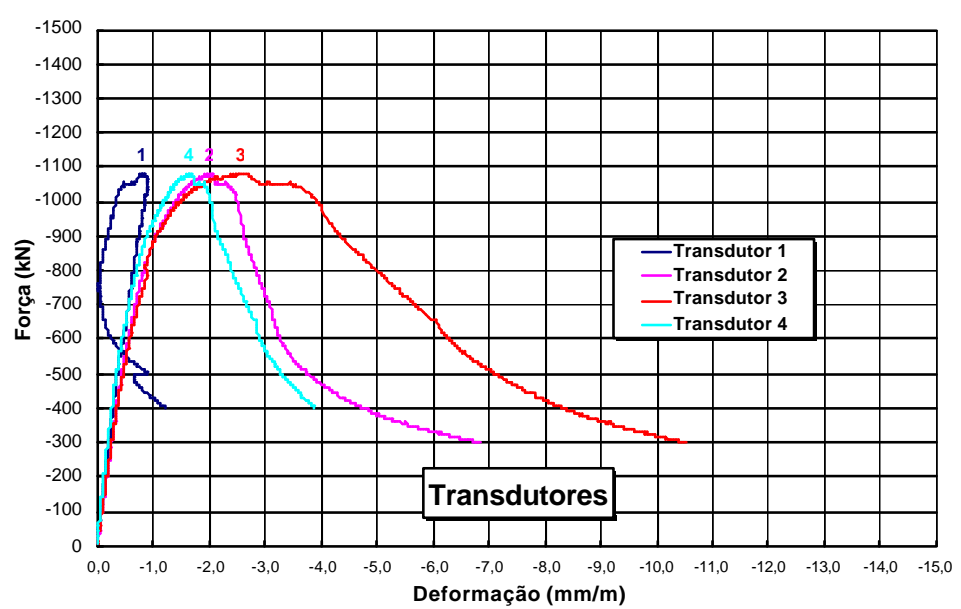

Figura 5.25. Diagrama relativo aos transdutores do pilar P1-12,5-200.

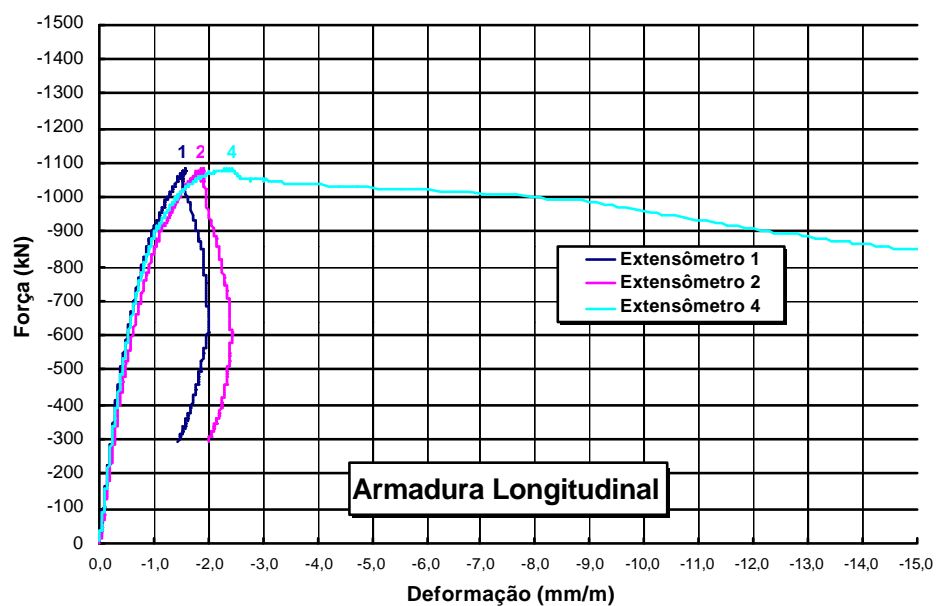

Figura 5.26. Diagrama relativo aos extensômetros da armadura longitudinal do pilar P1-12,5-200. 


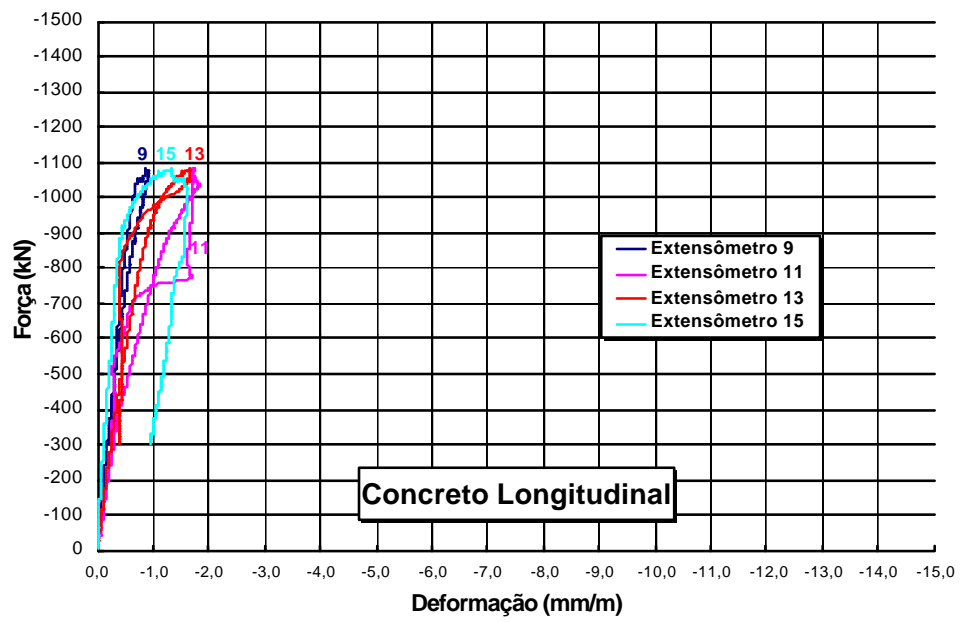

Figura 5.27. Diagrama relativo aos extensômetros dispostos longitudinalmente sobre as faces do pilar P1-12,5-200.

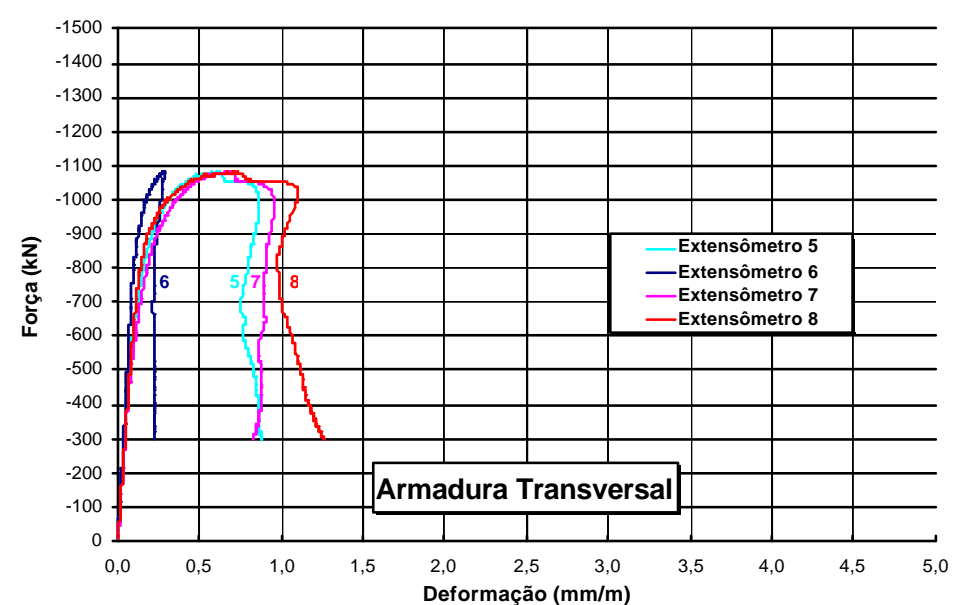

Figura 5.28. Diagrama relativo aos extensômetros da armadura transversal do pilar P1-12,5-200.

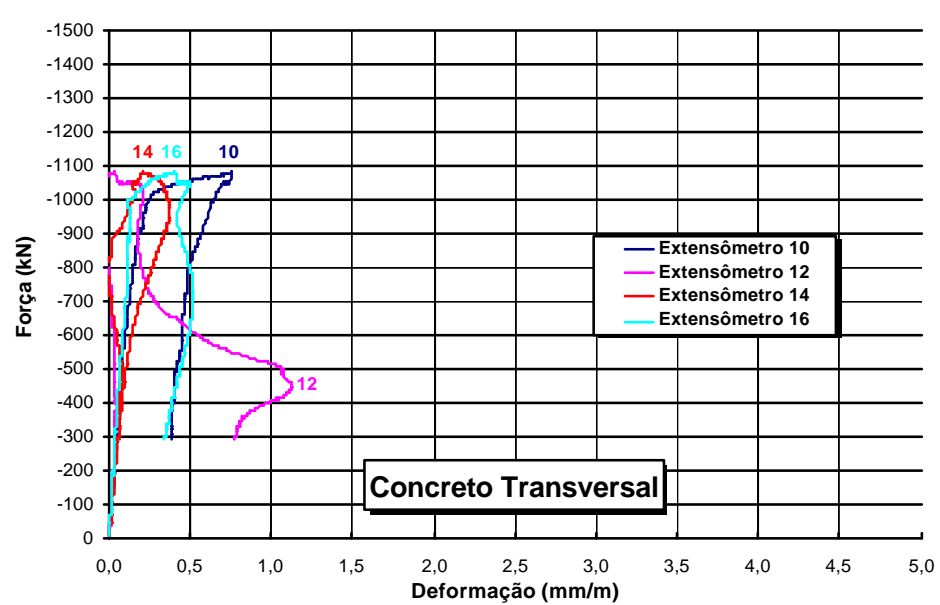

Figura 5.29. Diagrama relativo aos extensômetros dispostos transversalmente sobre as faces do pilar P1-12,5-200. 
c) Pilar P1-12,5-150

$$
\begin{aligned}
& f_{c, \text { pilar }}=27,1 \mathrm{MPa} \\
& \mathrm{F}_{\text {experimental }}=1223 \mathrm{kN}
\end{aligned}
$$

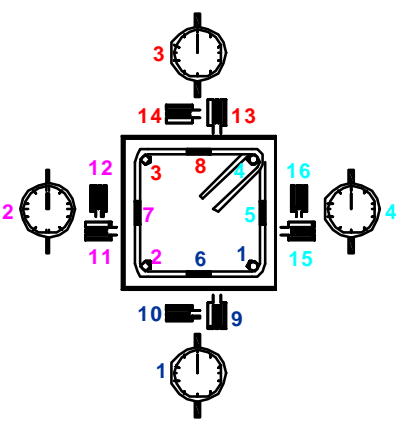

Figura 5.30. Numeração dos transdutores e extensômetros do pilar

P1-12,5-150.

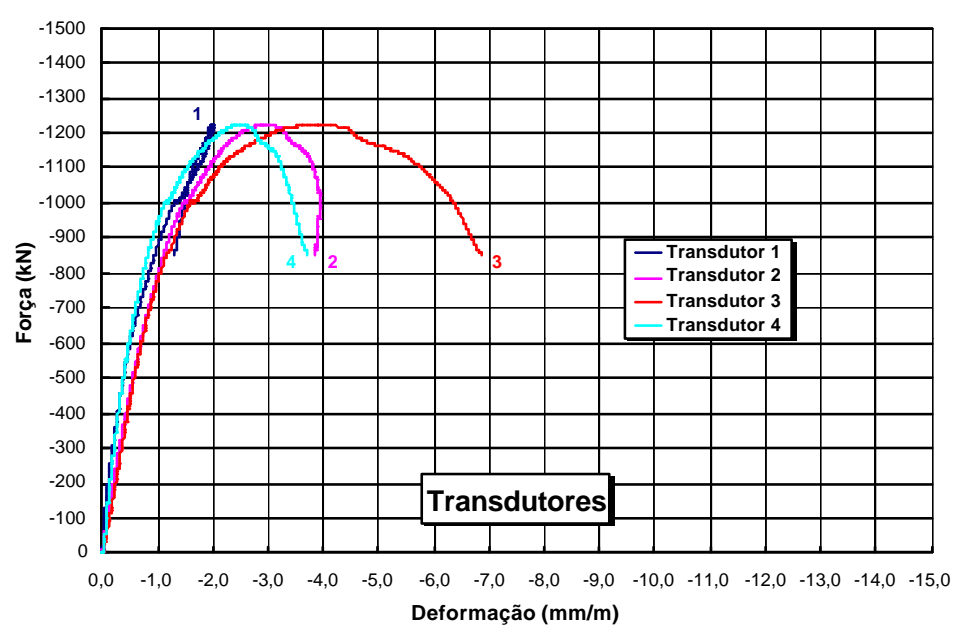

Figura 5.31. Diagrama relativo aos transdutores do pilar P1-12,5-150.

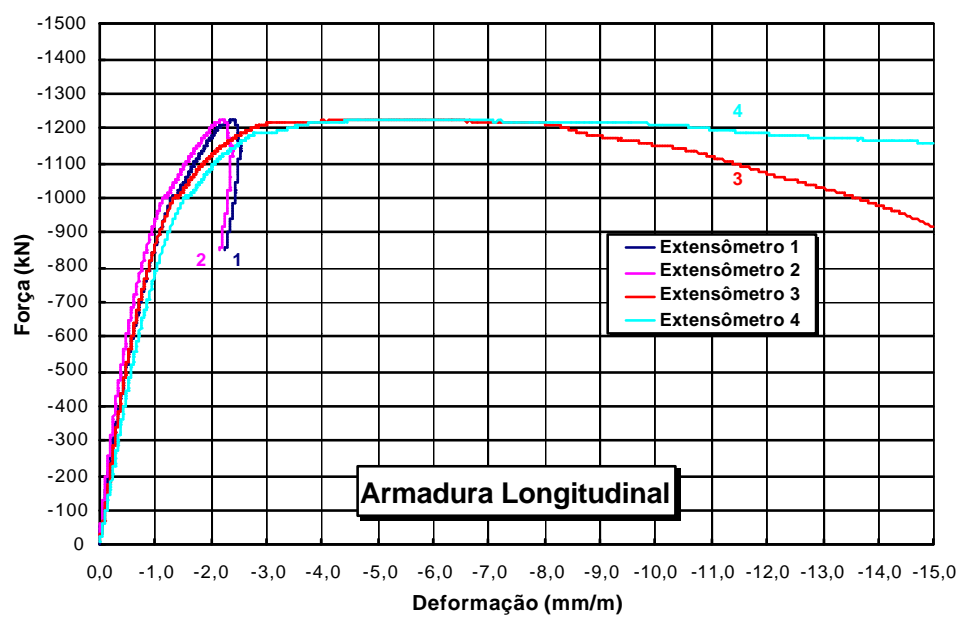

Figura 5.32. Diagrama relativo aos extensômetros da armadura longitudinal do pilar P1-12,5-150. 


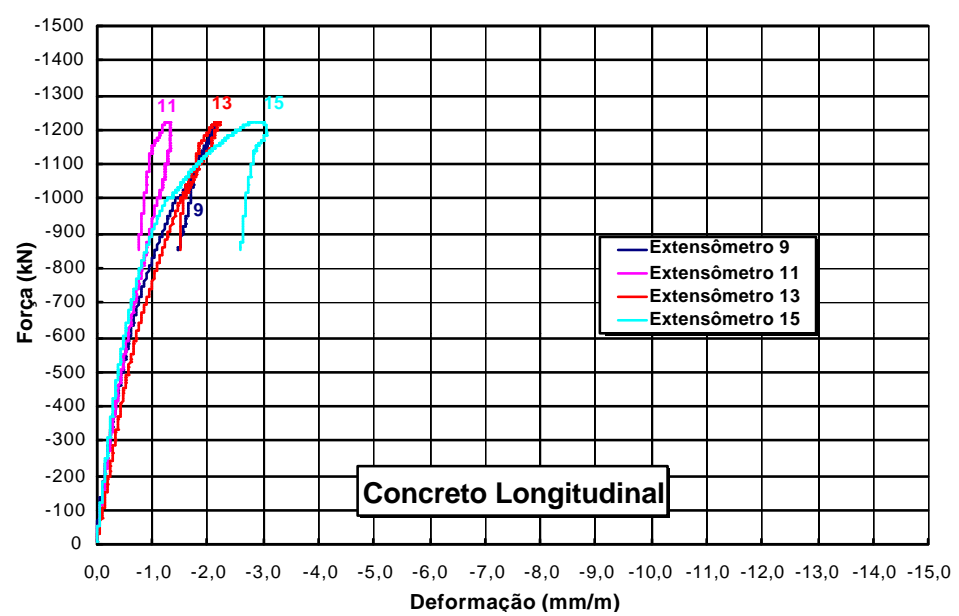

Figura 5.33. Diagrama relativo aos extensômetros dispostos

longitudinalmente sobre as faces do pilar P1-12,5-150.

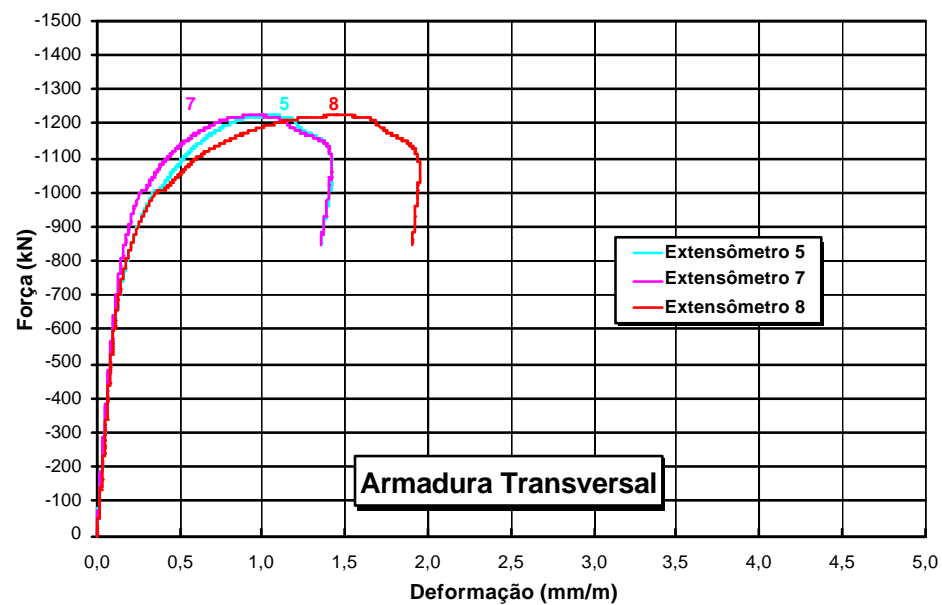

Figura 5.34. Diagrama relativo aos extensômetros da armadura transversal do pilar P1-12,5-150.

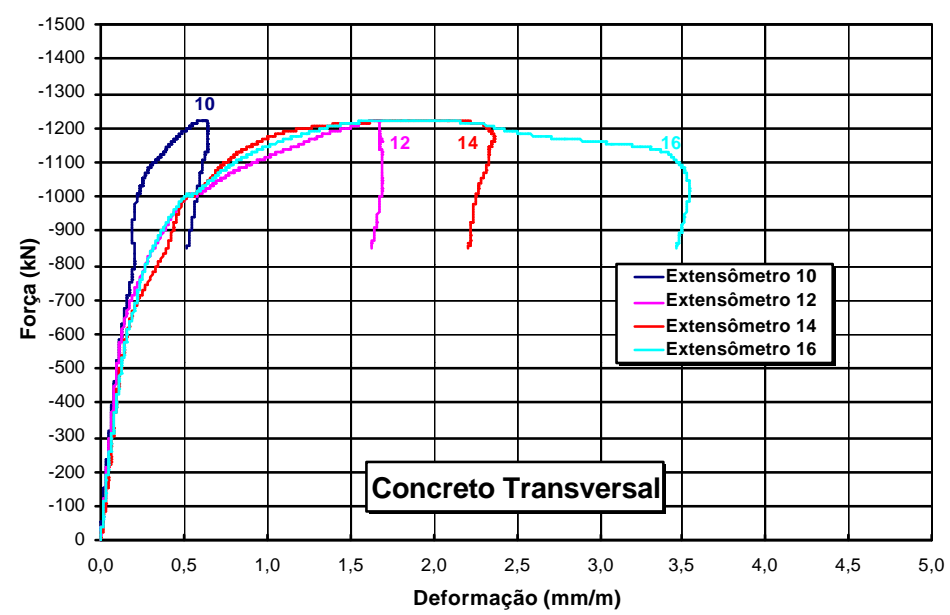

Figura 5.35. Diagrama relativo aos extensômetros dispostos transversalmente sobre as faces do pilar P1-12,5-150. 
d) Pilar P1-12,5-100

$$
\begin{aligned}
& f_{c, \text { pilar }}=27,1 \mathrm{MPa} \\
& \mathrm{F}_{\text {experimental }}=1292 \mathrm{kN}
\end{aligned}
$$

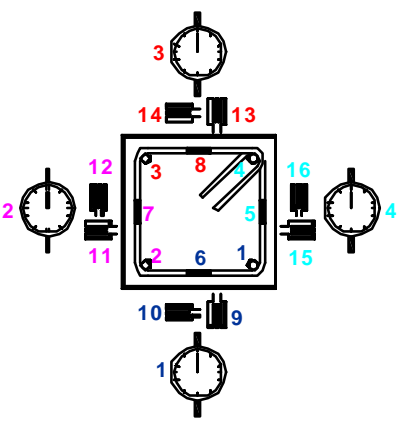

Figura 5.36. Numeração dos transdutores e extensômetros do pilar P1-12,5-100.

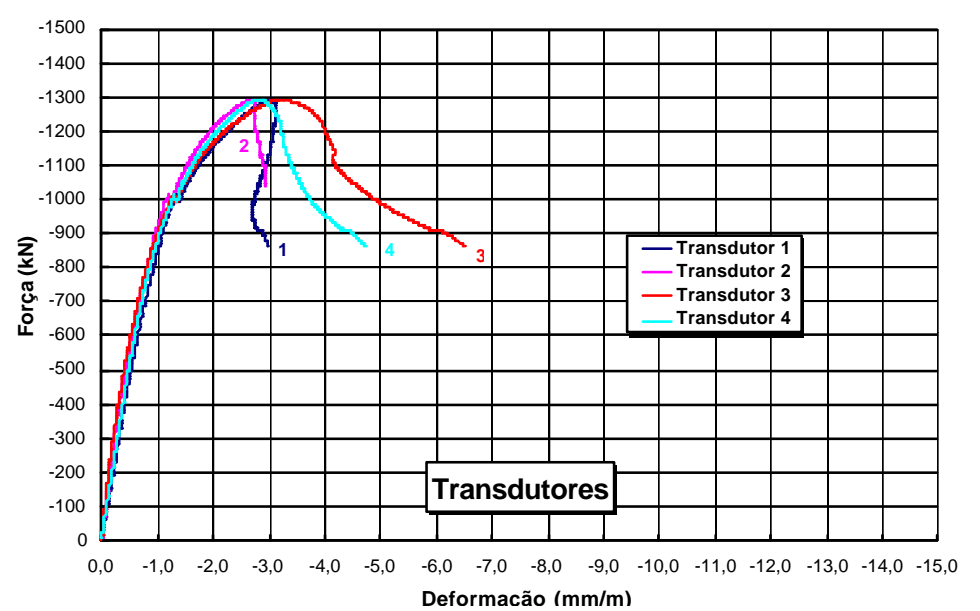

Figura 5.37. Diagrama relativo aos transdutores do pilar P1-12,5-100.

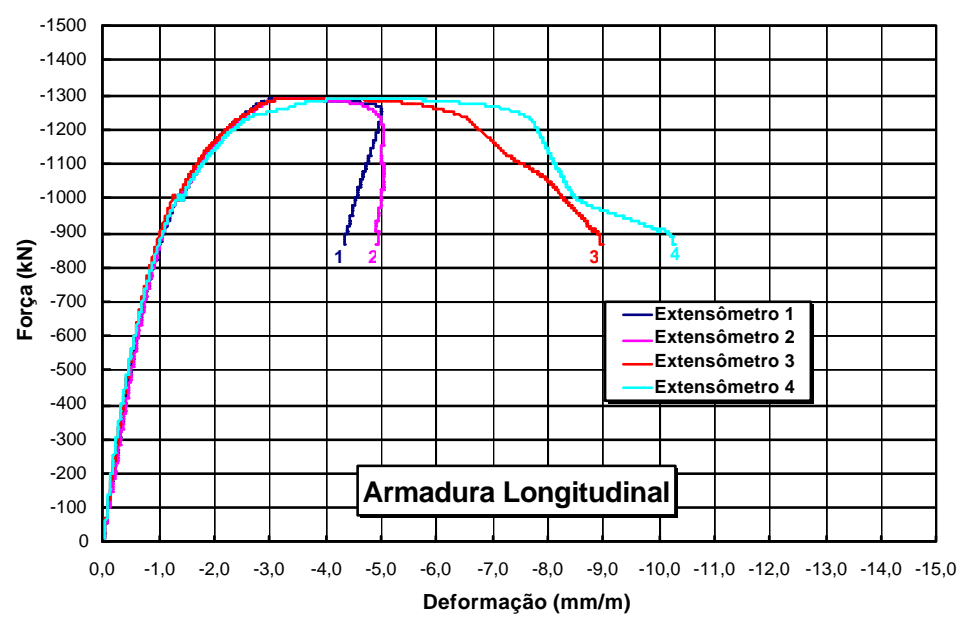

Figura 5.38. Diagrama relativo aos extensômetros da armadura longitudinal do pilar P1-12,5-100. 


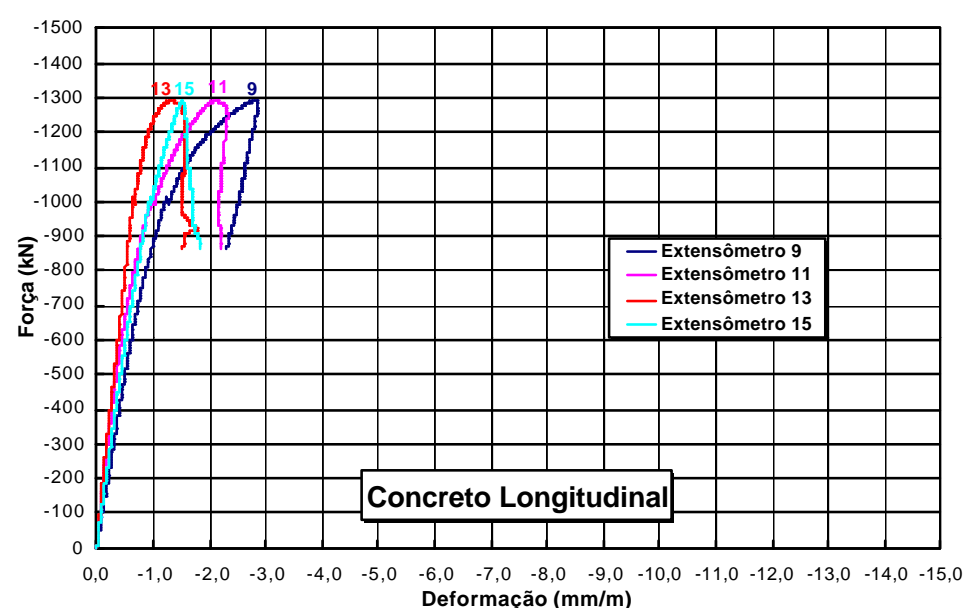

Figura 5.39. Diagrama relativo aos extensômetros dispostos longitudinalmente sobre as faces do pilar P1-12,5-100.

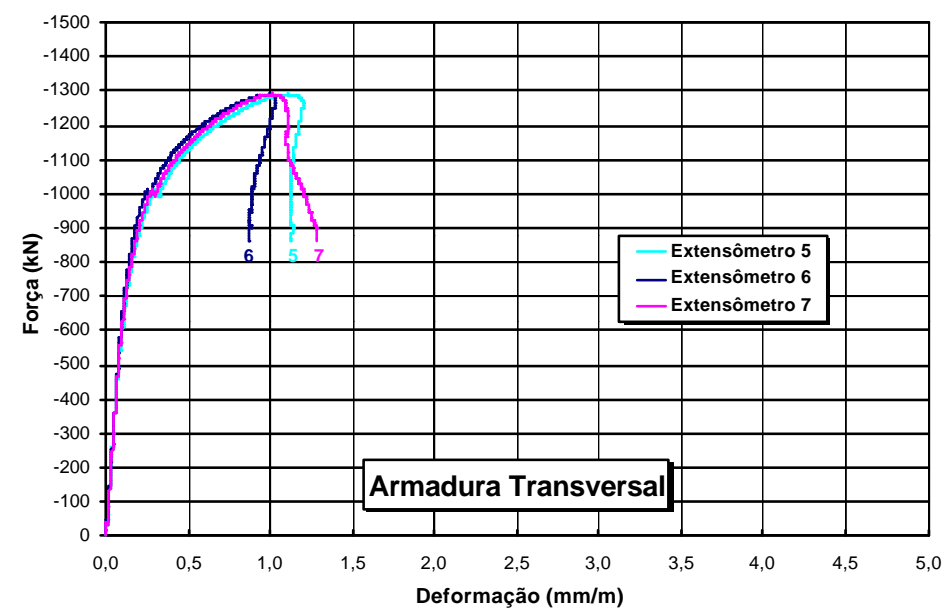

Figura 5.40. Diagrama relativo aos extensômetros da armadura transversal do pilar P1-12,5-100.

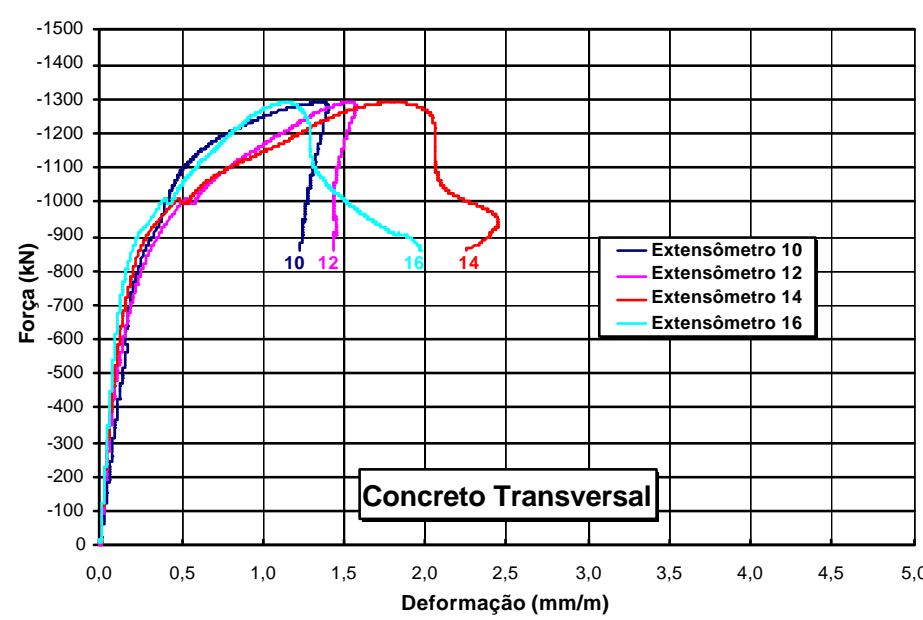

Figura 5.41. Diagrama relativo aos extensômetros dispostos transversalmente sobre as faces do pilar P1-12,5-100. 
e) Pilar P2-12,5-150

$$
\begin{aligned}
& f_{c, \text { pilar }}=22,3 \mathrm{MPa} \\
& \mathrm{F}_{\text {experimental }}=1400 \mathrm{kN}
\end{aligned}
$$

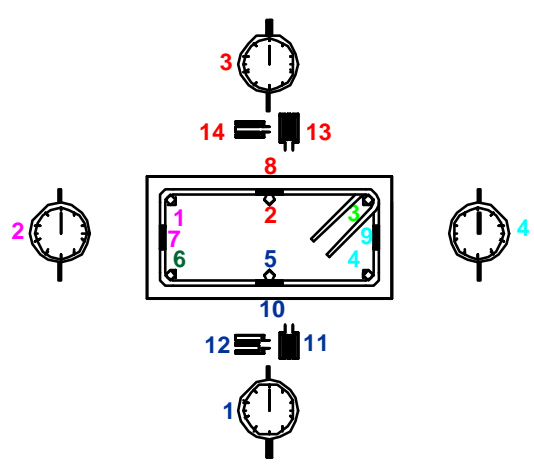

Figura 5.42. Numeração dos transdutores e extensômetros do pilar P2-12,5-150.

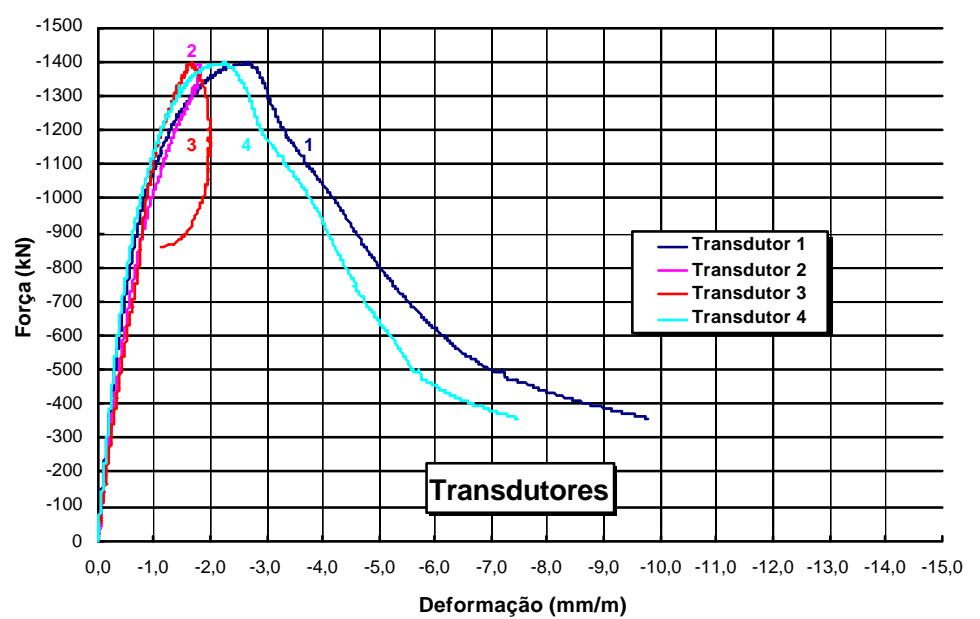

Figura 5.43. Diagrama relativo aos transdutores do pilar P2-12,5-150.

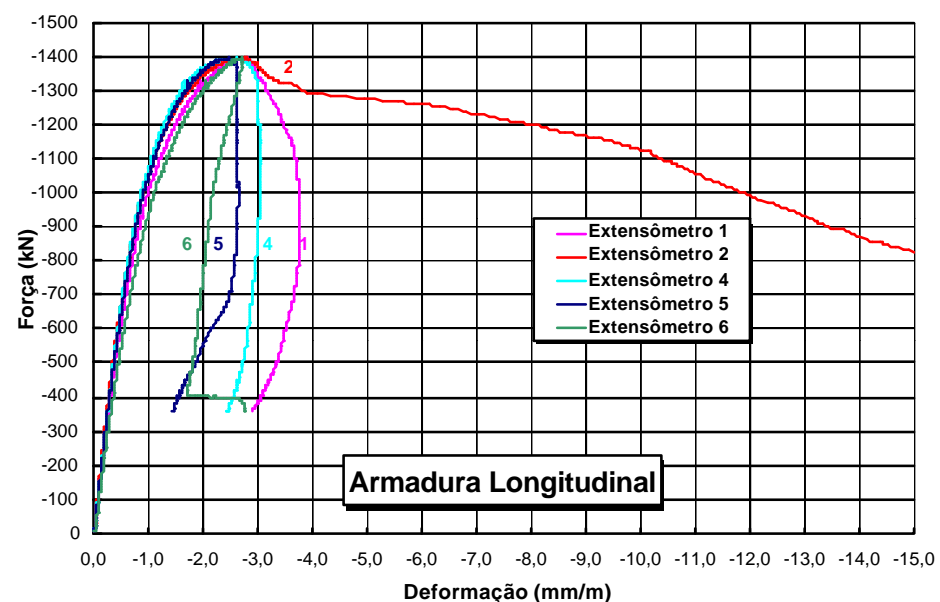

Figura 5.44. Diagrama relativo aos extensômetros da armadura longitudinal do pilar P2-12,5-150. 


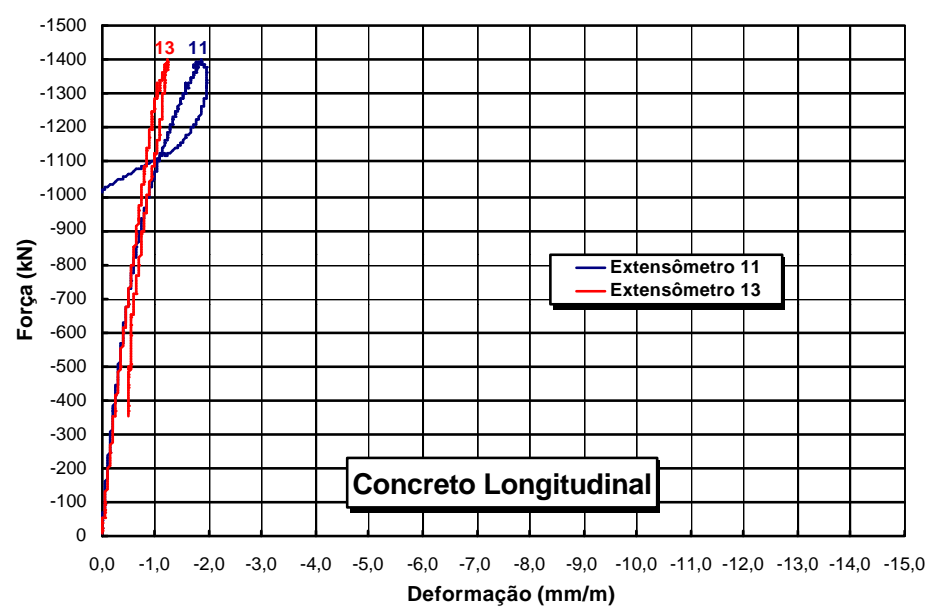

Figura 5.45. Diagrama relativo aos extensômetros dispostos longitudinalmente sobre as faces do pilar P2-12,5-150.

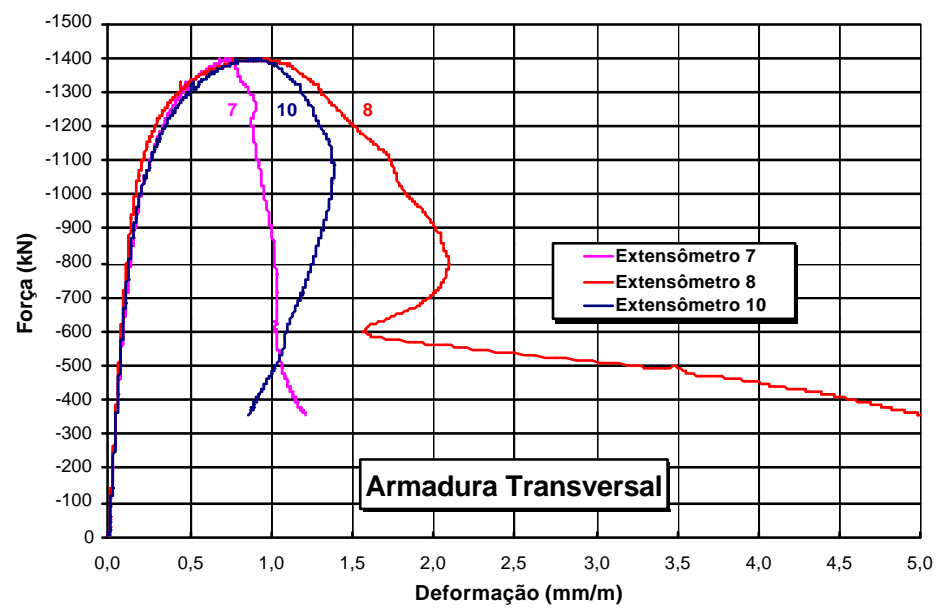

Figura 5.46. Diagrama relativo aos extensômetros da armadura transversal do pilar P2-12,5-150.

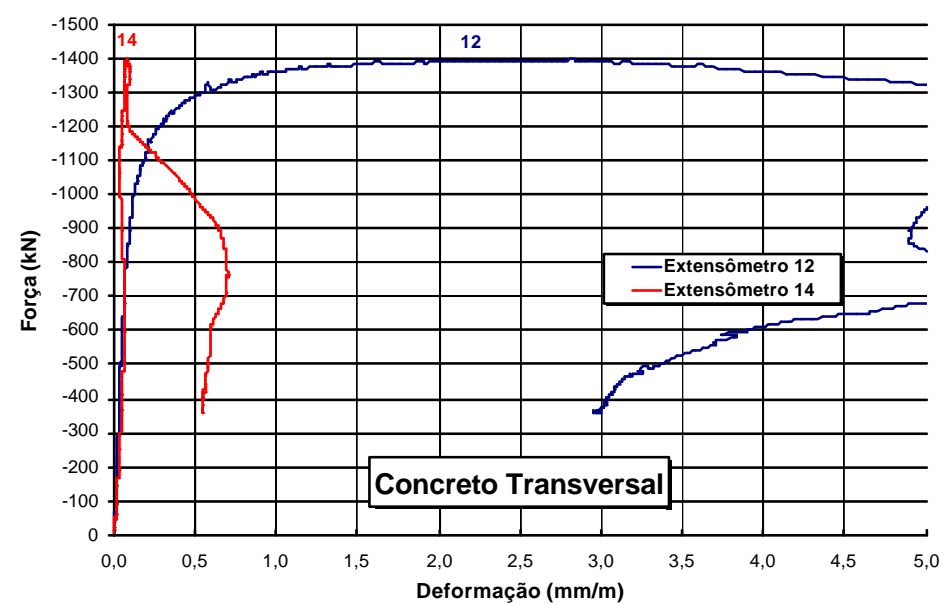

Figura 5.47. Diagrama relativo aos extensômetros dispostos transversalmente sobre as faces do pilar P2-12,5-150. 
f) Pilar P2-12,5-100

$$
\begin{gathered}
f_{c, \text { pilar }}=23,3 \mathrm{MPa} \\
\mathrm{F}_{\text {experimental }}=1175 \mathrm{kN}
\end{gathered}
$$

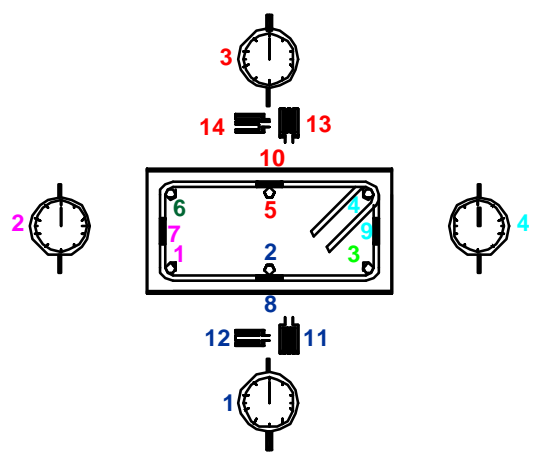

Figura 5.48. Numeração dos transdutores e extensômetros do pilar P2-12,5-100.

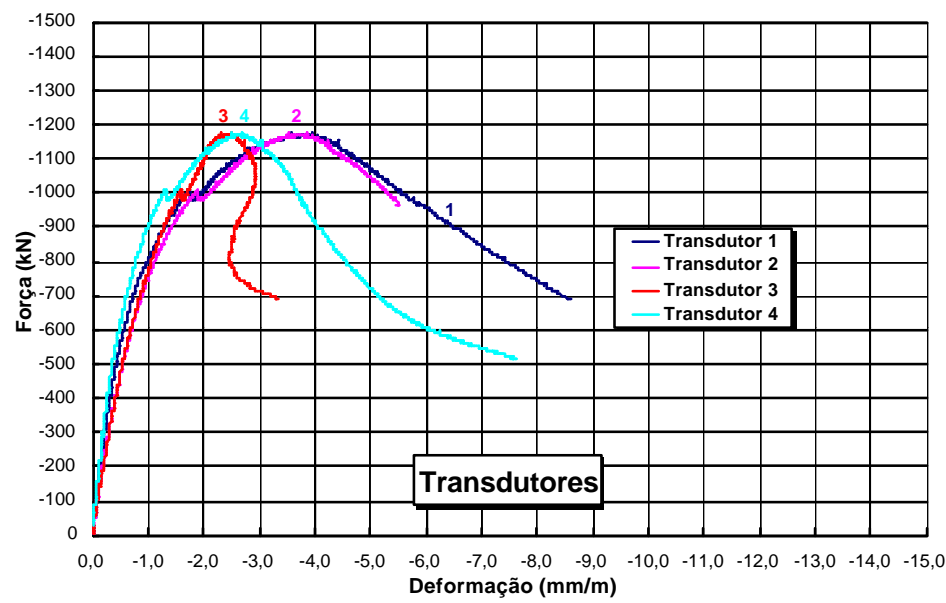

Figura 5.49. Diagrama relativo aos transdutores do pilar P2-12,5-100.

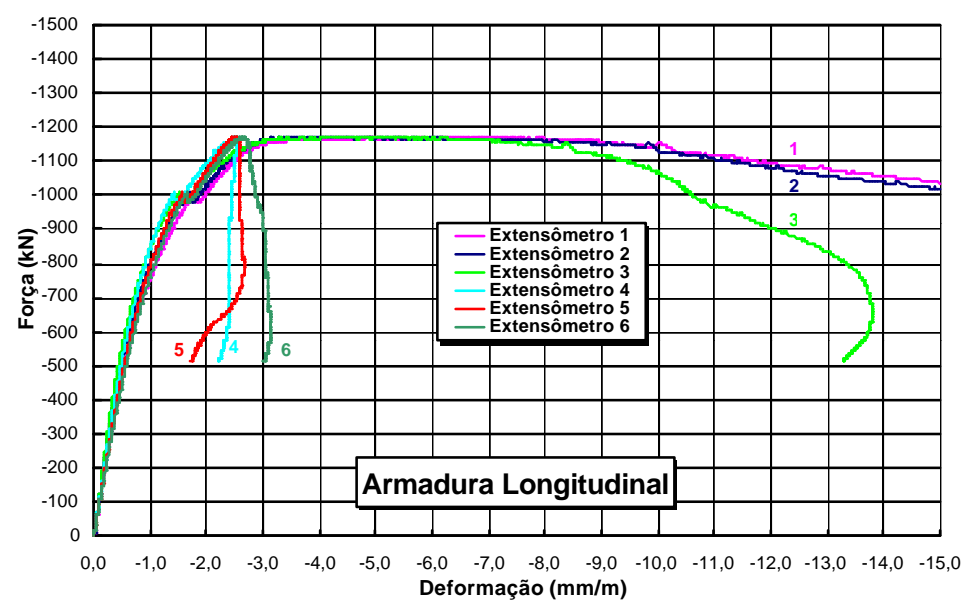

Figura 5.50. Diagrama relativo aos extensômetros da armadura longitudinal do pilar P2-12,5-100. 


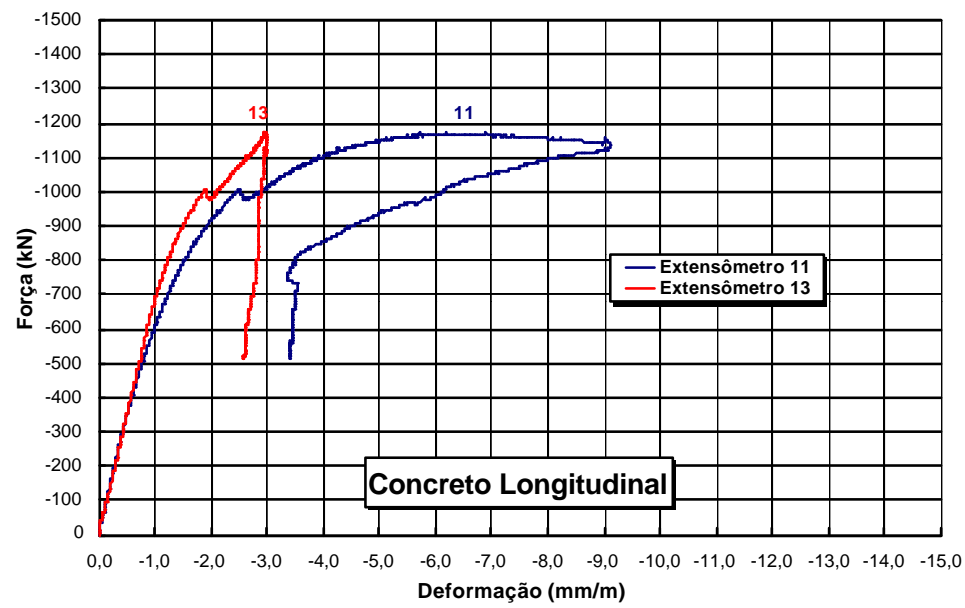

Figura 5.51. Diagrama relativo aos extensômetros dispostos longitudinalmente sobre as faces do pilar P2-12,5-100.

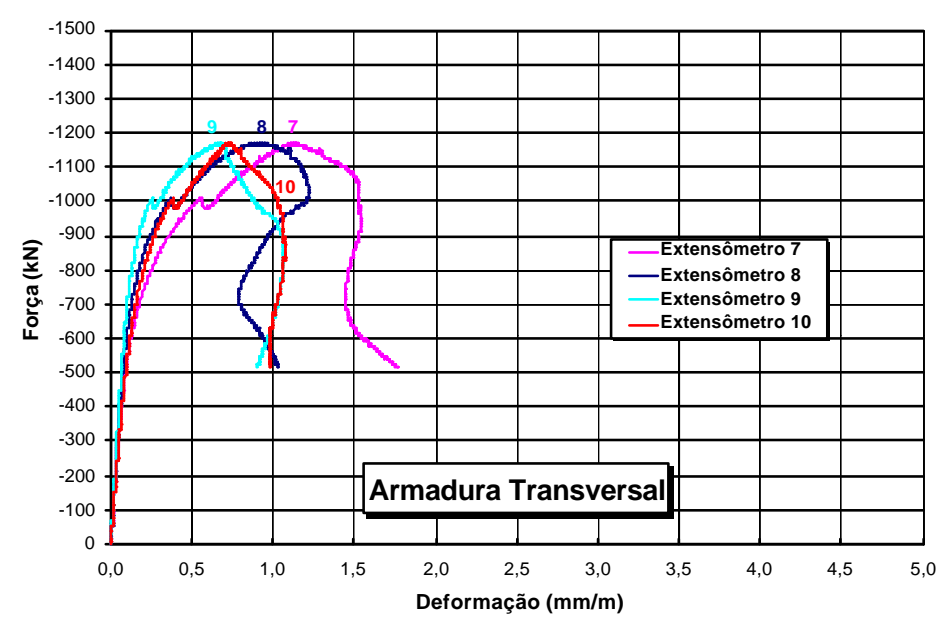

Figura 5.52. Diagrama relativo aos extensômetros da armadura transversal do pilar P2-12,5-100.

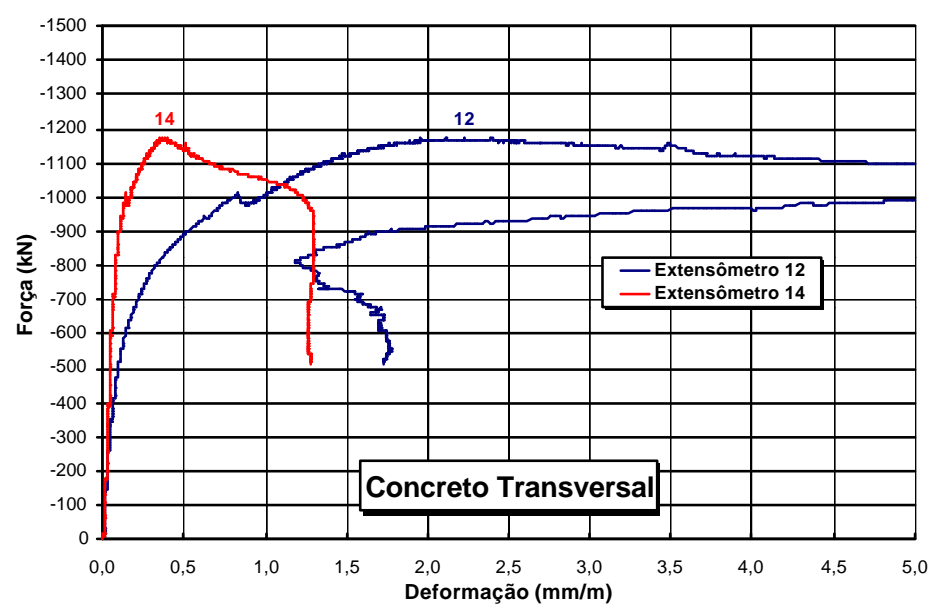

Figura 5.53. Diagrama relativo aos extensômetros dispostos transversalmente sobre as faces do pilar P2-12,5-100. 
g) Pilar P2-12,5-75

$$
\begin{aligned}
& f_{c, \text { pilar }}=23,3 \mathrm{MPa} \\
& \mathrm{F}_{\text {experimental }}=1215 \mathrm{kN}
\end{aligned}
$$

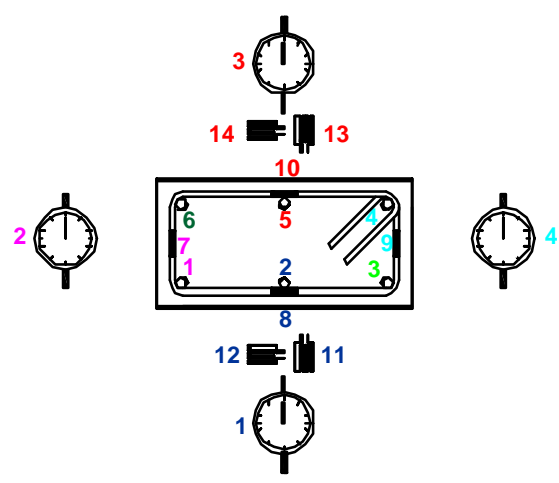

Figura 5.54. Numeração dos transdutores e extensômetros do pilar P2-12,5-75.

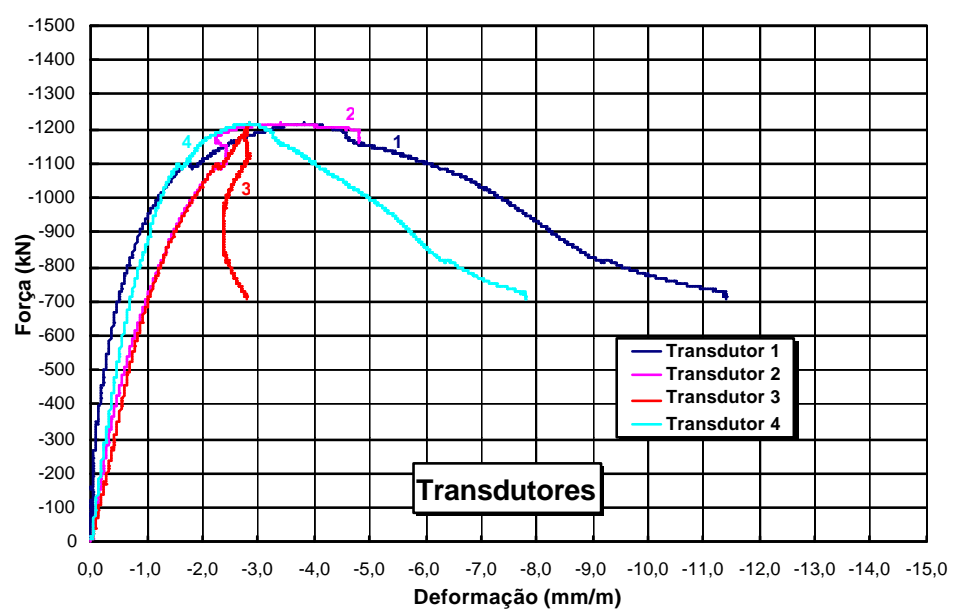

Figura 5.55. Diagrama relativo aos transdutores do pilar P2-12,5-75.

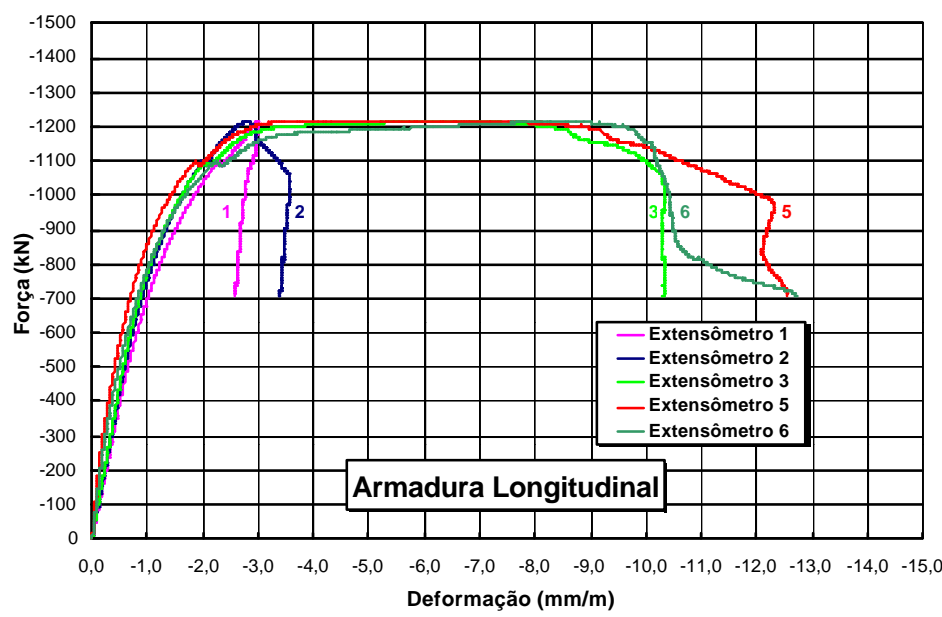

Figura 5.56. Diagrama relativo aos extensômetros da armadura longitudinal do pilar P2-12,5-75. 


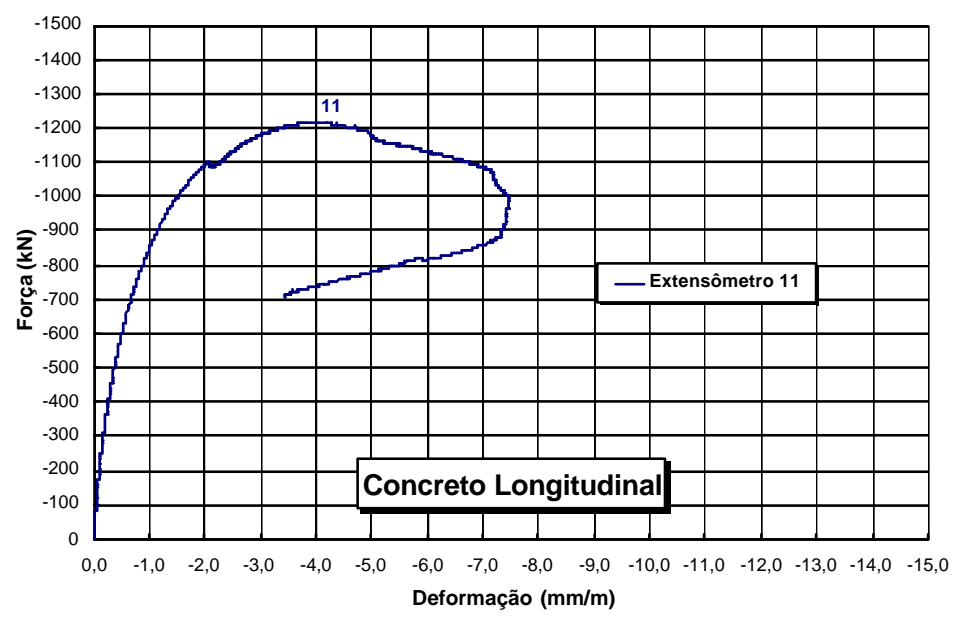

Figura 5.57. Diagrama relativo aos extensômetros dispostos longitudinalmente sobre as faces do pilar P2-12,5-75.

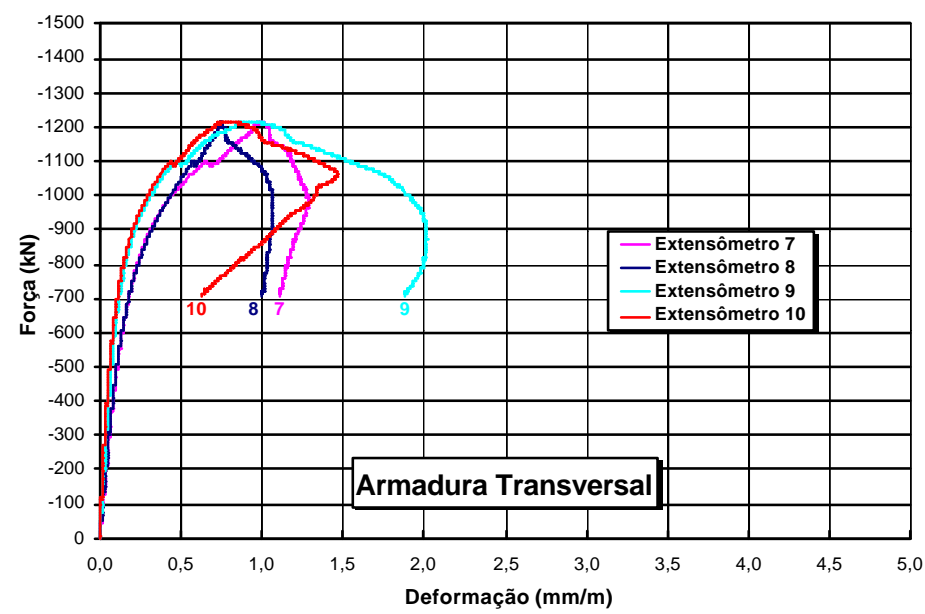

Figura 5.58. Diagrama relativo aos extensômetros da armadura transversal do pilar P2-12,5-75.

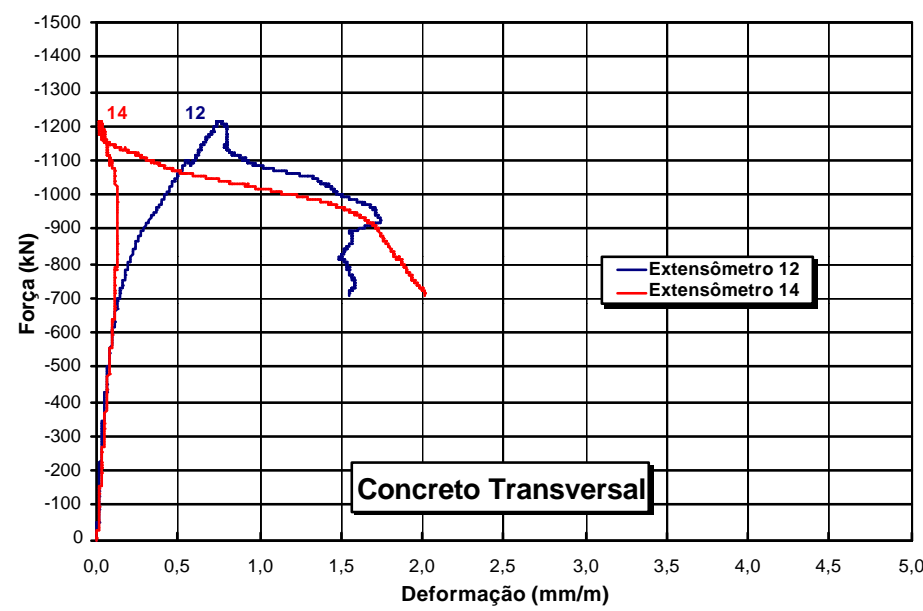

Figura 5.59. Diagrama relativo aos extensômetros dispostos transversalmente sobre as faces do pilar P2-12,5-75. 
h) Pilar P3-10,0-120

$$
\begin{aligned}
& f_{c, \text { pilar }}=26,1 \mathrm{MPa} \\
& \mathrm{F}_{\text {experimental }}=1265 \mathrm{kN}
\end{aligned}
$$

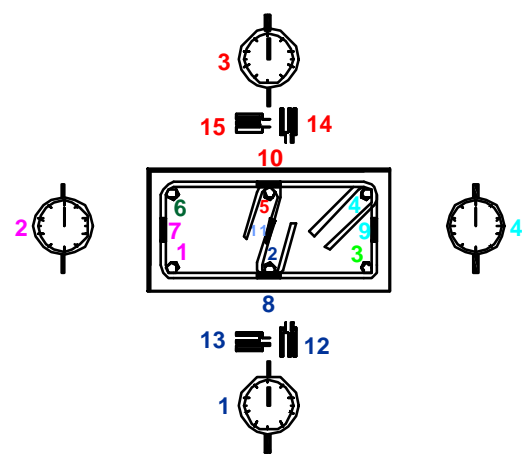

Figura 5.60. Numeração dos transdutores e extensômetros do pilar

P3-10,0-120.

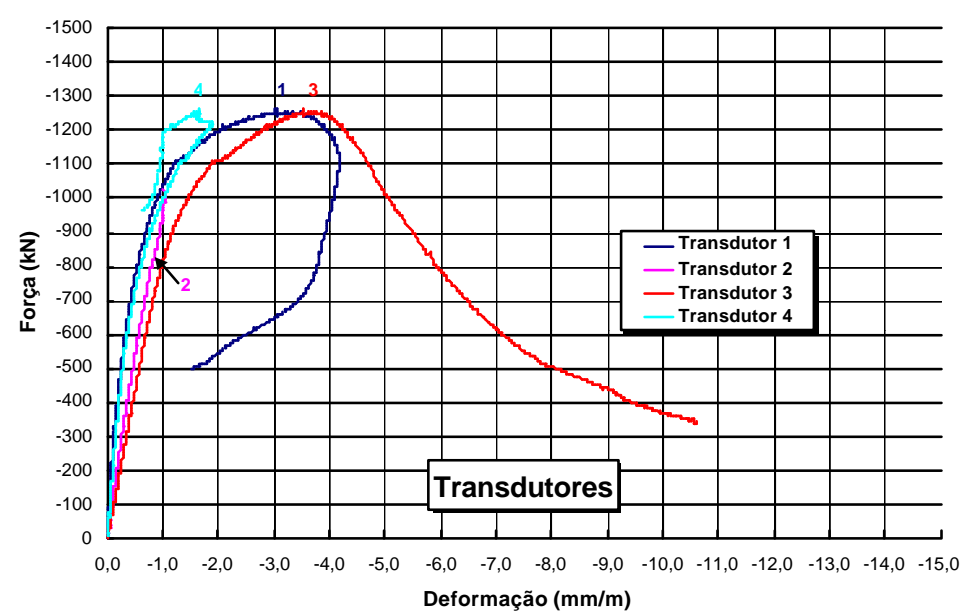

Figura 5.61. Diagrama relativo aos transdutores do pilar P3-10,0-120.

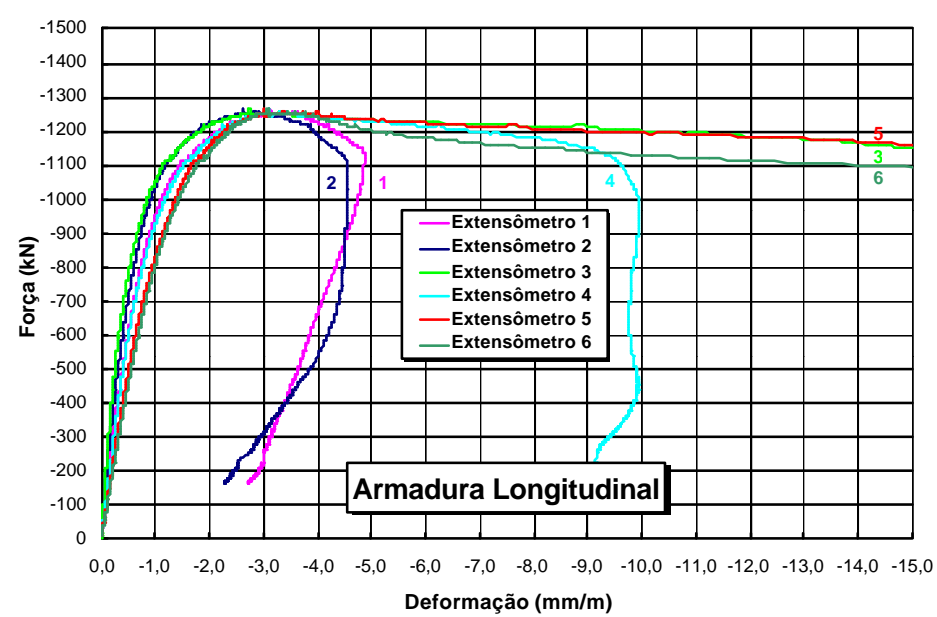

Figura 5.62. Diagrama relativo aos extensômetros da armadura longitudinal do pilar P3-10,0-120. 


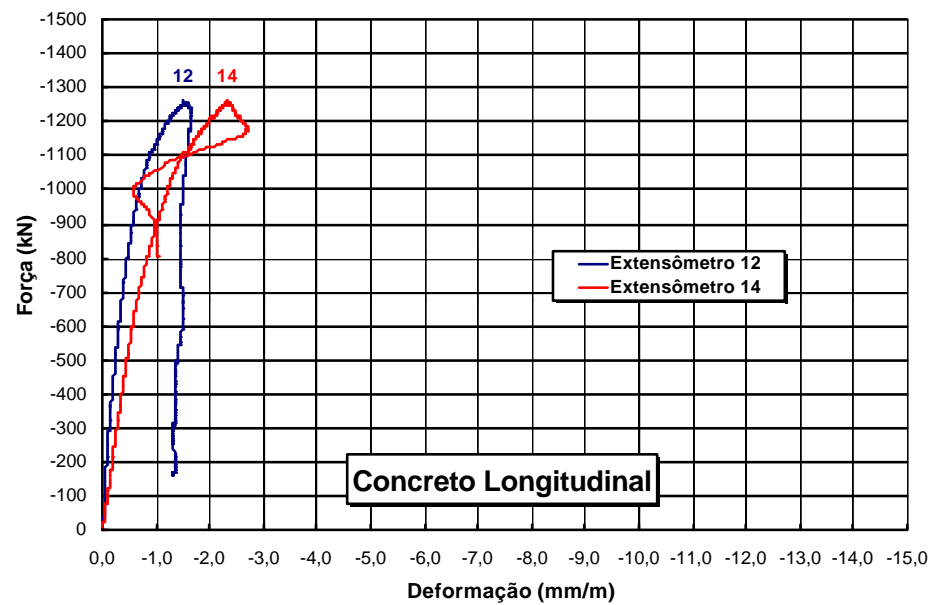

Figura 5.63. Diagrama relativo aos extensômetros dispostos longitudinalmente sobre as faces do pilar P3-10,0-120.

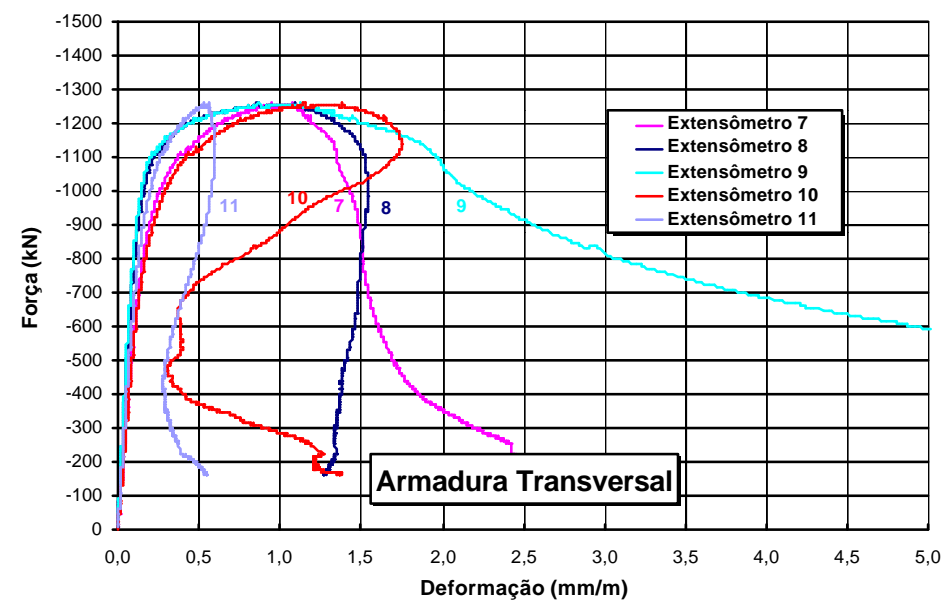

Figura 5.64. Diagrama relativo aos extensômetros da armadura transversal do pilar P3-10,0-120.

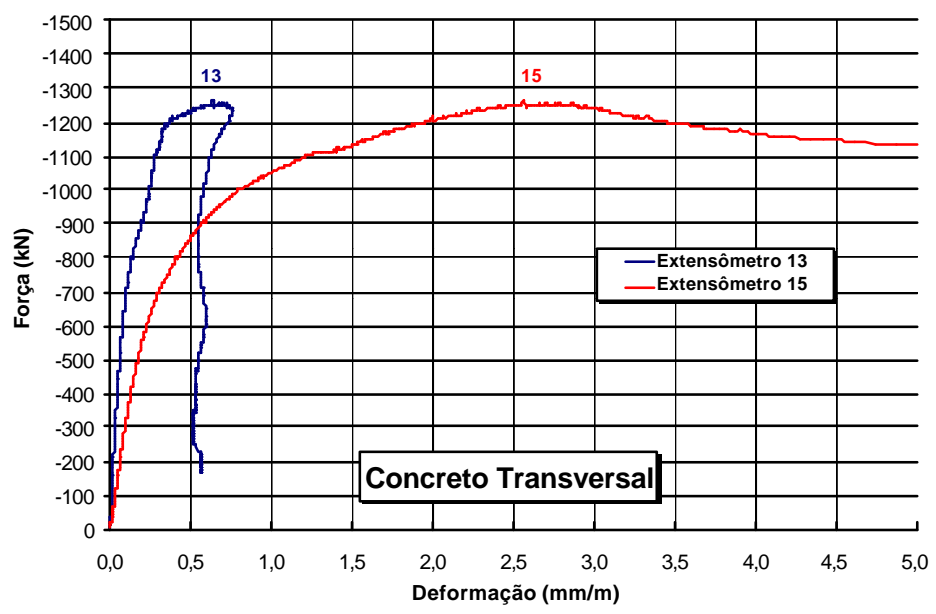

Figura 5.65. Diagrama relativo aos extensômetros dispostos transversalmente sobre as faces do pilar P3-10,0-120. 
i) Pilar P3-12,5-150

$$
\begin{aligned}
& f_{c, \text { pilar }}=26,1 \mathrm{MPa} \\
& \mathrm{F}_{\text {experimental }}=1322 \mathrm{kN}
\end{aligned}
$$

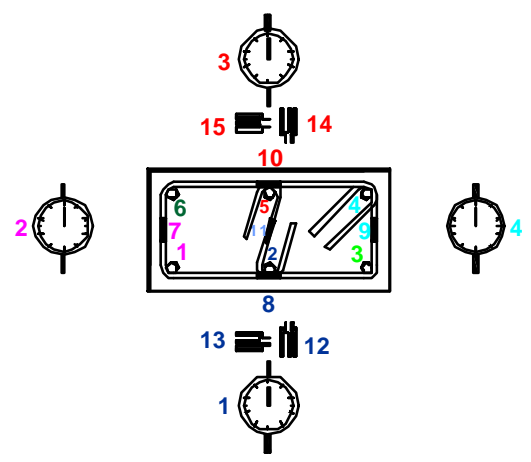

Figura 5.66. Numeração dos transdutores e extensômetros do pilar P3-12,5-150.

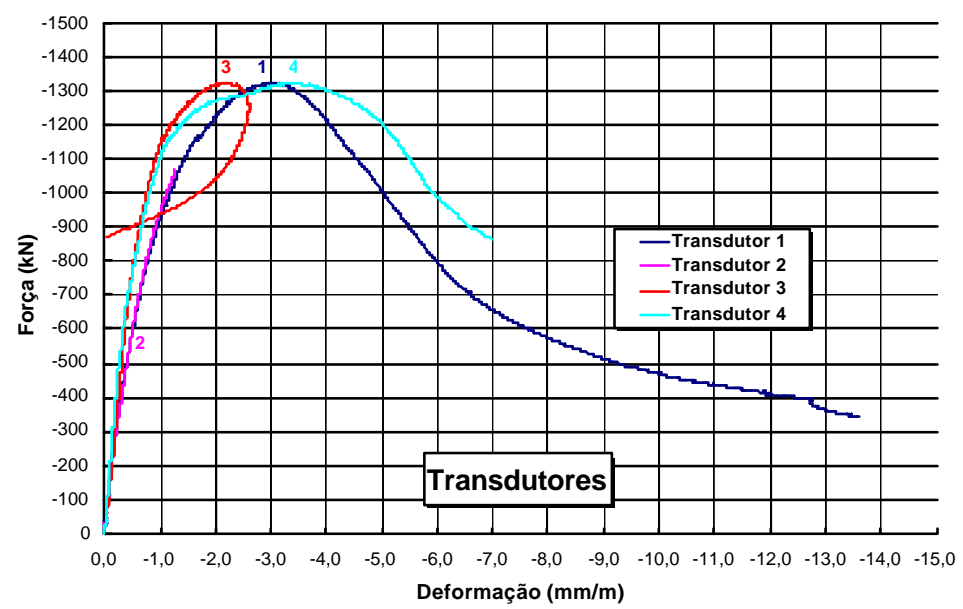

Figura 5.67. Diagrama relativo aos transdutores do pilar P3-12,5-150.

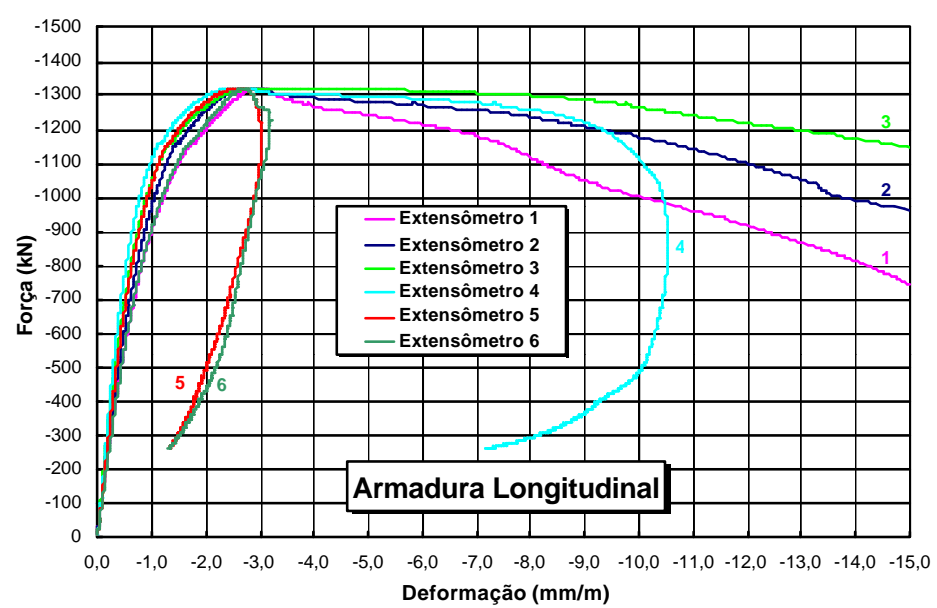

Figura 5.68. Diagrama relativo aos extensômetros da armadura longitudinal do pilar P3-12,5-150. 


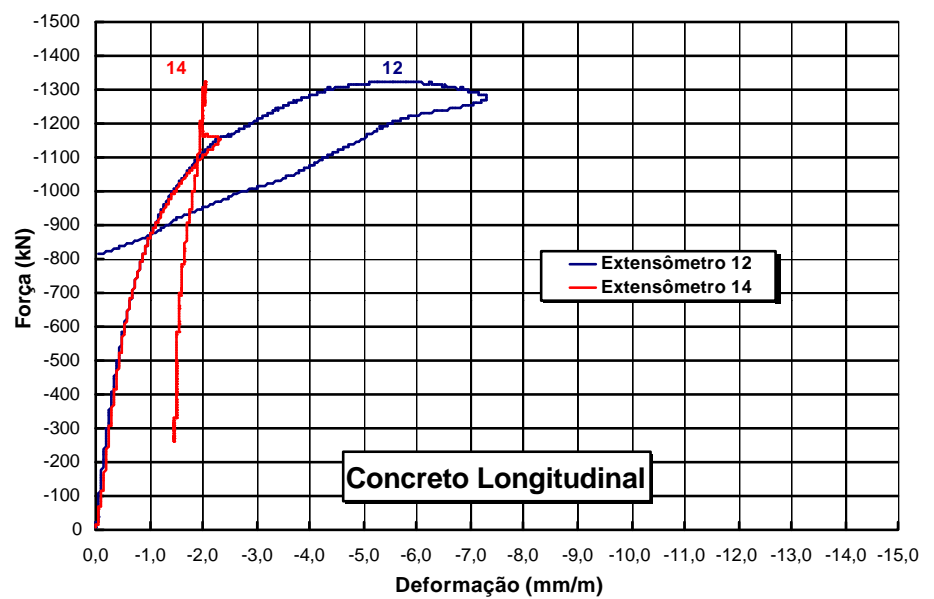

Figura 5.69. Diagrama relativo aos extensômetros dispostos

longitudinalmente sobre as faces do pilar P3-12,5-150.

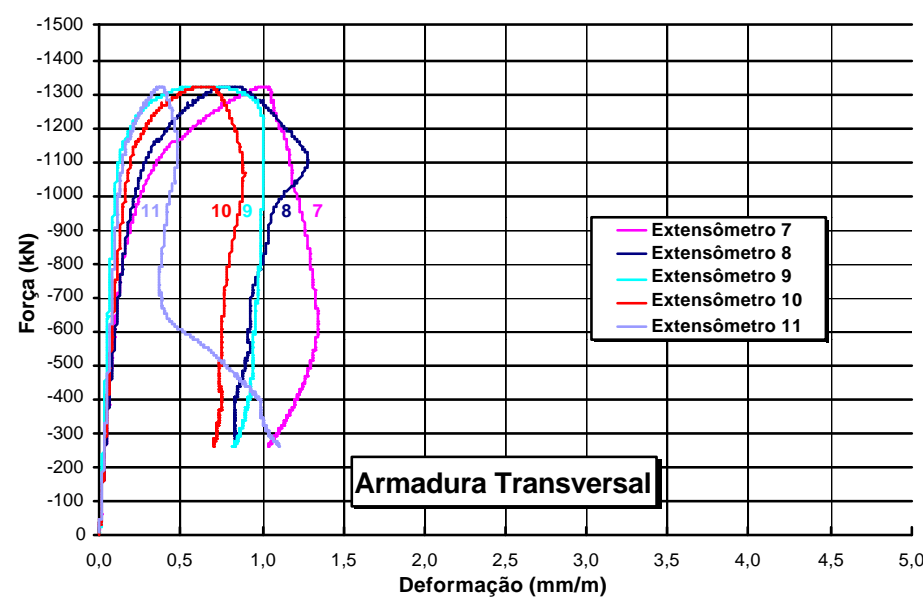

Figura 5.70. Diagrama relativo aos extensômetros da armadura transversal do pilar P3-12,5-150.

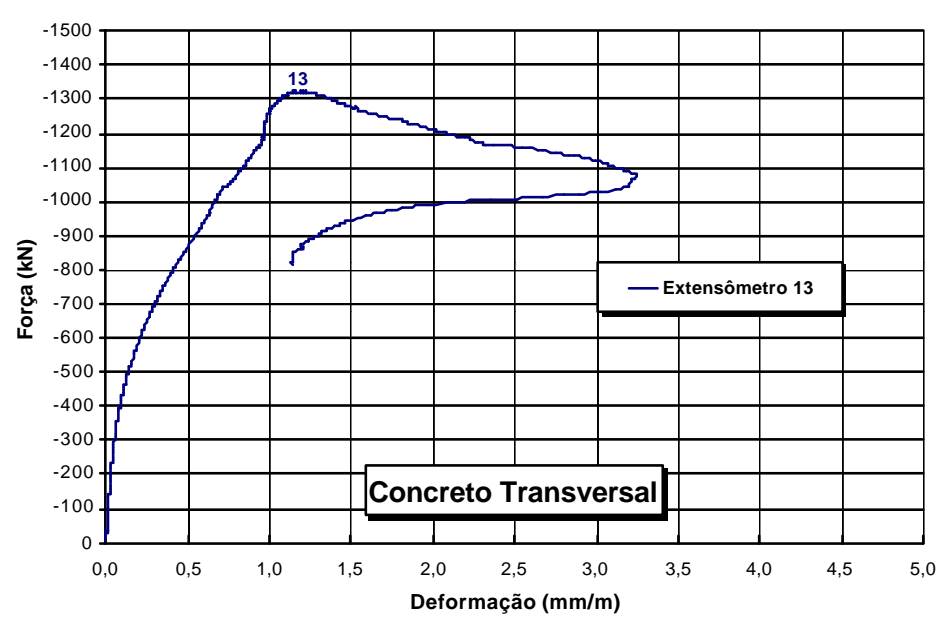

Figura 5.71. Diagrama relativo aos extensômetros dispostos transversalmente sobre as faces do pilar P3-12,5-150. 
j) Pilar P3-12,5-100

$$
\begin{aligned}
& f_{c, \text { pilar }}=22,8 \mathrm{MPa} \\
& \mathrm{F}_{\text {experimental }}=1468 \mathrm{kN}
\end{aligned}
$$

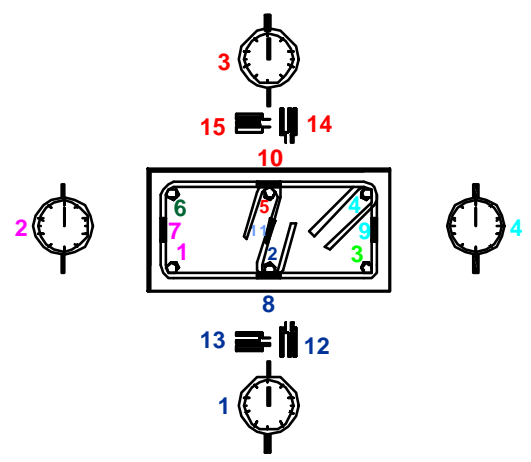

Figura 5.72. Numeração dos transdutores e extensômetros do pilar P3-12,5-100.

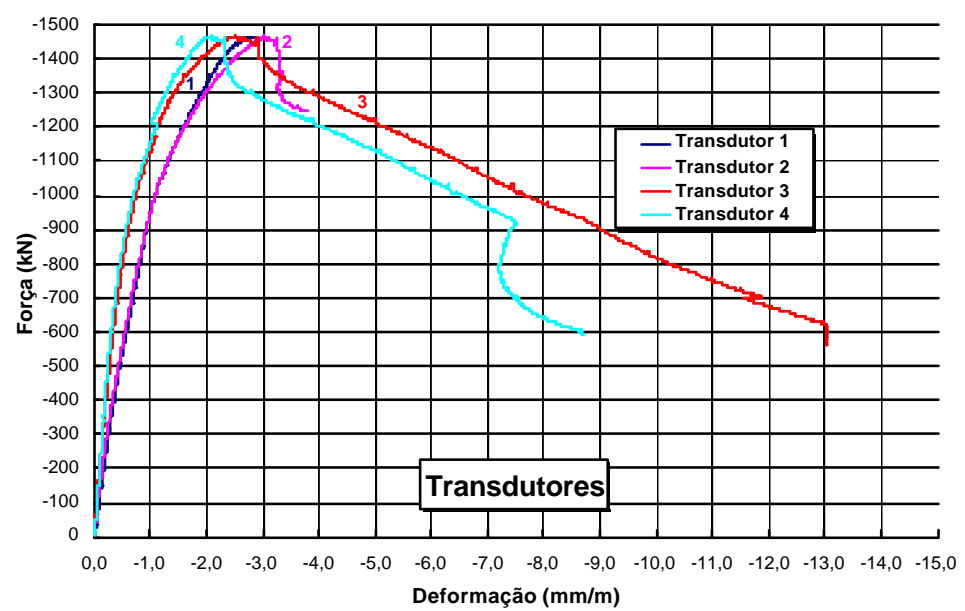

Figura 5.73. Diagrama relativo aos transdutores do pilar P3-12,5-100.

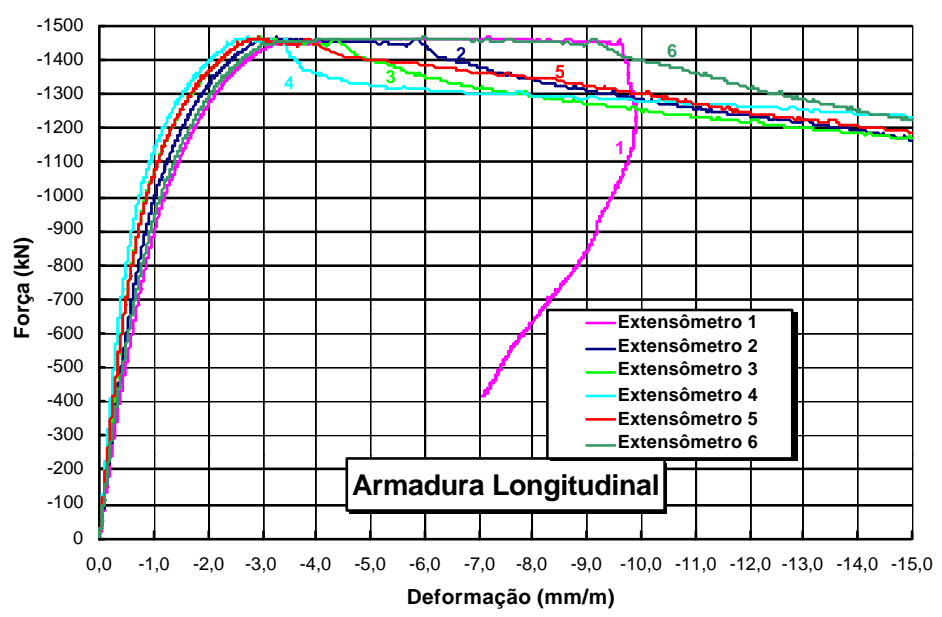

Figura 5.74. Diagrama relativo aos extensômetros da armadura longitudinal do pilar P3-12,5-100. 


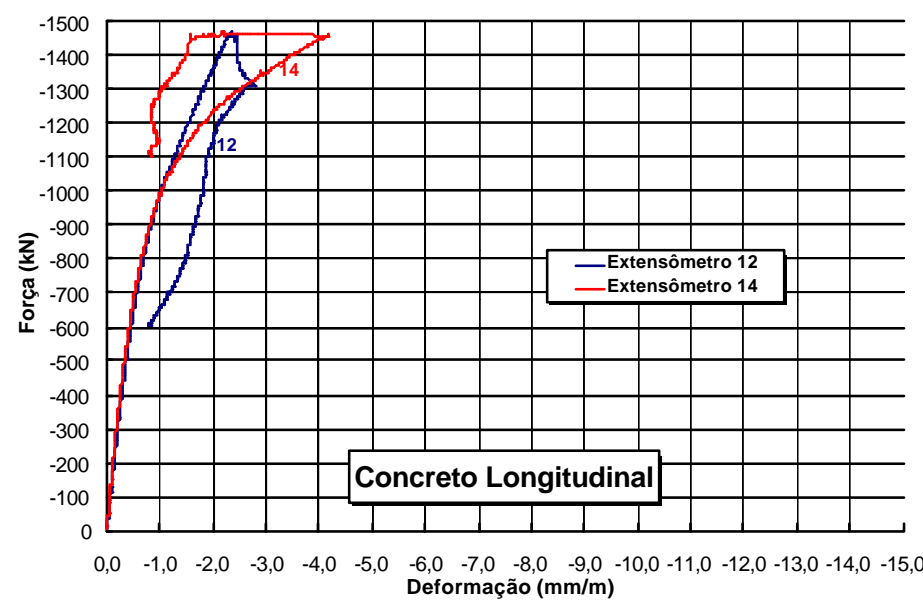

Figura 5.75. Diagrama relativo aos extensômetros dispostos longitudinalmente sobre as faces do pilar P3-12,5-100.

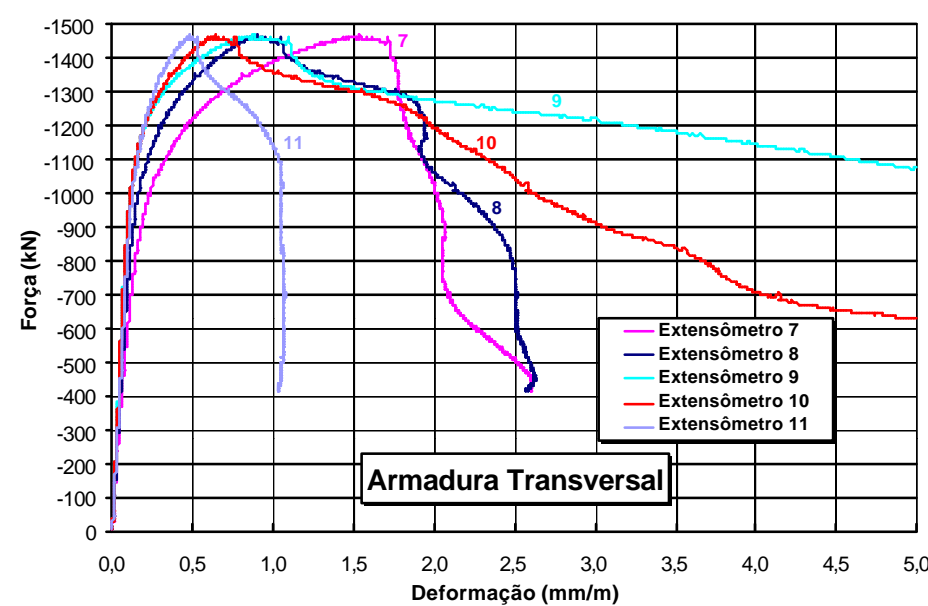

Figura 5.76. Diagrama relativo aos extensômetros da armadura transversal do pilar P3-12,5-100.

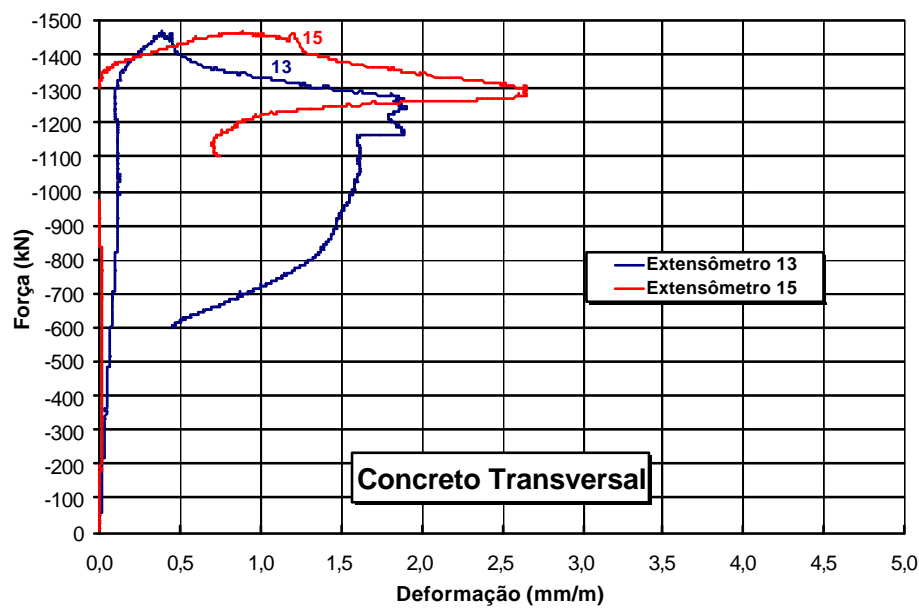

Figura 5.77. Diagrama relativo aos extensômetros dispostos transversalmente sobre as faces do pilar P3-12,5-100. 
k) Pilar P3-12,5-75

$f_{c, \text { pilar }}=22,8 \mathrm{MPa}$

$F_{\text {experimental }}=1485 \mathrm{kN}$

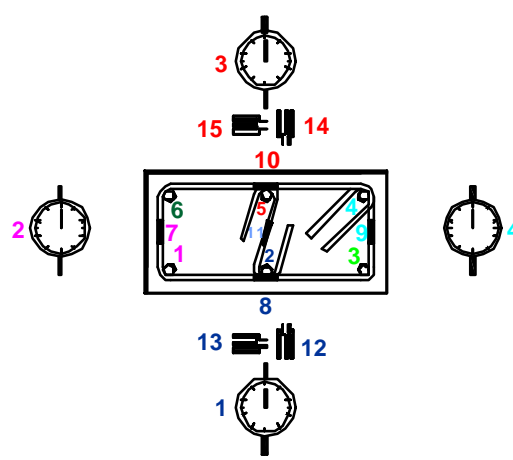

Figura 5.78. Numeração dos transdutores e extensômetros do pilar

P3-12,5-75.

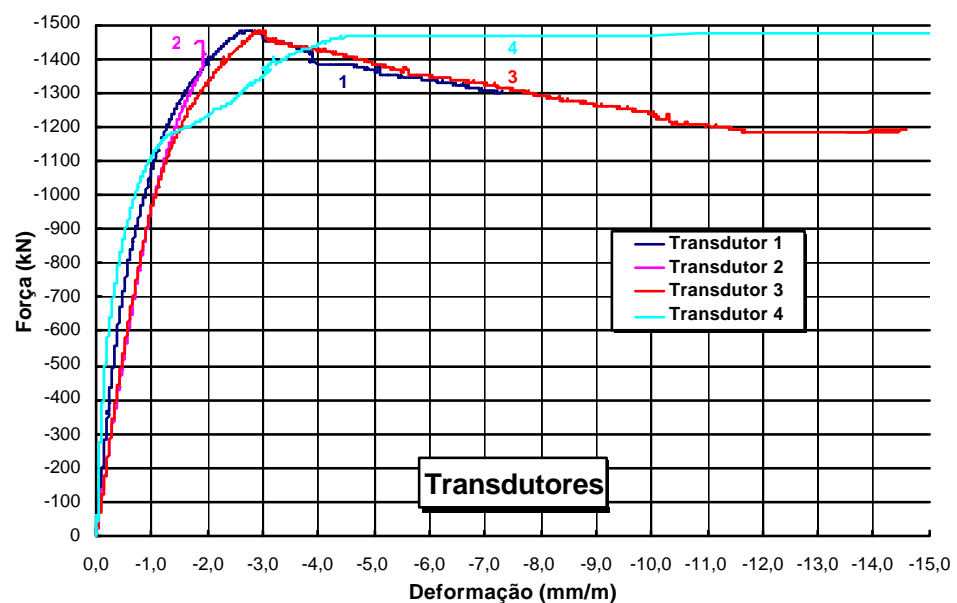

Figura 5.79. Diagrama relativo aos transdutores do pilar P3-12,5-75.

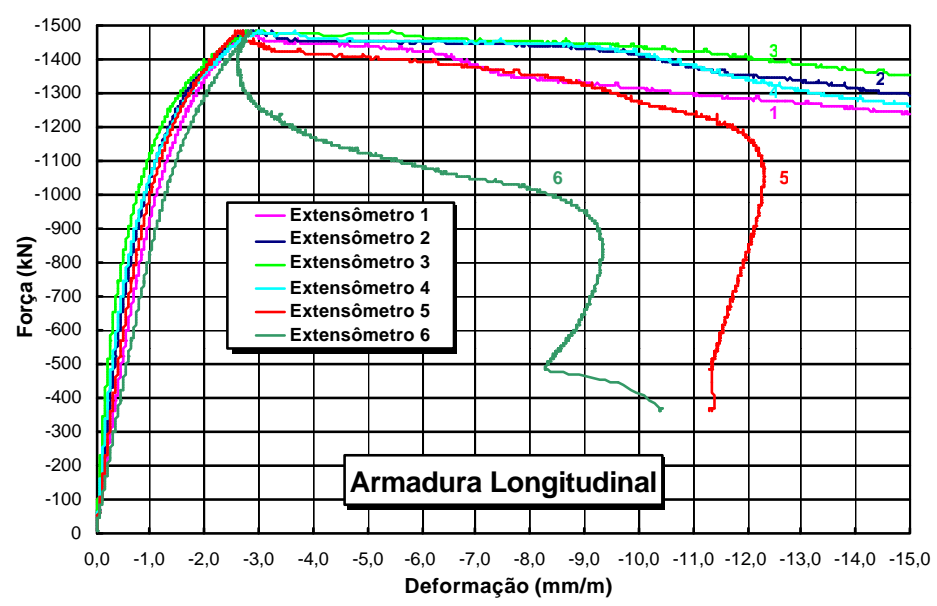

Figura 5.80. Diagrama relativo aos extensômetros da armadura longitudinal do pilar P3-12,5-75. 


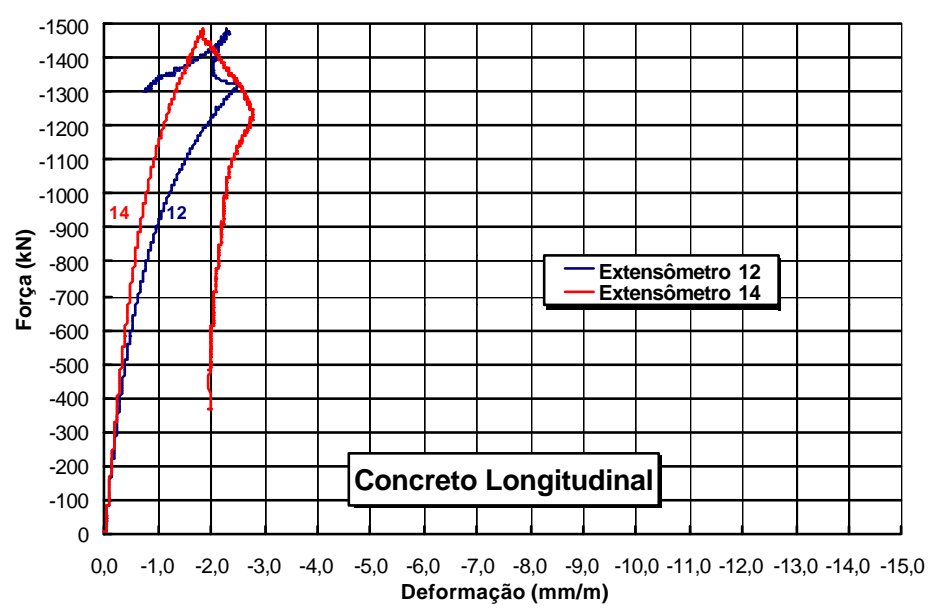

Figura 5.81. Diagrama relativo aos extensômetros dispostos

longitudinalmente sobre as faces do pilar P3-12,5-75.

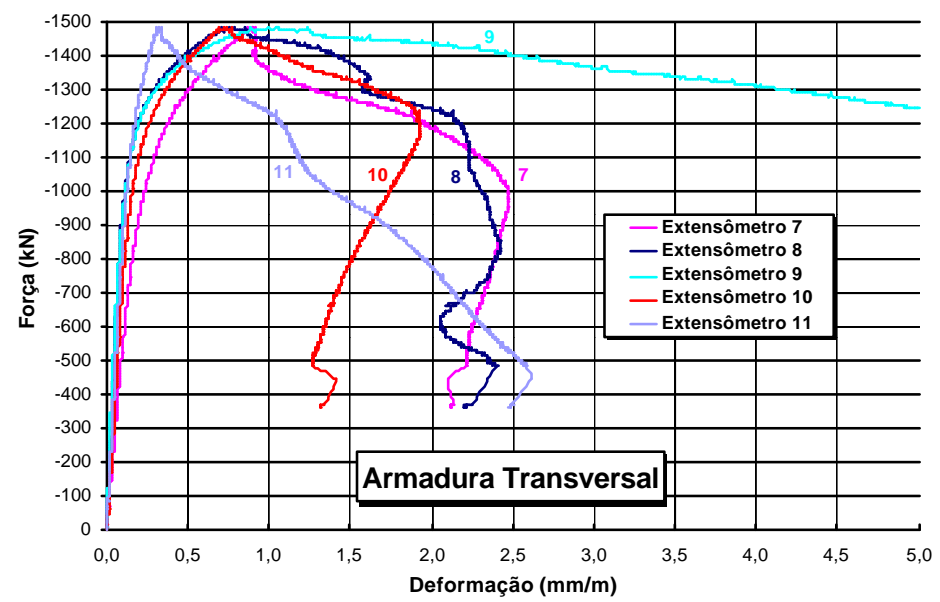

Figura 5.82. Diagrama relativo aos extensômetros da armadura transversal do pilar P3-12,5-75.

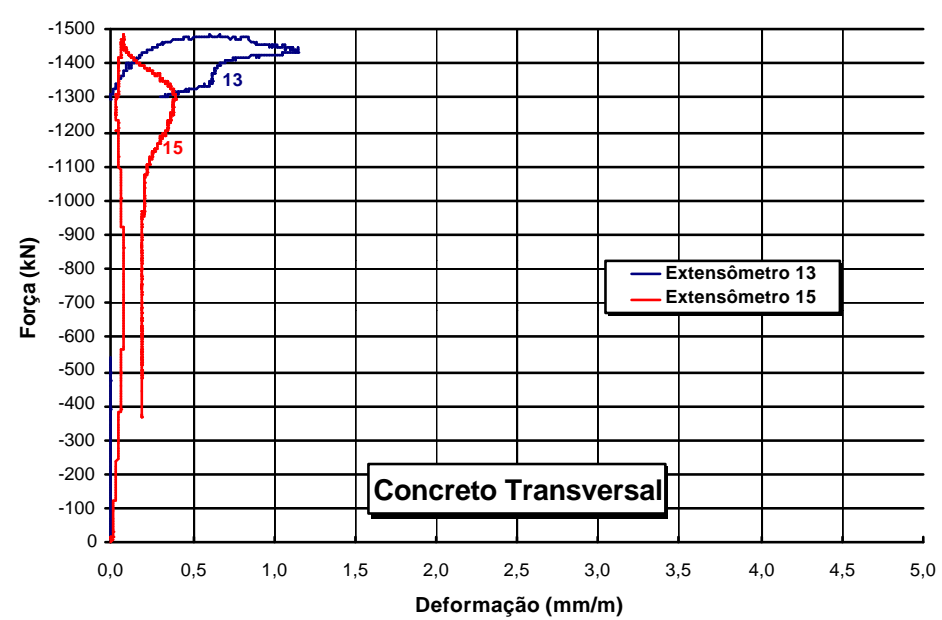

Figura 5.83. Diagrama relativo aos extensômetros dispostos transversalmente sobre as faces do pilar P3-12,5-75. 


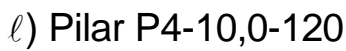

$f_{\text {c,pilar }}=22,1 \mathrm{MPa}$

$F_{\text {experimental }}=1238 \mathrm{kN}$

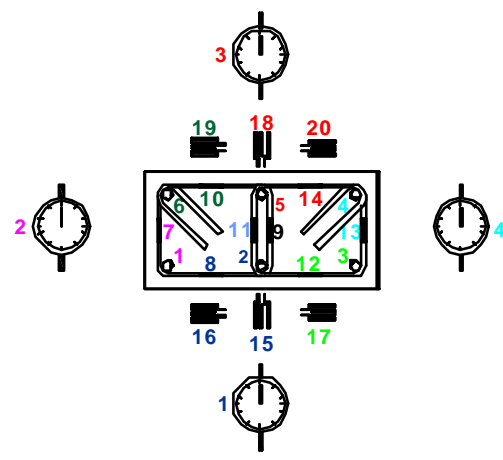

Figura 5.84. Numeração dos transdutores e extensômetros do pilar

P4-10,0-120.

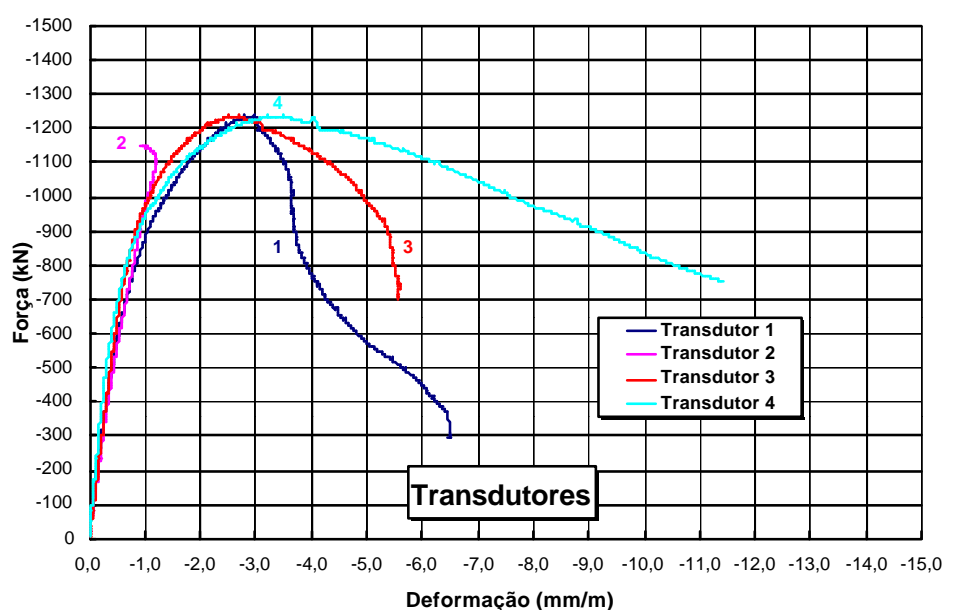

Figura 5.85. Diagrama relativo aos transdutores do pilar P4-10,0-120.

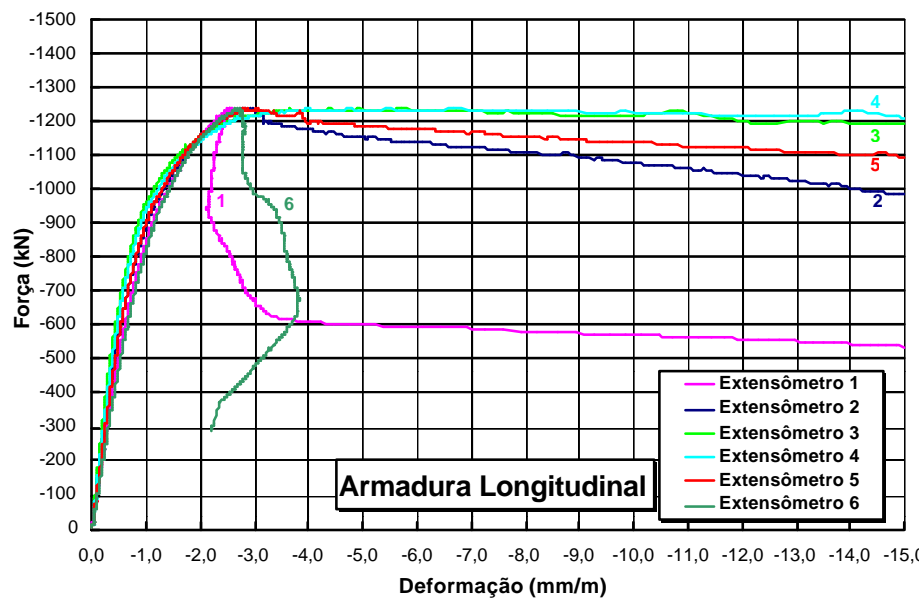

Figura 5.86. Diagrama relativo aos extensômetros da armadura longitudinal do pilar P4-10,0-120. 


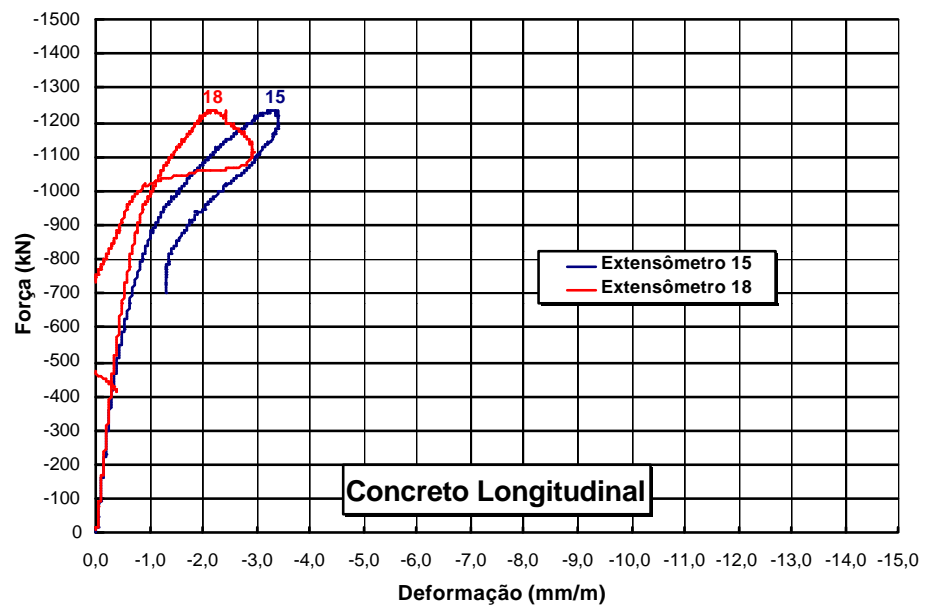

Figura 5.87. Diagrama relativo aos extensômetros dispostos

longitudinalmente sobre as faces do pilar P4-10,0-120.

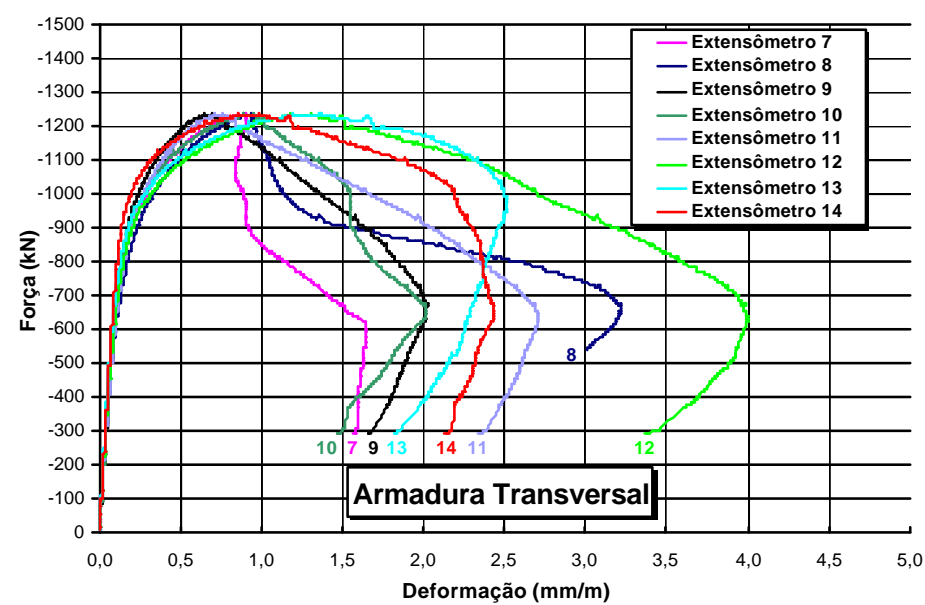

Figura 5.88. Diagrama relativo aos extensômetros da armadura transversal do pilar P4-10,0-120.

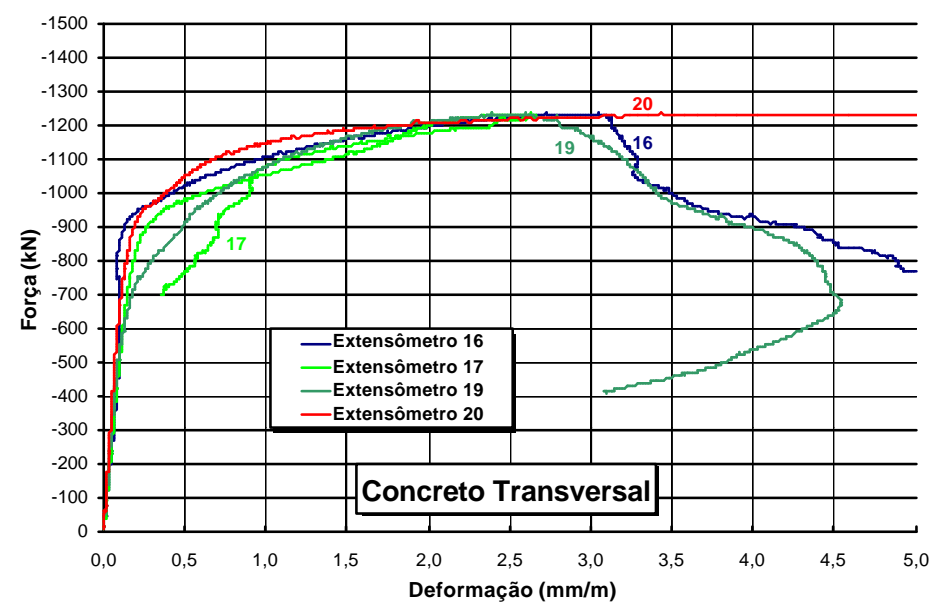

Figura 5.89. Diagrama relativo aos extensômetros dispostos transversalmente sobre as faces do pilar P4-10,0-120. 
m) Pilar P4-12,5-150

$$
\begin{aligned}
& f_{c, \text { pilar }}=22,1 \mathrm{MPa} \\
& \mathrm{F}_{\text {experimental }}=1340 \mathrm{kN}
\end{aligned}
$$

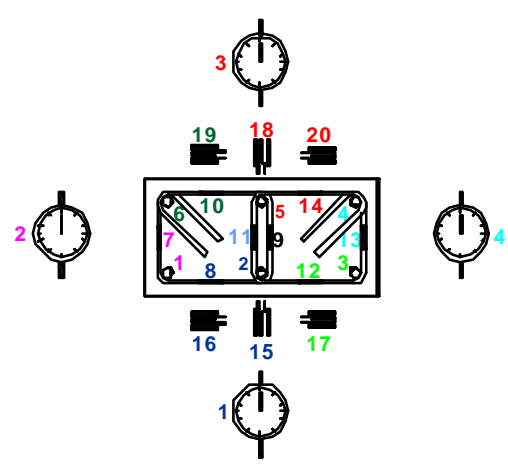

Figura 5.90. Numeração dos transdutores e extensômetros do pilar

P4-12,5-150.

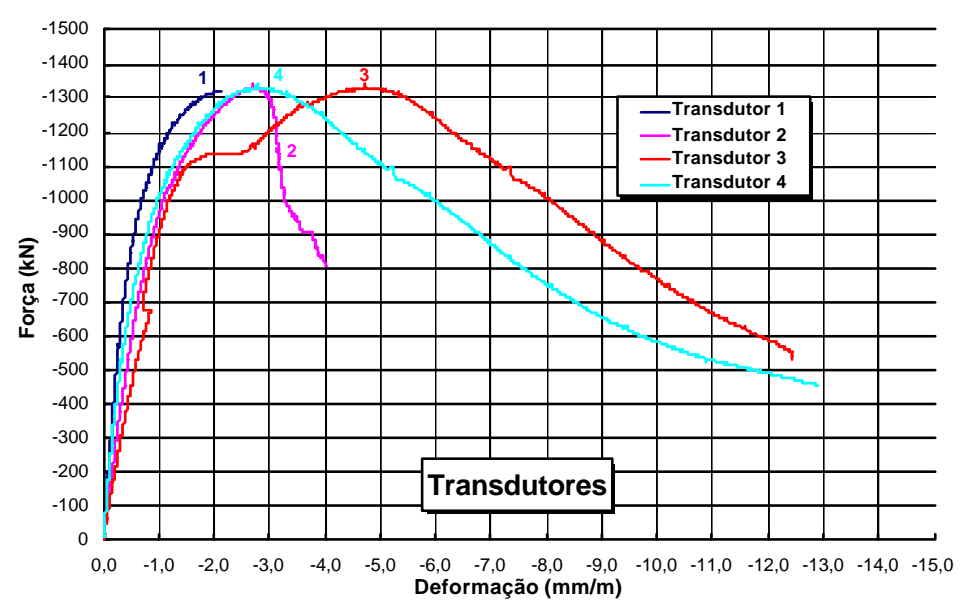

Figura 5.91. Diagrama relativo aos transdutores do pilar P4-12,5-150.

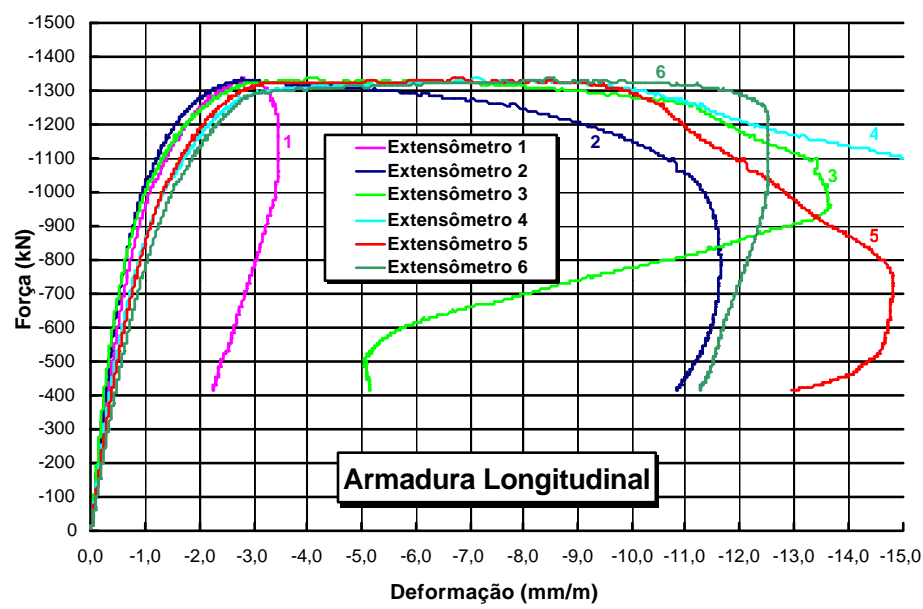

Figura 5.92. Diagrama relativo aos extensômetros da armadura longitudinal do pilar P4-12,5-150. 


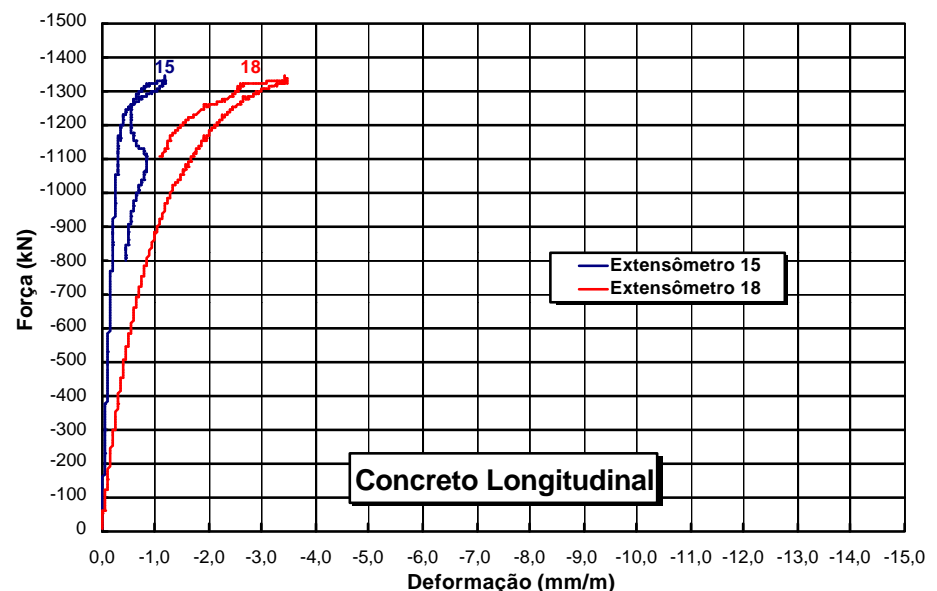

Figura 5.93. Diagrama relativo aos extensômetros dispostos

longitudinalmente sobre as faces do pilar P4-12,5-150.

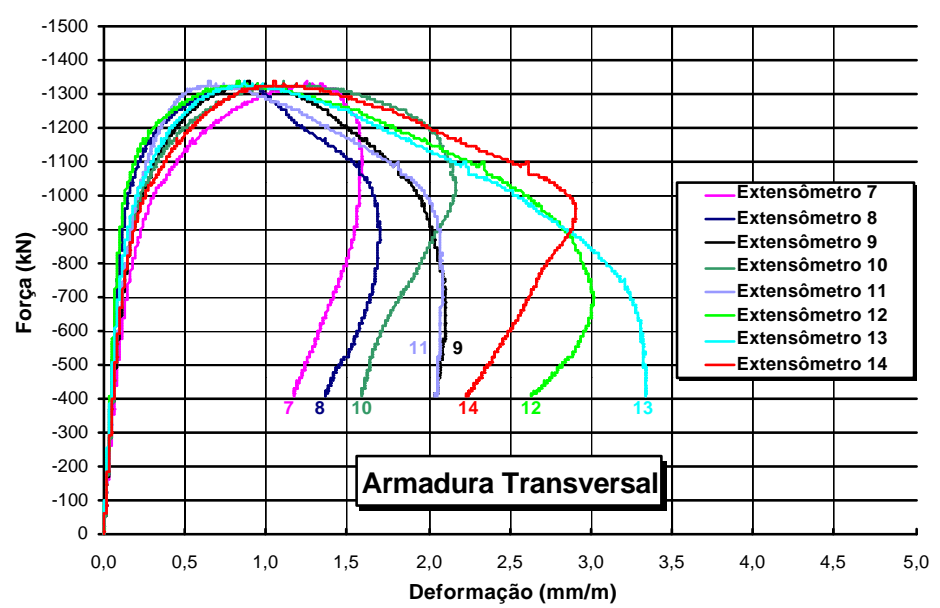

Figura 5.94. Diagrama relativo aos extensômetros da armadura transversal do pilar P4-12,5-150.

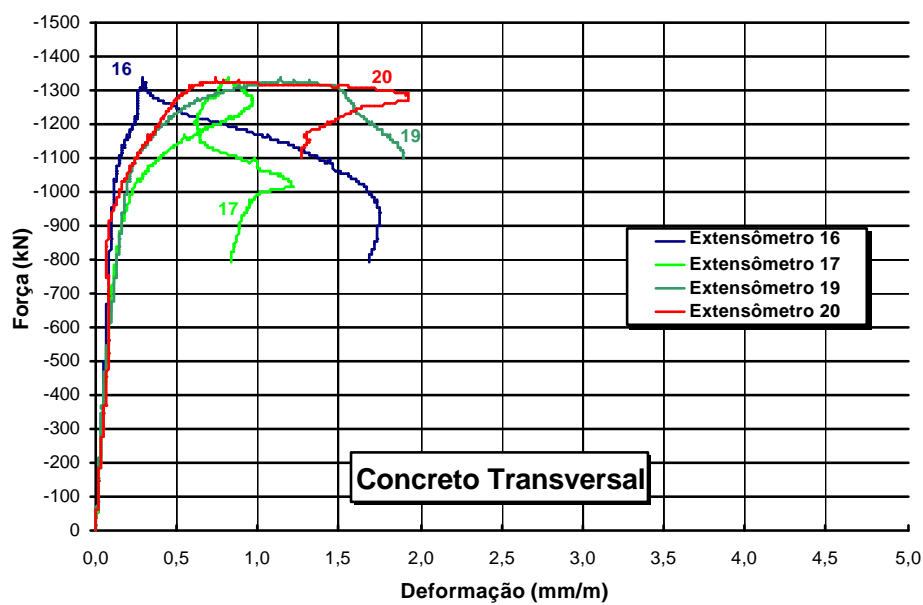

Figura 5.95. Diagrama relativo aos extensômetros dispostos transversalmente sobre as faces do pilar P4-12,5-150. 
n) Pilar P4-12,5-100

$$
\begin{aligned}
& f_{c, \text { pilar }}=22,5 \mathrm{MPa} \\
& \mathrm{F}_{\text {experimental }}=1355 \mathrm{kN}
\end{aligned}
$$

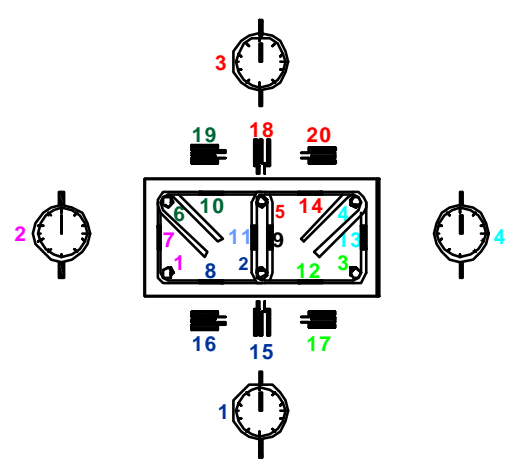

Figura 5.96. Numeração dos transdutores e extensômetros do pilar

P4-12,5-100.

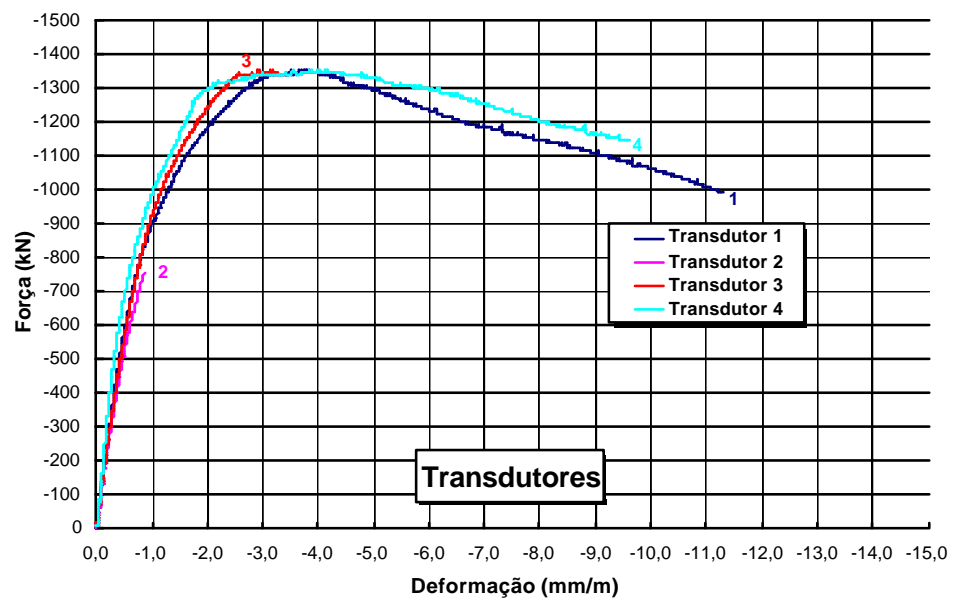

Figura 5.97. Diagrama relativo aos transdutores do pilar P4-12,5-100.

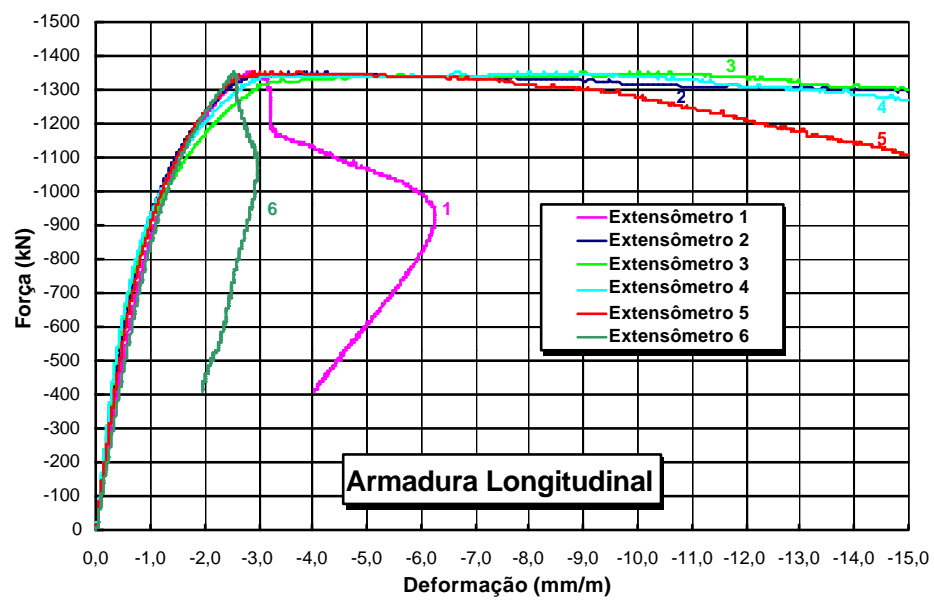

Figura 5.98. Diagrama relativo aos extensômetros da armadura longitudinal do pilar P4-12,5-100. 


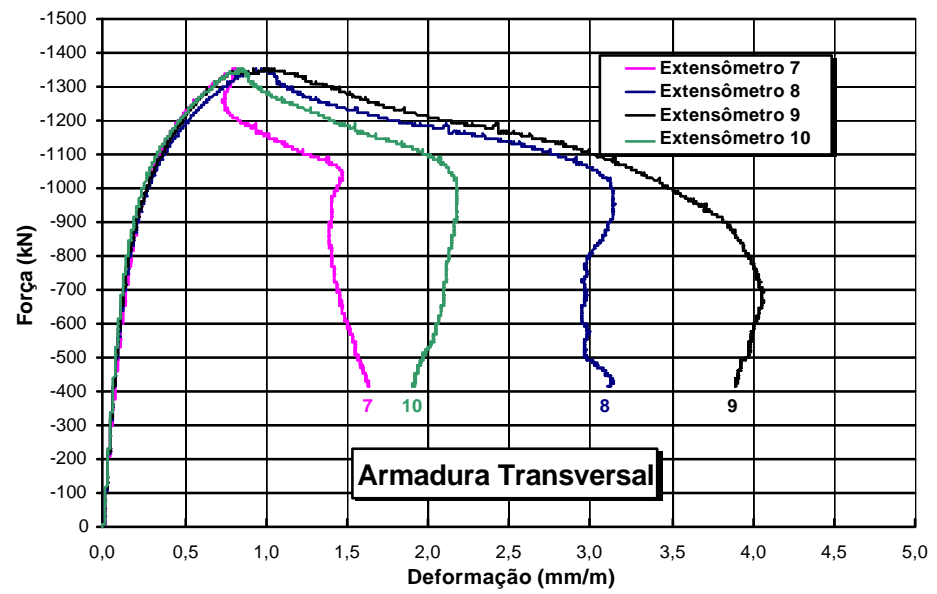

Figura 5.99. Diagrama relativo aos extensômetros da armadura transversal do pilar P4-12,5-100. 
o) Pilar P4-12,5-75

$$
\begin{aligned}
& f_{c, \text { pilar }}=22,5 \mathrm{MPa} \\
& \mathrm{F}_{\text {experimental }}=1365 \mathrm{kN}
\end{aligned}
$$

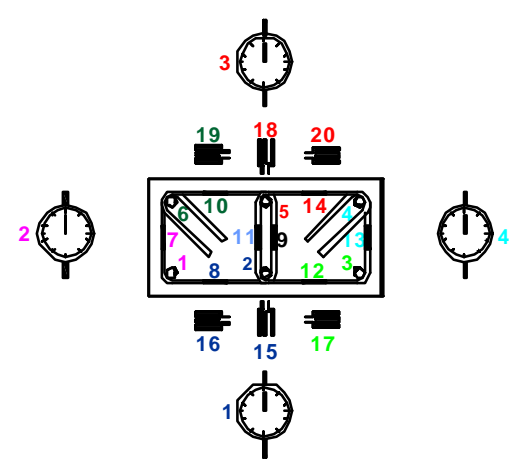

Figura 5.100. Numeração dos transdutores e extensômetros do pilar

P4-12,5-75.

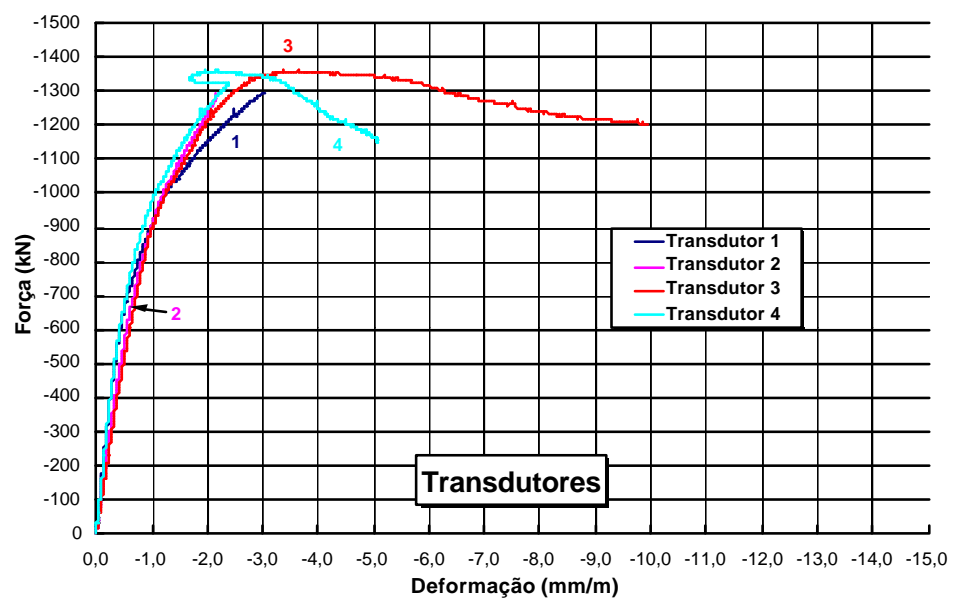

Figura 5.101. Diagrama relativo aos transdutores do pilar P4-12,5-75.

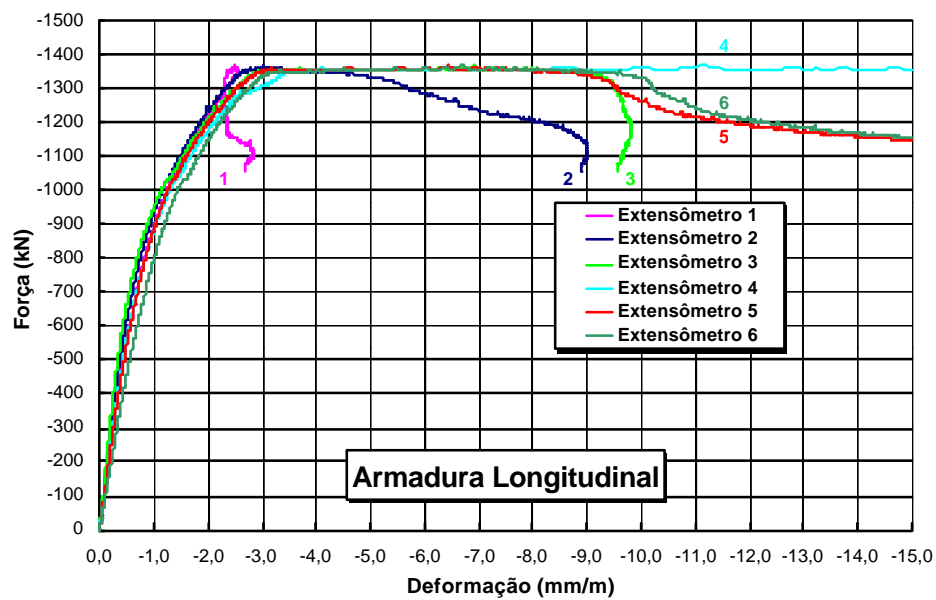

Figura 5.102. Diagrama relativo aos extensômetros da armadura longitudinal do pilar P4-12,5-75. 


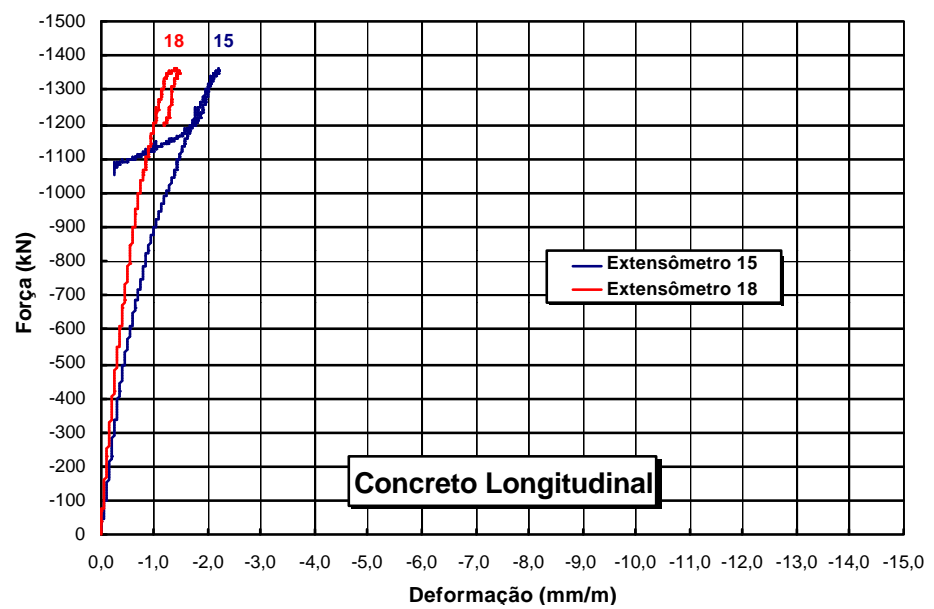

Figura 5.103. Diagrama relativo aos extensômetros dispostos longitudinalmente sobre as faces do pilar P4-12,5-75.

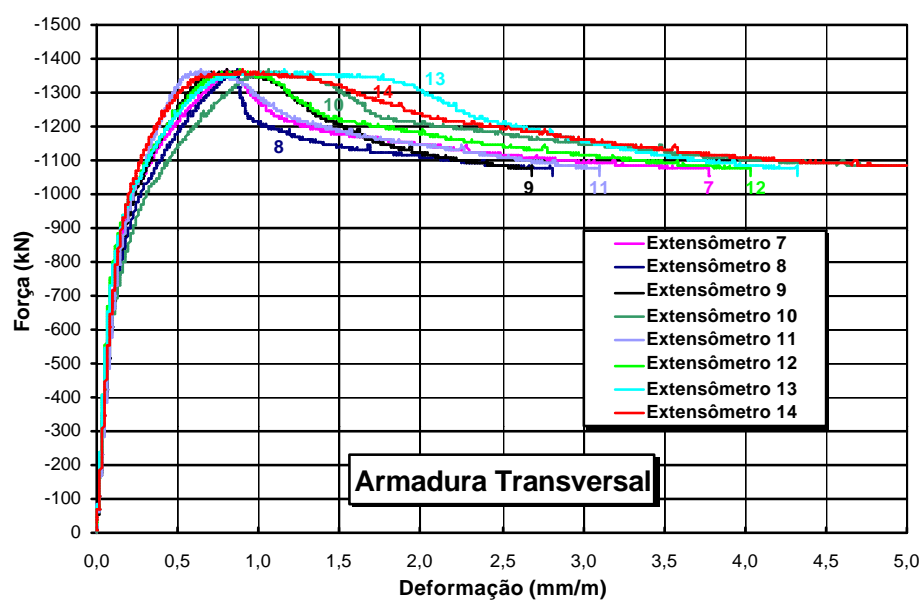

Figura 5.104. Diagrama relativo aos extensômetros da armadura transversal do pilar P4-12,5-75.

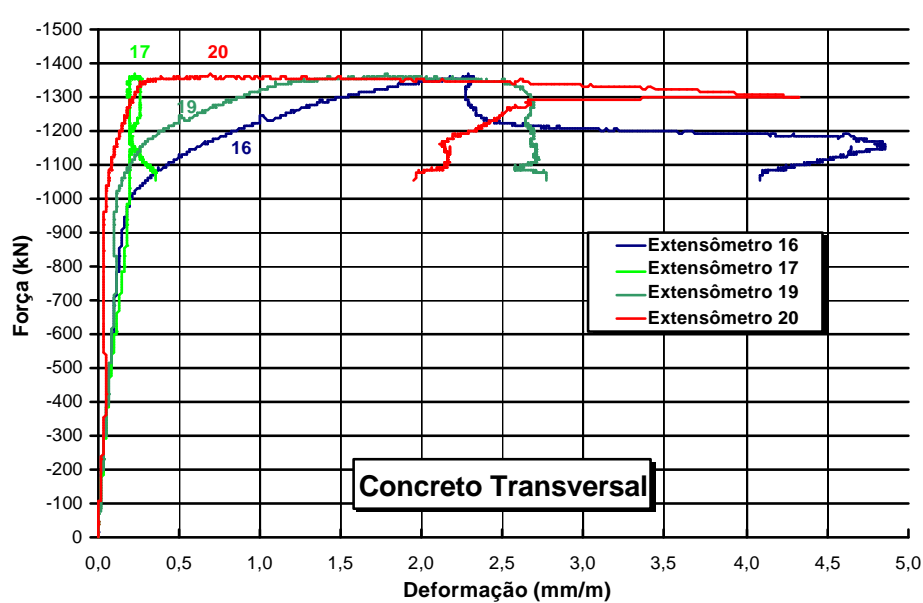

Figura 5.105. Diagrama relativo aos extensômetros dispostos transversalmente sobre as faces do pilar P4-12,5-75. 


\subsubsection{Deformações Registradas na Ruína}

Com os propósitos de visualização e criação de subsídios para o emprego dos modelos teóricos de cálculo da capacidade de carga de pilares e do confinamento do concreto, são apresentadas, a seguir, as deformações de pico registradas no instante da força máxima nos modelos.

Tabela 5.1. Deformações de pico nos pilares da série $P 1$, em $\mathrm{mm} / \mathrm{m}$.

\begin{tabular}{|c|c|c|c|c|c|}
\hline \multirow{2}{*}{\multicolumn{2}{|c|}{ Instrumentação }} & \multicolumn{4}{|c|}{ PILAR } \\
\hline & & $\mathrm{P} 1-10,0-120$ & $\mathrm{P} 1-12,5-200$ & $\mathrm{P} 1-12,5-150$ & $P 1-12,5-100$ \\
\hline \multirow{5}{*}{ 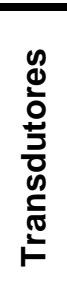 } & 1 & 2,65 & 0,78 & 1,99 & 3,04 \\
\hline & 2 & 1,93 & 2,07 & 2,96 & 2,70 \\
\hline & 3 & 1,11 & 2,67 & 3,88 & 3,24 \\
\hline & 4 & 1,76 & 1,70 & 2,48 & 2,84 \\
\hline & Média & 1,86 & 1,81 & 2,83 & 2,96 \\
\hline \multirow{10}{*}{ 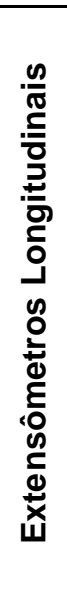 } & 1 & 3,17 & 1,57 & 2,37 & 3,11 \\
\hline & 2 & 3,33 & 1,91 & 2,19 & 3,30 \\
\hline & 3 & 1,59 & - & 3,20 & 3,31 \\
\hline & 4 & 1,38 & 2,44 & 4,08 & 4,40 \\
\hline & Média & 2,37 & 1,97 & 2,96 & 3,53 \\
\hline & 9 & 2,16 & 0,89 & 2,15 & 2,81 \\
\hline & 11 & 2,38 & 1,73 & 1,27 & 2,12 \\
\hline & 13 & 1,16 & 1,66 & 2,22 & 1,33 \\
\hline & 15 & 3,21 & 1,32 & 2,89 & 1,52 \\
\hline & Média & 2,23 & 1,40 & 2,13 & 1,95 \\
\hline \multirow{10}{*}{ 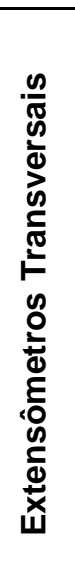 } & 5 & 0,74 & 0,62 & 1,04 & 1,11 \\
\hline & 6 & 1,35 & 0,29 & - & 0,99 \\
\hline & 7 & 0,91 & 0,70 & 0,93 & 1,01 \\
\hline & 8 & 0,35 & 0,74 & 1,45 & - \\
\hline & Média & 0,84 & 0,59 & 1,14 & 1,04 \\
\hline & 10 & 2,29 & 0,76 & 0,62 & 1,36 \\
\hline & 12 & 1,90 & 0,03 & 1,67 & 1,53 \\
\hline & 14 & 0,52 & 0,21 & 2,04 & 1,81 \\
\hline & 16 & 1,01 & 0,40 & 1,82 & 1,15 \\
\hline & Média & 1,43 & 0,35 & 1,54 & 1,46 \\
\hline
\end{tabular}


Tabela 5.2. Deformações de pico nos pilares da série $P 2$, em $\mathrm{mm} / \mathrm{m}$.

\begin{tabular}{|c|c|c|c|c|c|}
\hline \multicolumn{2}{|c|}{ Instrumentação } & \multicolumn{4}{|c|}{ PILAR } \\
\hline & & P2-10,0-120 & P2-12,5-150 & P2-12,5-100 & P2-12,5-75 \\
\hline \multirow{5}{*}{ 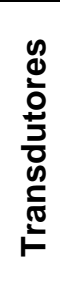 } & 1 & - & 2,68 & 3,97 & 3,65 \\
\hline & 2 & - & 1,70 & 3,87 & 3,15 \\
\hline & 3 & - & 1,67 & 2,50 & 2,82 \\
\hline & 4 & - & 2,26 & 2,72 & 2,70 \\
\hline & Média & - & 2,08 & 3,27 & 3,08 \\
\hline \multirow{10}{*}{ 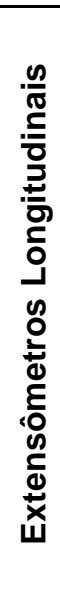 } & 1 & - & 2,81 & 3,51 & 2,97 \\
\hline & 2 & - & 2,77 & 3,20 & 2,75 \\
\hline & 3 & - & - & 3,45 & 4,00 \\
\hline & 4 & - & 2,61 & 2,53 & - \\
\hline & 5 & - & 2,49 & 2,54 & 3,20 \\
\hline & 6 & - & 2,72 & 2,67 & 4,50 \\
\hline & Média & - & 2,68 & 2,98 & 3,48 \\
\hline & 11 & - & 1,88 & 6,20 & 3,78 \\
\hline & 13 & - & 1,24 & 2,97 & - \\
\hline & Média & - & 1,56 & 4,59 & 3,78 \\
\hline \multirow{9}{*}{ 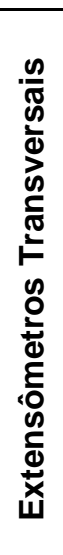 } & 7 & - & 0,76 & 1,15 & 0,99 \\
\hline & 9 & - & - & 0,68 & 0,89 \\
\hline & Média & - & 0,76 & 0,92 & 0,94 \\
\hline & 8 & - & 0,98 & 0,96 & 0,74 \\
\hline & 10 & - & 0,93 & 0,74 & 0,76 \\
\hline & Média & - & 0,96 & 0,85 & 0,75 \\
\hline & 12 & - & 2,22 & 2,11 & 0,74 \\
\hline & 14 & - & 0,08 & 0,39 & 0,02 \\
\hline & Média & - & 1,15 & 1,25 & 0,38 \\
\hline
\end{tabular}


Tabela 5.3. Deformações de pico nos pilares da série $\mathrm{P3}$, em $\mathrm{mm} / \mathrm{m}$.

\begin{tabular}{|c|c|c|c|c|c|}
\hline \multicolumn{2}{|c|}{ Instrumentação } & \multicolumn{4}{|c|}{ PILAR } \\
\hline & & P3-10,0-120 & P3-12,5-150 & P3-12,5-100 & P3-12,5-75 \\
\hline \multirow{5}{*}{ 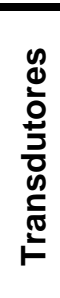 } & 1 & 3,04 & 3,10 & 2,37 & 2,73 \\
\hline & 2 & - & - & 3,03 & - \\
\hline & 3 & 3,52 & 2,22 & 2,53 & 2,93 \\
\hline & 4 & 1,65 & 3,44 & 2,08 & 4,77 \\
\hline & Média & 2,74 & 2,92 & 2,50 & 3,48 \\
\hline \multirow{10}{*}{ 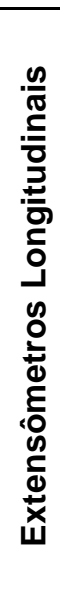 } & 1 & 3,09 & 3,03 & 3,32 & 2,83 \\
\hline & 2 & 2,64 & 2,88 & 3,27 & 2,87 \\
\hline & 3 & 2,73 & 3,23 & 2,95 & 2,97 \\
\hline & 4 & 3,10 & 2,64 & 2,71 & 2,98 \\
\hline & 5 & 3,00 & 2,66 & 2,91 & 2,63 \\
\hline & 6 & 3,07 & 2,73 & 3,03 & 2,83 \\
\hline & Média & 2,94 & 2,86 & 3,03 & 2,85 \\
\hline & 12 & 1,52 & 5,72 & 2,34 & 2,31 \\
\hline & 14 & 2,31 & 2,03 & 4,18 & 1,84 \\
\hline & Média & 1,92 & 3,88 & 3,26 & 2,08 \\
\hline \multirow{10}{*}{ 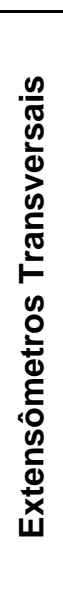 } & 7 & 0,95 & 1,02 & 1,54 & 0,89 \\
\hline & 9 & 0,86 & 0,67 & 0,88 & 1,00 \\
\hline & 11 & 0,53 & 0,38 & 0,49 & 0,32 \\
\hline & Média & 0,78 & 0,69 & 0,97 & 0,74 \\
\hline & 8 & 0,86 & 0,82 & 0,90 & 0,76 \\
\hline & 10 & 1,15 & 0,66 & 0,64 & 0,72 \\
\hline & Média & 1,01 & 0,74 & 0,77 & 0,74 \\
\hline & 13 & 0,64 & 1,21 & 0,39 & 0,61 \\
\hline & 15 & 2,57 & - & 0,89 & 0,07 \\
\hline & Média & 1,61 & 1,21 & 0,64 & 0,34 \\
\hline
\end{tabular}


Tabela 5.4. Deformações de pico nos pilares da série $\mathrm{P} 4$, em $\mathrm{mm} / \mathrm{m}$.

\begin{tabular}{|c|c|c|c|c|c|}
\hline \multicolumn{2}{|c|}{ Instrumentação } & \multicolumn{4}{|c|}{ PILAR } \\
\hline & & P4-10,0-120 & P4-12,5-150 & P4-12,5-100 & P4-12,5-75 \\
\hline \multirow{5}{*}{ 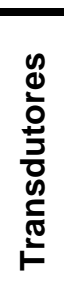 } & 1 & 2,86 & 2,14 & 3,51 & - \\
\hline & 2 & - & 2,70 & - & - \\
\hline & 3 & 2,59 & 4,72 & 2,91 & 3,66 \\
\hline & 4 & 3,34 & 2,77 & 3,00 & 2,17 \\
\hline & Média & 2,93 & 3,08 & 3,14 & 2,92 \\
\hline \multirow{10}{*}{ 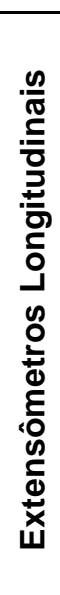 } & 1 & 2,54 & 2,84 & 2,79 & 2,51 \\
\hline & 2 & 2,84 & 2,79 & 3,56 & 3,02 \\
\hline & 3 & 3,65 & 3,00 & 4,00 & 3,48 \\
\hline & 4 & 3,96 & 4,04 & 3,06 & 3,51 \\
\hline & 5 & 2,88 & 3,15 & 2,91 & 3,51 \\
\hline & 6 & 2,70 & 4,00 & 2,53 & 3,45 \\
\hline & Média & 3,10 & 3,30 & 3,14 & 3,25 \\
\hline & 15 & 3,27 & 1,21 & - & 2,22 \\
\hline & 18 & 2,15 & 3,43 & - & 1,40 \\
\hline & Média & 2,71 & 2,32 & - & 1,81 \\
\hline \multirow{15}{*}{ 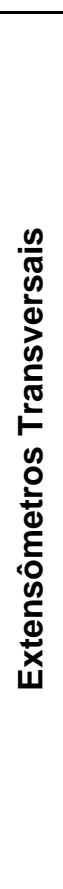 } & 7 & 0,89 & 1,25 & 0,80 & 0,80 \\
\hline & 9 & 0,67 & 0,89 & 0,93 & 0,81 \\
\hline & 11 & 0,74 & 0,65 & - & 0,65 \\
\hline & 13 & 1,27 & 0,87 & - & 1,16 \\
\hline & Média & 0,89 & 0,92 & 0,87 & 0,86 \\
\hline & 8 & 0,91 & 0,83 & 0,95 & 0,86 \\
\hline & 10 & 0,92 & 1,11 & 0,83 & 1,07 \\
\hline & 12 & 1,24 & 0,83 & - & 0,88 \\
\hline & 14 & 0,92 & 1,05 & - & 0,90 \\
\hline & Média & 1,00 & 0,96 & 0,89 & 0,93 \\
\hline & 16 & 2,90 & 0,29 & - & 2,29 \\
\hline & 19 & 2,50 & 1,14 & - & 1,78 \\
\hline & 17 & 2,52 & 0,82 & - & 0,23 \\
\hline & 20 & 3,02 & 0,74 & - & 0,70 \\
\hline & Média & 2,74 & 0,75 & - & 1,25 \\
\hline
\end{tabular}




\subsection{Ensaios Complementares}

Este item irá identificar e apresentar os resultados dos ensaios realizados com os corpos-de-prova de controle do concreto utilizado na execução dos modelos.

\subsubsection{Ensaios de Compressão e Tração do Concreto}

Corpos-de-prova cilíndricos com diâmetro de $150 \mathrm{~mm}$ e altura de $300 \mathrm{~mm}$ foram moldados e ensaiados com o intuito de se estimar a resistência do concreto presente nos modelos de pilares. Para a aplicação da força de compressão, foi utilizada uma máquina hidráulica com capacidade nominal de $2000 \mathrm{kN}$, da marca ELE Autotest 2000 (ver a figura 5.106.b e 5.106.c), pertencente ao Laboratório de Estruturas da EESC-USP. Ao invés do tradicional capeamento dos corpos-de-prova com enxofre, foram empregadas placas de neoprene coladas em placas metálicas (ver a figura 5.106.a). A figura 5.107.a apresenta o instrumento utilizado nos ensaios dos corpos-de-prova à tração. É importante salientar que os ensaios à tração e à compressão foram conduzidos de acordo com as normas brasileiras NBR 7222 (1983) e NBR 5739 (1980), respectivamente.

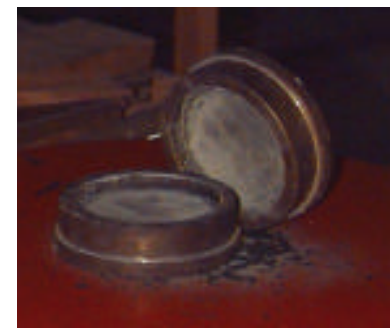

a)

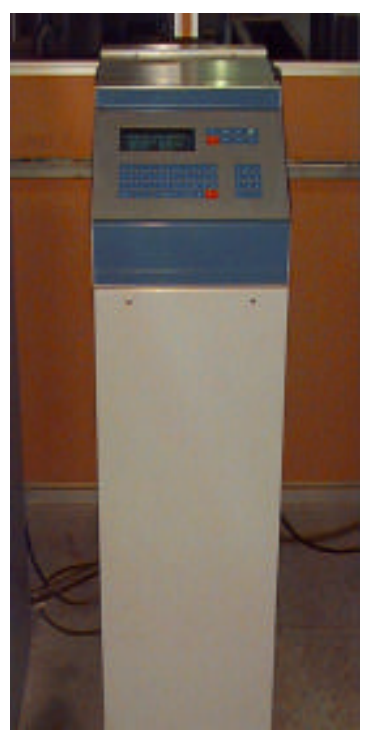

b)

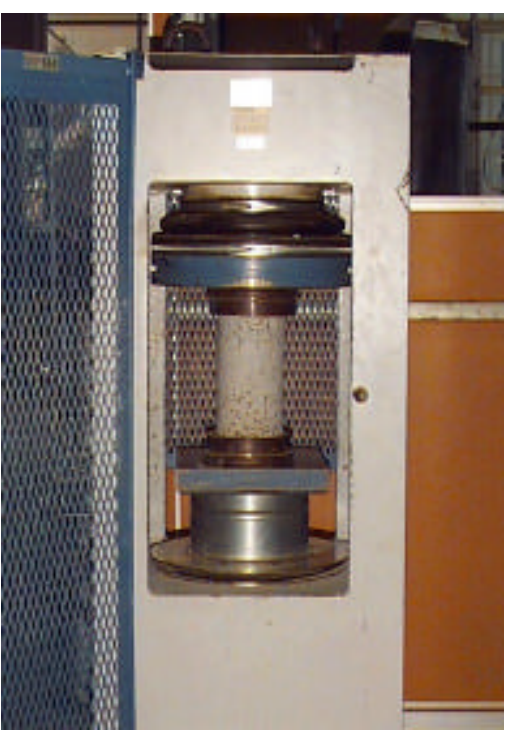

c)

Figura 5.106. Esquema de ensaio à compressão dos corpos -de-prova: a) Placas de neoprene; b) Painel de Controle da ELE Autotest; e c) Corpo-deprova na máquina ELE Autotest. 


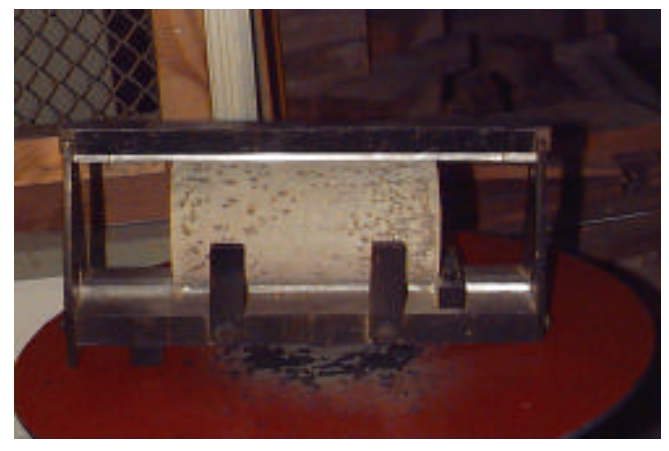

a)

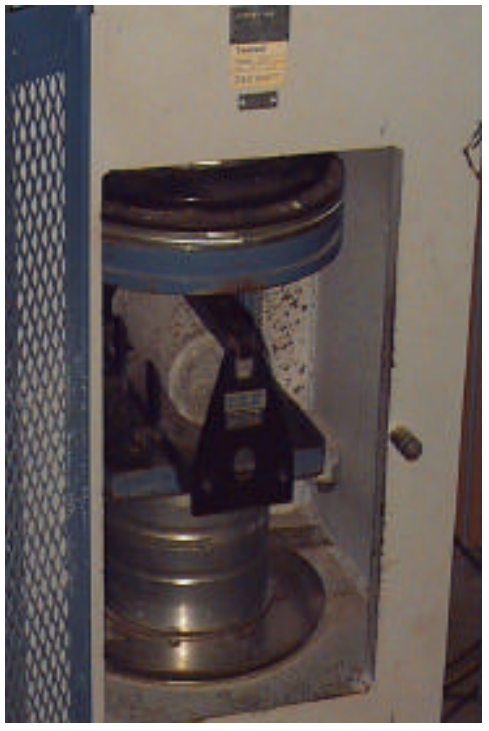

b)

Figura 5.107. Esquema de ensaio àtração dos corpos-de-prova:

a) Instrumento empregado no ensaio de tração; e b) Corpo-de-prova na máquina ELE Autotest.

No que tange ao ensaio destinado à determinação da resistência à tração, apenas os pilares P1-12,5-150, P1-12,5-100, P2-12,5-100 e P2-12,5-75 tiveram corpos-de-prova ensaiados na idade de 13 dias, para os dois primeiros, e 14 dias, para os outros dois. Os ensaios de compressão uniaxial de corpos-de-prova cilíndricos foram feitos para todos os pilares na idade de 14 dias. Além disso, de forma complementar, foi realizado o acompanhamento do ganho de resistência à compressão a partir de corpos-de-prova ensaiados nas idades de 3, 7 e 28 dias. $\mathrm{Na}$ tabela 5.5, são apresentados os resultados obtidos com os ensaios realizados nas idades de 13 e 14 dias. 
Tabela 5.5. Resultados dos ensaios dos corpos-de-prova aos 13 e 14 dias.

\begin{tabular}{ccccc}
\hline Pilar & $\begin{array}{c}\text { Idade } \\
\text { (dias) }\end{array}$ & $\begin{array}{c}\text { Resistência à } \\
\text { Compressão dos } \\
\text { Corpos-de-Prova } \\
\text { (MPa) }\end{array}$ & $\begin{array}{c}\text { Resistência à } \\
\text { Compressão do } \\
\text { Concreto do Pilar * } \\
\text { (MPa) }\end{array}$ & $\begin{array}{c}\text { Resistência à } \\
\text { Tração dos } \\
\text { Corpos-de-Prova } \\
\text { (MPa) }\end{array}$ \\
\hline P1-10,0-120 & 14 & 24,9 & 23,7 & - \\
P1-12,5-200 & 14 & 24,9 & 23,7 & - \\
P1-12,5-150 & 13 & 28,5 & 27,1 & 2,60 \\
P1-12,5-100 & 13 & 28,5 & 27,1 & 2,60 \\
P2-10,0-120 & 14 & 23,5 & 22,3 & - \\
P2-12,5-150 & 14 & 23,5 & 22,3 & - \\
P2-12,5-100 & 14 & 24,5 & 23,3 & 2,35 \\
P2-12,5-75 & 14 & 24,5 & 23,3 & - \\
P3-10,0-120 & 14 & 27,5 & 26,1 & - \\
P3-12,5-150 & 14 & 27,5 & 26,1 & - \\
P3-12,5-100 & 14 & 24,1 & 22,8 & - \\
P3-12,5-75 & 14 & 24,1 & 22,8 & - \\
P4-10,0-120 & 14 & 23,3 & 22,1 & - \\
P4-12,5-150 & 14 & 23,3 & 22,1 & - \\
P4-12,5-100 & 14 & 23,7 & 22,5 & - \\
P4-12,5-75 & 14 & 23,7 & 22,5 & - \\
\hline
\end{tabular}

* A resistência do concreto do pilar foi calculada mediante a multiplicação da resistência do concreto do corpo-de-prova pelo coeficiente de modificação $k_{\text {mod }}=0,95$, conforme exposto no item 2.9.1.

\subsubsection{Ensaio de Módulo de Deformação Longitudinal do Concreto}

De acordo com MEHTA \& MONTEIRO (1994), pode-se calcular o módulo de deformação secante a partir da declividade da reta traçada da origem a um ponto da curva tensão-deformação correspondente a 40\% da tensão de ruptura. Assim sendo, para a determinação deste módulo, foram ensaiados dois corpos-de-prova aos 14 dias de idade, instrumentados com transdutores de deslocamento (ver a figura 5.108), com o objetivo de se obter as respectivas curvas de tensãodeformação (ver a figura 5.109). O equipamento utilizado na aplicação da força de compressão foi o mesmo dos ensaios de determinação da resistência à compressão e àtração do concreto (ver as figuras 5.106 e 5.107). 


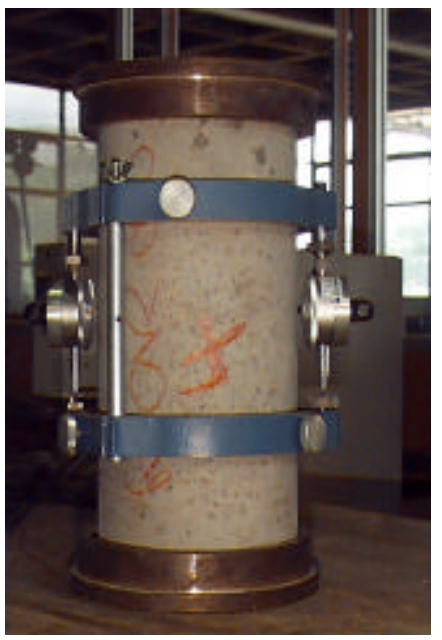

Figura 5.108. Corpo-de-prova instrumentado com dois transdutores de deslocamento.
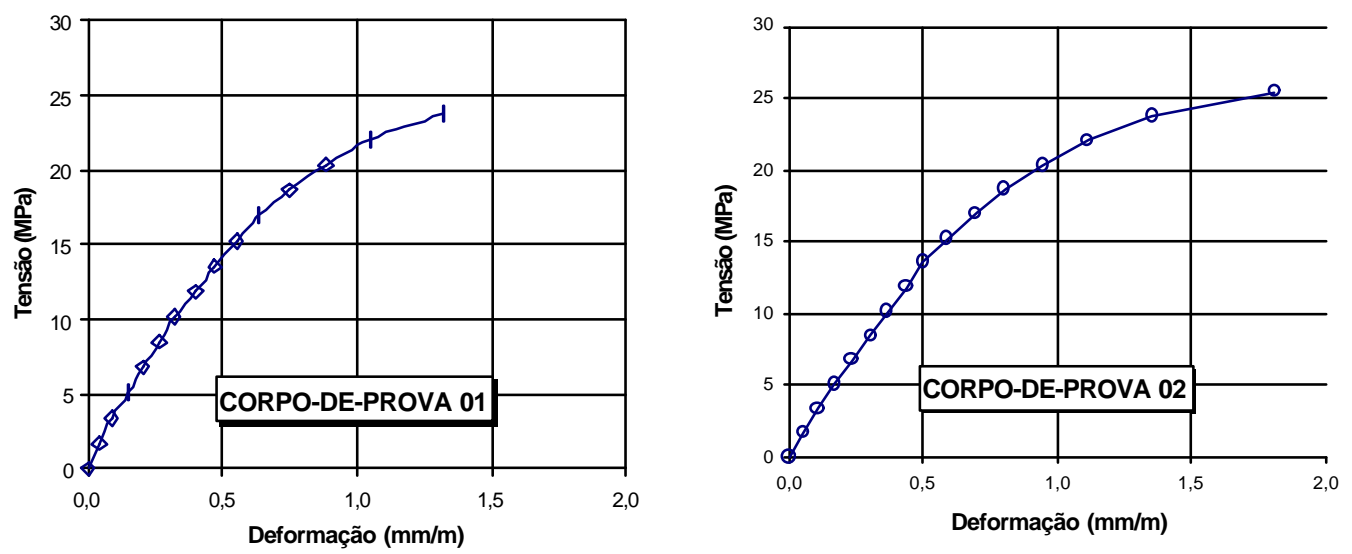

Figura 5.109. Diagramas tensão-deformação dos corpos-de-prova ensaiados.

Considerando os diagramas da figura 5.109, os corpos-de-prova 01 e 02 apresentaram módulos secantes iguais a $32 \mathrm{GPa}$ e $28 \mathrm{GPa}$, respectivamente. Desta forma, o valor médio do módulo secante foi de 30GPa. 


\section{ANÁLISE DOS RESULTADOS}

\subsection{Considerações Iniciais}

Neste capítulo de análise dos resultados serão abordados os seguintes aspectos: estudo dos diagramas força-deformação dos pilares, relação entre as capacidades resistentes experimentais e teóricas dos modelos e verificação do comportamento apresentado pelos pilares em face aos fenômenos de ductilização e cintamento oriundos do confinamento provocado pela armadura transversal.

\subsection{Análise dos Diagramas Força-Deformação}

Visando um melhor entendimento, este item foi dividido em dois outros subitens que abordam as análises individual e geral dos diagramas forçadeformação dos pilares.

Antes de dar início às análises, é importante dizer que além dos canais de medida avariados, aqueles que apresentaram leituras incoerentes foram desconsiderados neste estudo. A seguir, listam-se alguns motivos pelos quais isto pode ter ocorrido:

- imperfeições na colagem dos extensômetros e bases dos transdutores;

- colagem dos extensômetros nas faces de concreto justamente sobre agregados graúdos. Com isso, em função do maior módulo de elasticidade dos agregados em relação à matriz de argamassa, estes extensômetros poderiam deformar-se menos e, portanto, suas medidas não seriam representativas do modelo; 
- formação de fissuras na região onde foram colados os extensômetros e as bases dos transdutores; e

- problemas no sistema de aquisição e leitura de dados.

\subsubsection{Análise Individual}

A análise dos diagramas feita de pilar em pilar contém verificações relativas ao estado de solicitações ao qual os modelos foram submetidos, ou seja, se compressão simples, flexão composta normal ou flexão composta oblíqua. Além disso, é feita uma análise da eficiência das armaduras, tendo-se como parâmetros o modo e a intensidade como as mesmas foram solicitadas. Por fim, comparações entre as deformações medidas com o auxílio dos transdutores e aquelas obtidas por meio dos extensômetros colados no concreto e nas armaduras permitiram avaliar um pouco do comportamento estrutural de pilares de concreto armado executados com concreto de resistência usual.

a) $\mathrm{P} 1-10,0-120$

A ocorrência de flexão composta normal na direção do eixo que liga as faces onde estão localizados os transdutores 1 e 3 ficou evidente em função da maior deformação verificada pelo primeiro transdutor em contrapartida à menor deformação registrada pelo segundo. Além disso, os transdutores 2 e 4 apresentaram leituras semelhantes e situadas entre as medidas pelos transdutores 1 e 3. Para confirmar este estado de solicitação, têm-se os extensômetros 1 e 2, da armadura longitudinal, sob grandes deformações após a força de ruína, enquanto que os extensômetros 3 e 4, desta mesma armadura, permaneceram com suas deformações estacionadas em $1,5 \mathrm{~mm} / \mathrm{m}$. Ou seja, no lado mais comprimido, a armadura acumulou grandes deformações, enquanto que, no lado menos comprimido, ela chegou a parar de se deformar. Por fim, como era de se esperar, os extensômetros 5 e 7, e principalmente o 6, sofreram deformações maiores que as apresentadas pelo 8 .

Quanto à eficiência das armaduras, apenas as barras longitudinais com os extensômetros 1 e 2 chegaram próximas do escoamento no instante da força de 
pico. Menos ainda trabalharam as barras transversais, visto que a média de suas deformações de ruína foi de $0,84 \mathrm{~mm} / \mathrm{m}$ e, portanto, bem abaixo dos $5,7 \mathrm{~mm} / \mathrm{m}$ de escoamento determinado para as barras de diâmetro nominal de $5,0 \mathrm{~mm}$. O interessante a ser notado está no fato desta armadura ter apresentado grandes acréscimos de deformação quando a força aplicada estava próxima de causar a ruína do modelo.

Faz-se agora uma comparação entre as médias das deformações medidas no concreto e nas armaduras para 30\%, 50\%, 80\% e 100\% da força de ruína. Estes valores de referência foram escolhidos, pois estão associados ao processo de microfissuração do concreto exposto no item 2.9.5.

Tabela 6.1. Deformações longitudinais médias no pilar P1-10,0-120.

\begin{tabular}{|c|c|c|c|c|c|c|}
\hline $\begin{array}{l}\% F_{u} \\
(k N)\end{array}$ & $\begin{array}{c}\text { Transdutores } \\
\text { (T) } \\
(\mathrm{mm} / \mathrm{m})\end{array}$ & $\begin{array}{c}\text { Armadura } \\
\text { Long. (AL) } \\
(\mathrm{mm} / \mathrm{m})\end{array}$ & $\begin{array}{l}\text { Concreto } \\
\text { Long. (CL) } \\
(\mathrm{mm} / \mathrm{m})\end{array}$ & $(\mathrm{T}) /(\mathrm{AL})$ & $(\mathrm{T}) /(\mathrm{CL})$ & $(A L) /(C L)$ \\
\hline $30 \%=322$ & 0,24 & 0,27 & 0,27 & 0,89 & 0,89 & 1,00 \\
\hline $50 \%=536$ & 0,44 & 0,49 & 0,52 & 0,90 & 0,85 & 0,94 \\
\hline $80 \%=856$ & 0,86 & 1,00 & 1,11 & 0,86 & 0,77 & 0,90 \\
\hline$F_{u}=1072$ & 1,86 & 2,37 & 2,23 & 0,78 & 0,83 & 1,06 \\
\hline
\end{tabular}

Tabela 6.2. Deformações transversais médias no pilar P1-10,0-120.

\begin{tabular}{|c|c|c|c|}
\hline $\begin{array}{c}\% F_{u} \\
(k N)\end{array}$ & $\begin{array}{c}\text { Armadura } \\
\text { Transv. (AT) } \\
(\mathbf{m m} / \mathbf{m})\end{array}$ & $\begin{array}{c}\text { Concreto } \\
\text { Transv. (CT) } \\
(\mathrm{mm} / \mathrm{m})\end{array}$ & $(\mathrm{AT}) /(\mathrm{CT})$ \\
\hline $30 \%=320$ & 0,045 & 0,058 & 0,78 \\
\hline $50 \%=535$ & 0,085 & 0,120 & 0,71 \\
\hline $80 \%=855$ & 0,208 & 0,360 & 0,58 \\
\hline $\mathrm{Fu}=1072$ & 0,840 & 1,430 & 0,59 \\
\hline
\end{tabular}

Conforme apresentado na tabela 6.1 , as deformações registradas na armadura longitudinal foram sempre maiores que as leituras obtidas por meio dos transdutores. No entanto, o contrário foi observado quando se compararam as deformações da armadura com as do concreto até $80 \%$ de $F_{u}$. Já a relação entre transdutores e concreto longitudinal denunciou as maiores deformações neste último. Por enquanto, a única conclusão que pode ser obtida é que, conforme a força aplicada se aproximava da ruína, a diferença entre as leituras feitas nos 
canais "gêmeos" aumentava. Assim, supõe-se que com o aumento das fissuras na matriz e a instabilidade no processo de fissuração da zona de transição do concreto, ambos verificados após $50 \%$ a $70 \%$ de $F_{u}$, as leituras feitas principalmente com os extensômetros colados ao concreto deixaram de serem confiáveis. É bom lembrar que estes extensômetros são mais suscetíveis a apresentarem problemas por ocorrer imperfeição, heterogeneidade e formação de fissuras em suas superfícies de colagem.

Tal como comentado no parágrafo anterior, a tabela 6.2 demonstrou que as diferenças entre as medidas feitas no concreto e ra armadura transversal se intensificam de acordo com o aumento da força de compressão sobre o pilar. Além disso, estas diferenças mostram-se grandes mesmo para baixos níveis de força.

b) $\mathrm{P} 1-12,5-200$

Apesar de ter se apresentado avariado o extensômetro 3 da armadura longitudinal, as demais leituras permitiram com facilidade identificar a presença de flexão composta normal na direção dos transdutores 1 e 3 . O lado mais comprimido deste pilar foi o do transdutor 3, não só pelas maiores deformações aí registradas, como também pelas maiores solicitações na armadura longitudinal associada ao extensômetro 4. Inclusive a armadura transversal confirmou este quadro, visto que os extensômetros 5, 7 e 8 apresentaram maiores deformações que o 6.

As deformações na armadura longitudinal ficaram um pouco distantes do escoamento no instante da ruína. Apenas a barra associada ao extensômetro 4 apresentou a deformação de $2,44 \mathrm{~mm} / \mathrm{m}$ correspondente a uma tensão de aproximadamente $470 \mathrm{MPa}$, ou seja, um pouco distante dos $561 \mathrm{MPa}$ relativos à deformação de escoamento de $3,2 \mathrm{~mm} / \mathrm{m}$. No que diz respeito à armadura transversal, sua deformação média de pico de $0,59 \mathrm{~mm} / \mathrm{m}$ ficou bem abaixo do valor de $5,4 \mathrm{~mm} / \mathrm{m}$ registrado para o escoamento da barra de $6,3 \mathrm{~mm}$ de diâmetro nominal. Por fim, como verificado para o pilar P1-10,0-120, altas taxas de deformação no estribo instrumentado foram observadas quando a força aplicada estava próxima de causar a ruína do modelo. 
Tabela 6.3. Deformações longitudinais médias no pilar P1-12,5-200.

\begin{tabular}{|c|c|c|c|c|c|c|}
\hline $\begin{array}{c}\% F_{u} \\
(k N)\end{array}$ & $\begin{array}{c}\text { Transdutores } \\
\text { (T) } \\
(\mathrm{mm} / \mathrm{m})\end{array}$ & $\begin{array}{c}\text { Armadura } \\
\text { Long. (AL) } \\
(\mathrm{mm} / \mathrm{m})\end{array}$ & $\begin{array}{l}\text { Concreto } \\
\text { Long. (CL) } \\
(\mathrm{mm} / \mathrm{m})\end{array}$ & $(T) /(A L)$ & $(\mathrm{T}) /(\mathrm{CL})$ & $(\mathrm{AL}) /(\mathrm{CL})$ \\
\hline $30 \%=325$ & 0,25 & 0,26 & 0,23 & 0,96 & 1,09 & 1,13 \\
\hline $50 \%=545$ & 0,45 & 0,48 & 0,43 & 0,94 & 1,05 & 1,12 \\
\hline $80 \%=870$ & 0,87 & 0,97 & 0,78 & 0,90 & 1,12 & 1,24 \\
\hline $\mathrm{Fu}=1085$ & 1,81 & 1,97 & 1,40 & 0,92 & 1,29 & 1,41 \\
\hline
\end{tabular}

Tabela 6.4. Deformações transversais médias no pilar P1-12,5-200.

\begin{tabular}{cccc}
\hline$\% F_{\mathbf{u}}$ & $\begin{array}{c}\text { Armadura } \\
\text { Transv. (AT) } \\
(\mathbf{k N})\end{array}$ & $\begin{array}{c}\text { Concreto } \\
\text { Transv. (CT) } \\
(\mathbf{m m} / \mathbf{m})\end{array}$ & $\begin{array}{c}(\mathbf{m m} / \mathbf{m}) \\
\text { (AT)/(CT) }\end{array}$ \\
\hline $30 \%=325$ & 0,045 & 0,048 & 0,94 \\
$50 \%=545$ & 0,078 & 0,075 & 1,04 \\
$80 \%=870$ & 0,173 & 0,143 & 1,21 \\
$\mathrm{Fu}=1085$ & 0,590 & 0,350 & 1,69 \\
\hline
\end{tabular}

De acordo com a tabela 6.3, a armadura longitudinal continuou a apresentar maiores deformações que os transdutores. Porém, ao contrário do modelo anteriormente analisado, tanto a armadura como os transdutores mostraram-se mais deformados que as faces do pilar.

Apesar da relação entre as deformações transversais da armadura e do concreto serem próximas da unidade até $50 \%$ de $F_{u}$ (ver a tabela 6.4 ), os valores encontrados para os demais níveis de força e a verificação visual dos diagramas correspondentes demonstraram o quanto as medidas feitas com os extensômetros colados na superfície do concreto armado podem estar fora da realidade.

c) $P 1-12,5-150$

Neste pilar ocorreu flexão composta normal na direção dos transdutores 1 e 3, sendo o lado mais comprimido aquele com o transdutor 3. As barras do lado menos comprimido associadas aos extensômetros 1 e 2 chegaram a parar de deformar após a força última, enquanto que o contrário se deu com as que foram instrumentadas com os extensômetros 3 e 4 . Apesar dos resultados obtidos com o extensômetro 6 da armadura transversal não terem sido aproveitados, a maior 
deformação verificada no ramo do estribo com o extensômetro 8 definiu bem a presença de esforços de flexão neste pilar.

As barras longitudinais com os extensômetros 3 e 4 alcançaram 0 escoamento na força de pico, enquanto que as outras duas ficaram próximas desta situação. No estribo, neste mesmo instante, a deformação média foi de $1,14 \mathrm{~mm} / \mathrm{m}$, ou seja, longe da deformação de escoamento do aço $(5,4 \mathrm{~mm} / \mathrm{m})$. Além disso, como comentado para o modelo P1-12,5-200, grandes acréscimos de deformação foram verificados com a proximidade da ruína do pilar. Confirmada esta tendência, a explicação para este fato pode estar associada a dois elementos. Primeiramente, conforme sugerido por QUEIROGA (1999), a flambagem prematura de alguma barra longitudinal poderia solicitar o estribo causando o aumento da deformação. No entanto, para este pilar, não foi verificada a flambagem de alguma barra antes da força última. Além disso, esta hipótese conta com o fato de que a flambagem ocorra justamente na região onde se localiza o estribo instrumentado. Ainda assim, parece difícil garantir que este fenômeno poderia resultar num comportamento igual de todos os ramos do estribo, conforme observado no diagrama da figura 5.34. Um segundo elemento que poderia explica melhor o aumento das taxas de deformação com a proximidade da ruína é o processo de microfissuração do concreto. Ou seja, após $50 \%$ de $F_{u}$ têm-se o desenvolvimento das fissuras na matriz e o sistema de fissuras na zona de transição torna-se instável. Como resultado disso, ocorre um aumento das taxas de deformação do concreto, tanto na direção longitudinal como na transversal que, por sua vez, em função da aderência concreto-armadura, também faz aumentar a deformação nas armaduras. Até então, nenhuma novidade. O interessante mesmo é que este aumento mostrou-se maior na direção transversal, significando, assim, que o coeficiente de Poisson, caso sua definição fosse estendida para além da fase linear, aumenta de acordo com o crescimento da força aplicada. Para se ter uma idéia em termos de números, basta calcular as relações entre as deformações transversais e longitudinais (Poisson) das armaduras para os diferentes níveis de força. Assim, para o pilar P1-12,5-150, tevese: 0,173 para $30 \%$ de $F_{u} ; 0,175$ para $50 \%$ de $F_{u} ; 0,236$ para $80 \%$ de $F_{u}$ e 0,385 em $100 \%$ de $F_{u}$. 
Tabela 6.5. Deformações longitudinais médias no pilar P1-12,5-150.

\begin{tabular}{ccccccc}
\hline $\begin{array}{c}\text { \% } \mathrm{F}_{\mathrm{u}} \\
(\mathbf{k N})\end{array}$ & $\begin{array}{c}\text { Transdutores } \\
(\mathbf{T})\end{array}$ & $\begin{array}{c}\text { Armadura } \\
\text { Long. }(\mathbf{A L}) \\
(\mathbf{m m} / \mathbf{m})\end{array}$ & $\begin{array}{c}\text { Concreto } \\
(\mathbf{m m} / \mathbf{m})\end{array}$ & $\begin{array}{c}\text { Long. }(\mathbf{C L}) \\
(\mathbf{m m} / \mathbf{m})\end{array}$ & $\begin{array}{c}(\mathbf{T}) /(\mathbf{A L}) \\
(\mathbf{T}) /(\mathbf{C L})\end{array}$ & $(\mathbf{A L}) /(\mathbf{C L})$ \\
\hline $30 \%=365$ & 0,33 & 0,33 & 0,32 & 1,00 & 1,03 & 1,03 \\
$50 \%=610$ & 0,61 & 0,61 & 0,61 & 1,00 & 1,00 & 1,00 \\
$80 \%=980$ & 1,32 & 1,27 & 1,28 & 1,04 & 1,03 & 0,99 \\
$\mathrm{Fu}=1223$ & 2,83 & 2,96 & 2,13 & 0,96 & 1,33 & 1,39 \\
\hline
\end{tabular}

Tabela 6.6. Deformações transversais médias no pilar P1-12,5-150.

\begin{tabular}{cccc}
\hline $\begin{array}{c}\text { \% } \mathrm{F}_{\mathbf{u}} \\
(\mathbf{k N})\end{array}$ & $\begin{array}{c}\text { Armadura } \\
\text { Transv. (AT) } \\
(\mathbf{m m} / \mathbf{m})\end{array}$ & $\begin{array}{c}\text { Concreto } \\
\text { Transv. (CT) } \\
(\mathbf{m m} / \mathbf{m})\end{array}$ & (AT)/(CT) \\
\hline $30 \%=365$ & 0,057 & 0,073 & 0,78 \\
$50 \%=610$ & 0,107 & 0,145 & 0,74 \\
$80 \%=980$ & 0,300 & 0,415 & 0,72 \\
$\mathrm{Fu}=1223$ & 1,140 & 1,540 & 0,74 \\
\hline
\end{tabular}

Pela tabela 6.5, pôde-se observar que as deformações médias da armadura longitudinal e dos transdutores foram praticamente iguais em todos os níveis de força. Aliás, houve semelhança também entre as deformações medidas pelos demais dispositivos, exceto quando atuou a força de ruína.

As relações entre as deformações da armadura e do concreto transversais apresentaram-se menores que 1 (ver a tabela 6.6). Como nos pilares anteriores registraram-se leituras contraditórias, qualquer comentário relativo a estes resultados deverão ser feitos quando forem analisados um maior número de modelos.

d) P1-12,5-100

Dentre os pilares de seção quadrada, este foi o único em que o esforço de flexão foi quase imperceptível no trecho ascendente dos diagramas forçadeformação. Assim, apenas no pós-pico, as grandes deformações registradas nas barras com os extensômetros 3 e 4 e o cessar nas deformações das barras com os extensômetros 1 e 2, sugerem que o pilar foi submetido àflexão composta normal com pequena excentricidade. A direção da flexão coincidiu com o eixo que liga os 
transdutores 1 e 3 , sendo o lado mais comprimido aquele que continha o último transdutor.

Praticamente todas as barras longitudinais alcançaram a tensão de escoamento (561MPa) no instante em que se deu a força máxima sobre o pilar. É interessante observar que nesta série $\mathrm{P} 1$ parece ter ocorrido uma pequena ductilização dos pilares no pré-pico, a qual foi percebida considerando as maiores deformações de pico registradas nas armaduras longitudinais e nos transdutores dos modelos com menores espaçamentos entre estribos. Quanto às deformações na armadura transversal, as mesmas verificações feitas para os pilares anteriores são aqui aplicáveis, porém, a deformação média no instante da ruína do modelo foi de $1,04 \mathrm{~mm} / \mathrm{m}$. Vale dizer que o extensômetro número 8 apresentou valores incoerentes e, portanto, teve suas leituras descartadas da análise e da composição do diagrama da figura 5.40 .

Tabela 6.7. Deformações longitudinais médias no pilar P1-12,5-100.

\begin{tabular}{ccccccc}
\hline $\begin{array}{c}\text { \% } \mathrm{F}_{\mathrm{u}} \\
(\mathbf{k N})\end{array}$ & $\begin{array}{c}\text { Transdutores } \\
(\mathbf{T})\end{array}$ & $\begin{array}{c}\text { Armadura } \\
\text { Long. }(\mathbf{A L}) \\
(\mathbf{m m} / \mathbf{m})\end{array}$ & $\begin{array}{c}\text { Concreto } \\
(\mathbf{m m} / \mathbf{m})\end{array}$ & $\begin{array}{c}\text { Long. }(\mathbf{C L}) \\
(\mathbf{m m} / \mathbf{m})\end{array}$ & $\begin{array}{c}(\mathbf{T}) /(\mathbf{A L}) \\
(\mathbf{T}) /(\mathbf{C L})\end{array}$ & $(\mathbf{A L}) /(\mathbf{C L})$ \\
\hline $30 \%=390$ & 0,34 & 0,36 & 0,30 & 0,94 & 1,13 & 1,20 \\
$50 \%=645$ & 0,63 & 0,65 & 0,52 & 0,97 & 1,21 & 1,25 \\
$80 \%=1035$ & 1,43 & 1,50 & 1,04 & 0,95 & 1,38 & 1,44 \\
$\mathrm{Fu}=1292$ & 2,96 & 3,53 & 1,95 & 0,84 & 1,52 & 1,81 \\
\hline
\end{tabular}

Tabela 6.8. Deformações transversais médias no pilar P1-12,5-100.

\begin{tabular}{|c|c|c|c|}
\hline $\begin{array}{l}\% F_{u} \\
(k N)\end{array}$ & $\begin{array}{c}\text { Armadura } \\
\text { Transv. (AT) } \\
(\mathrm{mm} / \mathrm{m})\end{array}$ & $\begin{array}{c}\text { Concreto } \\
\text { Transv. (CT) } \\
(\mathrm{mm} / \mathrm{m})\end{array}$ & $(\mathrm{AT}) /(\mathrm{CT})$ \\
\hline $30 \%=390$ & 0,060 & 0,075 & 0,80 \\
\hline $50 \%=645$ & 0,103 & 0,138 & 0,75 \\
\hline $80 \%=1035$ & 0,330 & 0,538 & 0,61 \\
\hline $\mathrm{Fu}=1292$ & 1,040 & 1,460 & 0,71 \\
\hline
\end{tabular}

Conforme a tabela 6.7 , as deformações na armadura longitudinal foram ligeiramente maiores que as registradas nos transdutores. Como esta tendência foi verificada até agora em todos os modelos analisados, cabe procurar entender 0 porque desta constatação. Há uma hipótese de que, durante a vibração do 
concreto, parte do ar, ao tentar sair de dentro da massa, tende a se encaminhar pela interface com a armadura. Como se sabe que nem todo ar é expelido no processo de vibração, algumas bolhas acabam ficando junto das barras. Este fenômeno, aliado ao processo de microfissuração do concreto, diminui a tensão de aderência entre o concreto e a armadura de aço, fazendo com que as barras longitudinais, em função da sua maior rigidez, absorvam mais força e, assim, deformem mais do que o concreto. Outra explicação, que não necessariamente desconsidera a primeira, seria a da formação de um núcleo resistente delimitado pelos eixos dos estribos, o qual acabaria por se deformar mais do que o cobrimento. Isto foi verificado nos pilares de concreto de alta resistência por LIMA et al. (1997) e QUEIROGA et al. (1999). No entanto, para os pilares de concreto de resistência usual, a verificação da hipótese de que as deformações diferenciais entre as barras longitudinais e as registradas pelos transdutores ocorrem por conta da formação de núcleo resistente só poderá ser realizada quando for efetuado o cálculo da relação entre a resistência experimental do modelo e sua capacidade teórica. Ou seja, se esta relação for menor que 1 , significa que há formação de núcleo resistente. Apenas no caso de ocorrer um cintamento significativo do concreto em virtude da armadura transversal adotada, esta relação poderia ser maior do que 1 e, ainda assim, ocorrer a formação do núcleo no pré-pico. Vale dizer que no pós-pico, com o descolamento da camada de cobrimento, há a formação natural de um núcleo resistente. Isto pode ser verificado por meio das maiores deformações sofridas pela armadura em relação aos transdutores no trecho descendente do diagrama força-deformação.

Por fim, tal como no pilar P1-12,5-150, as deformações nos estribos mostraram-se menores que as registradas nas faces do pilar (ver a tabela 6.8).

e) P2-10,0-120

Para este modelo, nenhuma análise pôde ser realizada, pois todas as leituras dos transdutores e extensômetros foram perdidas por ocasião de um problema no sistema de aquisição de dados. 


\section{f) $P 2-12,5-150$}

Apesar das avarias observadas nos extensômetros 3 e 9 das armaduras longitudinal e transversal, respectivamente, a análise dos trechos ascendentes dos diagramas força-deformação dos transdutores e da armadura longitudinal, revelaram o estado de solicitação de compressão simples neste modelo.

As barras longitudinais não alcançaram o escoamento na força de pico, porém, a média das tensões nesta armadura foi de 520MPa, ou seja, próximo dos $561 \mathrm{MPa}$ necessários ao escoamento. Para o estribo, a máxima deformação registrada na força de pico foi de $0,98 \mathrm{~mm} / \mathrm{m}$.

Tabela 6.9. Deformações longitudinais médias no pilar P2-12,5-150.

\begin{tabular}{ccccccc}
\hline $\begin{array}{c}\text { \% } \mathrm{F}_{\mathrm{u}} \\
(\mathbf{k N})\end{array}$ & $\begin{array}{c}\text { Transdutores } \\
(\mathbf{T})\end{array}$ & $\begin{array}{c}\text { Armadura } \\
\text { Long. }(\mathbf{A L}) \\
(\mathbf{m m} / \mathbf{m})\end{array}$ & $\begin{array}{c}\text { Concreto } \\
(\mathbf{m m} / \mathbf{m})\end{array}$ & $\begin{array}{c}\text { Long. }(\mathbf{C L}) \\
(\mathbf{m m} / \mathbf{m})\end{array}$ & $\begin{array}{c}(\mathbf{T}) /(\mathbf{A L}) \\
(\mathbf{T}) /(\mathbf{C L})\end{array}$ & $(\mathbf{A L}) /(\mathbf{C L})$ \\
\hline $30 \%=420$ & 0,29 & 0,31 & 0,27 & 0,94 & 1,07 & 1,15 \\
$50 \%=700$ & 0,53 & 0,56 & 0,49 & 0,95 & 1,08 & 1,14 \\
$80 \%=1120$ & 1,07 & 1,20 & 0,98 & 0,89 & 1,09 & 1,22 \\
$\mathrm{Fu}=1400$ & 2,08 & 2,68 & 1,56 & 0,78 & 1,33 & 1,72 \\
\hline
\end{tabular}

Tabela 6.10. Deformações transversais médias no pilar P2-12,5-150.

\begin{tabular}{cccc}
\hline $\begin{array}{c}\text { \% } \mathrm{F}_{\mathbf{u}} \\
(\mathbf{k N})\end{array}$ & $\begin{array}{c}\text { Armadura } \\
\text { Transv. (AT) } \\
(\mathbf{m m} / \mathbf{m})\end{array}$ & $\begin{array}{c}\text { Concreto } \\
\text { Transv. }(\mathbf{C T}) \\
(\mathbf{m m} / \mathbf{m})\end{array}$ & (AT)/(CT) \\
\hline $30 \%=420$ & 0,055 & 0,040 & 1,38 \\
$50 \%=700$ & 0,095 & 0,065 & 1,46 \\
$80 \%=1120$ & 0,185 & 0,085 & 2,18 \\
$\mathrm{Fu}=1400$ & 0,960 & 1,150 & 0,83 \\
\hline
\end{tabular}

De acordo com o alerta feito no item 6.2, a possibilidade dos agregados graúdos influenciarem nas deformações dos extensômetros colados ao concreto é muito grande. Talvez seja por isso que as deformações longitudinais registradas pelos extensômetros colados nas superfícies dos pilares mostraram-se, na maioria das vezes, menores que as obtidas por meio de outros dispositivos (ver a tabela 6.9). 
Quanto à relação entre as deformações transversais das armaduras e do concreto (ver a tabela 6.10), mais uma vez os resultados não permitiram que fosse feita conclusão alguma, a menos do fato de que os extensômetros colados ao concreto podem estar fornecendo valores ruins por causa dos problemas que este dispositivo enfrenta. É por este motivo, ou seja, pela incerteza no aproveitamento dos resultados destes extensômetros, que se sugere que os mesmos sirvam apenas como forma de controle das leituras realizadas por meio dos transdutores e extensômetros colados nas armaduras.

g) P2-12,5-100

Observando-se os diagramas, concluiu-se que ocorreu flexão composta oblíqua com a região mais comprimida localizada no quadrante formado pelos transdutores 1 e 2, tendo-se a maior excentricidade manifestada no sentido do primeiro transdutor. Esta verificação ficou clara com as maiores deformações registradas pelos transdutores 1 e 2 em contrapartida às menores deformações medidas pelos transdutores 3 e 4 . Além disso, depois de alcançada a força máxima no pilar, observaram-se grandes deformações nos extensômetros 1, 2 e 3, da armadura longitudinal, e a estagnação nas deformações dos extensômetros 4, 5 e 6.

As barras longitudinais associadas aos extensômetros 1, 2 e 3 alcançaram o escoamento na força de pico. No entanto, as demais barras, apesar de não chegarem a escoar, sofreram tensões muito próximas da tensão relativa ao escoamento. Na armadura transversal, deformações da ordem de $0,90 \mathrm{~mm} / \mathrm{m}$ foram observadas quando atuou a força de ruína. Como em todos os pilares analisados até agora, maiores acréscimos de deformação transversal foram registrados depois de $75 \%$ a $80 \%$ da força última. 
Tabela 6.11. Deformações longitudinais médias no pilar P2-12,5-100.

\begin{tabular}{|c|c|c|c|c|c|c|}
\hline $\begin{array}{c}\% F_{u} \\
(k N)\end{array}$ & $\begin{array}{c}\text { Transdutores } \\
\qquad \begin{array}{c}(\mathrm{T}) \\
(\mathrm{mm} / \mathrm{m})\end{array}\end{array}$ & $\begin{array}{c}\text { Armadura } \\
\text { Long. (AL) } \\
(\mathrm{mm} / \mathrm{m})\end{array}$ & $\begin{array}{l}\text { Concreto } \\
\text { Long. (CL) } \\
(\mathrm{mm} / \mathrm{m})\end{array}$ & $(\mathrm{T}) /(\mathrm{AL})$ & $(\mathrm{T}) /(\mathrm{CL})$ & $(A L) /(C L)$ \\
\hline $30 \%=355$ & 0,31 & 0,33 & 0,52 & 0,94 & 0,60 & 0,63 \\
\hline $50 \%=590$ & 0,60 & 0,62 & 0,91 & 0,97 & 0,66 & 0,68 \\
\hline $80 \%=940$ & 1,40 & 1,37 & 1,88 & 1,02 & 0,74 & 0,73 \\
\hline $\mathrm{Fu}=1175$ & 3,27 & 2,98 & 4,59 & 1,10 & 0,71 & 0,65 \\
\hline
\end{tabular}

Tabela 6.12. Deformações transversais médias no pilar P2-12,5-100.

\begin{tabular}{|c|c|c|c|}
\hline $\begin{array}{l}\% F_{u} \\
(k N)\end{array}$ & $\begin{array}{c}\text { Armadura } \\
\text { Transv. (AT) } \\
(\mathbf{m m} / \mathbf{m})\end{array}$ & $\begin{array}{c}\text { Concreto } \\
\text { Transv. (CT) } \\
(\mathrm{mm} / \mathrm{m})\end{array}$ & $(\mathrm{AT}) /(\mathrm{CT})$ \\
\hline $30 \%=355$ & 0,055 & 0,040 & 1,38 \\
\hline $50 \%=590$ & 0,100 & 0,090 & 1,11 \\
\hline $80 \%=940$ & 0,295 & 0,365 & 0,81 \\
\hline $\mathrm{Fu}=1175$ & 0,850 & 1,250 & 0,68 \\
\hline
\end{tabular}

A tabela 6.11 mostra as relações entre as deformações dos transdutores e das barras longitudinais girando em torno de 1. No entanto, a medida das deformações nas faces do pilar demonstrou uma tendência totalmente diferente da sugerida na análise do pilar P2-12,5-150, ou seja, neste caso, estas deformações apresentam-se sempre maiores que as leituras dos transdutores e extensômetros das armaduras.

Na tabela 6.12, também foi observada uma incongruência nas relações entre as deformações transversais das armaduras e do concreto quando comparadas àquelas verificadas no pilar P2-12,5-150.

h) P2-12,5-75

As maiores deformações medidas pelos transdutores 2 e 3 , no trecho ascendente do diagrama força-deformação, revelaram a ocorrência de flexão composta oblíqua com a região mais comprimida localizada no quadrante formado pelos transdutores em questão. Aparentemente, a maior excentricidade se deu no sentido do transdutor 3 , visto que as barras com os extensômetros 5 e 6 
acumularam grandes deformações após o pico de força, enquanto que aquelas com os extensômetros 1 e 2 tiveram suas deformações estagnadas.

Grandes deformações foram observadas nas armaduras longitudinais no instante da força de ruína. Para se ter idéia, a barra menos deformada $(2,75 \mathrm{~mm} / \mathrm{m})$ foi solicitada por uma tensão de $525 \mathrm{MPa}$, ou seja, próximo dos $561 \mathrm{MPa}$ relativos ao escoamento das barras com diâmetro nominal de $12,5 \mathrm{~mm}$. Enquanto isso, na armadura transversal, ocorreram deformações de pico da ordem de $0,85 \mathrm{~mm} / \mathrm{m}$. Por fim, vale dizer que avarias constatadas durante 0 ensaio inutilizaram os extensômetros 4 e 13 da armadura e concreto longitudinais, respectivamente.

Tabela 6.13. Deformações longitudinais médias no pilar P2-12,5-75.

\begin{tabular}{ccccccc}
\hline $\begin{array}{c}\text { \% } \mathrm{F}_{\mathrm{u}} \\
(\mathbf{k N})\end{array}$ & $\begin{array}{c}\text { Transdutores } \\
(\mathbf{T})\end{array}$ & $\begin{array}{c}\text { Armadura } \\
\text { Long. }(\mathbf{A L}) \\
(\mathbf{m m} / \mathbf{m})\end{array}$ & $\begin{array}{c}\text { Concreto } \\
(\mathbf{m m} / \mathbf{m})\end{array}$ & $\begin{array}{c}\text { Long. }(\mathbf{C L}) \\
(\mathbf{m m} / \mathbf{m})\end{array}$ & $\begin{array}{c}(\mathbf{T}) /(\mathbf{A L}) \\
(\mathbf{T}) /(\mathbf{C L})\end{array}$ & $(\mathbf{A L}) /(\mathbf{C L})$ \\
\hline $30 \%=365$ & 0,33 & 0,37 & 0,23 & 0,89 & 1,43 & 1,61 \\
$50 \%=610$ & 0,65 & 0,70 & 0,52 & 0,93 & 1,25 & 1,35 \\
$80 \%=970$ & 1,43 & 1,53 & 1,39 & 0,93 & 1,03 & 1,10 \\
$\mathrm{Fu}=1215$ & 3,08 & 3,48 & 3,78 & 0,89 & 0,81 & 0,92 \\
\hline
\end{tabular}

Tabela 6.14. Deformações transversais médias no pilar P2-12,5-75.

\begin{tabular}{cccc}
\hline $\begin{array}{c}\text { \% } \mathrm{F}_{\mathbf{u}} \\
(\mathbf{k N})\end{array}$ & $\begin{array}{c}\text { Armadura } \\
\text { Transv. (AT) } \\
(\mathbf{m m} / \mathbf{m})\end{array}$ & $\begin{array}{c}\text { Concreto } \\
\text { Transv. }(\mathbf{C T}) \\
(\mathbf{m m} / \mathbf{m})\end{array}$ & $(\mathbf{A T}) /(\mathbf{C T})$ \\
\hline $30 \%=365$ & 0,055 & 0,045 & 1,22 \\
$50 \%=610$ & 0,110 & 0,100 & 1,10 \\
$80 \%=970$ & 0,335 & 0,255 & 1,31 \\
$\mathrm{Fu}=1215$ & 0,750 & 0,380 & 1,97 \\
\hline
\end{tabular}

A única coisa que se pode afirmar com a apreciação das tabelas 6.13 e 6.14 é que as deformações longitudinais previstas pelas armaduras mantiveram a tendência de serem um pouco maiores que as registradas pelos transdutores.

Ao término das análises das séries $\mathrm{P} 1$ e $\mathrm{P} 2$, pode-se, definitivamente, afirmar que as medidas feitas com extensômetros colados na superfície do concreto servem apenas para supervisionar as leituras efetuadas por meio de outros dispositivos. Como mais uma prova desta pouca confiabilidade, basta comparar as deformações transversais das armaduras e das faces dos pilares de uma mesma 
série e com mesmas resistências e diâmetros das armaduras (por exemplo o P212,5-100 e P2-12,5-75). Usando deste artifício, observou-se que as deformações dos estribos foram sempre próximas de um pilar para o outro nos diferentes níveis de força, enquanto que, o mesmo não aconteceu com os extensômetros colados ao concreto, principalmente após $80 \%$ de $F_{\mathrm{u}}$. Isso demonstra como os extensômetros elétricos colados ao concreto fornecem medidas de pouca credibilidade, ainda mais quando o processo de microfissuração do concreto está avançado.

i) P3-10,0-120

A flexão composta oblíqua ocorreu neste pilar com o lado mais comprimido situado no quadrante formado pelos transdutores 2 e 3. Para tanto, foi observado que estes transdutores e os extensômetros 7 e 10, locados nos ramos do estribo principal, registraram as maiores deformações antes da força de ruína. Para esta análise, as deformações obtidas no transdutor 2 foram tomadas apenas até a força de $1050 \mathrm{kN}$, pois, exatamente neste momento, o referido transdutor caiu por conta de uma fissura formada bem abaixo de sua base.

Apesar de nenhuma barra ter alcançado o escoamento na força máxima, todas elas foram solicitadas a ponto de apresentarem tensões da ordem de $600 \mathrm{MPa}$, ou seja, bem próximas da tensão relativa ao escoamento das barras de diâmetro de 10,0mm (611 MPa). Somente as barras associadas aos extensômetros 2 e 3 foram submetidas a tensões menores, da ordem de 540MPa. Para a armadura transversal, a novidade esteve na instrumentação do estribo suplementar presente em todos os modelos da série P3. O comportamento desta armadura se diferenciou do observado no estribo principal, pois ela não apresentou grandes acréscimos de deformação com a proximidade da força última. Em função disso, a deformação de pico verificada neste elemento foi de $0,53 \mathrm{~mm} / \mathrm{m}$, enquanto que, no estribo principal foi da ordem de $0,95 \mathrm{~mm} / \mathrm{m}$. 
Tabela 6.15. Deformações longitudinais médias no pilar P3-10,0-120.

\begin{tabular}{ccccccc}
\hline $\begin{array}{c}\text { \% } \mathrm{F}_{\mathrm{u}} \\
(\mathbf{k N})\end{array}$ & $\begin{array}{c}\text { Transdutores } \\
(\mathbf{T}) \\
(\mathbf{m m} / \mathbf{m})\end{array}$ & $\begin{array}{c}\text { Armadura } \\
\text { Long. }(\mathbf{A L}) \\
(\mathbf{m m} / \mathbf{m})\end{array}$ & $\begin{array}{c}\text { Concreto } \\
\text { Long. }(\mathbf{C L}) \\
(\mathbf{m m} / \mathbf{m})\end{array}$ & $\begin{array}{c}(\mathbf{T}) /(\mathbf{A L}) \\
(\mathbf{T}) /(\mathbf{C L})\end{array}$ & $(\mathbf{A L}) /(\mathbf{C L})$ \\
\hline $30 \%=380$ & 0,28 & 0,29 & 0,25 & 0,97 & 1,12 & 1,16 \\
$50 \%=635$ & 0,52 & 0,54 & 0,46 & 0,96 & 1,13 & 1,17 \\
$80 \%=1010$ & 1,13 & 1,18 & 0,98 & 0,96 & 1,15 & 1,20 \\
$\mathrm{Fu}=1265$ & 2,74 & 2,94 & 1,92 & 0,93 & 1,43 & 1,53 \\
\hline
\end{tabular}

Tabela 6.16. Deformações transversais médias no pilar P3-10,0-120.

\begin{tabular}{|c|c|c|c|}
\hline $\begin{array}{l}\% F_{u} \\
(k N)\end{array}$ & $\begin{array}{l}\text { Armadura } \\
\text { Transv. (AT) } \\
(\mathbf{m m} / \mathbf{m})\end{array}$ & $\begin{array}{c}\text { Concreto } \\
\text { Transv. (CT) } \\
(\mathrm{mm} / \mathrm{m})\end{array}$ & $(\mathrm{AT}) /(\mathrm{CT})$ \\
\hline $30 \%=380$ & 0,050 & 0,080 & 0,63 \\
\hline $50 \%=635$ & 0,100 & 0,165 & 0,61 \\
\hline $80 \%=1010$ & 0,235 & 0,545 & 0,43 \\
\hline $\mathrm{Fu}=1265$ & 1,010 & 1,610 & 0,63 \\
\hline
\end{tabular}

Como comentários para os resultados das tabelas 6.15 e 6.16 , valem os mesmos feitos para os pilares analisados anteriormente.

\section{j) $P 3-12,5-150$}

As grandes deformações de pós-pico das barras longitudinais com os extensômetros 1,2 e 3 , e a estagnação nas deformações sofridas pelos extensômetros 5 e 6, sugerem que ocorreu flexão composta no pilar P3-12,5-150. Entretanto, é a partir das maiores leituras dos transdutores 1 e 2 e dos extensômetros 7 e 8 , da armadura transversal, que se pode afirmar que o modelo foi submetido àflexão composta oblíqua, sendo a região mais comprimida aquela referente ao quadrante localizado entre os transdutores 1 e 2. Além disso, em virtude das deformações nas barras longitudinais, a maior excentricidade parece ter incidido no sentido do transdutor 1. Semelhante ao ocorrido com o pilar P3-10,0-120, as deformações obtidas pelo transdutor 2 foram tomadas apenas até a força de pré-pico de $1080 \mathrm{kN}$, pois, exatamente neste instante, o referido transdutor caiu em virtude da formação de uma fissura bem abaixo de sua base. 
Apenas a barra longitudinal com o extensômetro 3 alcançou a deformação de escoamento na força última. Apesar disso, a média das tensões atuantes nas demais barras (528MPa) esteve próxima da tensão de escoamento (561MPa). Para a armadura transversal, a maior deformação registrada no pico de força foi de $1,02 \mathrm{~mm} / \mathrm{m}$. Este valor esteve muito abaixo da deformação de escoamento de $5,4 \mathrm{~mm} / \mathrm{m}$, verificada em ensaio de tração para a barra de diâmetro nominal de $6,3 \mathrm{~mm}$. Para o estribo suplementar, a deformação de pico foi de $0,38 \mathrm{~mm} / \mathrm{m}$ e seu comportamento idêntico ao verificado no pilar P3-10,0-120.

Tabela 6.17. Deformações longitudinais médias no pilar P3-12,5-150.

\begin{tabular}{|c|c|c|c|c|c|c|}
\hline $\begin{array}{l}\% F_{u} \\
(k N)\end{array}$ & $\begin{array}{c}\text { Transdutores } \\
\qquad(\mathrm{T}) \\
(\mathrm{mm} / \mathrm{m})\end{array}$ & $\begin{array}{c}\text { Armadura } \\
\text { Long. (AL) } \\
(\mathrm{mm} / \mathrm{m})\end{array}$ & $\begin{array}{l}\text { Concreto } \\
\text { Long. (CL) } \\
(\mathrm{mm} / \mathrm{m})\end{array}$ & $(\mathrm{T}) /(\mathrm{AL})$ & $(\mathrm{T}) /(\mathrm{CL})$ & $(A L) /(C L)$ \\
\hline $30 \%=395$ & 0,26 & 0,29 & 0,32 & 0,90 & 0,81 & 0,91 \\
\hline $50 \%=660$ & 0,49 & 0,53 & 0,62 & 0,92 & 0,79 & 0,85 \\
\hline $80 \%=1060$ & 1,09 & 1,14 & 1,74 & 0,96 & 0,63 & 0,66 \\
\hline $\mathrm{Fu}=1322$ & 2,92 & 2,86 & 3,88 & 1,02 & 0,75 & 0,74 \\
\hline
\end{tabular}

Tabela 6.18. Deformações transversais médias no pilar P3-12,5-150.

\begin{tabular}{cccc}
\hline$\% \mathrm{~F}_{\mathrm{u}}$ & $\begin{array}{c}\text { Armadura } \\
\text { Transv. (AT) } \\
(\mathbf{k N})\end{array}$ & $\begin{array}{c}\text { Concreto } \\
\text { Transv. (CT) } \\
(\mathbf{m m})\end{array}$ & $\begin{array}{c}\mathbf{( A T )}) \\
\text { (AT) }\end{array}$ \\
\hline $30 \%=395$ & 0,055 & 0,080 & 0,69 \\
$50 \%=660$ & 0,100 & 0,260 & 0,38 \\
$80 \%=1060$ & 0,210 & 0,770 & 0,27 \\
$\mathrm{Fu}=1322$ & 0,740 & 1,210 & 0,61 \\
\hline
\end{tabular}

Os comentários relativos às tabelas 6.17 e 6.18 são os mesmos feitos para os pilares anteriores.

k) P3-12,5-100

Os transdutores 1 e 2 registraram as maiores deformações até a força de ruína. Ainda neste intervalo, o mesmo comportamento foi observado para os extensômetros 7 e 8 da armadura transversal. Assim sendo, pode-se dizer que 
houve flexão composta oblíqua com a região mais comprimida localizada no quadrante formado pelos transdutores 1 e 2 .

Com a definição do estado de solicitação ao qual o pilar foi submetido, o que chamou atenção foi o recuo na deformação da barra longitudinal associada ao extensômetro 1. Isto porque a mesma se localizava na região mais comprimida do modelo e, portanto, deveria deformar-se ainda mais, e não o contrário. A explicação para este fato está nas observações feitas durante o ensaio (item 5.1.2), as quais revelaram ter ocorrido a flambagem desta barra pouco depois de atingida a força de ruína. Ou seja, com a flambagem, houve uma diminuição da tensão sobre a armadura, o que resultou na redução da deformação da barra.

Apesar de apenas duas barras longitudinais terem atingido a deformação de escoamento na força de ruína, a média das tensões nas demais (545MPa) ficou próxima da de escoamento (561MPa). No estribo principal, o ramo mais solicitado teve uma deformação de pico igual a $1,54 \mathrm{~mm} / \mathrm{m}$. Já para o estribo suplementar, esta deformação foi de $0,49 \mathrm{~mm} / \mathrm{m}$.

Tabela 6.19. Deformações longitudinais médias no pilar P3-12,5-100.

\begin{tabular}{|c|c|c|c|c|c|c|}
\hline $\begin{array}{l}\% F_{u} \\
(k N)\end{array}$ & $\begin{array}{c}\text { Transdutores } \\
\text { (T) } \\
(\mathrm{mm} / \mathrm{m})\end{array}$ & $\begin{array}{c}\text { Armadura } \\
\text { Long. (AL) } \\
(\mathrm{mm} / \mathrm{m})\end{array}$ & $\begin{array}{l}\text { Concreto } \\
\text { Long. (CL) } \\
(\mathrm{mm} / \mathrm{m})\end{array}$ & $(T) /(A L)$ & $(\mathrm{T}) /(\mathrm{CL})$ & $(\mathrm{AL}) /(\mathrm{CL})$ \\
\hline $30 \%=440$ & 0,31 & 0,32 & 0,30 & 0,97 & 1,03 & 1,07 \\
\hline $50 \%=735$ & 0,57 & 0,60 & 0,59 & 0,95 & 0,97 & 1,02 \\
\hline $80 \%=1175$ & 1,30 & 1,39 & 1,58 & 0,94 & 0,82 & 0,88 \\
\hline $\mathrm{Fu}=1468$ & 2,50 & 3,03 & 3,26 & 0,83 & 0,77 & 0,93 \\
\hline
\end{tabular}

Tabela 6.20. Deformações transversais médias no pilar P3-12,5-100.

\begin{tabular}{cccc}
\hline $\begin{array}{c}\text { \% } \mathrm{F}_{\mathrm{u}} \\
(\mathbf{k N})\end{array}$ & $\begin{array}{c}\text { Armadura } \\
\text { Transv. (AT) } \\
(\mathbf{m m} / \mathbf{m})\end{array}$ & $\begin{array}{c}\text { Concreto } \\
\text { Transv. (CT) } \\
(\mathbf{m m} / \mathbf{m})\end{array}$ & (AT)/(CT) \\
\hline $30 \%=440$ & 0,050 & 0,030 & 1,67 \\
$50 \%=735$ & 0,085 & 0,050 & 1,70 \\
$80 \%=1175$ & 0,230 & 0,040 & 5,75 \\
$\mathrm{Fu}=1468$ & 0,770 & 0,640 & 1,20 \\
\hline
\end{tabular}


Os comentários relativos às tabelas 6.19 e 6.20 são os mesmos feitos para os pilares anteriormente analisados.

\section{८) P3-12,5-75}

Como descrito no item 5.1.2, mesmo com o ajuste do pilar na posição central da máquina de ensaio, durante a aplicação da força de escorvamento foi observado que a deformação medida pelo transdutor 2 mostrava-se bem superior à do transdutor 4. Com o propósito de diminuir esta excentricidade, aparentemente causada pela heterogeneidade do concreto, deslocou-se o pilar no sentido do transdutor 2. Ainda assim, o transdutor 2 continuou a registrar maiores deformações que o 4 até $80 \%$ da força de ruína (ver a figura 5.79). Ou seja, ocorreu flexão composta normal com a região mais comprimida localizada no lado do transdutor 2. Porém, a partir deste nível de força, foram verificadas maiores deformações no transdutor 4 em relação ao 2, fato este que significou a mudança no sentido do esforço de flexão. Mais uma vez, a explicação para tal fenômeno encontra-se no processo de microfissuração do concreto. Acontece que depois de $80 \%$ de $F_{u}$, as fissuras na zona de transição e na matriz do concreto encontram-se totalmente espalhadas, o que cria uma certa homogeneização na seção resistente. A partir de então, estando a seção resistindo por igual, aquela excentricidade dada ao pilar com o objetivo de equilibrar as deformações acabou por aumentar consideravelmente as deformações medidas pelo transdutor 4 e, com isto, inverter o sentido da flexão sobre o pilar.

Apesar de nenhuma barra longitudinal ter atingido o escoamento, a tensão média atuante nesta armadura, no instante da força máxima, foi de $537 \mathrm{MPa}$, ou seja, próxima da de escoamento (561MPa). Para o estribo principal, esta deformação foi de $0,84 \mathrm{~mm} / \mathrm{m}$, enquanto que, no suplementar foi de $0,32 \mathrm{~mm} / \mathrm{m}$. Como o comportamento do estribo suplementar foi igual em todos os modelos da série P3, ou seja, apresentou pequenas deformações no instante da ruína, isto sugere que este elemento não contribui muito para acentuar os efeitos oriundos do confinamento, ou sejam, o cintamento e a ductilidade dos pilares. No entanto, de acordo com a função de proteger as barras longitudinais contra flambagem prematura, o estribo adicional mostrou-se eficiente, pois não foi observada a ocorrência deste fenômeno antes que a força de pico fosse atingida. 
Tabela 6.21. Deformações longitudinais médias no pilar P3-12,5-75.

\begin{tabular}{ccccccc}
\hline$\% F_{\mathrm{u}}$ & $\begin{array}{c}\text { Transdutores } \\
(\mathbf{k N})\end{array}$ & $\begin{array}{c}\text { Armadura } \\
(\mathbf{m m} / \mathbf{m})\end{array}$ & $\begin{array}{c}\text { Concreto } \\
\text { Long. }(\mathbf{A L}) \\
(\mathbf{m m} / \mathbf{m})\end{array}$ & $\begin{array}{c}\text { Long. }(\mathbf{C L}) \\
(\mathbf{m m} / \mathbf{m})\end{array}$ & $\begin{array}{c}(\mathbf{T}) /(\mathbf{A L}) \\
(\mathbf{T}) /(\mathbf{C L})\end{array}$ & $(\mathbf{A L}) /(\mathbf{C L})$ \\
\hline $30 \%=445$ & 0,30 & 0,33 & 0,31 & 0,91 & 0,97 & 1,06 \\
$50 \%=745$ & 0,58 & 0,63 & 0,60 & 0,92 & 0,97 & 1,05 \\
$80 \%=1190$ & 1,40 & 1,40 & 1,47 & 1,00 & 0,95 & 0,95 \\
$\mathrm{Fu}=1485$ & 3,48 & 2,85 & 2,08 & 1,22 & 1,67 & 1,37 \\
\hline
\end{tabular}

Tabela 6.22. Deformações transversais médias no pilar P3-12,5-75.

\begin{tabular}{cccc}
\hline$\% F_{\mathbf{u}}$ & $\begin{array}{c}\text { Armadura } \\
\text { Transv. (AT) } \\
(\mathbf{k N})\end{array}$ & $\begin{array}{c}\text { Concreto } \\
\text { Transv. (CT) } \\
(\mathbf{m m} / \mathbf{m})\end{array}$ & $\begin{array}{c}(\mathbf{m m} / \mathbf{m}) \\
(\mathbf{A T}) /(\mathbf{C T})\end{array}$ \\
\hline $30 \%=445$ & 0,050 & 0,060 & 0,83 \\
$50 \%=745$ & 0,085 & 0,070 & 1,21 \\
$80 \%=1190$ & 0,165 & 0,050 & 3,30 \\
$\mathrm{Fu}=1485$ & 0,740 & 0,340 & 2,18 \\
\hline
\end{tabular}

Os comentários relativos æ̀̀ tabelas 6.21 e 6.22 são os mesmos feitos para os pilares anteriormente analisados.

m) $P 4-10,0-120$

O mesmo problema de acerto do pilar na máquina de ensaio, verificado no modelo anteriormente analisado, ocorreu no pilar P4-10,0-120. Assim sendo, seu comportamento foi semelhante ao do P3-12,5-75, inclusive no que diz respeito ao estado de solicitação ao qual ele foi submetido. A estagnação nas deformações das barras localizadas no lado menos comprimido e o avanço nas deformações das barras do lado mais comprimido confirmam esta condição.

Em função da fissura formada bem abaixo da base do transdutor 2, a qual provocou sua queda, as deformações relativas a este transdutor só puderam ser aproveitadas até a força de $1150 \mathrm{kN}$. Esta persistente queda de alguns transdutores, antes se alcançar a força de ruína, talvez pudesse ter sido evitada. Bastaria ter utilizado uma cola que absorvesse melhor as deformações advindas da fissuração do pilar, visto que, a cola empregada não se mostrou capaz disto. 
No que diz respeito æ̀ solicitações nas armaduras no instante da ruína, duas barras longitudinais apresentaram deformações além da de escoamento. As demais tiveram uma deformação média de $2,74 \mathrm{~mm} / \mathrm{m}$. Quanto aos dois estribos principais, - localizado no lado do transdutor 2 teve uma deformação média de pico de $0,89 \mathrm{~mm} / \mathrm{m}$, enquanto que, o outro apresentou uma deformação de $1,00 \mathrm{~mm} / \mathrm{m}$. 0 interessante no diagrama força-deformação da armadura transversal é a maior suavidade em seu trecho descendente, se comparada ao verificado nos pilares até agora analisados.

Tabela 6.23. Deformações longitudinais médias no pilar P4-10,0-120.

\begin{tabular}{ccccccc}
\hline $\begin{array}{c}\% F_{\mathbf{u}} \\
(\mathbf{k N})\end{array}$ & $\begin{array}{c}\text { Transdutores } \\
(\mathbf{T}) \\
(\mathbf{m m} / \mathbf{m})\end{array}$ & $\begin{array}{c}\text { Armadura } \\
\text { Long. }(\mathbf{A L}) \\
(\mathbf{m m} / \mathbf{m})\end{array}$ & $\begin{array}{c}\text { Concreto } \\
\text { Long. }(\mathbf{C L})\end{array}$ & $\begin{array}{c}(\mathbf{m}) /(\mathbf{A L}) \\
(\mathbf{m})\end{array}$ & $\begin{array}{c}(\mathrm{T}) /(\mathbf{C L}) \\
(\mathbf{A L}) /(\mathbf{C L})\end{array}$ \\
\hline $30 \%=370$ & 0,27 & 0,31 & 0,26 & 0,87 & 1,04 & 1,19 \\
$50 \%=620$ & 0,51 & 0,56 & 0,49 & 0,91 & 1,04 & 1,14 \\
$80 \%=990$ & 1,16 & 1,27 & 1,26 & 0,91 & 0,92 & 1,01 \\
$\mathrm{Fu}=1238$ & 2,93 & 3,10 & 2,71 & 0,95 & 1,08 & 1,14 \\
\hline
\end{tabular}

Tabela 6.24. Deformações transversais médias no pilar P4-10,0-120.

\begin{tabular}{cccc}
\hline$\% F_{\mathbf{u}}$ & $\begin{array}{c}\text { Armadura } \\
\text { Transv. (AT) }\end{array}$ & $\begin{array}{c}\text { Concreto } \\
\text { Transv. (CT) } \\
(\mathbf{m m} / \mathbf{m})\end{array}$ & $\begin{array}{c}(\mathbf{m m} / \mathbf{m}) \\
\text { (AT)/(CT) }\end{array}$ \\
\hline $30 \%=370$ & 0,050 & 0,065 & 0,77 \\
$50 \%=620$ & 0,098 & 0,110 & 0,89 \\
$80 \%=990$ & 0,273 & 0,490 & 0,56 \\
$\mathrm{Fu}=1238$ & 1,000 & 2,740 & 0,36 \\
\hline
\end{tabular}

Os comentários relativos às tabelas 6.23 e 6.24 são os mesmos feitos para os pilares analisados anteriormente.

n) $P 4-12,5-150$

A ocorrência de flexão composta normal na direção do eixo que liga as faces onde estão localizados os transdutores 1 e 3 ficou evidente em função da maior deformação verificada no segundo transdutor em contrapartida à menor 
deformação do primeiro. Além disso, os transdutores 2 e 4 apresentaram leituras semelhantes e situadas entre as registradas pelos transdutores 1 e 3 . Para confirmar esta condição, têm-se os extensômetros 10 e 14, da armadura transversal, sofrendo as maiores deformações registradas nos estribos. Perante este quadro, pode-se dizer que a excentricidade da força aplicada manifestou-se no sentido do transdutor 3 .

Três barras longitudinais tiveram deformações de pico acima da deformação de escoamento, enquanto que as demais foram solicitadas por uma tensão média de 540MPa. Para o estribo situado no lado do transdutor 2, a deformação média de pico foi de $0,92 \mathrm{~mm} / \mathrm{m}$ e, para o outro, de $0,96 \mathrm{~mm} / \mathrm{m}$.

Tabela 6.25. Deformações longitudinais médias no pilar P4-12,5-150.

\begin{tabular}{ccccccc}
\hline $\begin{array}{c}\text { \% } \mathrm{F}_{\mathrm{u}} \\
(\mathbf{k N})\end{array}$ & $\begin{array}{c}\text { Transdutores } \\
(\mathbf{T})\end{array}$ & $\begin{array}{c}\text { Armadura } \\
\text { Long. }(\mathbf{A L}) \\
(\mathbf{m m} / \mathbf{m})\end{array}$ & $\begin{array}{c}\text { Concreto } \\
(\mathbf{m m} / \mathbf{m})\end{array}$ & $\begin{array}{c}\text { Long. }(\mathbf{C L}) \\
(\mathbf{m m} / \mathbf{m})\end{array}$ & $\begin{array}{c}(\mathbf{T}) /(\mathbf{A L}) \\
(\mathbf{T}) /(\mathbf{C L})\end{array}$ & $(\mathbf{A L}) /(\mathbf{C L})$ \\
\hline $30 \%=400$ & 0,29 & 0,33 & 0,21 & 0,88 & 1,38 & 1,57 \\
$50 \%=670$ & 0,56 & 0,63 & 0,40 & 0,89 & 1,40 & 1,58 \\
$80 \%=1070$ & 1,17 & 1,44 & 0,94 & 0,81 & 1,24 & 1,53 \\
$\mathrm{Fu}=1340$ & 3,08 & 3,30 & 2,32 & 0,93 & 1,33 & 1,42 \\
\hline
\end{tabular}

Tabela 6.26. Deformações transversais médias no pilar P4-12,5-150.

\begin{tabular}{cccc}
\hline$\% \mathrm{~F}_{\mathrm{u}}$ & $\begin{array}{c}\text { Armadura } \\
\text { Transv. (AT) } \\
(\mathbf{k N})\end{array}$ & $\begin{array}{c}\text { Concreto } \\
\text { Transv. (CT) } \\
(\mathbf{m m})\end{array}$ & $\begin{array}{c}\mathbf{( m m} / \mathbf{m}) \\
\text { (AT)/(CT) }\end{array}$ \\
\hline $30 \%=400$ & 0,050 & 0,053 & 0,94 \\
$50 \%=670$ & 0,085 & 0,085 & 1,00 \\
$80 \%=1070$ & 0,250 & 0,223 & 1,12 \\
$\mathrm{Fu}=1340$ & 0,960 & 0,750 & 1,28 \\
\hline
\end{tabular}

Os comentários relativos às tabelas 6.25 e 6.26 são os mesmos feitos para os pilares analisados anteriormente. 
o) P4-12,5-100

As grandes deformações de pós-pico das barras longitudinais com os extensômetros 2, 3, 4 e 5, e a estagnação nas deformações sofridas pelos extensômetros 1 e 6 , sugerem que ocorreu flexão composta normal com a excentricidade da força atuando no sentido do transdutor 4. Para esta análise, as deformações referentes aos transdutores 2 e 3 só foram aproveitadas até as forças de $770 \mathrm{kN}$ e $1350 \mathrm{kN}$, respectivamente. Como já comentado anteriormente, isto se deu provavelmente pela formação de fissuras bem abaixo das bases destes transdutores.

O escoamento da armadura longitudinal no instante da força de ruína do modelo foi observado apenas nas barras associadas aos extensômetros 2 e 3 . No entanto, a tensão média a que foram solicitadas as demais barras (530MPa) ficou próxima da relativa ao escoamento (561MPa). Um erro cometido no manuseio do "software" de registro de dados comprometeu as leituras dos extensômetros 11 a 20. Com isso, apenas o estribo localizado no lado do transdutor 2 teve suas deformações medidas, sendo a média das deformações de pico igual a $0,88 \mathrm{~mm} / \mathrm{m}$.

Tabela 6.27. Deformações longitudinais médias no pilar P4-12,5-100.

\begin{tabular}{|c|c|c|c|c|c|c|}
\hline $\begin{array}{l}\% F_{u} \\
(k N)\end{array}$ & $\begin{array}{c}\text { Transdutores } \\
\qquad(\mathrm{T}) \\
(\mathrm{mm} / \mathrm{m})\end{array}$ & $\begin{array}{c}\text { Armadura } \\
\text { Long. (AL) } \\
(\mathrm{mm} / \mathrm{m})\end{array}$ & $\begin{array}{l}\text { Concreto } \\
\text { Long. (CL) } \\
(\mathrm{mm} / \mathrm{m})\end{array}$ & $(\mathrm{T}) /(\mathrm{AL})$ & $(\mathrm{T}) /(\mathrm{CL})$ & $(A L) /(C L)$ \\
\hline $30 \%=405$ & 0,33 & 0,34 & - & 0,97 & - & - \\
\hline $50 \%=680$ & 0,63 & 0,64 & - & 0,98 & - & - \\
\hline $80 \%=1085$ & 1,42 & 1,50 & - & 0,95 & - & - \\
\hline $\mathrm{Fu}=1355$ & 3,14 & 3,14 & - & 1,00 & - & - \\
\hline
\end{tabular}

Tabela 6.28. Deformações transversais médias no pilar P4-12,5-100.

\begin{tabular}{cccc}
\hline $\begin{array}{c}\text { \% } \mathrm{F}_{\mathbf{u}} \\
(\mathbf{k N})\end{array}$ & $\begin{array}{c}\text { Armadura } \\
\text { Transv. (AT) } \\
(\mathbf{m m} / \mathbf{m})\end{array}$ & $\begin{array}{c}\text { Concreto } \\
\text { Transv. (CT) } \\
(\mathbf{m m} / \mathbf{m})\end{array}$ & (AT)/(CT) \\
\hline $30 \%=405$ & 0,065 & - & - \\
$50 \%=680$ & 0,120 & - & - \\
$80 \%=1085$ & 0,340 & - & - \\
$\mathrm{Fu}=1355$ & 0,890 & - & - \\
\hline
\end{tabular}


Os comentários relativos às tabelas 6.27 e 6.28 são os mesmos feitos para os pilares analisados anteriormente.

p) P4-12,5-75

As maiores deformações apresentadas pelo transdutor 3 e barras longitudinais associadas aos extensômetros 4, 5 e 6, e o cessar nas deformações das demais barras, permitem concluir que houve flexão composta. Porém, em virtude das maiores deformações da armadura transversal estarem no estribo posicionado no lado do transdutor 4, observa-se que esta flexão composta ocorreu de forma oblíqua. Assim sendo, o lado mais comprimido da peça esteve no quadrante formado pelos transdutores 3 e 4, e a maior excentricidade da força atuou no sentido do transdutor 3 . Esta análise foi um pouco prejudicada por causa da queda prematura dos transdutores 1 e 2 quando atuava a força de $1300 \mathrm{kN}$ sobre o pilar.

Quanto æ̀s deformações nas armaduras, apenas duas barras longitudinais não atingiram o escoamento na força de ruína. Ainda assim, a média da tensão atuante sobre elas (520MPa) ficou próxima da de escoamento (561MPa). Para os estribos, a média das deformações de pico foi de $0,86 \mathrm{~mm} / \mathrm{m}$, para o elemento localizado ao lado do transdutor 2, e 0,93mm $/ \mathrm{m}$, para o outro. Apesar de mais uma vez os estribos terem se mostrado pouco solicitados no pré-pico, o contrário se deu no pós-pico, pois houve a formação de um patamar no diagrama força-deformação da armadura transversal.

Tabela 6.29. Deformações longitudinais médias no pilar P4-12,5-75.

\begin{tabular}{|c|c|c|c|c|c|c|}
\hline $\begin{array}{l}\% F_{u} \\
(k N)\end{array}$ & $\begin{array}{c}\text { Transdutores } \\
(\mathrm{T}) \\
(\mathrm{mm} / \mathrm{m})\end{array}$ & $\begin{array}{c}\text { Armadura } \\
\text { Long. (AL) } \\
(\mathrm{mm} / \mathrm{m})\end{array}$ & $\begin{array}{l}\text { Concreto } \\
\text { Long. (CL) } \\
(\mathrm{mm} / \mathrm{m})\end{array}$ & $(T) /(A L)$ & $(\mathrm{T}) /(\mathrm{CL})$ & $(\mathrm{AL}) /(\mathrm{CL})$ \\
\hline $30 \%=410$ & 0,31 & 0,34 & 0,29 & 0,91 & 1,07 & 1,17 \\
\hline $50 \%=680$ & 0,60 & 0,65 & 0,55 & 0,92 & 1,09 & 1,18 \\
\hline $80 \%=1090$ & 1,52 & 1,59 & 1,15 & 0,96 & 1,32 & 1,38 \\
\hline $\mathrm{Fu}=1365$ & 2,92 & 3,25 & 1,81 & 0,90 & 1,61 & 1,80 \\
\hline
\end{tabular}


Tabela 6.30. Deformações transversais médias no pilar P4-12,5-75.

\begin{tabular}{|c|c|c|c|}
\hline $\begin{array}{l}\% F_{u} \\
(k N)\end{array}$ & $\begin{array}{c}\text { Armadura } \\
\text { Transv. (AT) } \\
(\mathrm{mm} / \mathrm{m})\end{array}$ & $\begin{array}{c}\text { Concreto } \\
\text { Transv. (CT) } \\
(\mathrm{mm} / \mathrm{m})\end{array}$ & $(\mathrm{AT}) /(\mathrm{CT})$ \\
\hline $30 \%=410$ & 0,050 & 0,060 & 0,83 \\
\hline $50 \%=680$ & 0,103 & 0,093 & 1,11 \\
\hline $80 \%=1090$ & 0,343 & 0,218 & 1,57 \\
\hline $\mathrm{Fu}=1365$ & 0,895 & 1,250 & 0,72 \\
\hline
\end{tabular}

Os comentários relativos às tabelas 6.29 e 6.30 são os mesmos feitos para os pilares analisados anteriormente.

\subsubsection{Análise Geral}

Em forma de tópicos, são apresentados, a seguir, os padrões gerais de comportamento estrutural observados nos modelos de pilares ensaiados:

- conforme pode ser visto na tabela 6.31, a fissuração visível dos pilares ocorreu muito próxima da força experimental, ou seja, após $90 \%$ de $F_{u}$. Além disso, como descrito no item 5.1.2, a camada de cobrimento separou-se do núcleo de concreto apenas após ter sido alcançada a força última dos pilares;

- nos diagramas força-deformação de pilares como o P2-12,5-100 ocorreu uma pequena queda na força aplicada conforme mostrado no detalhe da figura 6.1. Este fenômeno foi decorrente da diminuição na velocidade de deslocamento dos ensaios a partir de $80 \%$ da força última estimada (ver o item 5.1.1);

- é sabido que para corpos-de-prova de concreto ensaiados à compressão simples e sob velocidade de deslocamento constante, a deformação correspondente àforça máxima deve situar-se entre $2 \mathrm{~mm} / \mathrm{m}$ e $2,5 \mathrm{~mm} / \mathrm{m}$. Como nos modelos de concreto armado desta pesquisa as deformações médias de pico dos transdutores ficaram entre $2 \mathrm{~mm} / \mathrm{m}$ e $3,5 \mathrm{~mm} / \mathrm{m}$, supõe-se que as presenças de armadura e de esforços de flexão nos ensaios causaram este aumento no limite superior; 
Tabela 6.31. Forças de primeira fissura e de ruína dos pilares.

\begin{tabular}{|c|c|c|c|}
\hline $\begin{array}{c}\text { Modelo } \\
\text { de } \\
\text { Pilar }\end{array}$ & $\begin{array}{c}F_{1 . a \text { fisssura }} \\
(\mathrm{kN})\end{array}$ & $\begin{array}{l}F_{\text {exp }} \\
(k N)\end{array}$ & $F_{1 . a}$ fissura $/ F_{\exp }$ \\
\hline $\mathrm{P} 1-10,0-120$ & 1000 & 1072 & 0,93 \\
\hline P1-12,5-200 & 1075 & 1085 & 0,99 \\
\hline P1-12,5-150 & 1100 & 1223 & 0,90 \\
\hline P1-12,5-100 & 1200 & 1292 & 0,93 \\
\hline P2-10,0-120 & 1200 & 1325 & 0,91 \\
\hline P2-12,5-150 & 1390 & 1400 & 0,99 \\
\hline P2-12,5-100 & 1090 & 1175 & 0,93 \\
\hline P2-12,5-75 & 1100 & 1215 & 0,91 \\
\hline P3-10,0-120 & 1200 & 1265 & 0,95 \\
\hline P3-12,5-150 & 1080 & 1322 & 0,82 \\
\hline P3-12,5-100 & 1330 & 1468 & 0,91 \\
\hline P3-12,5-75 & 1330 & 1485 & 0,90 \\
\hline P4-10,0-120 & 1150 & 1238 & 0,93 \\
\hline P4-12,5-150 & 1310 & 1340 & 0,98 \\
\hline P4-12,5-100 & 1340 & 1355 & 0,99 \\
\hline P4-12,5-75 & 1300 & 1365 & 0,95 \\
\hline
\end{tabular}

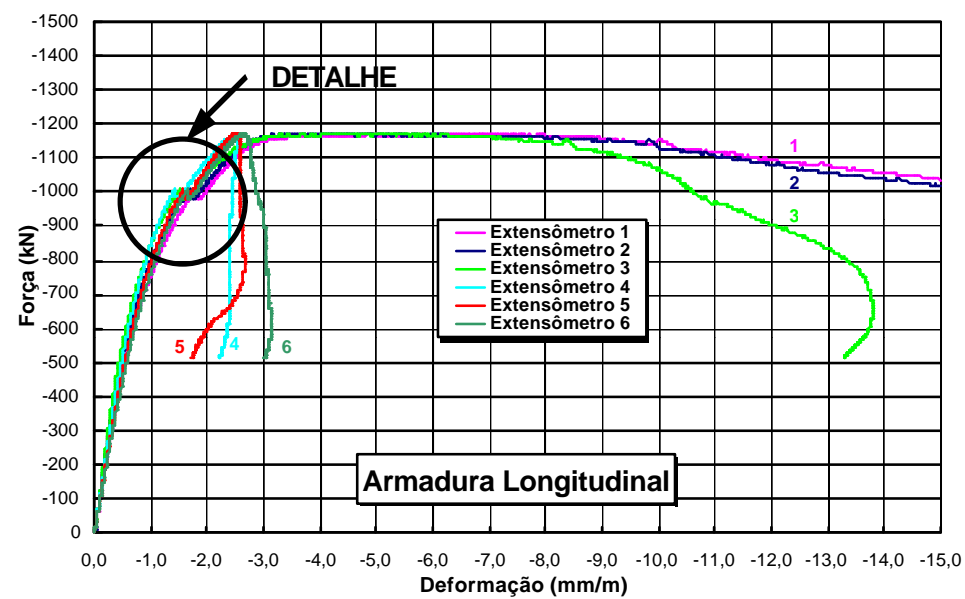

Figura 6.1. No detalhe do diagrama dos extensômetros da armadura longitudinal do pilar P2-12,5-100, observa-se a pequena queda na força aplicada decorrente da redução na velocidade de deslocamento dos ensaios. 
- como era de se esperar, os pilares com maiores taxas de armadura transversal apresentaram maior suavidade nos trechos descendentes dos diagramas força-deformação dos transdutores e armaduras. Ou seja, estes modelos mostram-se mais dúcteis na fase de pós-pico. Como exemplos, têm-se as figuras $6.2,6.3$ e 6.4 com os diagramas força-deformação dos pilares P3-12,5-150 e P3-12,5-75;
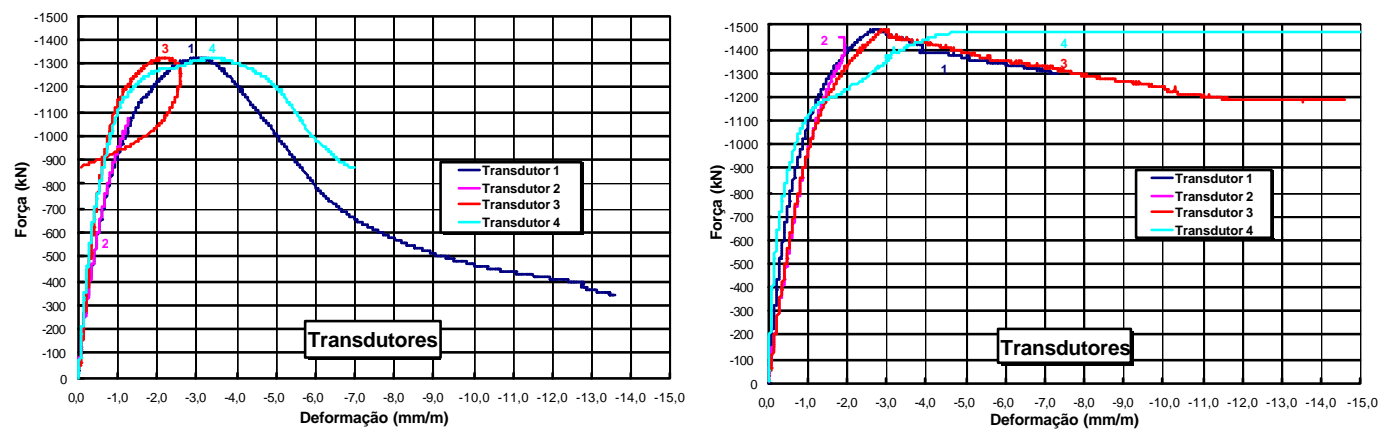

Figura 6.2. Da esquerda para a direita, diagramas dos transdutores dos pilares P3-12,5-150 e P3-12,5-75.
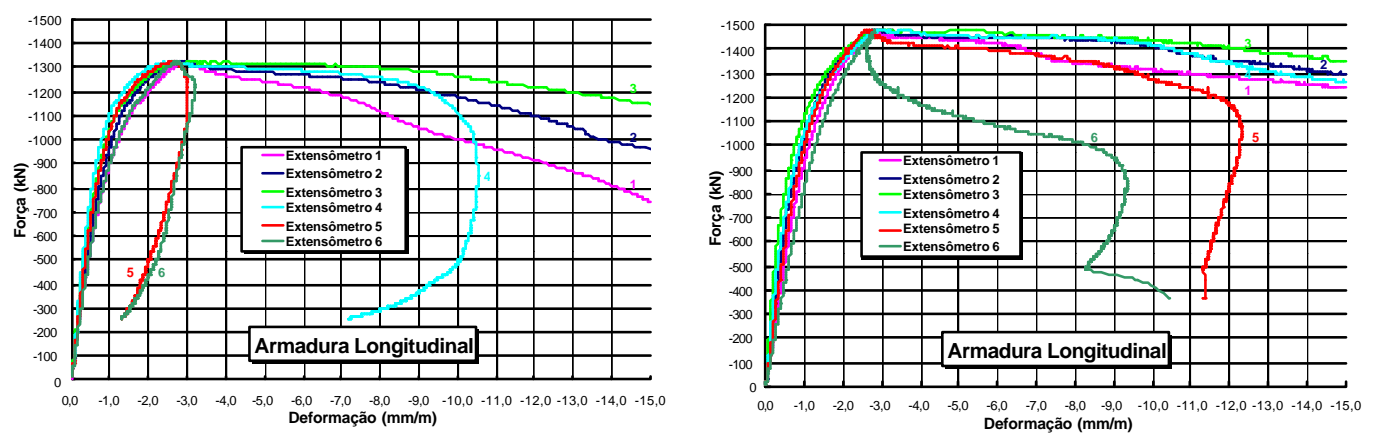

Figura 6.3. Da esquerda para a direita, diagramas da armadura longitudinal dos pilares P3-12,5-150 e P3-12,5-75.
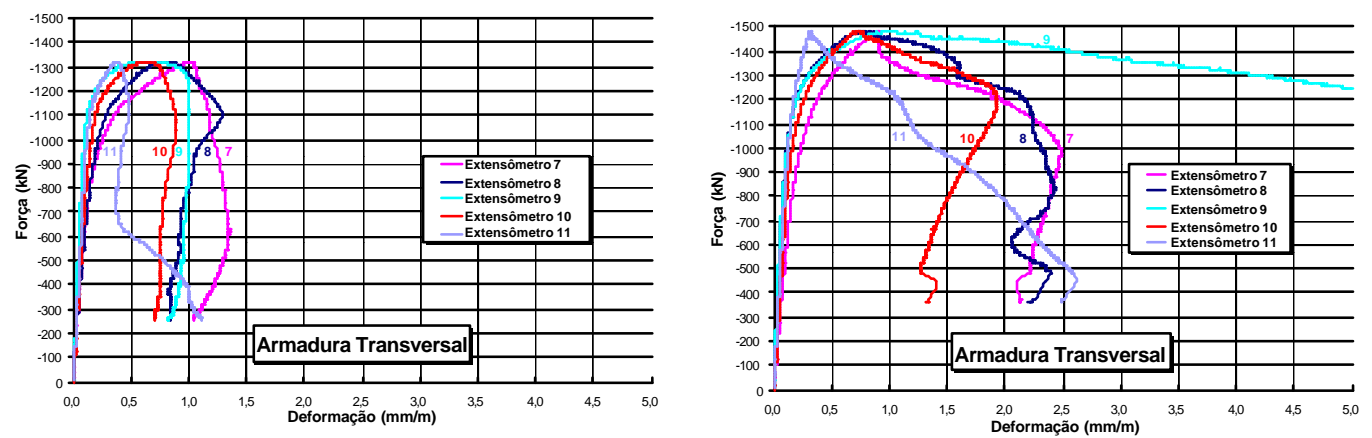

Figura 6.4. Da esquerda para a direita, diagramas da armadura transversal dos pilares P3-12,5-150 e P3-12,5-75. 
- como visto no item 6.2.1, a tentativa de se obter compressão simples levou à colocação dos pilares P3-12,5-75 e P4-10,0-120 na máquina de ensaio numa posição fora de centro. Contudo, além de prejudicar a análise dos resultados, isto poderia ter comprometido o experimento. Talvez o capeamento das extremidades ajudasse a diminuir a excentricidade inicial da força de compressão. E quanto à excentricidade decorrente da heterogeneidade do concreto? Apesar de não parecer ser o caso, maiores cuidados no amassamento e na vibração do concreto poderiam contribuir para a diminuição desta parcela;

- nos pilares com seção transversal quadrada, as excentricidades se deram na direção dos eixos principais de inércia e, portanto, ocorreu flexão composta normal em todos estes modelos; e

- nos pilares com seção transversal retangular, as maiores excentricidades ocorreram na direção do eixo de maior inércia, a menos dos ensaios em que foi forçado o contrário (P3-12,5-75 e P4-10,0-120) e no ensaio do pilar P2-12,5-150, onde ocorreu compressão simples. Desta forma, quase todos os modelos foram submetidos ao estado de solicitação de flexão composta normal ou oblíqua.

\subsection{Capacidade Resistente}

As capacidades resistentes dos modelos de pilares (ver a tabela 6.32) foram calculadas conforme descrito nos itens 3.4 e 4.4.8. Apenas vale dizer que as tensões nas armaduras foram consideradas como sendo aquelas referentes às deformações das barras longitudinais no instante da ruína dos modelos (ver as tabelas 5.1 a 5.4). Assim, para estimar as tensões nas barras conforme as deformações que lhes foram impostas na ruína, foram utilizados os resultados da caracterização das armaduras contidos no item 4.3.5.

De acordo com a tabela 6.32, o cálculo considerando-se a seção íntegra apresentou capacidades resistentes muito próximas dos valores obtidos

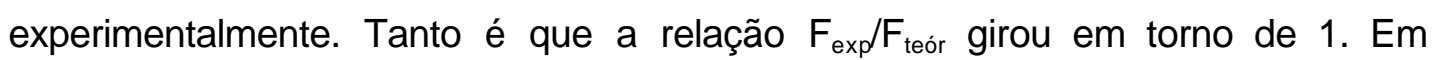
contrapartida, a consideração apenas de um núcleo delimitado pelos eixos dos estribos produziu relações bem superiores a unidade. Assim sendo, conclui-se que 
Tabela 6.32. Capacidades resistentes dos modelos de pilares ensaiados.

\begin{tabular}{|c|c|c|c|c|c|c|c|c|c|c|}
\hline $\begin{array}{c}\text { Modelo } \\
\text { de } \\
\text { Pilar }\end{array}$ & $\begin{array}{c}A_{c} \\
\left(\mathrm{~cm}^{2}\right)\end{array}$ & $\begin{array}{c}A_{c n} \\
\left(\mathrm{~cm}^{2}\right)\end{array}$ & $\begin{array}{l}f_{c, p i l a r} \\
\text { (MPa) }\end{array}$ & $\begin{array}{c}A_{s}^{\prime} \\
\left(\mathbf{c m}^{2}\right)\end{array}$ & $\begin{array}{l}\bar{\sigma}_{s, p i c o} \\
(\mathbf{M P a})\end{array}$ & $\begin{array}{l}F_{\text {teór }} \\
(k N)\end{array}$ & $\begin{array}{c}\mathbf{F}_{\text {teór,n }} \\
(\mathbf{k N})\end{array}$ & $\begin{array}{l}F_{\text {exp }} \\
(k N)\end{array}$ & $F_{\text {exp }} / F_{\text {teór }}$ & $\mathrm{F}_{\text {exp }} / \mathrm{F}_{\text {teór,n }}$ \\
\hline $\mathrm{P} 1-10,0-120$ & 400 & 272,2 & 23,65 & 3,12 & 458 & 1081 & 779 & 1072 & 0,99 & 1,38 \\
\hline$P 1-12,5-200$ & 400 & 268,0 & 23,65 & 4,78 & 382 & 1117 & 805 & 1085 & 0,97 & 1,35 \\
\hline P1-12,5-150 & 400 & 268,0 & 27,06 & 4,78 & 500 & 1308 & 951 & 1223 & 0,93 & 1,29 \\
\hline$P 1-12,5-100$ & 400 & 268,0 & 27,06 & 4,78 & 561 & 1337 & 980 & 1292 & 0,97 & 1,32 \\
\hline P2-10,0-120 & 450 & 304,7 & 22,29 & 4,69 & 600 & 1274 & 950 & 1325 & 1,04 & 1,39 \\
\hline P2-12,5-150 & 450 & 299,8 & 22,29 & 7,17 & 515 & 1356 & 1022 & 1400 & 1,03 & 1,37 \\
\hline$P 2-12,5-100$ & 450 & 299,8 & 23,26 & 7,17 & 526 & 1407 & 1058 & 1175 & 0,84 & 1,11 \\
\hline P2-12,5-75 & 450 & 299,8 & 23,26 & 7,17 & 554 & 1427 & 1077 & 1215 & 0,85 & 1,13 \\
\hline P3-10,0-120 & 450 & 304,7 & 26,08 & 4,69 & 583 & 1434 & 1055 & 1265 & 0,88 & 1,20 \\
\hline P3-12,5-150 & 450 & 299,8 & 26,08 & 7,17 & 533 & 1537 & 1145 & 1322 & 0,86 & 1,15 \\
\hline P3-12,5-100 & 450 & 299,8 & 22,84 & 7,17 & 550 & 1405 & 1062 & 1468 & 1,04 & 1,38 \\
\hline P3-12,5-75 & 450 & 299,8 & 22,84 & 7,17 & 537 & 1396 & 1053 & 1485 & 1,06 & 1,41 \\
\hline$P 4-10,0-120$ & 450 & 304,7 & 22,11 & 4,69 & 577 & 1255 & 934 & 1238 & 0,99 & 1,33 \\
\hline P4-12,5-150 & 450 & 299,8 & 22,11 & 7,17 & 550 & 1373 & 1041 & 1340 & 0,98 & 1,29 \\
\hline P4-12,5-100 & 450 & 299,8 & 22,47 & 7,17 & 540 & 1382 & 1045 & 1355 & 0,98 & 1,30 \\
\hline P4-12,5-75 & 450 & 299,8 & 22,47 & 7,17 & 547 & 1387 & 1050 & 1365 & 0,98 & 1,30 \\
\hline
\end{tabular}

nos pilares de concreto de resistência usual, considerando-se as taxas e configurações das armaduras empregadas, não há formação de núcleo resistente e, portanto, o cobrimento participa como seção resistente. Isto está de acordo com as verificações feitas por MÖRSCH (1952) e PAIVA (1994). No entanto, exceção se faz quando são analisados os resultados dos modelos P2-12,5-100, P2-12,5-75, P3-10,0-120 e P3-12,5-150. Isto pois, estes pilares tiveram suas forças máximas bem abaixo dos valores calculados teoricamente para a seção plena. A seguir, listam-se algumas das hipóteses que poderiam explicar esta incongruência entre as capacidades teórica e experimental destes pilares:

- problemas na determinação da resistência do concreto;

- flambagem prematura das barras longitudinais; e 
- ruptura prematura da cabeça do pilar por motivos de adensamento, ineficiência da armadura de fretagem, aplicação da força de compressão não centrada etc.

Para saber se a resistência do concreto foi ou não estimada da forma correta, basta analisar os resultados dos ensaios à compressão dos corpos-de-prova de controle. No caso dos modelos P2-12,5-100 e P2-12,5-75, três corpos-de-prova foram ensaiados aos 14 dias, sendo os resultados, já multiplicados pelo $k_{\text {mod }}=0,95$, iguais a $23,4 \mathrm{MPa}, 22,7 \mathrm{MPa}$ e $23,7 \mathrm{MPa}$. Visto que estes valores estiveram muito próximos uns dos outros, sendo a maior diferença de $4 \%$, seria muito difícil que a resistência do concreto do pilar pudesse ser menor do que a média destes valores. Fazendo a conta inversa para P2-12,5-100, ou seja, supondo-se que a capacidade teórica e a experimental deste modelo fossem iguais, a resistência do seu concreto deveria ser de $18 \mathrm{MPa}$. Isto significa assumir um erro de $23 \%$ na determinação da resistência e, pior, no sentido da sua redução. sto pois, sabe-se que a determinação da resistência do corpo-de-prova num ensaio está sujeita a problemas como imperfeições em suas extremidades, os quais poderiam diminuir sua resistência potencial, e não contrário. Ou seja, se a média dos ensaios foi de 23,26MPa, já inserido o coeficiente de modificação, então, seria mais provável que a resistência potencial média fosse maior do que este valor, e não menor. Como estas verificações também foram observadas nos demais pilares, ficou claro que não foram problemas na determinação da resistência do concreto os responsáveis pelas diferenças entre as capacidades teóricas e experimentais destes modelos.

Quanto à possibilidade de ter ocorrido a flambagem prematura das barras longitudinais, tanto nos itens de descrição dos ensaios (5.1) como no de análise dos diagramas (6.2) foi constatado não ter ocorrido este fenômeno em nenhum dos pilares.

Deste modo, acredita-se que a última hipótese possa explicar a ruína prematura dos modelos P2-12,5-100, P2-12,5-75, P3-10,0-120 e P3-12,5-150. Acontece que além do estado de flexão composta oblíqua, foi verificada, nestes modelos, a ruptura prematura das quinas de suas cabeças. Assim, supõe-se que a flexo-compressão aliada à falta de capeamento das extremidades dos modelos provocaram as rupturas prematuras das cabeças dos pilares. Por conseqüência, 
houve uma diminuição da seção resistente que resultou em capacidades experimentais menores que as teóricas.

Vale comentar que não foram feitos os capeamentos dos pilares com enxofre, pois a dificuldade de manuseio dos modelos, decorrente de seus tamanhos e massas, tornaria esta operação muito complicada. Além disso, a utilização de massa plástica automotiva, feita por outros pesquisadores, parece não ter sido bem sucedida pela dificuldade em se obter o ângulo de $90^{\circ}$ entre as faces transversais capeadas e as faces longitudinais dos pilares. Contudo, mediante o ocorrido com os modelos P2-12,5-100, P2-12,5-75, P3-10,0-120 e P3-12,5-150, talvez seja o caso de em futuras pesquisas estudar-se outras técnicas ou materiais que possibilitem um eficiente capeamento dos pilares.

\subsection{Confinamento}

Apesar dos resultados presentes na tabela 6.32 parecerem demonstrar que não houve cintamento do concreto, ainda assim, aplicou-se o modelo teórico de confinamento de SAATCIOGLU \& RAZVI (1992) (ver as tabelas 6.33 e 6.34) com o objetivo de observar se o mesmo seria capaz de confirmar esta constatação.O motivo da escolha deste modelo em detrimento dos demais levantados no capítulo 3 deve-se ao fato do mesmo ser o mais recente entre eles.

Da análise da tabela 6.34, observou-se que o cálculo considerando-se 0 confinamento distanciou ainda mais da unidade a relação $F_{\text {exp }} / F_{\text {teór,nc+cobr. Além }}$ disso, a verificação dos valores de $F_{\text {exp }} / F_{\text {teór,nc }}$ permitiu concluir que $F_{\text {teór,nc não }}$ representa a capacidade resistente dos modelos. Deste modo, reafirma-se que para pilares de concreto de resistência usual e taxas e configurações das armaduras semelhantes æ̀̀ adotadas nesta pesquisa, não ocorre formação de núcleo resistente na fase de pré-pico. Isto não quer necessariamente dizer que não ocorreu confinamento do concreto, mas apenas que este confinamento não excluiu o cobrimento da seção resistente dos pilares.

Apesar do modelo de confinamento empregado não ter sido capaz de aproximar as capacidades resistentes teóricas das experimentais, a comparação das forças de ruína dos pilares com mesma configuração e diâmetro de estribos e mesma resistência do concreto, revelou que os modelos com maiores 
Tabela 6.33. Resistências dos concretos dos pilares de acordo com o modelo teórico de confinamento de SAATCIOGLU \& RAZVI (1992).

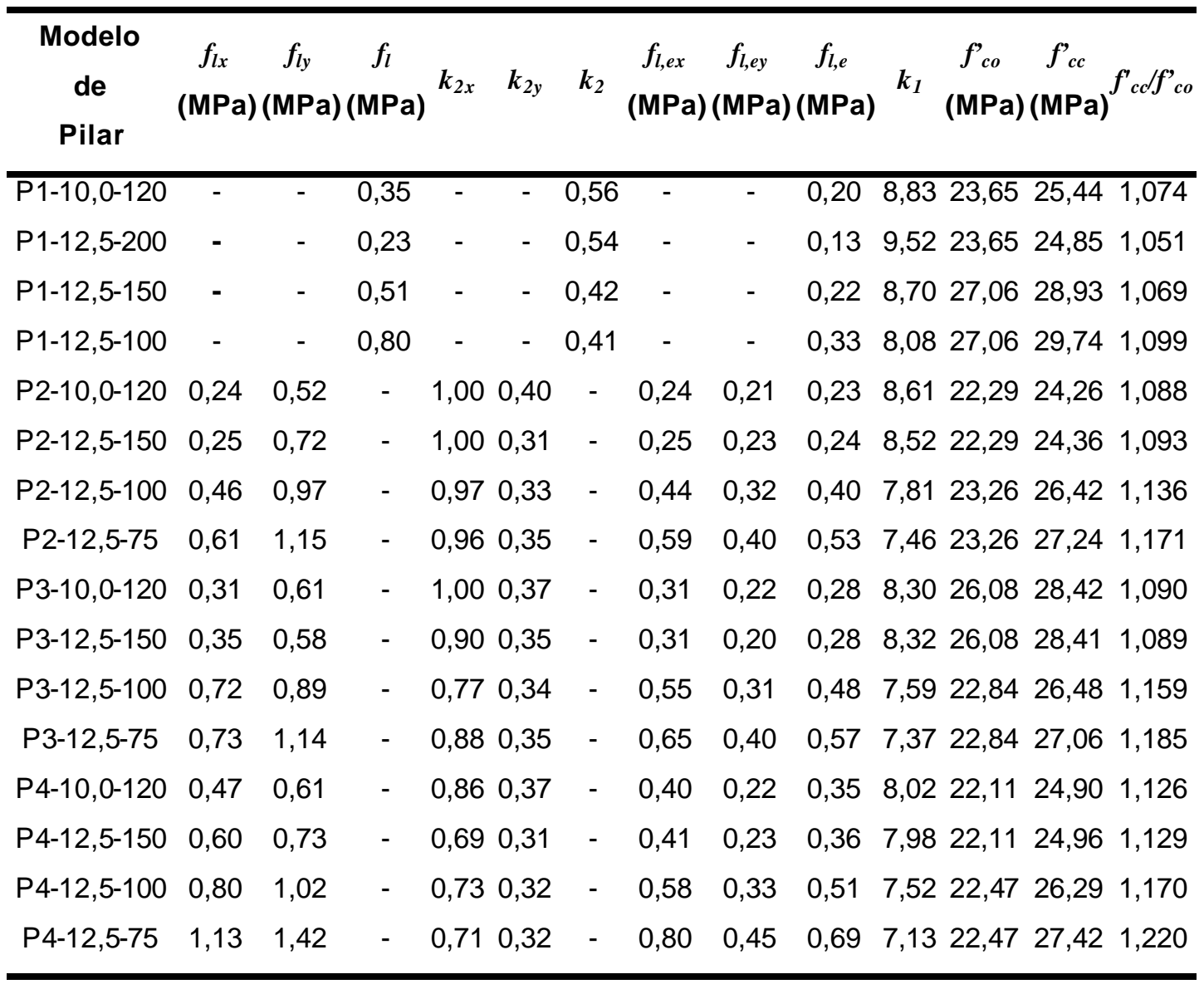

taxas de armadura transversal e, portanto, teoricamente mais confinados, tiveram um ligeiro aumento em suas resistências (ver a tabela 6.35). Assim, o ganho de resistência no concreto por conta do emprego de maiores taxas de armadura transversal aconteceu, porém, não conforme estimado na tabela 6.33. Vale ainda dizer que este efeito de cintamento foi mais pronunciado na série de seção transversal quadrada (série P1).

Por fim, da análise dos I.E.C., há uma concordância com o que foi dito até agora, pois a faixa dos valores obtidos, sendo o maior de 3,09\%, enquadra a eficiência do confinamento na Classe 1 , ou seja, baixa eficiência do confinamento em virtude de não ter ocorrido ganhos significativos de resistência. No entanto, esta mesma classe sugere que os pilares seriam pouco dúcteis. Porém, foi verificado no item 6.2.2 que os modelos com maiores taxas de armadura transversal apresentaram-se bastante dúcteis, visto que a fase descendente de seus diagramas força-deformação teve uma queda suave na força aplicada. A verdade é 
Tabela 6.34. I.E.C. e capacidades resistentes dos pilares considerando-se o confinamento dado pela armadura transversal de acordo com SAATCIOGLU \& RAZVI (1992).

\begin{tabular}{|c|c|c|c|c|c|c|c|}
\hline $\begin{array}{c}\text { Modelo } \\
\text { de } \\
\text { Pilar }\end{array}$ & $\begin{array}{c}\text { r wv } \\
(\%)\end{array}$ & $\begin{array}{c}\text { I.E.C. } \\
\text { (\%) }\end{array}$ & $\begin{array}{c}\mathrm{F}_{\text {teór,nc+cobr }}{ }^{*} \\
(\mathrm{kN})\end{array}$ & $\begin{array}{c}\mathrm{F}_{\text {teór,nc }}{ }^{* *} \\
(\mathrm{kN})\end{array}$ & $\begin{array}{l}F_{\text {exp }} \\
(k N)\end{array}$ & $F_{\text {exp }} / F_{\text {teór,nc+cobr }}$ & $F_{\text {exp }} / F_{\text {teór,nc }}$ \\
\hline $\mathrm{P} 1-10,0-120$ & 0,27 & 0,83 & 1128 & 826 & 1072 & 0,95 & 1,30 \\
\hline P1-12,5-200 & 0,26 & 0,53 & 1149 & 836 & 1085 & 0,94 & 1,30 \\
\hline P1-12,5-150 & 0,34 & 0,80 & 1358 & 1000 & 1223 & 0,90 & 1,22 \\
\hline P1-12,5-100 & 0,51 & 1,23 & 1408 & 1051 & 1292 & 0,92 & 1,23 \\
\hline P2-10,0-120 & 0,28 & 1,03 & 1333 & 1009 & 1325 & 0,99 & 1,31 \\
\hline P2-12,5-150 & 0,35 & 1,09 & 1417 & 1082 & 1400 & 0,99 & 1,29 \\
\hline P2-12,5-100 & 0,52 & 1,74 & 1500 & 1150 & 1175 & 0,78 & 1,02 \\
\hline$P 2-12,5-75$ & 0,70 & 2,29 & 1543 & 1194 & 1215 & 0,79 & 1,02 \\
\hline P3-10,0-120 & 0,32 & 1,09 & 1504 & 1126 & 1265 & 0,84 & 1,12 \\
\hline P3-12,5-150 & 0,40 & 1,08 & 1605 & 1213 & 1322 & 0,82 & 1,09 \\
\hline P3-12,5-100 & 0,60 & 2,10 & 1512 & 1169 & 1468 & 0,97 & 1,26 \\
\hline P3-12,5-75 & 0,80 & 2,51 & 1520 & 1177 & 1485 & 0,98 & 1,26 \\
\hline P4-10,0-120 & 0,36 & 1,58 & 1338 & 1017 & 1238 & 0,92 & 1,22 \\
\hline P4-12,5-150 & 0,45 & 1,62 & 1456 & 1124 & 1340 & 0,92 & 1,19 \\
\hline P4-12,5-100 & 0,68 & 2,26 & 1494 & 1156 & 1355 & 0,91 & 1,17 \\
\hline P4-12,5-75 & 0,91 & 3,09 & 1532 & 1194 & 1365 & 0,89 & 1,14 \\
\hline
\end{tabular}

* $F_{\text {teór,nc+cobr }}=$ capacidade do núcleo confinado + capacidade do cobrimento não confinado.

${ }^{* *} F_{\text {teór,nc }}=$ capacidade resistente apenas do núcleo confinado.

que as três classes sugeridas por CUSSON \& PAULTRE (1993) foram calibradas considerando-se o emprego de concreto de alta resistência, ou seja, de um material menos suscetível aos efeitos oriundos do confinamento dado pela armadura transversal, conforme predito por MÖRSCH (1952) e outros pesquisadores. Assim, para o caso dos concretos de resistência usual, o conceito que envolve o I.E.C. pode ser usado, todavia, uma nova divisão das classes de eficiência deve ser estudada com base em mais resultados experimentais. 
Tabela 6.35. Efeito de cintamento causado pelo confinamento dado pelas armaduras.

\begin{tabular}{|c|c|c|c|}
\hline $\begin{array}{l}\text { Modelo } \\
\text { de } \\
\text { Pilar }\end{array}$ & $\begin{array}{c}\text { r w v } \\
\text { (\%) }\end{array}$ & $\begin{array}{l}F_{\text {exp }} \\
(k N)\end{array}$ & $\begin{array}{c}\frac{F_{\text {exp }, i+1}-F_{\text {exp }, i}}{F_{\text {exp }, i}} \\
(\%)\end{array}$ \\
\hline $\mathrm{P} 1-12,5-150$ & 0,34 & 1223 & \multirow{2}{*}{5,64} \\
\hline P1-12,5-100 & 0,51 & 1292 & \\
\hline P2-12,5-100 & 0,52 & 1175 & \multirow{2}{*}{3,40} \\
\hline$P 2-12,5-75$ & 0,70 & 1215 & \\
\hline P3-12,5-100 & 0,60 & 1468 & \multirow{2}{*}{1,16} \\
\hline P3-12,5-75 & 0,80 & 1485 & \\
\hline P4-12,5-100 & 0,68 & 1355 & \multirow{2}{*}{0,74} \\
\hline$P 4-12,5-75$ & 0,91 & 1365 & \\
\hline
\end{tabular}

\subsection{Ductilidade}

Tendo em vista o comportamento pós-pico dos diagramas força-deformação dos transdutores e extensômetros, foi demonstrado no item 6.2.2 que os pilares com maiores taxas de armadura transversal apresentaram-se mais dúcteis que os demais. Entretanto, em virtude desta constatação ser apenas visual, é apresentada, na tabela 6.36, uma avaliação numérica da ductilidade dos pilares ensaiados com o emprego de um critério desenvolvido por LIMA JUNIOR \& GIONGO (2001). Para a aplicação deste critério, foram adaptados e utilizados os diagramas forçadeformação dos transdutores. Assim, ao invés do eixo y referir-se àforça aplicada, este foi tomado como sendo a relação entre a força aplicada e a experimental. Além disso, foram feitas regressões polinomiais com o objetivo de se obterem curvas únicas e que fossem representativas das deformações sofridas por cada pilar. $\mathrm{Na}$ figura 6.5, tem-se um exemplo desta adaptação para o modelo P4-12,5-100. Apenas para os pilares P1-12,5-150, P1-12,5-100 e P2-10,0-120 esta análise não pôde ser realizada, pois os resultados dos ensaios não foram suficientes para que 0 critério proposto pudesse ser aplicado. 


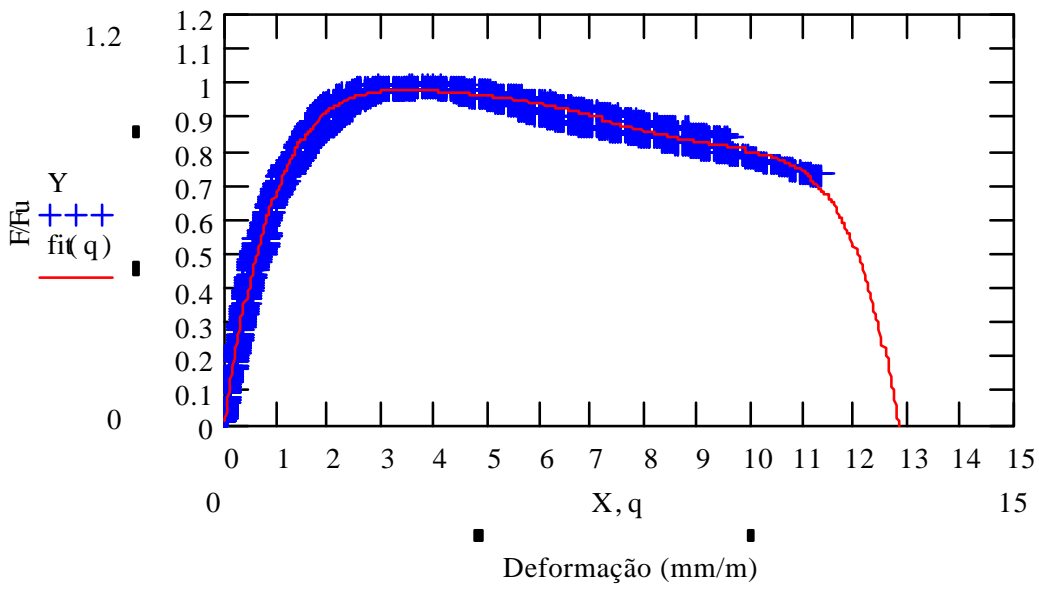

Figura 6.5. Diagrama F/F $\mathrm{u}$ x Deformação dos transdutores do pilar P4-12,5-100 e a curva resultante da regressão polinomial feita com o auxílio do programa de cálculos matemáticos MATHCAD 7.0.

Tabela 6.36. Avaliação numérica da ductilidade com o emprego do critério desenvolvido por LIMA JUNIOR \& GIONGO (2001).

\begin{tabular}{|c|c|c|c|c|c|c|c|c|c|}
\hline $\begin{array}{c}\text { Modelo } \\
\text { de } \\
\text { Pilar }\end{array}$ & $\begin{array}{l}\mathbf{r}_{\mathrm{wv}} \\
(\%)\end{array}$ & $\begin{array}{c}\mathbf{e}_{\mathrm{co}} \\
(\mathrm{mm} / \mathrm{m})\end{array}$ & $\begin{array}{c}\mathbf{e}_{\mathrm{cu}} \\
(\mathrm{mm} / \mathrm{m})\end{array}$ & $\begin{array}{c}\mathbf{e}_{\text {ela }} \\
(\mathrm{mm} / \mathrm{m})\end{array}$ & $\begin{array}{l}e_{p-p r e ́} \\
(m m / m)\end{array}$ & $\begin{array}{l}e_{p-p o ́ s} \\
(\mathrm{~mm} / \mathrm{m})\end{array}$ & $I_{\text {ela }}$ & $I D_{\text {p-pré }}$ & $I D_{\text {p-pós }}$ \\
\hline $\mathrm{P} 1-10,0-120$ & $\overline{0,270}$ & $\overline{1,814}$ & 5,442 & 0,708 & 1808 & 2,739 & 0,390 & 1,046 & 1,510 \\
\hline P1-12,5-200 & 0,255 & 1,576 & 4,728 & 0,605 & 1,608 & 2,277 & 0,384 & 1,020 & 1,445 \\
\hline P1-12,5-150 & 0,340 & - & - & - & - & - & - & - & - \\
\hline$P 1-12,5-100$ & 0,510 & - & - & - & - & - & - & - & - \\
\hline P2-10,0-120 & 0,277 & - & - & - & - & - & - & - & - \\
\hline P2-12,5-150 & 0,349 & 2,090 & 6,270 & 0,842 & 2,106 & 2,836 & 0,403 & 1,008 & 1,357 \\
\hline P2-12,5-100 & 0,523 & 2,892 & 8,676 & & & & 0,441 & 1,003 & 1,493 \\
\hline P2-12,5-75 & 0,697 & 2,970 & 8,910 & 1,114 & 3,228 & 5,028 & 0,375 & 1,087 & 1,693 \\
\hline P3-10,0-120 & 0,319 & 3,193 & 9,579 & 0,716 & 4,308 & 4,027 & 0,224 & 1,349 & 1,261 \\
\hline P3-12,5-150 & 0,401 & 2,457 & 7,371 & 0,919 & 2,696 & 3,879 & 0,374 & 1,097 & 1,579 \\
\hline P3-12,5-100 & 0,602 & 2,296 & 6,888 & 0,979 & 2,310 & 3,959 & 0,426 & 1,006 & 1,724 \\
\hline P3-12,5-75 & 0,802 & 2,982 & 8,946 & 1,035 & 3,447 & 5,596 & 0,347 & 1,156 & 1,877 \\
\hline P4-10,0-120 & 0,361 & 2,240 & 6,720 & 0,956 & 2,228 & 3,359 & 0,427 & 0,995 & 1,500 \\
\hline P4-12,5-150 & 0,454 & 3,025 & 9,075 & 1,410 & 3,094 & 4,659 & 0,466 & 1,023 & 1,540 \\
\hline P4-12,5-100 & 0,681 & 3,477 & 10,431 & 0,949 & 4,440 & 6,348 & 0,273 & 1,277 & 1,826 \\
\hline P4-12,5-75 & 0,907 & 4,006 & 12,018 & 0,831 & 5,454 & 7,404 & 0,207 & 1,361 & 1,848 \\
\hline
\end{tabular}




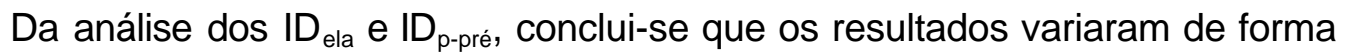
aleatória, sem uma ligação com a taxa de armadura tansversal utilizada. No entanto, se for lembrado como foram determinados estes índices (ver o item 3.6), percebe-se que a influência sobre eles poderia ser maior caso fosse variada a resistência do concreto. Ou seja, quando esta aumentasse, maior e mais inclinado seria o trecho linear do diagrama força-deformação do pilar e, portanto, mais próximo da unidade estaria $0 I D_{\text {ela }}$ e mais próximo de zero estaria $0 \quad I_{p \text {-pré, }}$ resultando em um comportamento de pré-pico tendendo ao modelo elástico-linear. Deste modo, o contrário aconteceria no sentido de se diminuir a resistência do concreto, pois, neste caso, o comportamento de pré-pico tenderia ao modelo plástico-perfeito, com $I D_{\text {ela }}$ e $I D_{\text {p-pré }}$ mais próximos de 0 e 2 , respectivamente. $\mathrm{Na}$ concretagem dos modelos da presente pesquisa, foram utilizados concretos de baixa resistência e com pequena variabilidade desta propriedade entre eles. Assim sendo, o cálculo destes índices de ductilidade revelaram um comportamento de pré-pico mais próximo do plástico-perfeito, pois $\mathrm{ID}_{\text {ela }}$ esteve sempre menor que 0,5 e $\mathrm{ID}_{\text {p-pré }}$ acima de 1.

Como era de se esperar, o cálculo do Índice de Deformação Plástica de PósPico ( $\left(\mathrm{I}_{\mathrm{p} \text {-pós }}\right)$ demonstrou a relação direta desta grandeza com a taxa de armadura transversal, ou seja, conforme se aumentou a taxa, maior foi o índice registrado. Além disso, sabendo-se que a faixa de valores deste índice está situada entre 0 (frágil-perfeito) e 2 (plástico-perfeito), pode-se afirmar que todos os pilares apresentaram comportamento de pós-pico tendendo ao modelo plástico-perfeito, pois $I_{\text {p-pós }}$ variou de 1,261 a 1,877. Nota-se também o fato dos pilares com seção transversal quadrada (série $\mathrm{P} 1$ ) terem obtido índices mais altos do que os verificados nos pilares de seção transversal retangular com taxas transversais semelhantes.

A figura 6.6 ilustra a relação $I D_{\text {p-pós }} \times r_{w}$ para os modelos de seção retangular e diâmetros das armaduras transversais e longitudinais de $6,3 \mathrm{~mm}$ e $12,5 \mathrm{~mm}$, respectivamente. A curva mostrada nesta figura foi obtida mediante a regressão polinomial dos dados experimentais, sendo que a maior diferença entre os valores experimentais e aqueles calculados pela equação da curva não foram maiores do que $8 \%$. 


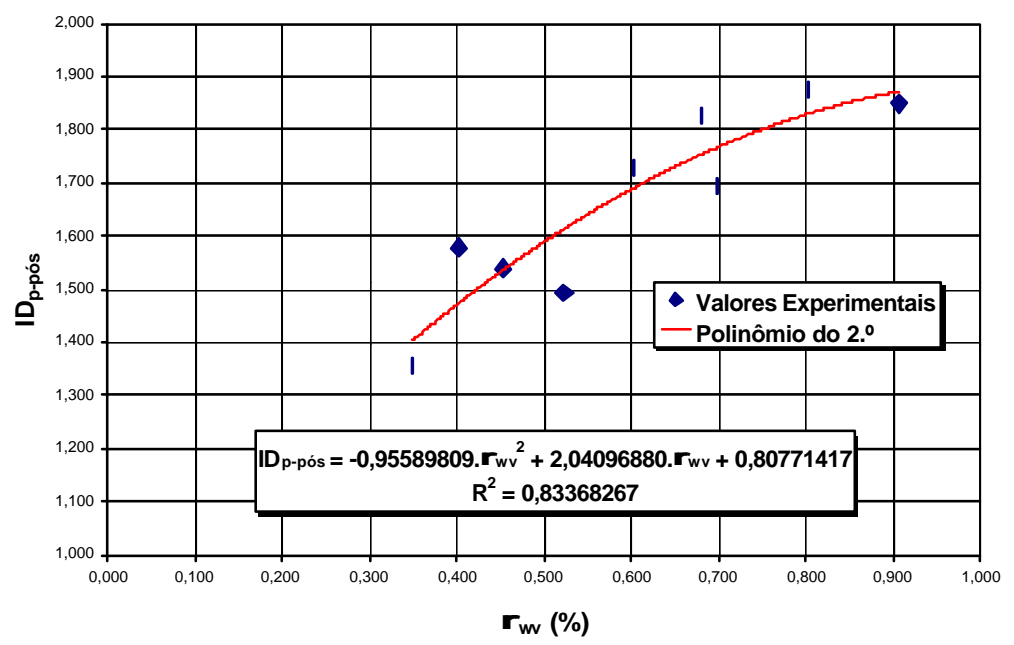

Figura 6.6. Relação $I D_{\text {p-pós }} x \mathbf{r}$ wv para os modelos de seção retangular.

O critério de avaliação da ductilidade de LIMA JUNIOR \& GIONGO (2001) não prediz se um pilar é frágil, medianamente dúctil ou dúctil. Porém, ele dá uma idéia da ductilidade apresentada por este elemento estrutural. Além do mais, serve como parâmetro para a determinação das taxas mínimas de armadura a serem empregadas em pilares de concreto de alta resistência (CAR). Por exemplo, em uma região sem abalos sísmicos, um pilar de CAR deve ter um comportamento referente àductilidade pelo menos igual ao apresentado por pilares de concreto de baixa resistência (CBR) projetados de acordo com a NBR 6118 (1978). Assim, um pilar de alta resistência, com características geométricas semelhantes ao P2-12,5-150, deveria ter sua armadura, no que diz respeito a ductilidade, calculada com o objetivo de que o $I D_{\text {p-pós }}$ fosse maior ou igual ao do modelo de referência, isto é, $I D_{\text {p-pós }} \geq 1,357$. 


\section{CONCLUSÃO}

\subsection{Considerações Iniciais}

Por meio deste capítulo final, são apresentadas as principais conclusões obtidas neste trabalho, bem como algumas sugestões para a continuidade e complementação da linha de pesquisa abordada.

\subsection{Conclusões}

O capítulo 6 foi dedicado à análise do comportamento estrutural apresentado pelos modelos de pilares ensaiados. Deste modo, as conclusões aqui levantadas abordam um resumo deste estudo em forma de tópicos, com o cuidado para que fossem comentados apenas os aspectos mais significativos. Assim, têm-se:

- a obtenção de um estado de solicitação de compressão simples é muito difícil. Isto pois, mesmo que sejam reduzidas as excentricidades na aplicação da força com o capeamento das extremidades, a heterogeneidade do concreto irá desviar a solicitação dentro da peça e, por conseqüência, criar esforços de flexão no pilar. No entanto, presume-se que esta parcela de excentricidade pode ser reduzida com maiores cuidados no amassamento e vibração do concreto;

- a utilização de armadura de fretagem como forma de se evitar a ruptura prematura das cabeças dos pilares mostrou-se eficiente. Contudo, a falta de capeamento nas extremidades permitiu o surgimento de excentricidades na aplicação da força que, por sua vez, provocaram a ruptura das quinas das cabeças, resultando em capacidades experimentais menores que as teóricas, conforme foi observado nos modelos P2-12,5-100, P2-12,5-75, P3-10,0-120 e P3-12,5-150. Vale 
lembrar que por conta das dificuldades de manuseio dos modelos e de emprego de materiais que pudessem garantir um capeamento eficiente dos pilares, esta medida não foi tomada;

- as maiores excentricidades da força aplicada ocorreram na direção do eixo de maior inércia, exceto nos modelos em que foi forçado o contrário;

- a fissuração visível dos pilares ocorreu a partir de $90 \%$ de $F_{u}$;

- o cobrimento separou-se do núcleo de concreto apenas no pós-pico;

- as capacidades resistentes teóricas considerando-se a seção íntegra forneceram valores muito próximos dos obtidos experimentalmente. Isto só não ocorreu nos modelos P2-12,5-100, P2-12,5-75, P3-10,0-120 e P3-12,5-150, visto que a presença de flexão composta oblíqua junto da falta de capeamento das cabeças provocaram suas rupturas prematuras. Assim, pode-se afirmar que para pilares de concreto de resistência usual e taxas e configurações das armaduras semelhantes æ̀̀ empregadas nesta pesquisa, não ocorre formação de núcleo resistente na fase pré-pico;

- a microfissuração do concreto aliada à presença de bolhas de ar junt o das armaduras diminuiu a aderência concreto-armadura fazendo com que as deformações das barras longitudinais fossem, mesmo em baixos níveis de força e de modo discreto, maiores que as registradas pelos transdutores;

- houve semelhança entre as deformações médias registradas pelos transdutores e as da armadura longitudinal durante a fase elástica. Mais uma vez, isto permitiu concluir que não ocorre formação de núcleo resistente na fase de prépico e, portanto, a seção resistente é a seção transversal total, inclusive com o cobrimento;

- como efeitos do confinamento dado pela armadura transversal, no intervalo das taxas utilizadas, foi observado um pequeno cintamento do concreto e um expressivo aumento na ductilidade dos pilares; 
- o modelo teórico de confinamento do concreto, proposto por SAATCIOGLU \& RAZVI (1992), não foi eficiente ao estimar o ganho de resistência no concreto por conta da armadura transversal empregada nos modelos;

- o I.E.C., de CUSSON \& PAULTRE (1993), previu o pequeno cintamento do concreto, porém, não acertou ao sugerir que os pilares ensaiados apresentariam comportamento pouco dúctil;

- o critério de avaliação da ductilidade, proposto por LIMA JUNIOR \& GIONGO (2001), deu uma idéia razoável sobre a ductilidade apresentada pelos pilares. Assim, demonstrou que tanto no pré-pico como no pós-pico, o comportamento dos elementos estruturais tendeu para o modelo plástico-perfeito, inclusive naqueles em que a armadura transversal era a de norma;

- o ganho de ductilidade no pré-pico rão depende da taxa de armadura transversal, mas sim da redução da resistência do concreto. Isto foi demonstrado a partir dos valores obtidos para os Índices de Deformação Elástica (ID ela) e Plástica de Pré-Pico ( $\left(\mathrm{D}_{\mathrm{p} \text {-pré}}\right)$ dos pilares desta pesquisa (ver a tabela 6.36) e para os corposde-prova cilíndricos de concreto ensaiados por LIMA JUNIOR \& GIONGO (2001) (ver a tabela 7.1);

- o ganho de ductilidade no pós-pico depende do aumento da taxa de armadura transversal e da redução da resistência do concreto. Isto foi demonstrado a partir dos valores obtidos para o Índice de Deformação Plástica Pós-Pico (ID p-pós) dos pilares desta pesquisa (ver a tabela 6.36) e para os corpos-de-prova cilíndricos de concreto ensaiados por LIMA JUNIOR \& GIONGO (2001) (ver a tabela 7.1);

Tabela 7.1. Índices de ductilidade obtidos a partir dos ensaios de corpos-deprova cilíndricos de dimensões de $15 \mathrm{~cm}$ x $30 \mathrm{~cm}$, adaptado de LIMA JUNIOR \& GIONGO (2001).

\begin{tabular}{ccccccccc}
\hline $\begin{array}{c}\text { Resistência } \\
(\mathbf{M P a})\end{array}$ & $\begin{array}{c}\mathbf{e}_{\mathrm{co}} \\
(\mathbf{m m} / \mathbf{m})\end{array}$ & $\begin{array}{c}\mathbf{e}_{\mathrm{cu}} \\
(\mathbf{m m} / \mathbf{m})\end{array}$ & $\begin{array}{c}\mathbf{e}_{\text {ela }} \\
(\mathbf{m m} / \mathbf{m})\end{array}$ & $\begin{array}{c}\mathbf{e}_{\mathrm{p} \text {-pré }} \\
(\mathbf{m m} / \mathbf{m})\end{array}$ & $\begin{array}{c}\mathbf{e}_{\mathbf{p} \text {-pós }} \\
(\mathbf{m m} / \mathbf{m})\end{array}$ & $\mathbf{I D}_{\text {ela }}$ & ID $_{\text {p-pré }}$ & I $_{\text {p-pós }}$ \\
\hline 30 & 2,419 & 7,257 & 1,160 & 2,140 & 3,131 & 0,479 & 0,884 & 1,294 \\
60 & 2,623 & 7,869 & 2,000 & 0,970 & 0,954 & 0,764 & 0,369 & 0,363 \\
\hline
\end{tabular}


- como era de se esperar, os pilares com seção transversal quadrada (série P1) foram mais sensíveis aos efeitos do confinamento dado pela armadura transversal que os pilares de seção transversal retangular com taxas transversais semelhantes. Ou seja, apresentaram maior cintamento do concreto e maior índice de ductilidade plástica no pós-pico;

- o espaçamento máximo entre duas barras longitudinais sem que haja contenção lateral de uma delas, definido pela NBR 6118 (1978), foi suficiente para evitar a flambagem prematura das barras situadas fora das quinas nos modelos da série $\mathrm{P} 2$;

- apesar do formato dos diagramas força-deformação dos estribos suplementares indicarem o contrário, os valores semelhantes para os $I D_{\text {p-pós }}$ dos modelos das séries 3 e 4 sugerem que estes elementos contribuíram tanto quanto os estribos duplos para acentuar os efeitos oriundos do confinamento, ou sejam, o cintamento e a ductilidade dos pilares;

- como os ensaios realizados podem ser considerados rápidos, não foram contemplados os efeitos de maturação, retração e fluência do concreto observados nas estruturas sob cargas de longa duração. Assim, no cálculo da capacidade resistente dos pilares, a consideração destes efeitos deve ser feita com a introdução dos coeficientes de modificação da resistência do concreto relacionados no item 2.9.1. Além disso, a tensão na armadura longitudinal deve ser aquela relativa ao escoamento do aço. Quanto æ̀s análises de cintamento e ductilidade, somente ensaios levando em conta estes fenômenos poderão dar maiores informações sobre a aplicabilidade dos modelos teóricos descritos no capítulo 3 e empregados no capítulo 6. Contudo, de acordo com o gráfico da figura 2.4, parece claro que maiores deformações plásticas serão observadas tanto no pré-pico como no pós-pico e, portanto, mais dúcteis serão os pilares. Acrescenta-se também o fato de que as maiores deformações registradas na dreção transversal provocarão maiores solicitações nas barras transversais que, por sua vez, acabarão confinando melhor o núcleo de concreto dos pilares; e 
- por fim, a coerência observada nos resultados dos ensaios permitiu concluir que é possível não se utilizarem modelos gêmeos de pilares em estudos experimentais desta natureza.

\subsection{Sugestões para Continuidade da Pesquisa}

A seguir, apresentam-se algumas sugestões para novas pesquisas nesta área de estudo:

- refazer a análise teórica e experimental dos modelos de pilares considerando-se a atuação de cargas de longa duração;

- confrontar os resultados experimentais da pesquisa com valores obtidos a partir de programas numéricos que levem em consideração a não linearidade física do material; e

- fazer um apanhado das informações contidas nesta pesquisa e nas de LIMA (1997) e QUEIROGA (1999) objetivando-se elucidar o comportamento de pilares de concreto armado na faixa de resistência que vai de $20 \mathrm{MPa}$ a $80 \mathrm{MPa}$. Ainda neste sentido, podem ser sugeridos critérios e modelos teóricos destinados æ̀s análises de pilares de concreto armado. 


\section{REFERÊNCIAS BIBLIOGRÁFICAS}

AGOSTINI, L. R. S. (1992). Pilares de concreto de alta resistência. São Paulo. Tese (doutorado) - Escola Politécnica, Universidade de São Paulo.

AMARAL FILHO, E. M. (1997). Concreto de alto desempenho. In: NÚCLEO DE PESQUISA EM TECNOLOGIA DA ARQUITETURA E URBANISMO, org. Concreto de alto desempenho - Versão 1.0 [CD-ROM]. São Paulo, NUTAU/USP.

AMERICAN CONCRETE INSTITUTE (1995). ACI 318 - Building code requeriments structural concrete. Detroit, $\mathrm{ACI}$.

AMERICAN CONCRETE INSTITUTE (1989). ACI 318 - Building code requeriments for reinforced concrete and commentary. Detroit, $\mathrm{ACl}$.

ASSOCIAÇÃO BRASILEIRA DE NORMAS TÉCNICAS (2000). Projeto de Revisão da NBR 6118 - Projeto de estruturas de concreto. Rio de Janeiro, ABNT.

ASSOCIAÇÃO BRASILEIRA DE NORMAS TÉCNICAS (1996). NBR 7480 Barras e fios de aço destinados a armaduras para concreto armado. Rio de Janeiro, ABNT.

ASSOCIAÇÃO BRASILEIRA DE NORMAS TÉCNICAS (1994). NBR 5738 Moldagem e cura de corpos-de-prova cilíndricos ou prismáticos de concreto. Rio de Janeiro, ABNT. 
ASSOCIAÇÃO BRASILEIRA DE NORMAS TÉCNICAS (1991). NBR 12142 Concreto - determinação da resistência àtração na flexão. Rio de Janeiro.

ASSOCIAÇÃO BRASILEIRA DE NORMAS TÉCNICAS (1987). NBR 7217 Agregados - determinação da composição granulométrica. Rio de Janeiro.

ASSOCIAÇÃO BRASILEIRA DE NORMAS TÉCNICAS (1987). NBR 9776 Agregados - determinação da massa específica de agregados miúdos por meio do frasco de Chapman. Rio de Janeiro.

ASSOCIAÇÃO BRASILEIRA DE NORMAS TÉCNICAS (1984). NBR 8522 Concreto - determinação do módulo de deformação estática e diagrama tensão-deformação. Rio de Janeiro, ABNT.

ASSOCIAÇÃO BRASILEIRA DE NORMAS TÉCNICAS (1983). NBR 7211 Agregado para concreto. Rio de Janeiro, ABNT.

ASSOCIAÇÃO BRASILEIRA DE NORMAS TÉCNICAS (1983). NBR 7222 Argamassas e concretos - determinação da resistência à tração por compressão diametral de corpos-de-prova cilíndricos. Rio de Janeiro, ABNT.

ASSOCIAÇÃO BRASILEIRA DE NORMAS TÉCNICAS (1982). NBR 7251 Agregado em estado solto - determinação da massa unitária. Rio de Janeiro, ABNT.

ASSOCIAÇÃO BRASILEIRA DE NORMAS TÉCNICAS (1980). NBR 5739 Ensaio de compressão de corpos-de-prova cilíndricos de concreto. Rio de Janeiro, ABNT.

ASSOCIAÇÃO BRASILEIRA DE NORMAS TÉCNICAS (1978). NBR 6118 Projeto e execução de obras de concreto armado. Rio de Janeiro, ABNT.

CAMPOS, F. G. V. (2000). CAD: mais que durável, um grande negócio. Revista Ibracon, v.8, n.24, p.27-34. 
CLAESON, C.; GYLLTOFT, K.; GRAUERS, M. (1996). Experiments and numerical analyses of reinforced high strength concrete columns. In: INTERNATIONAL SYMPOSIUM ON THE UTILIZATION OF $\mathrm{HIGH}$ STRENGTH/HIGH-PERFORMANCE CONCRETE, 4., Paris, 1996. Proceedings. Paris, Laboratoire Central des Ponts et Chaussees. v.3, p.797806.

COLLINS, M.; MITCHELL, D.; MACGREGOR, J. G. (1993). Structural design considerations for high-strength concrete. Concrete International, v.15, n.1, p.27-34, May.

COMITÉ EURO-INTERNATIONAL DU BÉTON (1990). CEB-FIP model code 1990. Bulletin d'Information, n.213/214.

CUSSON, D.; PAULTRE, P. (1994). High-strength concrete columns confined by rectangular ties. ASCE Journal of Structural Engineering, v.120, n.3, p.783804, Mar.

CUSSON, D.; PAULTRE, P. (1993). Confinement model for high-strength tied columns. Department of Civil Engineering, Faculty of Applied Sciences, University of Sherbrooke, May.

DAL MOLIN, D. C.; VIEIRA, F. M. P.; WOLF, J. (1997). Concreto de alta resistência. In: NÚCLEO DE PESQUISA EM TECNOLOGIA DA ARQUITETURA E URBANISMO, org. Concreto de alto desempenho Versão 1.0 [CD-ROM]. São Paulo, NUTAU/USP.

FANTI, A. (1917). Costruzioni rurali in cemento armato. 2.ed. Pisa, EditoreLibraio della Real Casa Milano.

FUSCO, P. B. (1989). O cálculo de concreto armado em regime de ruptura. In: SIMPÓSIO EPUSP SOBRE ESTRUTURAS DE CONCRETO, 1, São Paulo, 1989. Anais. São Paulo, EPUSP. v.1, p.239-310.

FUSCO, P. B. (1986). Estruturas de concreto: solicitações normais; estados limites últimos; teoria e aplicações. Rio de Janeiro, Guanabara Dois. 
GIONGO, J. S.; FIORIN, E. (1999). Arranjos de armaduras para vigas e pilares de edifícios em concreto armado. In: SÁNCHEZ, E. S., org. Nova normalização brasileira para o concreto estrutural. Rio de Janeiro, Interciência. Cap.10, p.209-243.

HELENE, P. R. L.; TERZIAN, P. (1992). Manual de dosagem e controle do concreto. São Paulo, Pini.

KERSTEN, C. (1927). Guida teorica e pratica per le costruzioni in beton armato. 2.ed. Torino, Luigi Avalle.

LANGENDONCK, T. (1944). Cálculo de concreto armado. São Paulo, ABCP. 1 v.

LEONHARDT, F.; MÖNNIG, E. (1978). Construções de Concreto: princípios básicos sobre a armação de estruturas de concreto armado. Trad. por José M. Villas Boas. Rio de Janeiro, Interciência. 3v.

LIMA, F. B. (1997). Pilares de concreto de alto desempenho: fundamentos e experimentação. São Carlos, 1997. 170 p. Tese (Doutorado) - Escola de Engenharia de São Carlos, Universidade de São Paulo.

LIMA, F.B.; GIONGO, J.S.; TAKEYA, T. (1997). Análise experimental de pilares de concreto de alto desempenho solicitados à compressão centr ada. In: REUNIÃO DO IBRACON, 39., São Paulo, 1997. São Paulo, IBRACON. v.2, p.521-536.

LIMA JÚNIOR, H. C.; GIONGO, J. S. (2001). Avaliação da ductilidade do concreto de alta resistência reforçado com fibra de aço. In: REUNIÃO DO IBRACON, 43., Foz do Iguaçu, 2001. (Trabalho submetido a publicação).

MANDER, J. B.; PRIESTLEY, M. J. N.; PARK, R. (1988a). Observed stressstrain behavior of confined concrete. ASCE Journal of Structural Engineering, v.114, n.8, p.1827-1849, Aug. 
MANDER, J. B.; PRIESTLEY, M. J. N.; PARK, R. (1988b). Theoretical stressstrain model for confined concrete. ASCE Journal of Structural Engineering, v.114, n.8, p.1804-1826, Aug.

MANDER, J. B.; PRIESTLEY, M. J. N.; PARK, R. (1984). Seismic design of bridge piers. Research Report, $n^{\circ}$ 84-2, Univ. of Canterbury, Christchurch, New Zealand.

MEHTA, P. K.; MONTEIRO, P. J. M. (1994). Concreto: estrutura, propriedade e materiais. São Paulo, Pini.

MÖRSCH, E. (1959). Cálculo del hormigón armado. Barcelona, Gustavo Gili.

MÖRSCH, E. (1952). Teoria y prática del hormigón armado. Buenos Aires, Gustavo Gili. 1v.

NEVILLE, A.M. (1982) Propriedades do concreto. Trad. por Salvador E. Giammusso. São Paulo, Pini.

PAIVA, N. M. B. (1994). Pilares de concreto de alta resistência com seção transversal retangular solicitados à compressão simples. Campinas, 1994. 102p. Dissertação (mestrado) - Faculdade de Engenharia Civil, Universidade Estadual de Campinas.

PFEIL, W. (1983). Concreto armado, dimensionamento: compressão, flexão e cisalhamento. 4.ed. Rio de Janeiro, Livros Técnicos e Científicos.

PINHEIRO, L. M.; GIONGO, J. S. (1999). Concreto armado: propriedades dos materiais. São Carlos, Serviço Gráfico da EESC-USP.

QUEIROGA, M.V.M. (1999). Análise experimental de pilares de concreto de alto desempenho submetidos à compressão simples. São Carlos, 1999. 162p. Dissertação (Mestrado) - Escola de Engenharia de São Carlos, Universidade de São Paulo. 
QUEIROGA, M.V.M.; GIONGO, J.S.; TAKEYA, T. (1999). Pilares de concreto com resistência média de $60 \mathrm{MPa}$ submetidos à compressão simples .In: REUNIÃO DO IBRACON, 41., Salvador, 1999. Salvador, IBRACON.

RAZVI, S. R.; SAATCIOGLU, M. (1989). Confinement of reinforced concrete columns with welded wire fabric. ACI Structural Journal, v.86, n.5, p.615-623.

ROCHA, A.M. (1970). Novo curso prático de concreto armado. 10.ed. Rio de Janeiro, Editora Científica. 2v.

SAATCIOGLU, M.; RAZVI, S. R. (1992). Strength and ductility of confined concrete. ASCE Journal of Structural Engineering, v.118, n.6, p.1590-1607, June.

SEGURADO, J. E. S. (1921). Cimento Armado. 3.ed. Lisboa, Imprensa PortugalBrasil.

SHEIKH, S. A.; UZUMERI, S. M. (1982). Analytical model for concrete confinement in tied columns. ASCE Journal of Structural Engineering, v.108, n.ST12, p.2703-2722, Dec.

SHEIKH, S. A.; UZUMERI, S. M. (1980). Strength and ductility of tied concrete columns. ASCE Journal of Structural Engineering, v.106, n.ST5, p.10791102, May.

SILVA, L. F. (1983). Materiais de construção civil: "dosagem experimental do concreto"- método da ABCP. São Carlos, EESC-USP.

TAKEUTI, A. R. (1999). Reforço de pilares de concreto armado por meio de encamisamento com concreto de alto desempenho. São Carlos, 1999. 184p. Dissertação (Mestrado) - Escola de Engenharia de São Carlos, Universidade de São Paulo. 


\section{BIBLIOGRAFIA COMPLEMENTAR}

AGUIAR, E. A. B. (2000). Projeto de pilares de concreto de alto desempenho. São Carlos, 2000. 202p. Dissertação (Mestrado) - Escola de Engenharia de São Carlos, Universidade de São Paulo.

ASSOCIAÇÃO BRASILEIRA DE CIMENTO PORTLAND (1967). Vocabulário de teoria das estruturas. São Paulo, ABCP.

ASSOCIAÇÃO BRASILEIRA DE NORMAS TÉCNICAS (1992). NBR 8953 Concreto para fins estruturais - classificação por grupos de resistência. Rio de Janeiro, ABNT.

ASSOCIAÇÃO BRASILEIRA DE NORMAS TÉCNICAS (1992). NBR 12654 Controle tecnológico de materiais componentes do concreto. Rio de Janeiro, ABNT.

ASSOCIAÇÃO BRASILEIRA DE NORMAS TÉCNICAS (1992). NBR 6152 Materiais metálicos - Determinação das propriedades mecânicas à tração. Rio de Janeiro, ABNT.

ASSOCIAÇÃO BRASILEIRA DE NORMAS TÉCNICAS (1987). NBR 7220 Agregados - determinação de impurezas orgânicas húmicas em agregado miúdo. Rio de Janeiro.

ASSOCIAÇÃO BRASILEIRA DE NORMAS TÉCNICAS (1987). NBR 7219 Agregados - determinação do teor de materiais pulverulentos. Rio de Janeiro. 
ASSOCIAÇÃO BRASILEIRA DE NORMAS TÉCNICAS (1984). NBR 8681 Ações e segurança nas estruturas. Rio de Janeiro, ABNT.

ASSOCIAÇÃO BRASILEIRA DE NORMAS TÉCNICAS (1983). NBR 7809 Agregado graúdo - determinação do índice de forma pelo método do paquímetro. Rio de Janeiro, ABNT.

ASSOCIAÇÃO BRASILEIRA DE NORMAS TÉCNICAS (1982). NBR 7214 Areia normal para ensaio de cimento. Rio de Janeiro, ABNT.

ASSOCIAÇÃO BRASILEIRA DE NORMAS TÉCNICAS (1982). NBR 7223 Determinação da consistência pelo abatimento do tronco de cone. Rio de Janeiro, ABNT.

AUFIERI, F. A. (1997). Diretrizes para o dimensionamento e detalhamento de pilares de edifícios em concreto armado. São Carlos, 1997. 146p. Dissertação (Mestrado) - Escola de Engenharia de São Carlos, Universidade de São Paulo.

CARVALHO, R. C.; FIGUEIREDO FILHO, J. R. (2001). Cálculo e detalhamento de estruturas usuais de concreto armado. São Carlos, Editora da UFSCar.

CUSSON, D.; PAULTRE, P. (1993). Confinament model for high-strength concrete tied columns. Department of Civil Engineering, Faculty of Applied Sciences, University of Sherbrooke, May.

EUROCODE 2 (1992). Design of concrete structures - Part 1: General rules and rules for buildings. Brussels, CEN.

FUSCO, P.B. (1994). Técnica de armar as estruturas de concreto. São Paulo, Pini.

GUIMARÃES, A. E. P. (1999). Análise de pilares de concreto de alta resistência com adição de fibras metálicas submetidos à compressão centrada. São Carlos, 1999. 145p. Tese (Doutorado) - Escola de Engenharia de São Carlos, Universidade de São Paulo. 
LEONHARDT, F.; MÖNNIG, E. (1977). Construções de Concreto: princípios básicos do dimensionamento de estruturas de concreto armado. Trad. por David Fridman. Rio de Janeiro, Interciência. 1v.

MONTOYA, P.J.; MESEGUER, A. G.; CABRE, F. M. (1981). Hormigón armado. 11.ed. Barcelona, Gustavo Gili. 2v.

NÚCLEO DE PESQUISA EM TECNOLOGIA DA ARQUITETURA E URBANISMO (1997). Concreto de alto desempenho - Versão 1.0 [CD-ROM]. São Paulo, NUTAU/USP.

PFEIL, W. (1978). Concreto armado, dimensionamento: compressão, flexão e cisalhamento. 3.ed. Rio de Janeiro, Livros Técnicos e Científicos.

SAATCIOGLU, M.; RAZVI, S. R. (1998). High-strength concrete columns with square sections under concentric compression. ASCE Journal of Structural Engineering, v.124, n.12, p.1438-1447, Dec.

SANTOS, L.M. (1983). Cálculo de concreto armado segundo a NB-1/78 e o CEB. 2.ed. São Paulo, LMS. 1v.

SANTOS, L.M. (1981). Cálculo de concreto armado segundo a NB-1/78 e o CEB. São Paulo, LMS. 2v.

SANTOS, L.M. (1977). Cálculo de concreto armado. São Paulo, Edgard Blücher. $1 \mathrm{v}$.

UNIVERSIDADE DE SÃO PAULO. Escola de Engenharia de São Carlos. Serviço de Biblioteca (1993). Diretrizes para elaboração de dissertações e teses na EESC-USP. São Carlos.

VANDERLEI, R. D. (1999). Análise experimental de pilares de concreto armado de alta resistência sob flexo-compressão reta. São Carlos, 1999. 141p. Dissertação (Mestrado) - Escola de Engenharia de São Carlos, Universidade de São Paulo. 
VASCONCELOS, A. C. (1992). O concreto armado no Brasil. São Paulo, Pini. $1 \mathrm{v}$. 